\title{
Crossing the Energy Efficiency Chasm: An Assessment of the Barriers to Institutional Investment at Scale
}

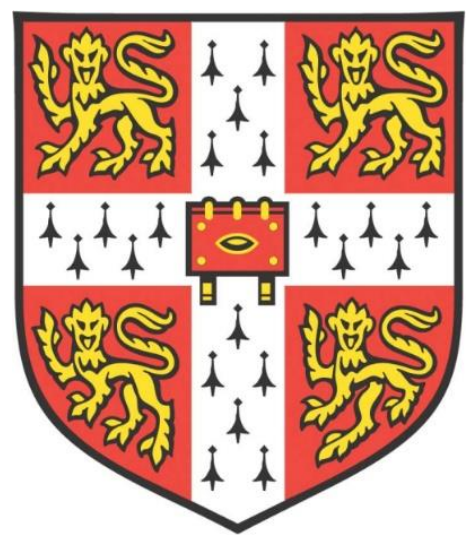

\author{
Martin Christopher Frederick Parker \\ Wolfson College
}

Centre for Sustainable Development

Department of Engineering

University of Cambridge

This dissertation is submitted for the degree of

Doctor of Philosophy

May 2018 


\section{Declaration}

This dissertation is the result of my own work and includes nothing, which is the outcome of work done in collaboration except where specifically indicated in the text. It is not substantially the same as any that I have submitted, or, is being concurrently submitted for a degree or diploma or other qualification at the University of Cambridge or any other University or similar institution except as declared in the Preface and specified in the text. I further state that no substantial part of my dissertation has already been submitted, or, is being concurrently submitted for any such degree, diploma or other qualification at the University of Cambridge or any other University of similar institution except as declared in the Preface and specified in the text.

In accordance with the Department of Engineering guidelines, this thesis does not exceed 65,000 words $(64,848)$ and it contains less than 150 figures (28 figures, 8 tables).

Signed:

Date:

Martin Christopher Frederick Parker BSc MSc MBA MSt

CEng MICE MACostE MRICS MCIOB

May 2018

Cambridge 
"Chasm crossing is not the end, but rather the beginning, of mainstream market development."

Geoffrey A Moore 


\begin{abstract}
Significant savings in $\mathrm{CO}_{2}$ emissions can be won from fabric upgrades, and improved forms of heating. An increase in the number of building retrofits and installations of energy efficient plant such as biomass boilers or CCHPs must be the aim if the UK is serious in meeting its commitment to $\mathrm{CO}_{2}$ reduction at both the domestic and EU level. A way of achieving this increase, which will need to be significant, would be to tap into the vast funds under management by institutional investors who are required to invest those funds to optimise its monetary return, taking into account the level of risk.
\end{abstract}

The aim of the research is to identify the enabling conditions that would need to exist to attract institutional investment in energy efficiency at scale. The UK Green Investment Bank has invested $£ 50 \mathrm{~m}$ into three energy efficiency funds, requiring each fund manager to match the amount by attracting investment from institutional investors. It is these funds that have been analysed as a single Green Investment Bank case study. Embedded units of analysis are on two levels with the individual funds being the first, and the institutional investors investing in those funds as the second. A hybrid deductive and inductive qualitative approach to the research was taken employing thematic analysis.

The findings of the research reported here indicate that the emerging key enabling conditions that would make energy efficiency an attractive proposition are firstly, the way energy efficiency investments are classified in terms of an investment asset class, secondly the contractual structure of the individual transactions made by the funds, and finally, the experience and familiarity of the fund manager. 


\section{Acknowledgements}

I would like to thank my supervisor Professor Peter Guthrie for his support and guidance during the long course of the research process and allowing me the flexibility to undertake it around my hectic work and home life. I would also like to thank my adviser Professor Michael Kelly and my external advisers Dr Angela Whelan and Mr Nick Silver for the help and assistance they provided, particularly early in the research design process. I would also like to acknowledge the interviewees, firstly for agreeing to participate which they were not obliged to do and secondly for providing such rich insights and data informing the research process.

Finally, I would like to thank Amanda my wife for enduring such an intrusion into our lives and without whose support this endeavour would not have been possible. 


\section{Abbreviations}

$\begin{array}{ll}\text { BMA } & \text { Building Management System } \\ \text { CCC } & \text { Committee on Climate Change } \\ \text { CCHP } & \text { Combined Cooling Heat and Power } \\ \text { CEM } & \text { Contract Energy Management } \\ \text { CfD } & \text { Contracts for Difference } \\ \text { CHP } & \text { Combined Heat and Power } \\ \text { CO }_{2} & \text { Carbon Dioxide } \\ \text { DEEP } & \text { De-risking Energy Efficiency Platform } \\ \text { ECM } & \text { Energy Conservation Measure } \\ \text { EEFIG } & \text { Energy Efficiency Financial Institutions Group } \\ \text { EPC } & \text { Energy Performance Contracting } \\ \text { ESA } & \text { Efficiency / Energy Services Agreement } \\ \text { ESCO } & \text { Energy Services Company } \\ \text { ESG } & \text { Environmental, Social, Governance } \\ \text { GHG } & \text { Green House Gases } \\ \text { GIB } & \text { Green Investment Bank } \\ \text { IEA } & \text { International Energy Agency } \\ \text { IGA } & \text { Investment Grade Audit } \\ \text { IMPVP } & \text { International Performance Measurement and Verification Protocol } \\ \text { M\&V } & \text { Measurement and Verification } \\ \text { MtCO } & \text { Metric Tonnes of Carbon Dioxide } \\ \text { MtCO } & \\ \text { PACE } & \text { Metric Tonnes of Carbon Dioxide Equivalent } \\ \text { RHI } & \text { Property Assessed Clean Energy } \\ \text { ROC } & \text { Renewable Hear Incentive } \\ \text { SDCL } & \text { Renewable Obligation Certificate } \\ \text { SRI } & \text { Socially Responsible Investments } \\ \text { United Nations Framework Convention on Climate Change }\end{array}$




\section{Contents}

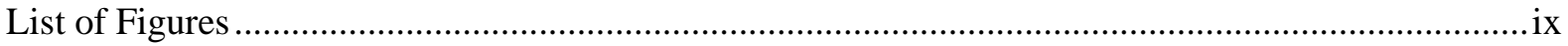

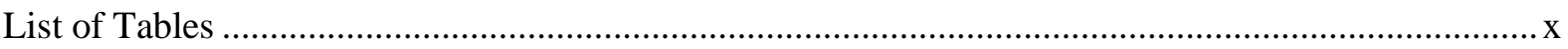

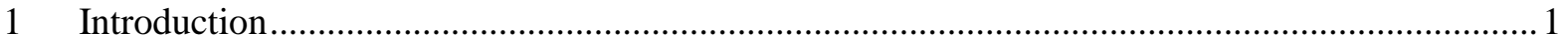

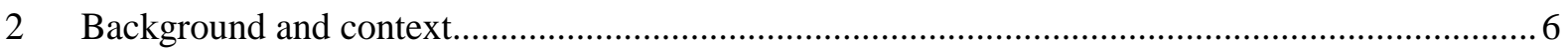

$2.1 \quad$ Energy Efficiency and Sustainable Development ............................................................ 6

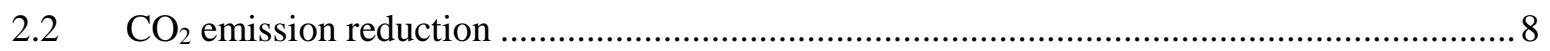

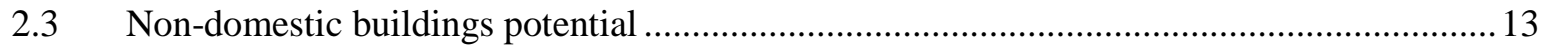

2.4 Pension fund and institutional investors' funds to invest.................................................. 15

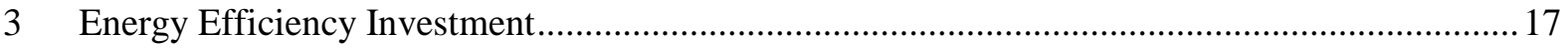

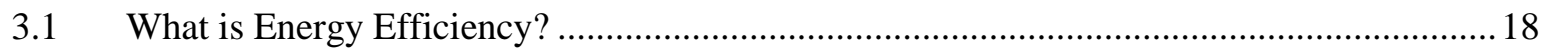

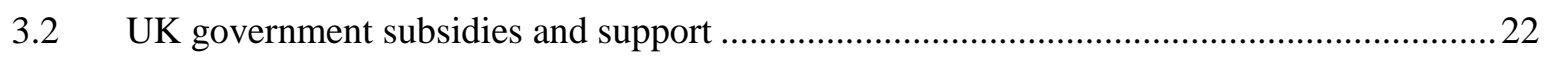

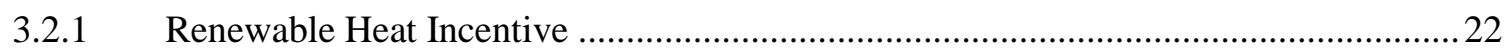

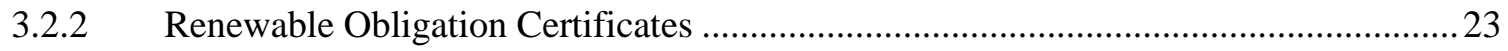

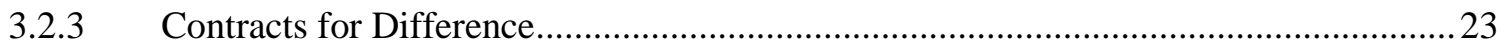

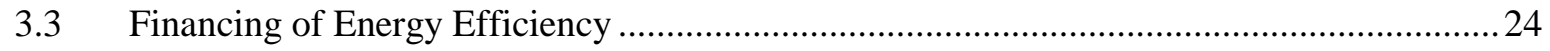

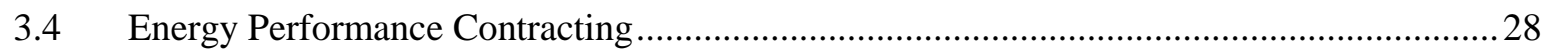

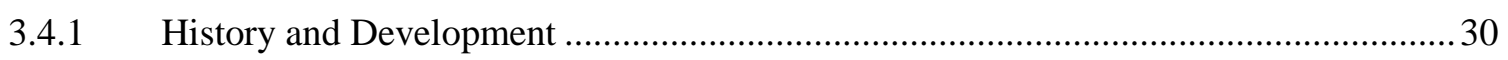

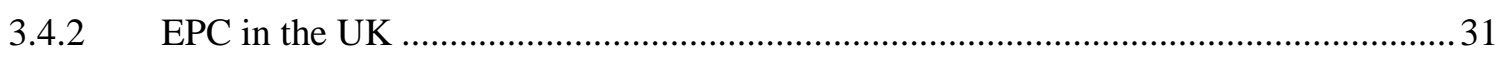

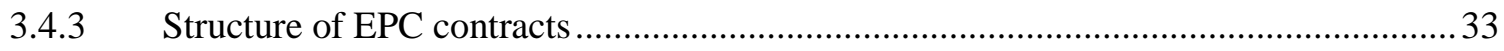

3.4.4 Criticism of Energy Performance Contracting ............................................................ 41

3.5 Investments by Institutional Investors in Energy Efficiency …............................................ 43

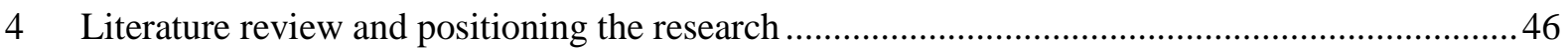

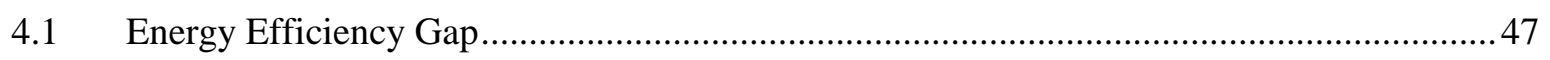

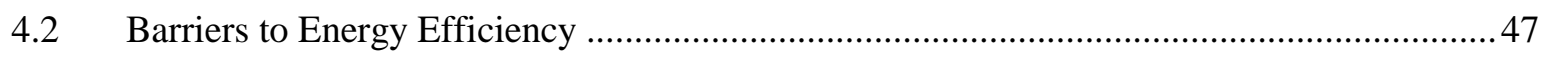

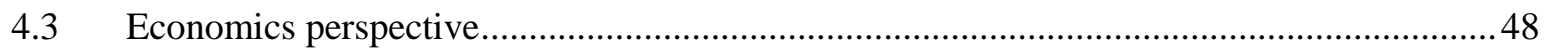

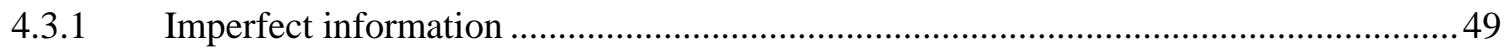

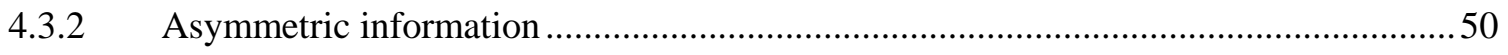

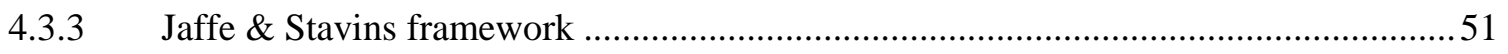

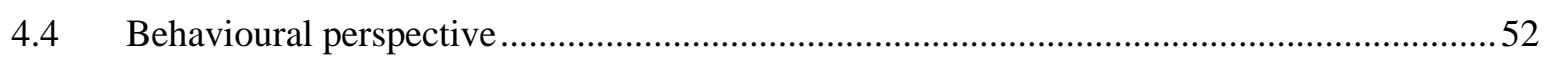

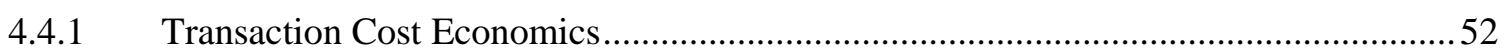

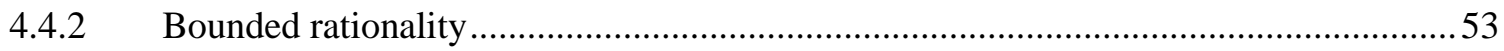

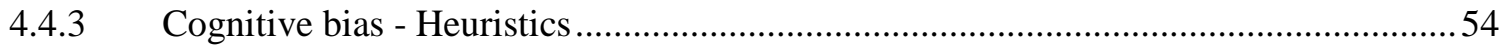

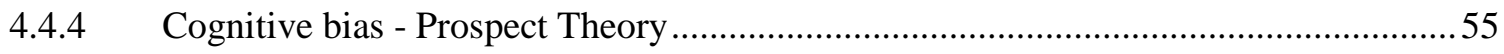

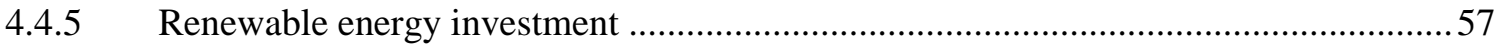

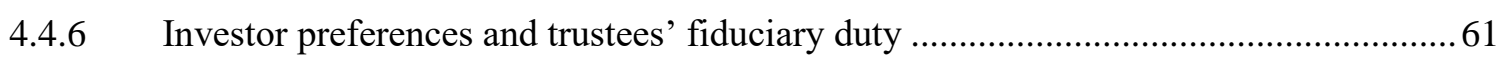

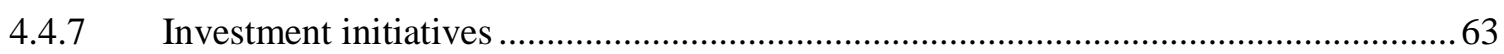


4.5 Conclusions

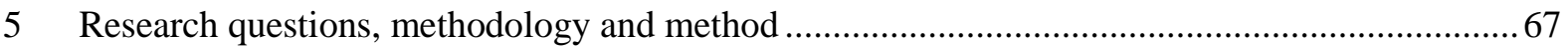

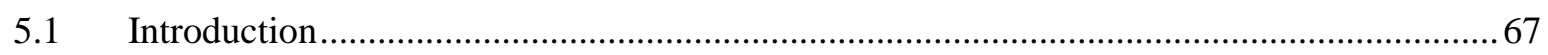

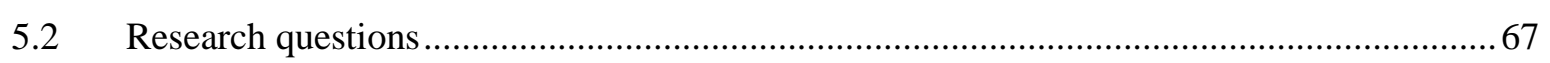

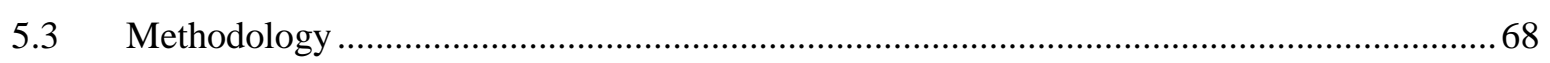

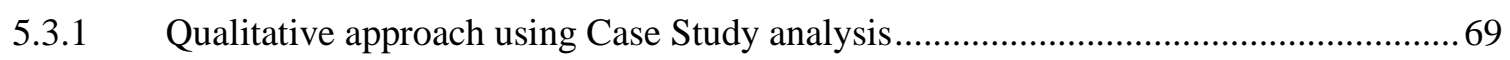

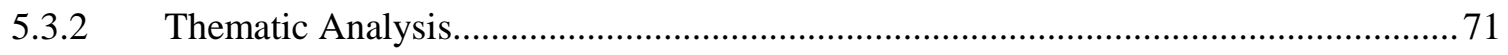

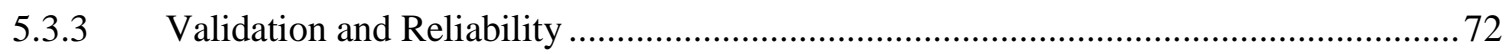

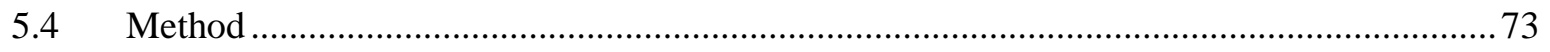

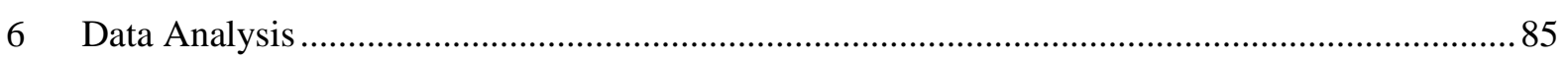

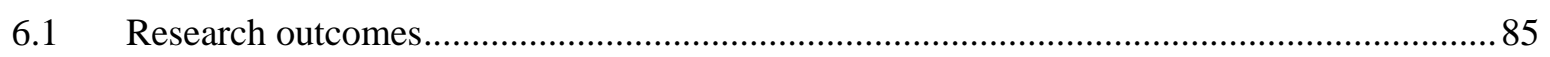

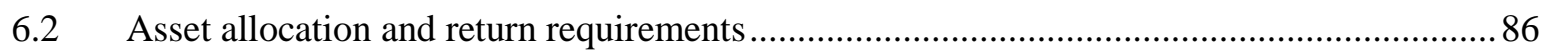

6.2.1 Investment Correlation and Asset Allocation Strategy .................................................. 86

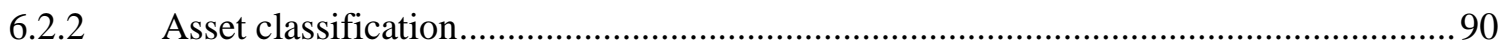

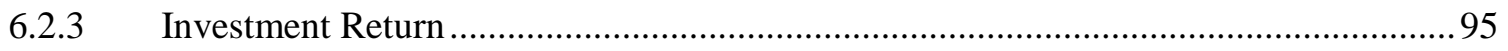

6.2.4 Inflation linked income matching liabilities ............................................................... 99

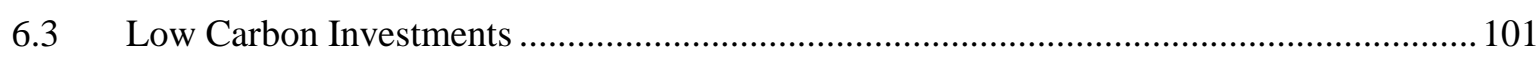

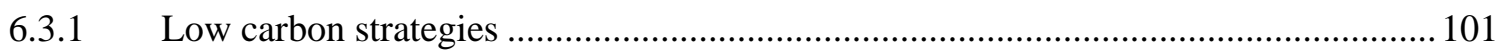

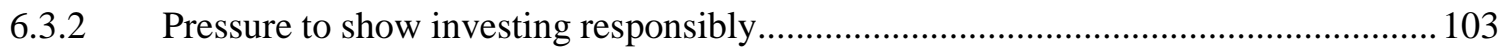

6.3.3 Low carbon strategy taken into account in investment decision................................. 105

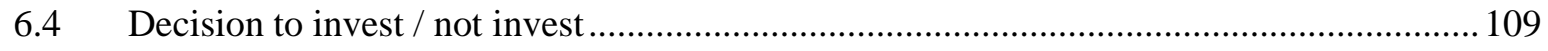

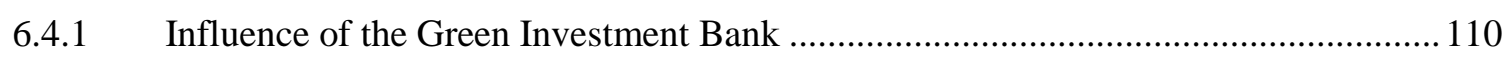

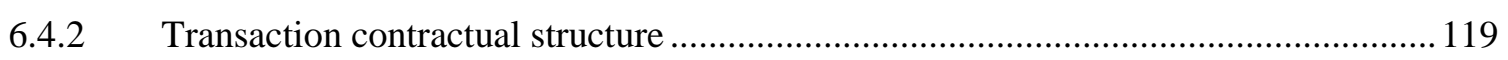

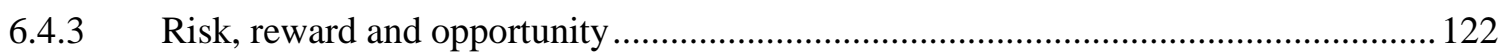

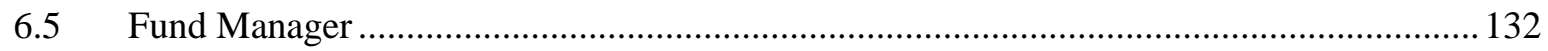

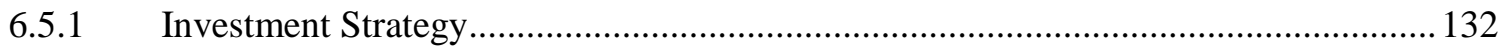

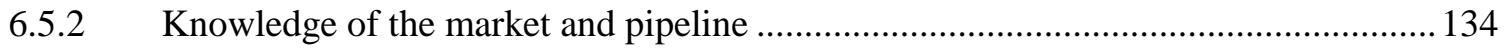

6.5.3 Track record and ability to deploy funds ................................................................ 135

6.5.4 Past relationship and familiarity with the fund manager........................................... 137

6.5.5 Quality of the team, depth of resource, trust and integrity......................................... 139

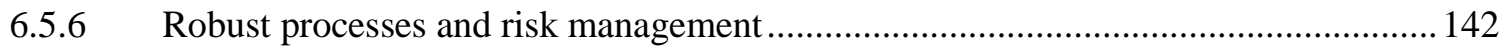

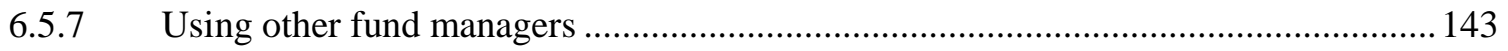

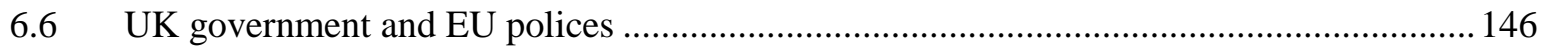

6.6.1 Were carbon reduction policies influential in the investment decision?..................... 146

6.6.2 Policies that could ensure or incentivise energy efficiency investment ...................... 150

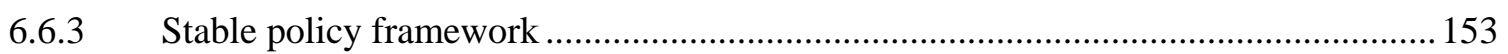

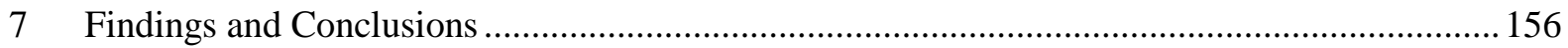




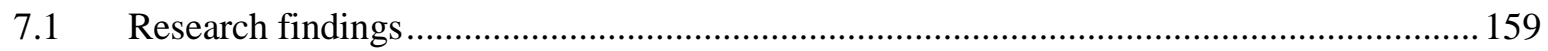

7.1.1 Asset allocation and return requirements .............................................................. 160

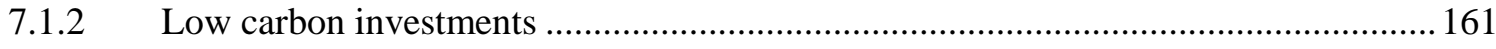

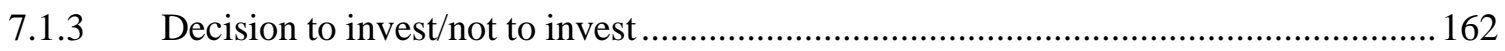

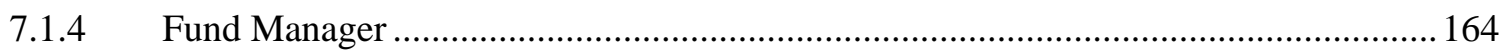

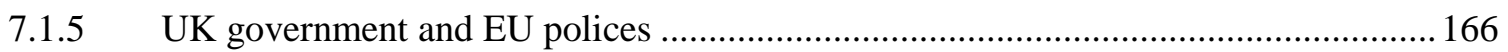

7.2 Conclusions and development of the conceptual model .................................................... 167

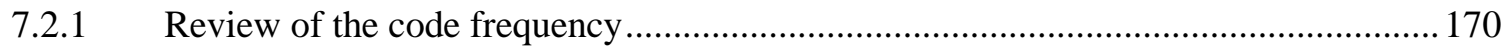

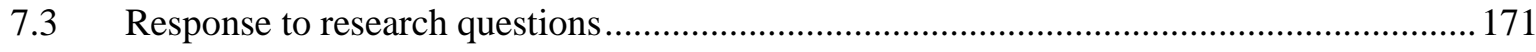

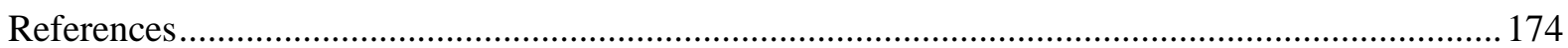

Appendix A: Examples of Energy Efficiency transactions made by each of the GIB funds.............. 186

Appendix B: Case study protocol, information sheet and consent form.............................................. 194

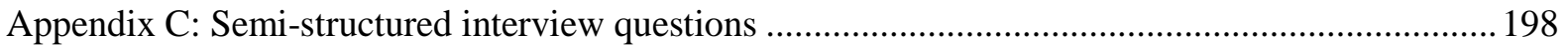

Appendix D: Semi-structured interview questions, a priori constructs and research questions .........201

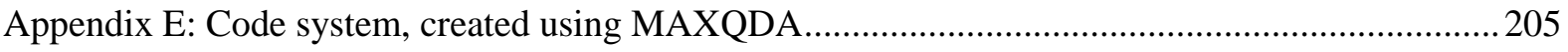

Appendix F: Semi-structured interview questions with codes mapped .............................................208 


\section{List of Figures}

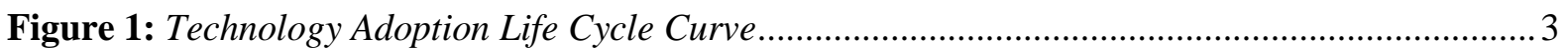

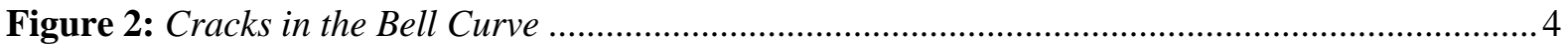

Figure 3: The three key elements of Sustainable Development ........................................................... 7

Figure 4: Reduction in emissions of 80\% by 2050 (vs. 1990 levels) .................................................. 11

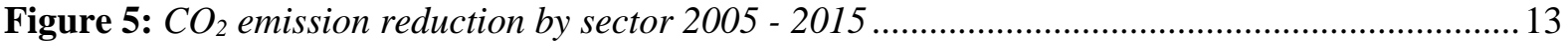

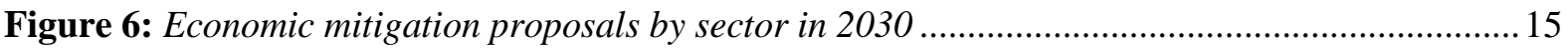

Figure 7: Typical \% share of funds under management in the UK.................................................. 16

Figure 8: Growth of funds under management in the UK ............................................................. 16

Figure 9: Asset allocation of funds under management, 2011 …....................................................... 17

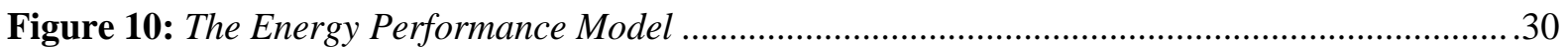

Figure 11: Overlaps in the UK marker for energy service contracts................................................ 32

Figure 12: Third party financing with ESCO and energy user / customer borrowing ...................... 36

Figure 13: Major types of Energy Performance Contracting models ................................................38

Figure 14: Special Purpose Entity/Vehicle (SPE/V) EPC financing model ....................................... 40

Figure 15: Efficiency Services Agreement contractual structure from Metrus .................................. 42

Figure 16: Conceptual model of cognitive decision processes ...........................................................57

Figure 17: Basic model of risk and return involving energy policy and investment ............................58

Figure 18: Differentiated model of risk and return involving energy policy and investment ..............61

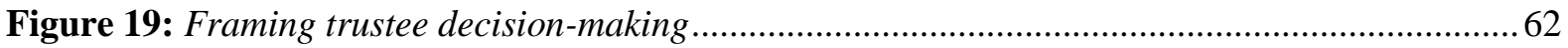

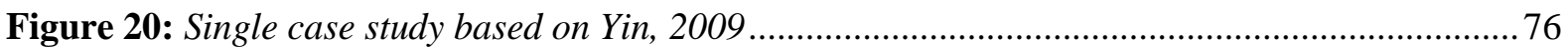

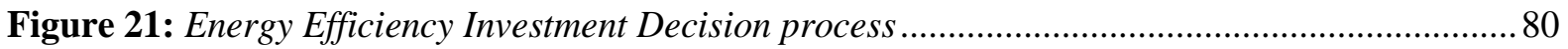

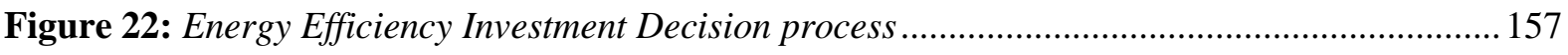

Figure 23: Energy Efficiency Investment Decision process - early findings .................................... 159

Figure 24: Energy Efficiency Investment Decision process - revised conceptual model .................. 169

Figure 25: Biomass boiler in the Equitix Roundwood transaction ................................................ 186

Figure 26: Biomass process at the Tomatin Distillery ...................................................................... 187

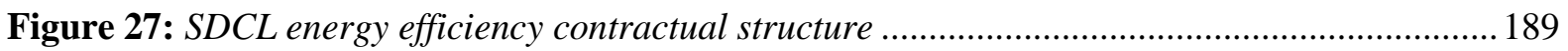

Figure 28: Bart's energy centre contractual structure ................................................................. 192 


\section{List of Tables}

Table 1: The Green Investment Bank view of non-domestic energy efficiency ...................................22

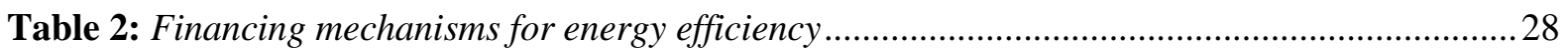

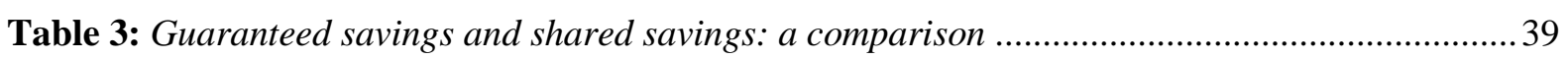

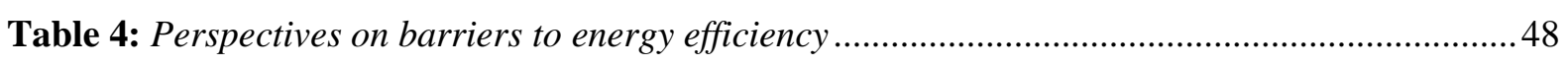

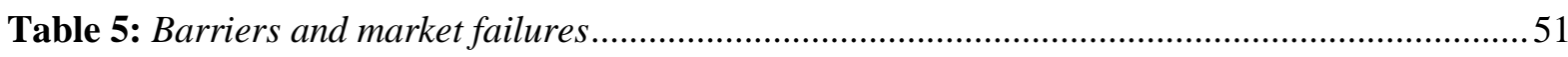

Table 6: Examples of transactions entered into by each GIB fund .................................................... 75

Table 7: Outline of the semi-structured interviews undertaken ........................................................... 78

Table 8: The top sixteen codes in terms frequency of allocation ................................................... 170 


\section{Crossing the Energy Efficiency Chasm: An Assessment of the Barriers to Institutional Investment at Scale}

\section{Introduction}

Investment in energy efficiency measures applied to buildings has been identified as one of the most effective ways of reducing $\mathrm{CO}_{2}$ emissions (EEFIG, 2015). It has been demonstrated that buildings emit up to $40 \%$ of all $\mathrm{CO}_{2}$ and that out of all the $\mathrm{CO}_{2}$ emitting sectors, buildings and their associated infrastructure form one where cost effective $\mathrm{CO}_{2}$ reduction can be achieved (EEFIG, 2015). However, investment into this area has been limited to date with low level of take up of the Green Deal in the domestic housing sector prior to its discontinuation in 2015, and minimal investment flowing into non-domestic or commercial and public buildings (Richards, 2016, Fankhauser, 2014). Barriers to investment in energy efficiency are well known; high upfront and transaction costs, and lack of awareness and understanding of the technology and processes involved, for example, so the focus of attention needs to be targeted on removing the barriers to allow a greater level of investment (International Chamber of Commerce, 2014). The Energy Efficiency Financial Institutions Group (EEFIG) was established in 2013 by the European Commission Directorate-General for Energy (DG Energy) and United Nations Environment Program Finance Initiative (UNEP FI). It created an open dialogue and work platform for public and private financial institutions, industry representatives and sector experts to identify the barriers to the long-term financing for energy efficiency and propose policy and market solutions to them. It has over 100-member organisations. The EEFIG proposed that a distinction should be made between investment in energy efficiency in domestic and non-domestic property, as the two sub sectors are significantly different in their characteristics (EEFIG, 2015), particularly in respect of scale and potential for aggregation and so the barriers to investment in energy efficiency within them are different with different measures necessary to attract investment. In fact, The EEFIG, in its 2015 report, identifies three sub-sectors, breaking down non-domestic properties into commercial and public buildings along with domestic residential buildings when assessing an efficient investment approach. The EEFIG stated that the approaches to and recommendations to increase energy efficiency investments in these three segments are materially different (EEFIG, 2015). This research is concerned with the non-domestic sector which is diverse in its nature and includes commercial and industrial as well as public buildings. 
A major issue to overcome is to understand what constitutes an energy efficiency investment. Much of the focus within the low carbon investment agenda has been on investments in renewable energy, such as wind or solar. Unlike renewable energy projects, energy efficiency projects do not generate cash flow from the generation of energy but, in the main, from the amount of energy that is saved. Many investors can easily understand and relate to the conceptual way a renewable energy project is structured, particularly if they have traditionally invested in infrastructure projects that typically provide positive cash flow once in operation or they have collateral in a tangible asset (Kaminker and Stewart, 2012, p27). Energy Efficiency investments may appear more risky when income is based on energy saved (Kaminker and Stewart, 2012, p27), however, energy efficiency projects represent a novel transaction structure for many. Energy efficiency projects also may involve, by some definitions of energy efficiency at least, what is deemed to be new or innovative technology such as biomass boilers, ground or air sourced heat pumps and combined heat and power (CHP), making them less attractive to investors and funders, although in reality much of this technology has been deployed for many years (Kaminker and Stewart, 2012).

Institutional investors such as pension funds and life insurance companies seek to invest their pensioners' or policy holders' cash in safe, long term investments that can match their longterm liabilities (Clark, 1998, p1002), if at all possible, acting in their best interest and having a fiduciary duty to do so (Clark, 1998, pp1007-1008). Many of these entities are increasingly investing in infrastructure traditionally seen as an 'Alternative' investment class, as opposed to the more usual investments of fixed income bonds and stocks. Although allocation to 'Alternatives' for investment purposes is only around 9\% of available funds (Maslakovic, 2012) which stood at $£ 6.2$ tr at the end of 2013 (Maslakovic, 2014a), this still represents around $£ 600$ bn in the UK alone and much more at the European and global level. If access to this source of funding could be facilitated for energy efficiency projects then the $\mathrm{CO}_{2}$ reduction potential becomes more realisable.

The issue of incentivising investors to invest their funds in projects that involve new or innovative technology at scale can be likened to that of marketing new technologically innovative products to mainstream customers, a concept developed by American marketing executive Geoffrey Moore. Moore (2006) references the Technology Adoption Life Cycle Curve (a bell curve) where the area under the curve is divided into classifications of buyers of 
new high technology products that are demarcated by their attitude to risk. It commences with the classification of buyers that are the innovators, moving on to the early adopters, the early majority, the late majority and finally the laggards, refer to Figure 1.

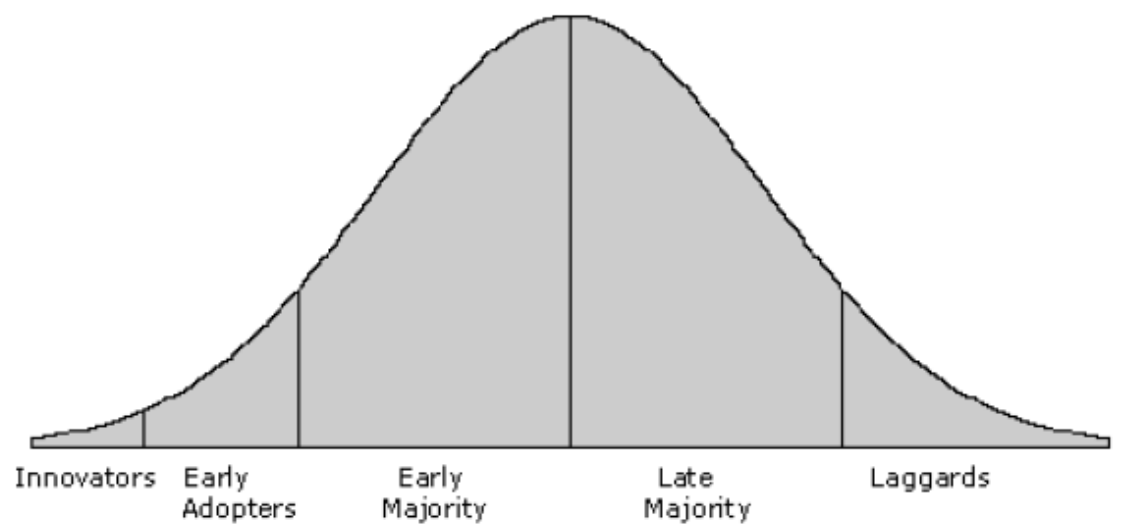

Source: Moore, 2006

Figure 1: Technology Adoption Life Cycle Curve

Moore quotes the High-Tech Marketing Model which states that:

The way to develop a high-tech market is to work the curve left to right, focusing first on the innovators, growing that market, then moving on to the early majority, growing that market, and so on [...]. In this effort, companies must use each 'captured' group as a reference base for going on to market to the next group. Thus, the endorsement of innovators becomes an important tool for developing a credible pitch to the early adopters, that of the early adopters to the early majority, and so on.

Moore, 2006, pp13-14

Moore goes on to assert however that the High-Tech Marketing Model is not an accurate reflection of the transition from one classification of buyer to the next and he suggests a more accurate model is his revised Technology Adoption Life Cycle, identifying a number of gaps in the bell curve that he characterises as 'cracks', refer to Figure 2. 


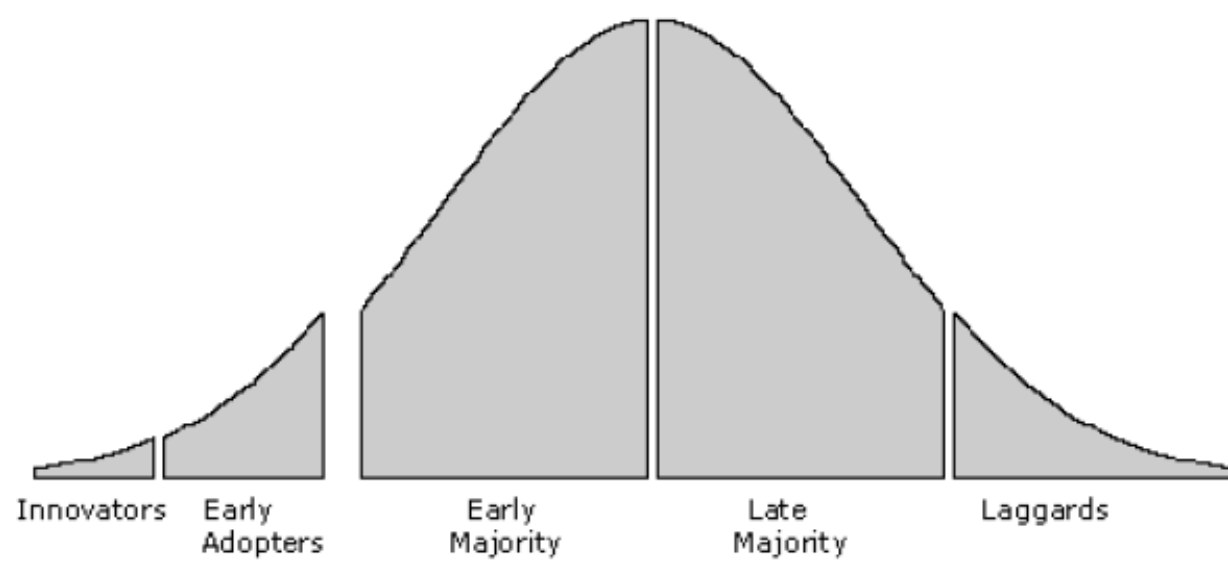

Source: Moore, 2006

Figure 2: Cracks in the Bell Curve

Moore suggests that the cracks in the bell curve between each buyer classification represent a situation where conditions need to exist for the technology to be comprehensively adopted by the next classification of buyers moving to the right on the curve, from say innovators to early adopters or from the early majority to the late majority. He asserts that the real breakthrough in the mainstream acceptance of high tech products is the transition from the early adopters to the early majority, however he also suggests that this transition is the most difficult to achieve and therefore he represents the crack in the bell curve in his model as much wider and describes it as a 'chasm'. He devotes much of his book to describing a marketing strategy to achieve the aim of closing the 'cracks' and the 'chasm'.

An analogy can be drawn with energy efficiency investments. Instead of a marketing strategy being formulated to market new high technology products to make them attractive beyond the relatively small segment of consumers characterised as innovators and early adopters to the vast numbers of mainstream consumers, a way needs to be found to identify the enabling conditions that would make investments in energy efficiency attractive to mainstream institutional investors. In short, a way has to be found to cross the Energy Efficiency investment 'Chasm' allowing the vast amounts available for investment to be unlocked and potentially be directed towards energy efficiency improvements. This would go some way to seeing the potential that energy efficiency improvements have in reducing $\mathrm{CO}_{2}$ emissions to being realised. 
This dissertation seeks to set out the background to this issue and describes research undertaken that investigated investment in non-domestic energy efficiency transactions. It has the objectives of better understanding the decision-making process of institutional investors when considering investments in energy efficiency and of identifying those enabling conditions that would allow investments to be made in energy efficiency at scale. The background and early findings from the research have been published in the Journal for Sustainable Finance and Investment (Parker and Guthrie, 2016).

The structure of this dissertation follows on from this introductory chapter one with chapter two setting out the background and context of the issue, with chapter three discussing how energy efficiency projects are funded and the investments currently being made. Chapter four contains a literature review focusing on the energy efficiency gap (the difference between current energy use and optimal energy use), the barriers to energy efficiency investment and economics and behavioural perspectives of the issue. Chapter five sets out the research questions and identifies a methodology and research method to be pursued. Chapter six outlines the data analysis and finally chapter seven presents the research findings and conclusions. 


\section{Background and context}

\subsection{Energy Efficiency and Sustainable Development}

The concept of requiring energy efficiency to be implemented at scale is not new. The Club of Rome commissioned 1972 report 'The Limits to Growth' identified in its key message that a combination of resource depletion and pollution, if untackled, would ultimately - i e within the next hundred years - bring the global economy down. It highlighted the issue of resource efficiency as a major contributory factor (Meadows et al., 1972).

In response to mounting concern surrounding ozone depletion, global warming, and other environmental problems associated with raising the standard of living of the world's population, the United Nations General-Secretary convened an international collection of politicians, civil servants and experts on the environment and development in 1983. An organisation was formed as the World Commission on Environment and Development under the chairpersonship of the then Prime Minister of Norway, Gro Harlem Brundtland which subsequently became known as the Brundtland Commission (Kates et al., 2008). The organisation was to be independent of the United Nations and was to focus on environmental and developmental problems and solutions.

In 1987 the Brundtland Commission issued its report 'Our Common Future' which subsequently became known as 'the Brundtland Report' (WCED, 1987). The Report introduced the concept of Sustainable Development and was primarily concerned with securing a global equity, and redistributing resources towards poorer nations whilst encouraging their economic growth (WCED, 1987). The report also suggested that equity, growth and environmental maintenance are simultaneously possible and that achieving this equity and sustainable growth would require technological and social change (WCED, 1987). The report highlighted three fundamental components to sustainable development: environmental protection, economic growth and social equity, with the message that the environment should be conserved and our resource base enhanced, by gradually changing the ways in which we develop and use technologies (WCED, 1987). 


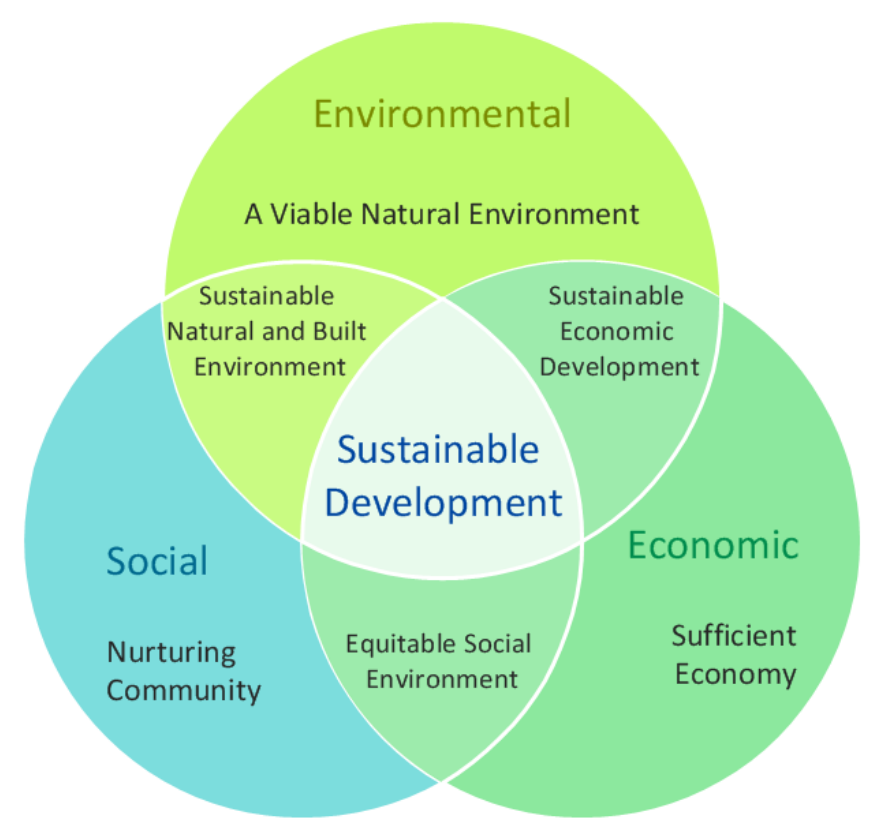

Source: Wordpress, 2018

Figure 3: The three key elements of Sustainable Development

The three key elements identified in the Brundtland Report, environmental protection, economic growth and social equity, are graphically illustrated in Figure 3 as different components of an interlocking venn-diagram. It has become the commonly accepted representation of the Sustainable Development concept as put forward by Brundtland. In the overlapping area of the Environment and Social components of the venn-diagram there is the label 'Sustainable Natural and Built Environment' and it is within this realm that energy efficiency predominately resides. However, it also has a role to play in the overlapping area of the Environment and Economic components, as it is not only concerned with the reduction of energy and $\mathrm{CO}_{2}$ emissions with a clear environmental impact, there is an economic impact also at a micro and macro level. The Brundtland Report emphasises in chapter 7: Energy: Choices for Environment and Development, the importance of maintaining energy efficiency and energy efficiency policies and in part VI of chapter 7 it states '...the Commission believes that energy efficiency should be the cutting edge of national energy policies for sustainable development (WCED, 1987).

The concept of Sustainable Development has further been developed by the United Nations, culminated in 2015 with the adoption of the 2030 Agenda for Sustainable Development and its 
17 Sustainable Development Goals (United Nations, 2015). The broad goals are interrelated though each has its own targets to achieve. There are a total of 169 targets to be addressed by 2030 (United Nations, 2015). The Sustainable Development Goals cover a broad range of social and economic development issues. These include poverty, hunger, health, education, climate change, gender equality, water, sanitation, energy, environment and social justice. Goal 7: Affordable and Clean Energy includes a target for energy efficiency which is to double the global rate of improvement in energy efficiency by 2030 (United Nations, 2015). Energy efficiency is clearly a key component of the Sustainable Development agenda.

Outside the direct Sustainable Development agenda, the issue of energy efficiency has been identified as a key component of meeting energy efficiency targets. The International Energy Agency for example has since 1993 issued its World Energy Outlook providing medium- to long-term energy projections using its large-scale simulation model. Updated each year, the WEO highlights recent trends in energy and energy policies including for energy efficiency with the latest being published in 2017 (IEA, 2017a). The IEA also publishes a series of energy efficiency reports and updates such its Energy Efficiency and Energy Efficiency Indicators reports providing information about global trends and statistics concerning energy eficicncy. The latest issue of each report was in 2017 (IEA, 2017b, IEA, 2017c). The IEA also publishes on energy efficiency policy being implemented around the world (IEA, 2011).

\section{$2.2 \mathrm{CO}_{2}$ emission reduction}

Global warming and changing climate conditions due to increased levels of greenhouse gas (GHG) emissions have forced the global community to set reduction targets and identify measures by which these emissions can be reduced (CCC, 2008).

The buildings sector is one where substantial reductions in GHG emissions are achievable (CCC, 2008). New buildings are addressed through amendments to building regulations, however in developed countries / UK the bulk of emissions are from the existing stock. A large proportion of these emissions are from the non-domestic sector, therefore a significant contribution to the meeting of reduction targets can be made by the installation of energy conservation measures in these buildings (CCC, 2008). 
The UK has committed itself to stringent GHG emissions reduction targets over and above those required in order to meet international agreements, including the recent Paris Agreement under which the UK has reassessed its $\mathrm{CO}_{2}$ reduction targets, outlined below. The built environment has not only been identified as a sector that produces a significant proportion of the emissions but also as a sector where cost effective reductions can be made (CCC, 2008).

Ambitious $\mathrm{CO}_{2}$ /GHG emissions targets were set by the UK government and by both the European Union and the global community via the Kyoto Protocol and more recently The Paris Agreement.

The Kyoto Protocol (KP) was a protocol to the United Nations Framework Convention on Climate Change (UNFCCC) which is an international environmental treaty with the goal of achieving "stabilisation" of greenhouse gas concentrations in the atmosphere at a level that would minimise dangerous anthropogenic interference with the climate system" (United Nations, 1992, p4). The UNFCCC, agreed at the Earth Summit in 1992, was only the first step in the international response to climate change and The Kyoto Protocol was agreed in 1997 and became legally binding in February 2005 (Department of Energy and Climate Change, 2010). As of January 2009, 184 states had accepted the Protocol, 84 of which had fully ratified it (United Nations, 2009). The industrialised countries, collectively known as "Annex I countries" agreed to commit to a reduction in four greenhouse gases (GHGs) including $\mathrm{CO}_{2}$ and two groups of gases produced by them, by 5.2\% of 1990 levels (United Nations, 2009). There was also an agreed method of converting the various greenhouse gas emissions into comparable $\mathrm{CO}_{2}$ emissions so that reduction figures can be expressed either in $\mathrm{GHG}$ or $\mathrm{CO}_{2}$ terms (United Nations, 2009). A second commitment period was agreed for the period 2012 to 2020, known as the Doha Amendment to the protocol, however this amendment is yet to enter into force.

The EU agreed a GHG reduction from 1990 levels of $8 \%$ by 2012 which was redistributed between member states according to their national circumstances (Department for Environment Food and Rural Affairs, 2006, p9). The UK's share was set at a 12.5\% reduction which became its legally binding Kyoto Protocol commitment. The UK government went on to set more ambitious targets and in 2000 they launched a Climate Change Programme which set a target reduction of $20 \%$ by 2010 (Department for Environment Food and Rural Affairs, 2006, p10). In 2003 The Energy White Paper: Our energy future - creating a low carbon economy, 
introduced a further long term aim of achieving a carbon dioxide emissions reduction of $60 \%$ by 2050 with real progress by 2020 (Department for Trade and Industry, 2003). Subsequently the Climate Change Act 2008 revised these targets to an emissions reduction of $80 \%$ of 1990 levels by 2050 and $34 \%$ by 2020 .

A further international agreement on $\mathrm{CO}_{2}$ emissions reduction was reached in December 2015 (CCC, 2016). The Paris Agreement is an agreement within the United Nations Framework Convention on Climate Change (UNFCCC) dealing with greenhouse gas emissions mitigation, adaptation and financing starting in the year 2020. The aims of the Agreement (i.e. to limit the rise in global temperatures to well below $2{ }^{\circ} \mathrm{C}$, to pursue efforts to hold it to $1.5^{\circ} \mathrm{C}$ and to reach net zero emissions in the second half of the century) are more ambitious than the basis of the UK's statutory target for 2050 (which aims to limit temperature rise to around $2^{\circ} \mathrm{C}$ ) $(\mathrm{CCC}$, 2016). Each signatory country determines, plans and regularly reports on its own contribution towards achieving the agreed target in order to mitigate global warming. The EU's target is $40 \%$ reduction on 1990 levels by 2030 . The UK government committed to reassess its stated $\mathrm{CO}_{2}$ reduction targets in light of the Paris Agreement and has now agreed its fifth carbon budget committing to a $57 \%$ reduction on 1990 levels by 2030 (CCC, 2016). 


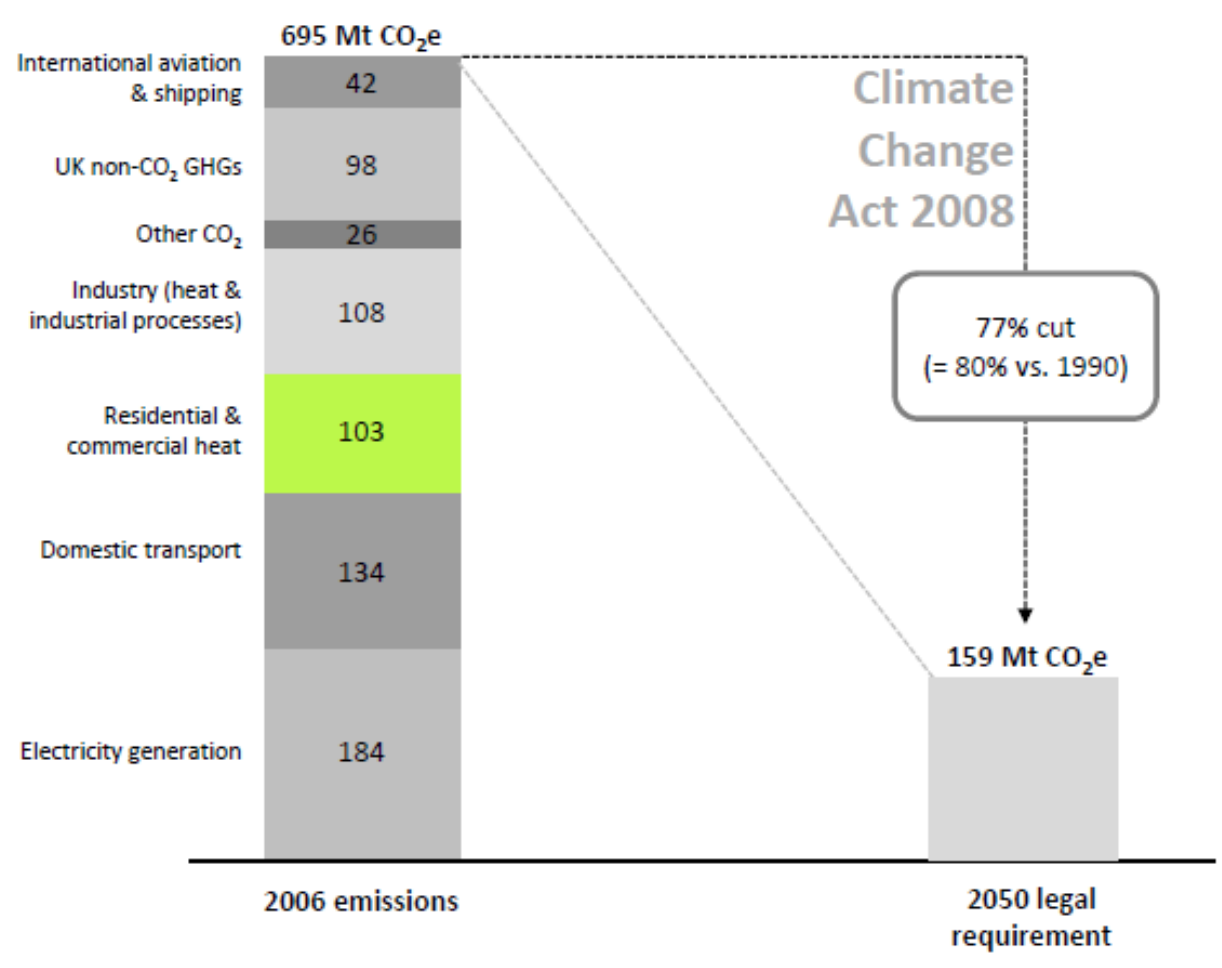

Source: Modified from LEEP, 2012

Figure 4: Reduction in emissions of $80 \%$ by 2050 (vs. 1990 levels)

Figure 4 above graphically illustrates the size of the task, identifying the output of emissions in 2006 and the Climate Change Act 2008 target of an emissions reduction of $80 \%$ of 1990 levels by 2050 , representing a $77 \%$ cut in the 2006 levels.

The government's way of ensuring achievement of the target was to set a series of five year "carbon budgets" via The Committee on Climate Change (CCC), commencing in 2008, which set out what was realistically achievable in each of the five-year periods. The first carbon budget for the period 2008 to 2012 established a requirement for the country's $\mathrm{CO}_{2}$ emissions to be limited to 3,018 $\mathrm{MtCO}_{2} \mathrm{e}(\mathrm{CCC}, 2008)$. This target was comfortably achieved with the CCC reporting in its annual progress report in July 2014 that the net carbon account was 2,982 $\mathrm{MtCO}_{2} \mathrm{e}$ for the first five year period $(\mathrm{CCC}, 2014)$. However, in the same report the CCC stated that achievement of the first carbon budget was met through a combination of the impact of the recent recession, and low-carbon polices in certain specific areas such as fuel efficiency of new cars and wind generation. Limited progress was made in other areas including energy efficiency improvement in the commercial and industrial sectors, uptake of electric vehicles 
and heat pumps, and demonstration of carbon capture and storage (CCC, 2014). The CCC went on to state in their report that more generally, the underlying pace of emissions reduction allowing for the impacts of the recession - through the first carbon budget period and in 2013 was insufficient to meet future carbon budgets. They had previously been more specific in their prediction in their 2013 progress report stating that:

The UK has met the first carbon budget and our assessment is that we are likely to meet the second carbon budget. However, we are not currently on track to meet the third and fourth carbon budgets.

(CCC, 2013, p10)

The CCC felt that there was significant work to do in terms of policy initiatives and incentives to reduce $\mathrm{CO}_{2}$ emissions if subsequent five-year carbon budgets are to be achieved on the way to meeting the UK 2050 target.

In its 2016 report the CCC reported that:

Whilst emissions have fallen by an average of $4.5 \%$ a year since 2012, this has been almost entirely due to progress in the power sector, particularly reduced use of coal as Government policies have driven an expansion of renewable generation.

There has been almost no progress in the rest of the economy, where emissions have fallen less than 1\% a year since 2012 on a temperature-adjusted basis. That is because there has been slow uptake of low-carbon technologies and behaviours in the buildings sector (i.e. low rates of insulation improvement, low take-up of low-carbon heat) and improved vehicle efficiency has been offset by increased demand for travel as the economy has grown and fuel prices have fallen. There is also minimal evidence of progress in the industrial and agriculture sectors.

Progress will need to be broader to meet the recommended fifth carbon budget and to prepare sufficiently for 2050. For example, while the complete replacement of coalfired generation with low-carbon generation in the power sector is an important part of our scenarios, this would provide less than half of the total emissions reduction required by 2030 .

(CCC, 2016, p12)

Therefore, it can be concluded that although progress in meeting the targets has been made, much greater progress needs to be achieved including within the buildings sector. 


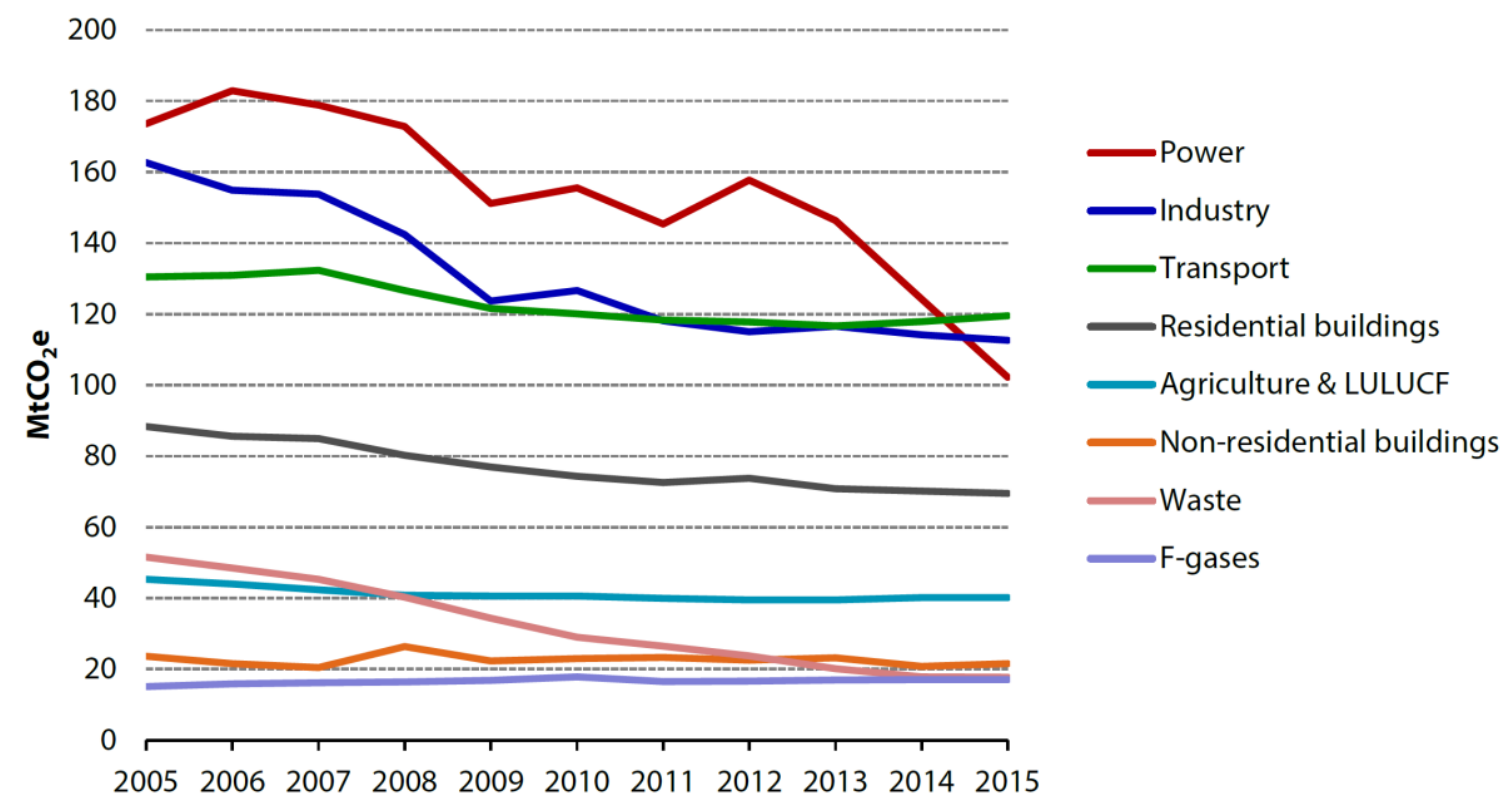

Source: CCC, 2016

Figure 5: $\mathrm{CO}_{2}$ emission reduction by sector 2005 - 2015

\subsection{Non-domestic buildings potential}

It is estimated that there are approaching two million commercial and public buildings, collectively known as non-domestic buildings, in the UK (Warren, 2009). These non-domestic buildings emit somewhere in the region of 100 million tonnes of $\mathrm{CO}_{2}$ per year, representing some $18 \%$ of the UK's total emissions (Caleb Management Services, 2009).

Caleb Management Services Ltd (2009) has identified a technical potential for 37 million tonnes of $\mathrm{CO}_{2}\left(\mathrm{MtCO}_{2}\right)$ savings, of which $20 \mathrm{MtCO}_{2}$ are a realistic potential. Earlier findings by the BRE (Pout et al., 2002), support this assessment with very similar figures.

The Committee on Climate Change (CCC) in their first report issued in 2008 identified the technical potential for savings of around $34 \mathrm{MtCO}_{2}$ by the year 2020 broken down in the following way: 
- Improving efficiency of heating/cooling of buildings could save over $5 \mathrm{MtCO}_{2}$

- Better management of energy - from motion sensitive lights to optimising heating temperatures and timing - could save over $8 \mathrm{MtCO}_{2}$

- Use of more efficient lights and appliances has the potential to reduce emissions by around $1.5 \mathrm{MtCO}_{2}$

- Microgeneration technologies have significant technical potential and could reduce emissions from buildings by up to $18 \mathrm{MtCO}_{2}$ comprising:

- Biomass boilers - $3 \mathrm{MtCO}_{2}$

- Heat pumps - Up to $5 \mathrm{MtCO}_{2}$

- Solar thermal - Around $2 \mathrm{MtCO}_{2}$

- $\quad$ Solar PV - Over $8 \mathrm{MtCO}_{2}$

(CCC, 2008)

More recently the consultancy firm Accenture undertook research for Barclays in an attempt to establish the amount of capital required to develop low carbon technologies, and to procure projects to implement them as low carbon investments in the EU during the period up to 2020 (Whitehouse et al., 2011). They broke down potential low carbon investments across all industry sectors into five categories including one for buildings. They also provided estimates of the level of $\mathrm{CO}_{2}$ that could be saved should these investments be realised. For the whole of the EU they estimated that $€ 88$ bn would be required in Development capital and $€ 600 \mathrm{bn}$ in Procurement capital for buildings alone, resulting in $403 \mathrm{MtCO}_{2}$ cumulative emissions savings. The report goes on to break down the figures for individual countries with the UK requiring $€ 77 \mathrm{bn}$ in Procurement capital, saving $49 \mathrm{MtCO}_{2}$ cumulative emissions (Whitehouse et al., 2011). Although the estimated emissions savings are higher than the other estimates stated, the Barclays report looks at all buildings including domestic dwellings.

Not only is there technical potential for reducing $\mathrm{CO}_{2}$ emissions in non-domestic buildings but the sector has been identified as one where the measures required to reduce emissions make economic sense in that they cost less per ton of carbon saved than the value of traded carbon credits, therefore they should be viable in investment terms (CCC, 2008). The Intergovernmental Panel on Climate Change, in its 2007 report, identified mitigation potential 
for different sectors worldwide with Buildings highlighted as having the most potential (IPCC, 2007), refer to Figure 6.

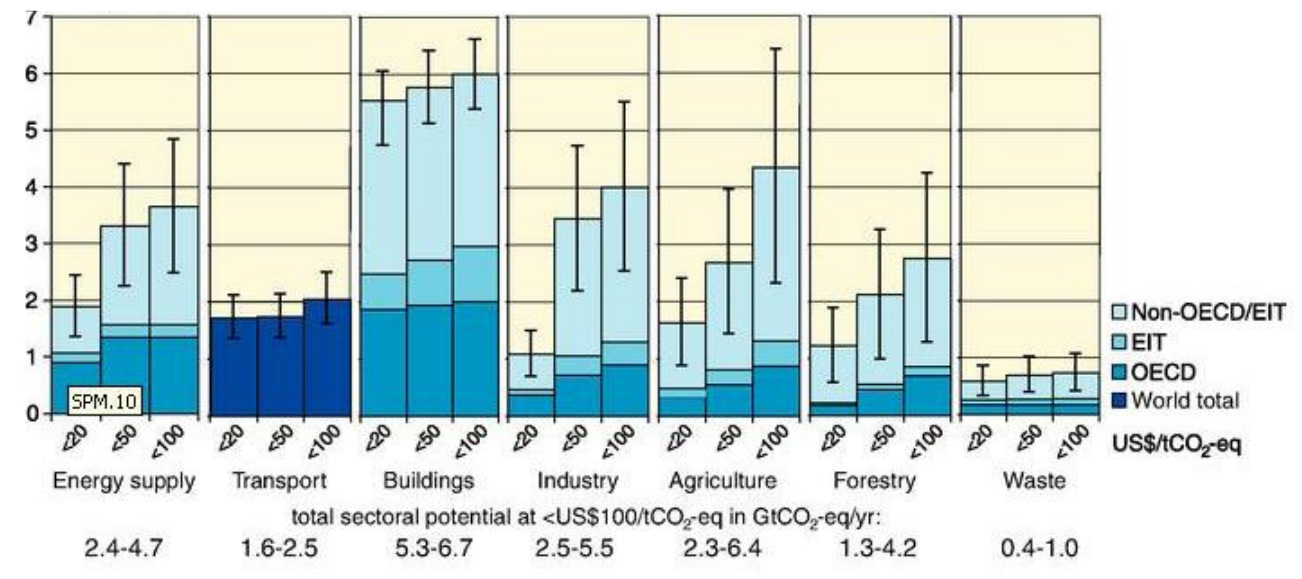

Source: IPCC, 2007

Figure 6: Economic mitigation proposals by sector in 2030

\subsection{Pension fund and institutional investors' funds to invest}

It is estimated that as of the end of 2016 there was around \$161trillion of funds under management globally, with \$101trillion in conventional funds consisting of Pension funds (\$36.4tr), Mutual funds (\$40.6tr) and Insurance funds (\$24.0tr), which was a 7\% increase on the previous year (Bardalai, 2018). This increasing trend is also reflected in the funds under management in the UK which is second only to the US with funds totaling $£ 8$.1trillion as of the end of 2016, a 17\% increase on the previous year (Bardalai, 2018). By far the largest proportion of funds comes from institutional investors, public and private pension funds and insurance companies. Figure 7 illustrates the typical percentage share of funds under management and Figure 8 indicates the continuing rise of funds under management. 


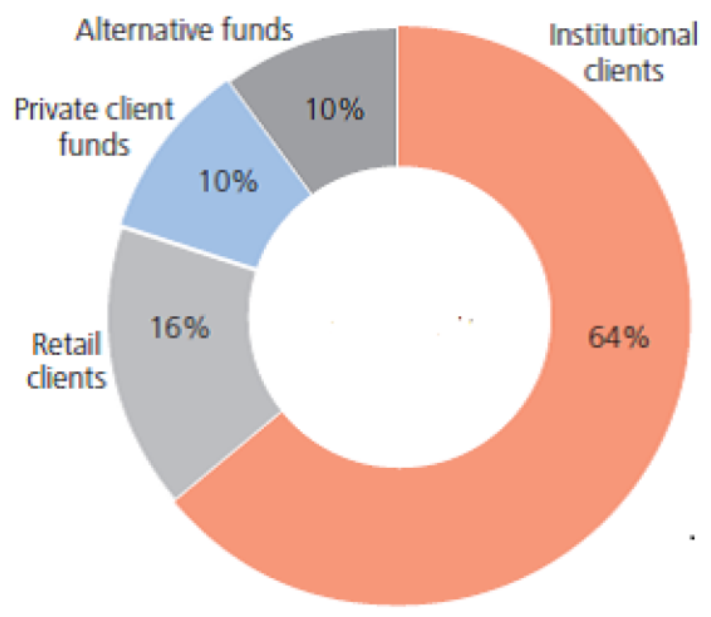

Source: Adapted from Maslakovic, 2014a

Figure 7: Typical \% share of funds under management in the UK

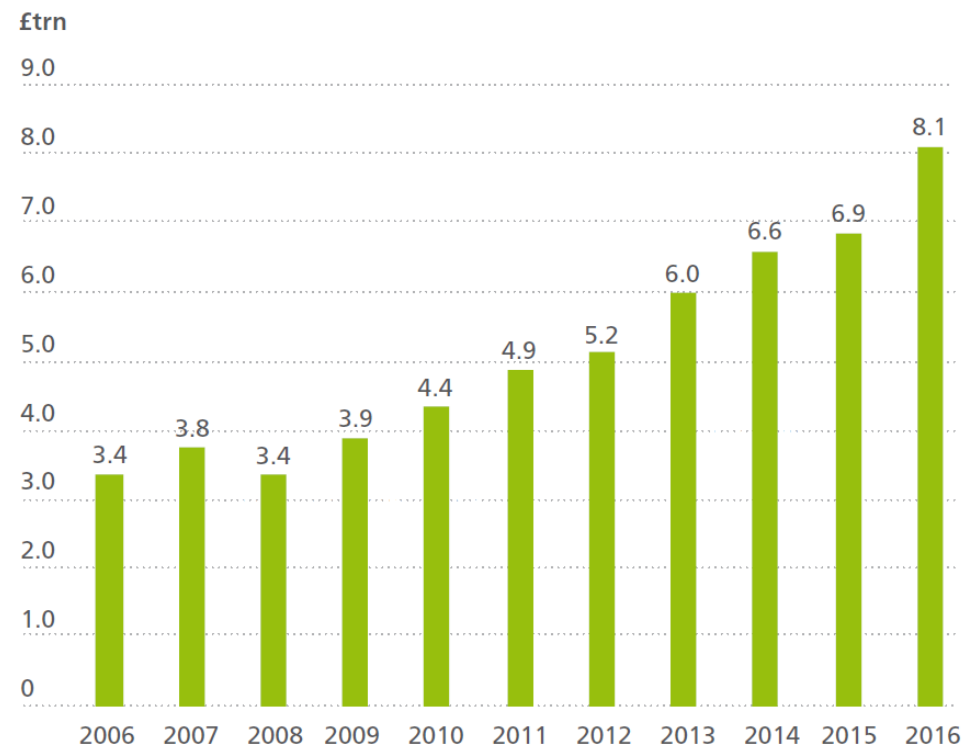

Source: Bardalai, 2018

Figure 8: Growth of funds under management in the UK

These funds are invested in established asset classes in order to create a well-diversified portfolio designed to optimise investment returns (Laboul, 2013). The largest proportion of funds is invested in the traditional asset classes of equities and bonds. The investment community is generally conservative in its approach to risk, therefore it is unlikely that there 
will be a significant shift away from these types of investments (Laboul, 2013). However, there are an increasing number of alternative asset classes that are increasing in importance, such as property, infrastructure and private equity, but these still only account for a small fraction of the available funds (Bekkers et al., 2009). As at the end of $201142 \%$ of managed funds in the UK were invested in equities and 38\% in fixed income bonds (Maslakovic, 2012). Figure 9 identifies the asset allocation of funds under management at the end of 2011. Although property has established itself as a distinct asset class, infrastructure for example, along with other nontraditional investments, remains firmly an alternative investment and therefore seen as higher risk and would fall within the 'Other' classification, which is running at about $9 \%$ of the available funds (Maslakovic, 2012).

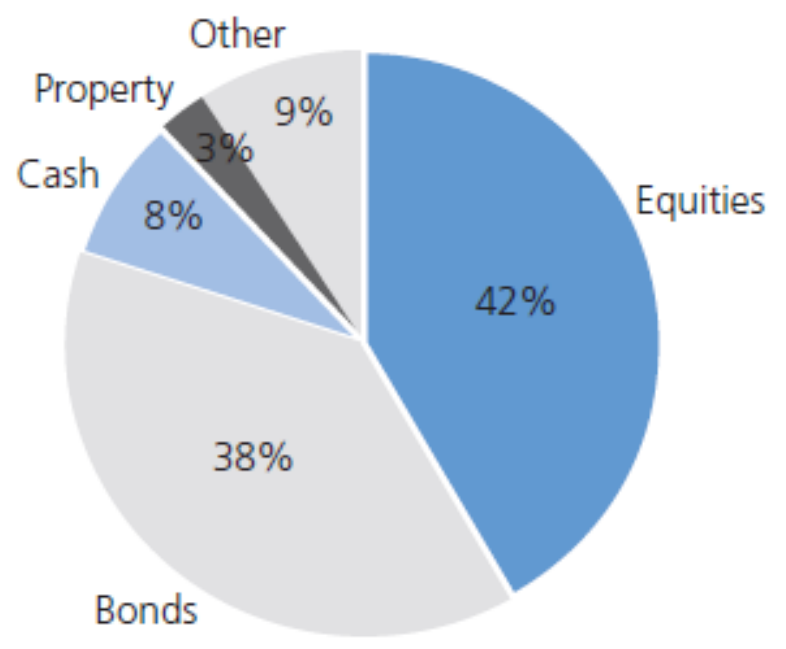

Figure 9: Asset allocation of funds under management, 2011

\section{Energy Efficiency Investment}

With its $\mathrm{CO}_{2}$ emission reduction potential, investment in energy efficiency in non-domestic buildings in the UK could go some significant way to meeting the $\mathrm{CO}_{2}$ reduction targets. However, significant investment capital running into billions is needed if this potential is to be realised with Accenture estimating $€ 77 \mathrm{bn}$ of investment being required in building energy efficiency retrofitting to 2020 (Whitehouse et al., 2011), albeit across the whole sector not just for non-domestic properties. (Note: the figure quoted above is in Euros as the Accenture report 
was Europewide and $€ 77 \mathrm{bn}$ of investment was identified as required for the UK only). In order to realise its potential, a way needs to be found to make these investments attractive for institutional investors who are actively looking to make investments that match their obligations with ever increasing sums under management.

The introduction of Public Private Partnerships in both the UK and globally has seen an increase in institutional investment into the infrastructure sector providing equity and more recently debt finance (Maslakovic, 2014b). To some extent this increase in funding of infrastructure by institutional investors has been driven by the fact that infrastructure transactions tend to have long term steady revenues that can be matched to investors' longterm obligations to their pension holders and policy holders. The objective of this research is to identify those enabling conditions that would allow investments to be made in energy efficiency at scale in much the same way as has been seen in infrastructure, and to better understand the decision-making process of institutional investors when deciding whether or not to invest in energy efficiency.

\subsection{What is Energy Efficiency?}

The first issue that needs to be addressed is that of definition. What is energy efficiency and what is an energy efficiency investment? These may appear to be unusual questions to ask but they are relevant if a new investment asset class is to be established and they are at the heart of solving the issue of increasing institutional investment into the sector. Although their characteristics are different, investment in energy efficiency is often discussed together with investment in renewable energy, and termed collectively as low carbon or green investments (Usher, 2008, UNEP, 2010). Whereas renewable energy creates a return from producing energy, energy efficiency creates its cash flow from energy conservation and therefore through costs being saved (Kaminker and Stewart, 2012, p27).

This concept is counterintuitive for investors and funders who will always look for structural cash flow protection in an investment (Inderst, 2009, p29). In an infrastructure or renewable energy investment this is often in the form of loan guarantees (ibid), direct agreements with paying authority or off take agreements. In the context of cash flow from energy saved they will look to the operational efficiency of the technology concerned, or will have to rely on the 
corporate covenant of an ESCO for example (Fawkes, 2013a, p166). This approach could prove more difficult and riskier as it is a move away from the norm (Kaminker and Stewart, 2012), which is important for investors that may be considering other more conventional investment opportunities alongside an energy efficiency potential investment and will intuitively tend towards the familiar where they may even have collateral in a tangible asset (Baddeley, 2013, p218).

Additionally, investors will need to decide where energy efficiency fits within the established asset classes (Fawkes, 2013a, p174). It falls within the 'Alternative' investment sphere but will it be grouped together with renewable energy? As will be seen from the interviews in this research energy efficiency is increasingly being seen as a subset of infrastructure but equally energy efficiency could be viewed as a real estate investment as in the main it relates to energy saving measures as applied to existing buildings or facilities and could therefore be included in a real estate 'pot'. A third option, that has again has been reflected in the research interviews, is that it could be regarded as Private Equity depending on the way the investment is made with short terms and high returns. The distinction is important as investors will expect different levels of return for classes of investment as risk perception changes between the classes. The desire by ethically aware institutional investors and pension funds for investment into Socially Responsible Investments (SRI), including those in environmental and low carbon projects, is often not at the expense of maximising returns (Viederman, 2008). Although there may be a strong ethical theme in an institutions investment strategy they will also have an overriding fiduciary duty to their pension holders or insurance policy holders and will therefore need to realise the best financial returns possible. Therefore, energy efficiency investments, as with other more mainstream investments, will traditionally need to at the very least maintain a commercial level of return if they are to compete for the funds available for investment, although they can of course use their green credentials to attract those investors that have an ethical strategy.

What is energy efficiency and how does it translate into a project that can be invested in and a return achieved. Energy Efficiency is typically seen as being applied to the Transport, Industrial and Buildings sectors and this, for example, is how the International Energy Agency presents its annual global tracker of energy efficiency trends and indicators (IEA, 2018). 
Energy efficiency essentially means a reduction in energy input to produce a certain output, for example reducing energy usage in a building from $300 \mathrm{kWh} / \mathrm{m} 2$ to $200 \mathrm{kWh} / \mathrm{m} 2$ per annum assuming constant comfort conditions and building usage (EEFIG, 2017). Installation of LED lighting is a typical example where a 16-watt LED that replaces a 34-watt fluorescent light produces the same light at roughly one half of the energy usage. Fawkes (2013a) asserts that the process of improving energy efficiency or reducing energy input for a given output is a process of technical and /or behavioural change that is driven by technical, financial, management, social and political drivers. It can certainly be demonstrated that improvements in energy efficiency can be achieved from changes in management practices and management systems where there has not necessarily been a change or upgrade in technology (EEFIG, 2017). Large gains in efficiency can be achieved for example by adjusting the control settings of existing equipment, or managing industrial processes within tighter limits, or reducing waste levels (EEFIG, 2017). However, the largest and most permanent energy savings can only be delivered through investment into more efficient equipment and processes (EEFIG, 2017).

Institutional investment into energy efficiency is most likely to be associated with a retrofit of a building or industrial process than the financing of a new building or factory where energy efficiency measures are integrated within the new facility and are regulated by a new building code requirement or an industry reference standard that has referenced new energy efficiency requirements. Retrofits or upgrades efficiency gains are typically measured by a performancebased comparison of new equipment, processes or the whole building/facility against those they replaced (EEFIG, 2017).

The EEFIG (2017), in the 'Resources' section of its underwriting tool kit has identified major energy efficiency technologies that can be implemented to reduce usage. It has also identified that energy efficiency is often associated with on-site generation of power (and heat), particularly renewables such as solar and biomass, and other technologies such as Combined Heat and Power (EEFIG, 2017). These measures do not themselves improve energy efficiency on the site but can reduce the usage, and hence cost, of purchased energy coming onto a site or into the building (EEFIG, 2017). Similarly, energy efficiency is also associated with demand response i.e. the short-term shifting of electrical load however this does not permanently reduce load. Although these measures are not true energy efficiency measures, they can improve the overall efficiency of the power system (EEFIG, 2017). 
If a strict view of energy efficiency is taken on-site generation of power and demand response should not be included as energy efficiency is about reducing the end use of energy for a given output (Fawkes, 2013a, p7, EEFIG, 2017). Renewable energy is just an alternative way of generating heat or electricity and does not reduce end-use efficiency (Fawkes, 2013a, p7). It is a way of substituting or reducing the consumption of fossil fuels and therefore assists in the achievement of a higher overall efficiency in the electricity system but Fawkes (2013a p7) suggests that renewable energy systems should not generally be thought of as part of 'energy efficiency'.

The Green Investment Bank (GIB) has specifically identified non-domestic energy efficiency along with offshore wind and waste as sectors that it would invest into with the aim of attracting greater institutional investment. (Watson, 2013). So how does the GIB define non-domestic energy efficiency? Table 1 identifies the GIB's view of the sector and includes a classification for some measures as being applicable to the Public Sector. Of course, those measures identified as non-domestic energy efficiency are also applicable to the Private Sector and the GIB has supported investments in the Private Sector in these areas. The GIB has also specifically identified measures for industrial processes and smart meters. However, its noteworthy that the GIB has specifically identified certain renewable energy measures and CHP within their definition of energy efficiency measure that they are willing to fund and encourage frther institutional investment when they are not strictly energy efficiency measures in the truest sense.

\section{Applicable to Public Sector}

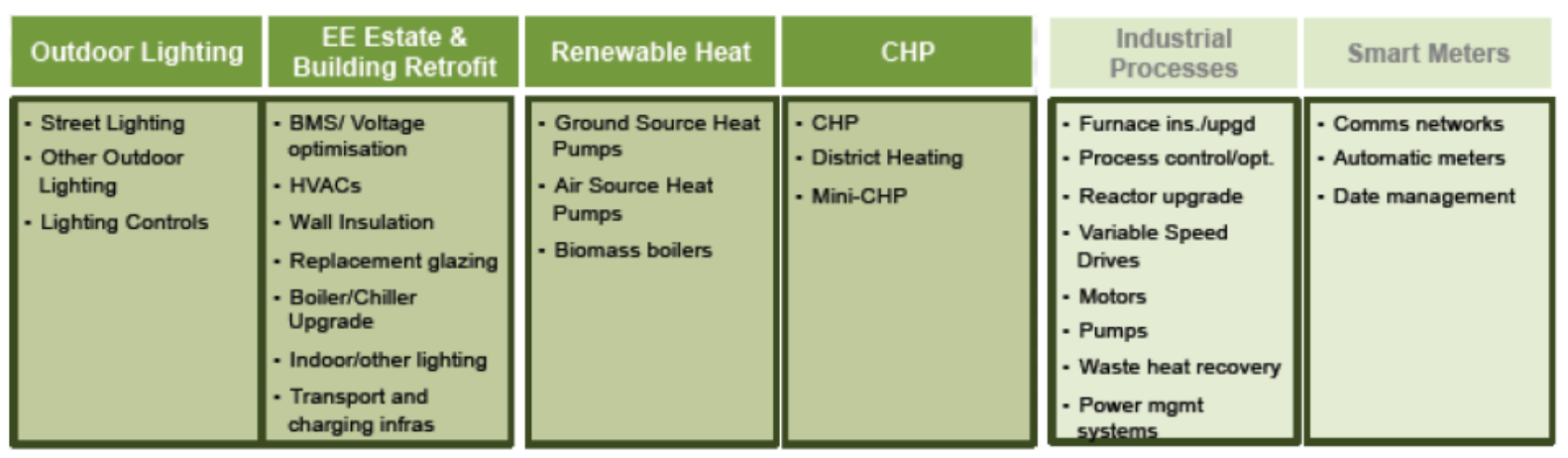

Source: (Watson, 2013) 
Table 1: The Green Investment Bank view of non-domestic energy efficiency

Just as there are many technologies that fall into the definition of energy efficiency, they are present in many different types of buildings and portfolios of buildings which affects the method of procuring and financing energy efficiency investments within those buildings or portfolios of buildings. The level of government subsidies and support for the renewable heat technologies, most notably biomass boilers, distinguishes them from building retrofit transactions for example that have no such subsidies. Depending on the size of the transaction, investment in a retrofit of buildings or portfolios of buildings may be suited to an Energy Performance Contract procurement method.

\subsection{UK government subsidies and support}

As outlined in the previous section, energy efficiency is hard to define and in its purest form it relates to conservation measures that save energy use, such as those listed in the building retrofit classification of the GIB view of non-domestic energy efficiency. However, renewable heat measures such as ground and air sourced heat pumps and biomass boilers can be viewed as energy efficiency measures, as they are installed to replace inefficient technology (in terms of carbon emissions) and the GIB certainly has classified them as such (Watson, 2013). They produce 'clean' energy without the emissions of the technology that they replace. The UK government has incentivised the use of these measures in the form of subsidies, making them a more attractive investment proposition, which will now be considered.

\subsubsection{Renewable Heat Incentive}

The Renewable Heat Incentive (RHI) for non-domestic buildings, launched in November 2011, is a government initiative designed to provide support to renewable heat technologies in order to increase deployment and aid market development, with the ultimate aim of reducing cost of installation (BEIS, 2016). It is available for the first 20 years of a project (BEIS, 2016). The RHI supports heat where that heat is used in a building for 'eligible purposes': heating a space, heating water, or for carrying out a process where the heat is used (BEIS, 2016). Heat utilised 
to produce or process the renewable fuel, or used for electricity generation, does not qualify for RHI (BEIS, 2016).

\subsubsection{Renewable Obligation Certificates}

Although now phased out, Renewable Obligation Certificates (ROCs) offered a way in which generators could secure a certain level of revenue for the life of a project. Electricity suppliers were obliged each year to source a certain percentage of their power from renewable sources (HMRC, 2016). To achieve this the government implemented the Renewables Obligation scheme. Through this scheme it set a percentage level of renewables that needed to be generated (HMRC, 2016). Renewable energy generators are issued with Renewable Obligation Certificates (ROCs), and suppliers have to present a certain amount of ROCs to the government (OFGEM, 2014). The obligation level was set each year.

For each MWh of renewable electricity that was generated, a generator received a certain amount of ROCs (OFGEM, 2014). Initially, one ROC was issued for each MWh that was generated. However, the number of ROCs issued ultimately became linked to technology type, to give more support to higher risk and emerging technologies. Some types of technology received more and some less than 1/MWh (OFGEM, 2014). A project was being supported with ROCs for 20 years from date of commissioning (OFGEM, 2014). The benefit of the ROC is that it delivered a steady revenue for the life of the project. Generators could either sell the ROCs on the open market or contract with an off taker, who might offer to pay a percentage of the total value.

The Renewables Obligation and ROCs were ended in April 2017 with the government having introduced an alternative subsidy scheme called Contracts for Difference (CfD) in 2014. Between the introduction of CfDs in 2014 and ROCs ceasing to be available in 2017 both schemes were running and developers could choose which scheme to apply for, to get government support (OFGEM, 2014). ROCs will remain available for generators that signed up prior to April 2017.

\subsubsection{Contracts for Difference}


The CfD works by guaranteeing renewable energy generators a price of electricity (called the strike price) (BEIS, 2017). The government will make up the difference between the market price and the strike price; if the market is lower the generator receives money, if the market is higher the generator will have to pay back whatever it has received that was above the strike price (BEIS, 2017).

\subsection{Financing of Energy Efficiency}

There have been many proposed financing mechanisms to fund energy efficiency, Ya He (2012) identified thirteen major financing mechanisms for energy efficiency including mechanisms such as the UK Green Deal which was discontinued in 2015 due to poor take up and lack of government support, although a version of it has emerged again in 2017 backed by the private sector (Richards, 2016, Affordable Warmth Scheme, 2017). Ya He (2012) also included US-centric mechanisms such as Property Assessed Clean Energy (PACE) (Fawkes, 2013b, Ya He, 2010). However, the more comprehensive and current summary of the financing mechanisms used to finance energy efficiency is provided by the EEFIG in their 2017 underwriting toolkit, refer to Table 2 (EEFIG, 2017).

This research project is concerned with investment at scale. In order to attract investment at scale there would need to be a fully developed liquid market where investments in transactions can be traded (CBI, 2018, Fawkes, 2013a, pp174-175, EEFIG, 2017). Scale will allow aggregation of investments and securitisation where cash flows from transactions are grouped together and a bond is issued and sold to institutional investors for which investors would need to have sufficient confidence in the underlying performance to make investment a realistic proposition (CBI, 2018, Kaminker and Stewart, 2012, pp26-27, EEFIG, 2017). Clearly those conditions do not exist currently, certainly not in the UK, however PACE loans have been successfully securitised in the US (Fawkes, 2014).

In order for securitisations to be successful investors will need to understand the performance of the underlying energy efficiency loans. The EEFIG in their 2015 report identified the lack of evidence on the performance of energy efficiency investments, and the lack of commonly agreed procedures and standards, among others, as problems in driving new finance for energy 
efficiency investments (EEFIG, 2015). The EEFIG response to these issues has been to instigate initiatives that directly address them. In order to address the lack of evidence on the performance of energy efficiency investments the EEFIG instigated the EEFIG De-risking project which created the De-risking Energy Efficiency Platform (DEEP). DEEP is an open source database for energy efficiency investments performance monitoring and benchmarking, based on evidence from implemented projects. The main objective of DEEP is to improve the understanding of the real risks (especially performance risks) and benefits of energy efficiency investments based on market evidence (EEFIG, 2016). At its launch in November 2016 the DEEP database included more than 7,800 energy efficiency projects in buildings and industry from 25 data providers (EEFIG, 2017). The issue of the lack of commonly agreed procedures and standards for energy efficiency investments has been, to a degree, addressed by the EEFIG DEEP and underwriting toolkit initiatives however it has been significantly developed and implemented by the EU funded Investor Confidence Project (EEFIG, 2017, ICP n.d.). The goal of these initiatives is to increase energy efficiency financing at competitive terms through improving risk assessment and reducing transaction costs (EEFIG, 2016).

One financing method, Energy Performance Contracting identified by Ya He and the EEFIG, has been established for a number of years and while it is not appropriate to every situation it has long been proposed as the way forward for energy efficiency (Fawkes, 2013c, Fawkes, 2013b), and is utilised in a significant proportion of investments forming the basis of the research and is therefore further outlined in the coming sections.

\begin{tabular}{|l|l|}
\hline Savings or Equity. & $\begin{array}{l}\text { Use of consumer or corporate funds to fund energy efficiency } \\
\text { improvements or projects. }\end{array}$ \\
\hline $\begin{array}{l}\text { Loans/mortgages specifically } \\
\text { for energy efficiency upgrades } \\
\text { in residential and commercial } \\
\text { commerce. }\end{array}$ & $\begin{array}{l}\text { Normal consumer and commercial lending. In most cases loans } \\
\text { are not specifically identified as energy efficiency lending as it is } \\
\text { not known whether energy efficiency is the main purpose of it is } \\
\text { embedded into a larger project. Most consumer and commercial } \\
\text { loans are recovered from the borrower in the normal way } \\
\text { however there are specialist means of means of recovery in the } \\
\text { global market which have potential for use in the European } \\
\text { Market, namely On-bill Recovery and Property Assessed Clean } \\
\text { Energy (PACE). }\end{array}$ \\
& $\begin{array}{l}\text { On-bill recovery. Once a consumer has applied for a loan } \\
\text { for an energy efficiency project, the repayments are } \\
\text { added to, and repaid, through its electricity bill. The UK } \\
\text { Green Deal was an On-bill recovery mechanism. }\end{array}$ \\
\hline
\end{tabular}




\begin{tabular}{|c|c|}
\hline & $\begin{array}{l}\text { PACE. Largely used in the US this form of financing } \\
\text { allows loans to be made for energy efficiency and } \\
\text { renewable energy projects repaid via an additional } \\
\text { payment on a property's regular property bill. }\end{array}$ \\
\hline $\begin{array}{l}\text { Loans/mortgages specifically } \\
\text { for the purchase of energy } \\
\text { efficient buildings }\end{array}$ & $\begin{array}{l}\text { A green or energy efficiency mortgage is one that issued to } \\
\text { finance a purchase of an energy efficient building or refurbish a } \\
\text { building to a higher standard of efficiency. }\end{array}$ \\
\hline $\begin{array}{l}\text { Leasing for energy efficiency } \\
\text { products }\end{array}$ & $\begin{array}{l}\text { Leasing is an established method of financing energy efficiency } \\
\text { projects and typically cover all material, labour and soft costs } \\
\text { associated with an energy efficiency project. The energy } \\
\text { efficiency equipment being installed is the collateral for the } \\
\text { financing. }\end{array}$ \\
\hline $\begin{array}{l}\text { Ensuring normal } \\
\text { lending/investment for } \\
\text { everyday building } \\
\text { refurbishments or upgrades } \\
\text { incorporate the optimum level } \\
\text { of costs-effective energy } \\
\text { efficiency products }\end{array}$ & $\begin{array}{l}\text { For everyday loans, mortgages, leases for and investments made } \\
\text { into new buildings, building refurbishments and replacement of } \\
\text { industrial processes and production plants are, in most cases, } \\
\text { not for energy efficiency as the primary purpose of the } \\
\text { investment. This means that many opportunities to improve } \\
\text { energy efficiency are missed. Banks and financial institutions can } \\
\text { play an active role in ensuring that financial projects of all types } \\
\text { achieve optimum levels of efficiency over and above business as } \\
\text { usual by adjusting their lending/investing processes to include } \\
\text { queries about energy efficiency. }\end{array}$ \\
\hline $\begin{array}{l}\text { Specialised energy efficiency } \\
\text { funds offering equity or debt } \\
\text { for projects }\end{array}$ & $\begin{array}{l}\text { Specialist funds for energy efficiency have long been in existence } \\
\text { created by multi-lateral banks such as the World Bank, the } \\
\text { Renewable Resources and Energy Efficiency Fund for example. } \\
\text { More recently a number of specialist funds have been } \\
\text { established using private and public sector funds offering a } \\
\text { range of equity and debt financings for energy efficiency often } \\
\text { using Energy Efficiency Contracts. Examples include the London } \\
\text { Energy Efficiency Fund, the SUSI Energy Efficiency Fund and the } \\
\text { three Green Investment Bank funds managed by Equitix, SDCL } \\
\text { ad Aviva. }\end{array}$ \\
\hline $\begin{array}{l}\text { Property funds specifically for } \\
\text { energy efficient/green } \\
\text { buildings }\end{array}$ & $\begin{array}{l}\text { Property funds based on purchasing properties and making them } \\
\text { more energy efficient have been established in a number of } \\
\text { countries. Examples include the Credit Suisse European Climate } \\
\text { Value Property Fund and the Low Carbon Workplace Fund. }\end{array}$ \\
\hline $\begin{array}{l}\text { Financing of specialised } \\
\text { energy service contracts } \\
\text { including: }\end{array}$ & $\begin{array}{l}\text { The two most common forms of energy service contract are } \\
\text { Energy Performance Contracts (EPCS) and Chauffage contracts. } \\
\text { Both have been in use in Europe for many years. They are } \\
\text { relatively complex and the cost of developing these contracts } \\
\text { means they are restricted to relatively large capital value } \\
\text { projects. They are described below together with other types of } \\
\text { energy services contracts that are starting to emerge. }\end{array}$ \\
\hline
\end{tabular}




\begin{tabular}{|c|c|c|}
\hline & $\begin{array}{l}\text { Energy Performance } \\
\text { Contracts }\end{array}$ & $\begin{array}{l}\text { EPCs are a contractual arrangement between the beneficiary } \\
\text { and the provider of an energy efficiency improvement measure } \\
\text { or measures in which the provider, an Energy Service Company } \\
\text { (ESCO) provides a guarantee of performance for the installed } \\
\text { measures. The ESCO does not generally provide the requited } \\
\text { capital but usually works with established lenders to facilitate } \\
\text { provision of finance, although the customer can also decide to } \\
\text { directly finance the project with its own equity. The ESCO's } \\
\text { guarantee is meant to ensure that the savings are sufficient to } \\
\text { pay debt service. If the is a shortfall, the host but not the lender, } \\
\text { has recourse to the ESCO. }\end{array}$ \\
\hline & Chauffage contracts & $\begin{array}{l}\text { Under Chauffage (Energy Supply Contracting) the contractor } \\
\text { takes over the provision of an agreed set of energy services. The } \\
\text { host pays the contractor some historical average of its energy } \\
\text { cost. The contractor then takes responsibility for all elements of } \\
\text { energy services, including purchasing fuel for the building and } \\
\text { upgrading systems. }\end{array}$ \\
\hline- & $\begin{array}{l}\text { Efficiency Services } \\
\text { Agreements }\end{array}$ & $\begin{array}{l}\text { In an Efficiency Services Agreement (ESA), a developer retrofits } \\
\text { the host property and the host property pays the developer the } \\
\text { savings, typically with a negotiated discount to the facility's } \\
\text { historical costs. }\end{array}$ \\
\hline- & $\begin{array}{l}\text { Managed Energy } \\
\text { Service Agreements }\end{array}$ & $\begin{array}{l}\text { In a Managed Energy Services Agreement (MESA) the developer } \\
\text { assumes responsibility for payment of utility bills on behalf of } \\
\text { the host asset. Rather than a bill based on savings, the host asset } \\
\text { pays the developer an amount equal to the historical energy } \\
\text { usage adjusted for current energy rates, weather, and } \\
\text { occupancy of the building. }\end{array}$ \\
\hline & $\begin{array}{l}\text { Metered Energy } \\
\text { Efficiency Transaction } \\
\text { Structure contracts }\end{array}$ & $\begin{array}{l}\text { The fundamental difference in th the Metered Energy Efficiency } \\
\text { Transaction Structure (MEETS) is that energy efficiency is } \\
\text { measured. This is achieved by combining smart meter } \\
\text { consumption data and building modelling to produce a dynamic } \\
\text { baseline, against which savings are measure. Units of energy } \\
\text { saved are then paid for on a per unit basis. }\end{array}$ \\
\hline- & $\begin{array}{l}\text { Lighting as a Service } \\
\text { contracts }\end{array}$ & $\begin{array}{l}\text { LED and internet enabled lighting offers rapid paybacks on } \\
\text { lighting conversions and Lighting as a Service (LaaS) models are } \\
\text { growing. The provider installs lighting at no cost to the end client } \\
\text { and finances the project, usually through leasing or asset } \\
\text { finance. They also take on maintenance of the system and lamp } \\
\text { replacements with the customer paying a regular service fee. }\end{array}$ \\
\hline \multicolumn{2}{|c|}{$\begin{array}{l}\text { Secondary financing can be } \\
\text { achieved through: }\end{array}$} & $\begin{array}{l}\text { In order to grow the energy efficiency financing market it is } \\
\text { essential to have an active market in secondary financing in } \\
\text { order to recycle capital. The secondary market is only now } \\
\text { starting to emerge due to the relatively small scale of the energy } \\
\text { efficiency market and the lack of standardisation and }\end{array}$ \\
\hline
\end{tabular}




\begin{tabular}{|c|c|c|}
\hline & & $\begin{array}{l}\text { aggregation of projects. The various secondary market financing } \\
\text { methods are outlined below. }\end{array}$ \\
\hline- & $\begin{array}{l}\text { Forfaiting funds } \\
\text { purchasing receivables } \\
\text { from energy service } \\
\text { contracts }\end{array}$ & $\begin{array}{l}\text { Energy service contracts such as Energy Performance Contracts } \\
\text { produce long-term stable cash flows which canbe an attractive } \\
\text { asset for long-term investors. Forfaiting funds can refinance EPC } \\
\text { contracts, allowing primary investors and funders to recycle } \\
\text { their capital into new projects. }\end{array}$ \\
\hline & Bonds & $\begin{array}{l}\text { Green bonds are likely to be important for the re-financing of } \\
\text { green mortgages and retrofit projects once a sufficient volume } \\
\text { of projects can be aggregated. A set of standardised projects can } \\
\text { be aggregated and refinanced through a bond issuance. Pooled } \\
\text { retrofits have been refinanced by bonds in the United States. A } \\
\text { secondary bond market would allow primary lenders for energy } \\
\text { efficiency to recycle capital and grow their energy efficiency } \\
\text { lending portfolios. }\end{array}$ \\
\hline & Yieldcos & $\begin{array}{l}\text { Yieldcos have emerged for renewable energy portfolios as this } \\
\text { market has matured and this may have a futre application in } \\
\text { energy efficiency. A yieldco bundles together a series of } \\
\text { renewable transactions and this aggregation blends risk and } \\
\text { allows for steady, predictable returns. It allows parent } \\
\text { companies to raise cheaper capital for established projects and } \\
\text { to recycle the capital for new project development. }\end{array}$ \\
\hline
\end{tabular}

Source: Extracted from EEFIG, 2017

Table 2: Financing mechanisms for energy efficiency

\subsection{Energy Performance Contracting}

Energy Performance Contracting (EPC) is a method of implementing an energy efficiency project on a building or portfolio of buildings. It is distinguished from a project supplying energy services only, employing an Energy Performance Provider Company (ESPC), in a very important way. An EPC project is a project implemented using an Energy Services Company (ESCO) and although they offer the same services as an ESPC, they either guarantee the energy savings and/or the provision of the same level of energy service at a lower cost (Hansen et al., 2009). 
ESCOs accept some degree of risk for the achievement of improved energy efficiency in a user's facility and have their payment for services delivered based on the achievement of the energy efficient improvements provided. EPC has been defined by Bertoldi and Rezessy (2005) as:

A form of 'creative financing' for capital improvement which allows funding energy efficiency upgrades from cost reductions. The approach is based on transfer of technical risks from the client to the ESCO based on performance guarantees given by the ESCO. In EPC, ESCO remuneration is based on demonstrated performance; a measure of performance is the level of energy or cost savings or the level of energy service. EPC is a means to deliver infrastructure improvements to facilities that lack energy engineering skills, manpower or management time, capital funding, and understanding of risk or technology information. Cash-poor, yet creditworthy, customers are therefore good potential clients for EPC.

(Bertoldi and Rezessy, 2005, p18)

Figure 10 graphically illustrates savings that are achieved in an EPC contract. Once the energy efficiency measures known generically in the EPC industry as Energy Conservation Measures (ECMs) are implemented, ongoing operational costs are reduced and the guaranteed savings are realised during the period that the contract is in place. During the contract period the ESCO provides an operational service managing the facility or facilities. Once the contract has finished the annual operational cost savings may continue to be realised. 


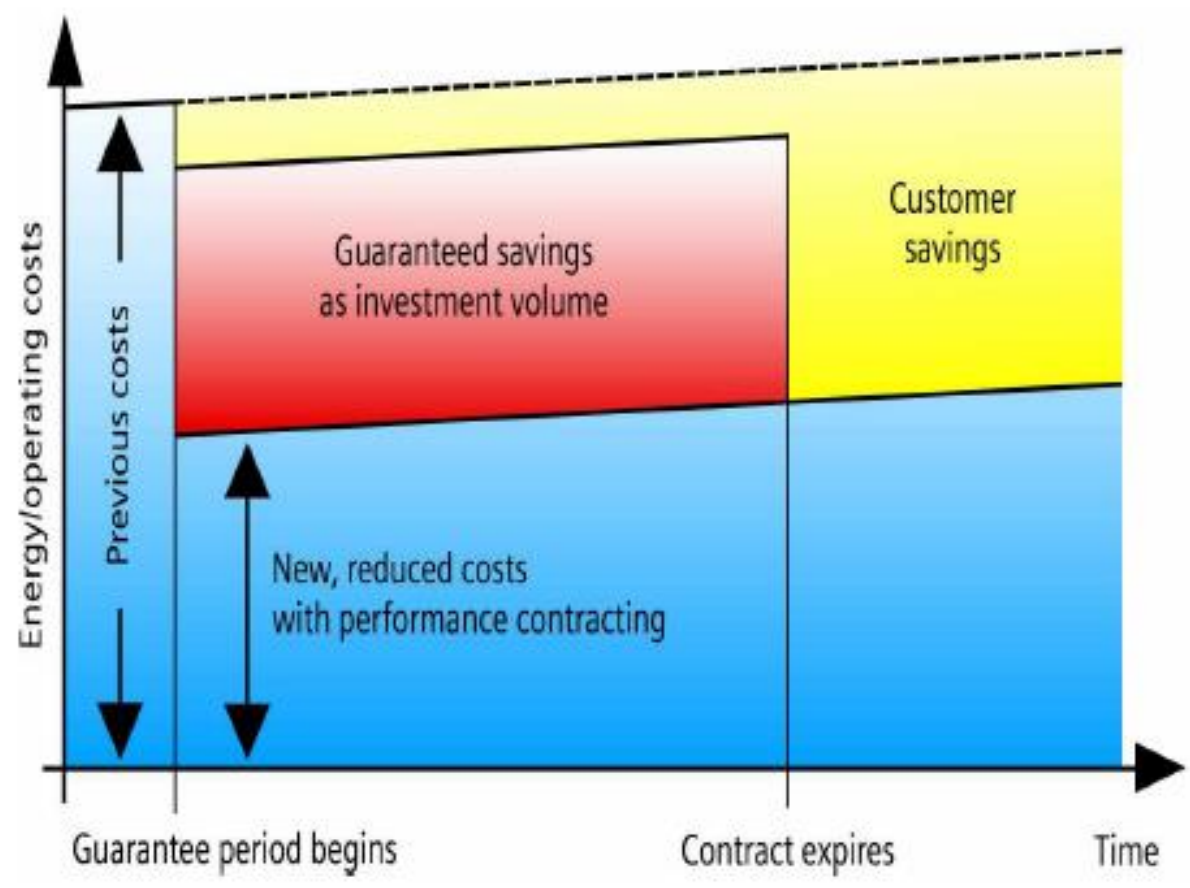

Source: McClain, 2008

Figure 10: The Energy Performance Model

\subsubsection{History and Development}

As far back as the late 1970s, energy services companies (ESCOs) and an energy efficiency business model started to emerge, although at that stage the driver was not necessarily the meeting of carbon reduction targets but saving money for the customer and the making of a profit for the provider. The first to offer such a service was a company called Scallop Thermal, a division of Royal Dutch Shell, which offered its customers in the UK and US to deliver conditioned space at 90 percent of their current utility bills (Hansen et al., 2009, p5). The concept provided that each party would share a predetermined percentage split of the energy financial savings and during the life of the contract the ESCO would expect its percentage of the cost savings to cover all its costs and provide a profit. However, in the mid-1980s the oil prices dropped and it took longer than expected for the ESCOs to recover their costs, and some paybacks became longer than the contracts they related to. This meant that the ESCOs could not make their payment to suppliers or financial backers and ultimately some defaulted on their commitments to customers on the shared savings of energy costs (Hanson et al, 2009 p5). As a result the concept became tainted. 
However, the fledgling energy efficiency industry survived with some modifications as with the increasing uncertainty in the industry and energy pricing, perceived risk levels grew and with them financing interest rates. In the US a new contract structure emerged which moved away from the established or 'shared savings' structure towards guaranteed energy performance or 'guaranteed savings' and became known as Energy Performance Contracting (EPC). This revised concept not only offered guaranteed savings in energy used, but also that the value of the saved energy would be sufficient to meet the customer's debt service requirements provided the price of energy did not drop below a specified floor price (Hansen et al., 2009, p6). The use of the original 'shared savings' agreements shrank to around 5 percent of the US market as 'guaranteed savings' became the dominant model (Hansen et al., 2009). Invariably a number of variants emerged however they were based on either of the two offerings and collectively they took on the term Energy Performance Contracting (ibid). The 'shared savings' model remained more popular in some markets, such as in the UK.

\subsection{2 $\mathrm{EPC}$ in the UK}

The concept of EPC is not well known or used in the UK and Energy Service Contracting is known as Contract Energy Management (CEM) (Fawkes, 2013a, p164, Fawkes, 2015, Hansen et al., 2009, p27). The UK market for energy service contracting could be said to have begun in 1984 when Shell 'Emstar' was established as an energy management company (Hansen et al., 2009, p27). They offered services modernising heating plant, installing new modular boilers and controls, clearing up the backlog of maintenance and changing the fuel, which very often involved converting oil-fired boilers to gas (Hansen et al., 2009, p27). However, the primary focus was heat supply via 'heat service' contracts (Sorrell, 2005, p41). This early model proved to be highly successful and influential and other fuel supply companies followed Shell, most notably BP with the formation of BP Energy. Energy supply contracts rather than energy performance contracts dominate the energy service market currently in the UK (Sorrell, 2005, p41). Initially most contracts were with the private sector as Treasury rules created an obstacle to the use of private finance within the public sector, until they were removed in 1992 to allow the Private Finance Initiative (PFI) to come forward (ibid). Even with this obstacle removed, the UK market is still biased towards the private sector (ibid). 
The energy services market grew steadily during the 1990s, however in the early 2000s serious stagnation was experienced (Bertoldi et al., 2007, p20). Gas and electricity market liberalisation proved to be an obstacle as declining energy prices led to clients losing interest in energy efficiency and focusing instead on energy purchasing (Sorrell, 2005, p42). This trend was reversed with the large increases in gas and electricity prices since 2003, providing a boost to the contracting market which by 2005 was experiencing an approximate $15 \%$ annual growth (ibid,).

The market in the UK is differentiated with numerous energy service companies originating from different sectors of the market offering differing services under the umbrella of 'Contract Energy Management' (Sorrell, 2005, p42). This, together with the numerous overlaps between the services being offered, makes it difficult to define the size and boundaries of the UK market for energy services contracting (ibid, 44). Figure 11 illustrates the various types of company offering services as energy service companies.

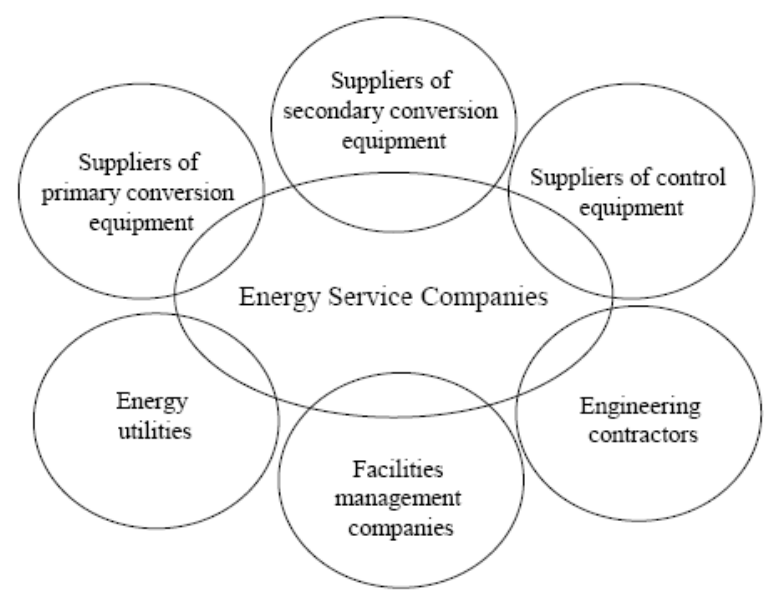

Source: Sorrell, 2005

Figure 11: Overlaps in the UK marker for energy service contracts

Combined Heat and Power (CHP) installations have been a feature in the UK energy services sector with both large-scale (e.g. hospitals) and smaller-scale cogeneration (such as leisure centres with pools) (Bertoldi et al., 2007, p21). 
The industry in the UK can be characterised as being dominated by supply contracting and is still biased towards the private sector, although hospitals have proved to be a promising market for CHP.

Emstar was taken over in 1998 by Dalkia, a French multinational (Sorrell, 2005, p42). Partly due to the unclear definition as to what constitutes energy services, it is very difficult to identify a size of the UK market. Also, how the size of the industry is measured is also an issue, should it be in terms of the annual revenue received, the capital value of new investment or the size of the annual energy bill under contract (Sorrell, 2005, p45). Most ESCOs indicate their turnover by the annual energy bills they handle. The Energy Systems Trade Association (ESTA), within which there is a Contract Energy Management Group, estimates the market size on the basis of turnover in 2001 to be approximately $£ 500$ million/year. This is compared to only $£ 127$ million/year in 1993, implying an annual growth rate of around $18 \%$ over this period. If this is compared to the total annual gas and electricity expenditure for the UK, the expenditure for the industrial, commercial and public sectors combined was approximately $£ 10$ billion in 2000 (Department for Trade and Industry, 2001) as cited by Sorrell, 2005. This suggests that provision of energy supplied by ESCOs represented 5\% of the market.

In 2017 EEFIG stated that the size of the global market for EPCs was US \$24 billion and of this US \$2.9 billion was in Europe (EEFIG, 2017).

\subsubsection{Structure of EPC contracts}

EPC projects include a number of processes and stages. Bertoldi and Rezzessy (2005) have attempted to identify a comprehensive list of elements/steps that an EPC project may include in their report for the European Commission in 2005, provided below:

$>$ Site survey and preliminary evaluation;

$>$ Investment grade audit;

Identification of possible energy saving and efficiency improving actions;

$>$ Financial presentation and client decision; 
$>$ Guarantee of the results by proper contract clauses;

$>$ Project financing;

$>$ Comprehensive engineering and project design and specifications;

$>$ Procurement and installation of equipment: final design and construction;

$>$ Project management, commissioning and acceptance;

$>$ Facility and equipment operation \& maintenance for the contract period;

$>$ Purchase of fuel \& electricity (to provide heat, comfort, light, etc);

$>$ Measurement and verification of the savings results;

$>$ Operation and maintenance.

(Bertoldi and Rezessy, 2005, p29)

Two aspects of the elements identified in the list are worth explaining further, the investment grade audit and measurement and verification of the savings results.

Firstly, an investment grade audit (IGA) attempts to provide a much more accurate assessment of the energy or cost saving potential that certain ECMs will have over the life of the project. A traditional audit will assume that all conditions stay the same; all paybacks are the same in varying conditions and ignore the human element (Hansen, 2003). IGA auditors consider the conditions under which ECAs will function during the life of the project and attempt to more accurately predict a building's future energy use by adding a 'risk assessment component' which evaluates conditions in a specific building and/or processes (Bertoldi and Rezessy, 2005, p29).

Secondly, measurement and verification $(\mathrm{M} \& \mathrm{~V})$ of the savings made is an important issue, as it forms the basis of not only the commercial guarantee provided by the ESCO, but of the funder's risk assessment of the energy efficiency project. It is a means by which customers, ESCOs and funders can rely on to effectively translate savings achieved into the project cash flow. The output of the $M \& V$ exercise will ultimately quantify the payments from the customer to the ESCO within whatever contractual structure is used.

An industry standard $\mathrm{M} \& \mathrm{~V}$ methodology has been developed called the International Performance Measurement and Verification Protocol (IPMVP), providing guidance for measuring the savings produced by energy efficiency measures. The IPMVP is administered by the Efficiency Valuation Organisation, a not for profit organisation supported by the US 
Department of Energy and a broad international coalition of industry bodies and entities such as facility owners and ESCOs (Van Der Like, 2007, p3). The IPMVP ensures that the approach taken is fully documented and agreed at the pre-contract stage. It identifies, against each Energy Conservation Measure, the level of expected savings, how they are to be achieved, and which measurement option is to be used, of which there are four alternatives.

The choice of option A, B, C or D should be related to the level of perceived risk in achieving the expected savings, as each option varies in terms of complexity and cost to the project. Options A and B (isolation retrofit approach) focus on the performance of specific ECMs such as items of equipment and installed retrofits that can be measured in isolation from the rest of the building (Van Der Like, 2007, p4). Before and after measurements are taken and compared to determine the savings. A lighting retrofit is a good example for Option A where performance can be verified once and is unlikely to change. Installation of variable speed drives is a good example for Option B, where continuous monitoring would be more appropriate (Van Der Like, 2007, pp4-5).

Options C and D (whole building approach) are used when the nature of the ECM is not easily measured in isolation from the rest of the building operations. Typically, this could be control changes that affect many areas of the building. The Option $\mathrm{C}$ approach assesses savings at the whole facility level by analysing utility bills before and after the implementation of the ECMs (Van Der Like, 2007, p5). Option D uses computer simulations and modelling of the whole facility. Options $\mathrm{C}$ and $\mathrm{D}$ are much more time consuming, requiring skilled resources, and therefore they are going to be the more costly approaches (Van Der Like, 2007, p5). As cited by The Clinton Foundation, 2009 the 2007 IPMVP guide (updated in 2009) states that M\&V costs are typically less than $10 \%$ of the project costs (Efficiency Valuation Organisation, 2009). In fact they range from as low as $1 \%$ up to $10 \%$, depending on the option selected (Clinton Foundation, 2009).

EPC projects can be financed in a number of alternative ways. ESCO financing is where the ESCO itself provides the finance, possibly through its own funds. However, this method is not popular as it tends to tie up the ESCO's funds and potentially restricts its ability to conduct business going forward. Alternatively, financing can be via the energy user or customer's own funds, however this would normally only be used in the guaranteed savings model where a guarantee is in place as security against the investment. Thirdly, EPC can be financed by third 
party financing where either the ESCO or the customer sources debt from a financial institution. Third party financing in either form is the more common approach.

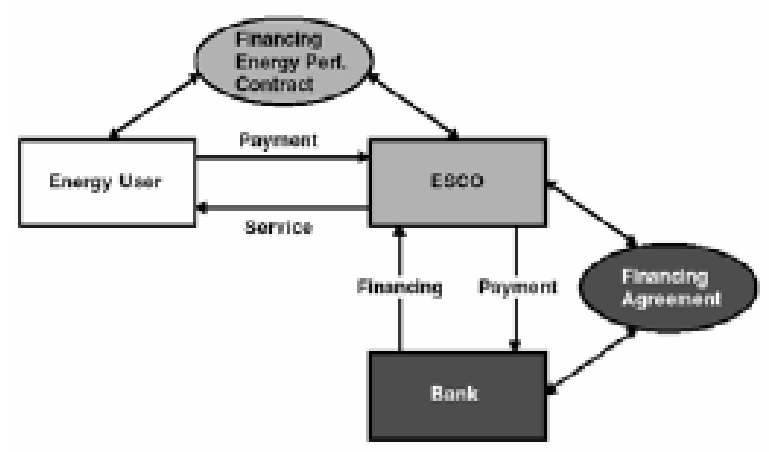

Third party financing with ESCO borrowing

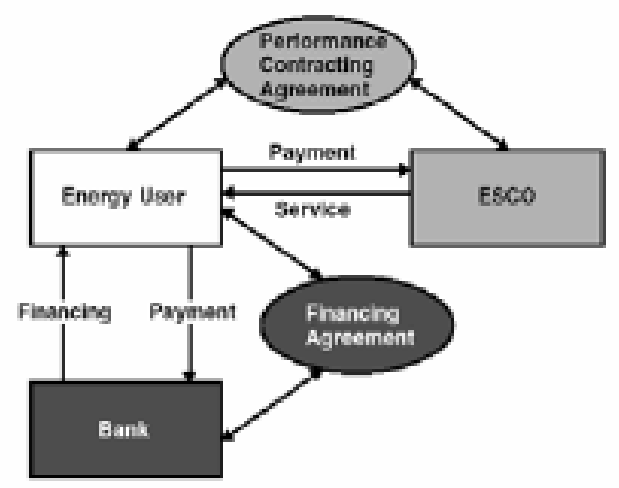

Third party financing with energy user / customer borrowing

Figure 12: Third party financing with ESCO and energy user / customer borrowing

Figure 12 illustrates the contractual relationships between an ESCO and the financial institution and between the energy user / customer and the financial institution in the different third-party 
financing structures. When the ESCO is the borrower the customer is protected from the financial risks of the project, as the debt is off balance sheet, appearing on the balance sheet of the ESCO (Bertoldi and Rezessy, 2005, p20). This is because the debt service is treated like an operational expense and not a capital obligation. This is important, as for highly leveraged companies or public authorities the obligation does not show up on their balance sheet. More debt could mean that its borrowing capacity is adversely affected (ibid). The exact criteria for this accounting treatment will vary from country to country. Although large ESCOs could to an extent contribute their own funds, they prefer not to as it ties up valuable capital in projects. They are essentially service companies and are not in the business of providing or risking finance. While the larger ESCOs would be able to borrow significant amounts of money, partly secured against the cash flow on the project and partly against the strength of its balance sheet, the smaller ESCOs would not have the ability to do so.

Figure 13 illustrates the relationships between the ESCO, customer and lender in the two major EPC models: shared savings and guaranteed savings. Under a shared savings contract the cost savings are split for a pre-determined length of time in accordance with a pre-arranged percentage. There is no standard split as this depends on the cost and length of the project and the risks taken by the ESCO and the consumer (Bertoldi and Rezessy, 2005, p23). Under a guaranteed savings contract the ESCO guarantees a certain level of energy savings and in this way shields the client from any performance risk (ibid). 


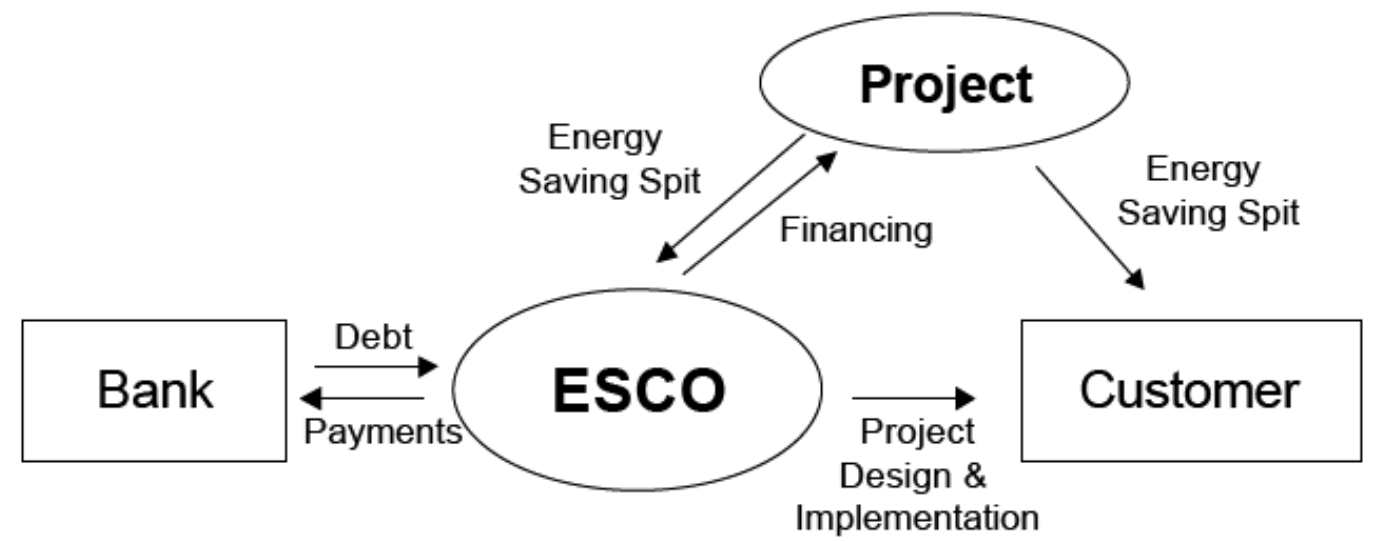

SHARED SAVINGS MODEL

GUARANTEED SAVINGS MODEL

Source: Stoner, 2003

Figure 13: Major types of Energy Performance Contracting models

Under a shared savings contract the ESCO assumes both performance and credit risk. The ESCO obtains the financing and assumes the finance repayment risk and the credit risk of the customer, should the customer go out of business or simply default on its payments. This could put the ESCO at risk. This is a model where the debt is off the customer's balance sheet. The ESCO shares in any savings that exceed expectations, therefore customers in this arrangement would need to guard against the ESCO attempting to set the saving threshold too low and receiving more of the excess savings (Bertoldi and Rezessy, 2005, p24). 
Under a guaranteed savings contract the ESCO assumes the design, installation and savings performance risk but none of the finance repayment or credit risks which reside with the customer. Therefore, guaranteed savings contracts are not applicable to ESCO financed projects, funded either through internally provided funds or third-party financing. The customer obtains the funding, which has the advantage of producing the cheapest form of finance as the funding institution will base the majority of its credit assessment on the customer itself, although it may also be based to some extent on the energy saving guaranteed provided by the ESCO. The customer repays the loan and assumes the repayment risk. If the guaranteed savings are not realised, which are sized to match the debt service, the ESCO is contractually obliged to cover the difference. If the savings exceed the guaranteed level then the customer pays an agreed percentage of the savings to the ESCO (Bertoldi and Rezessy, 2005, p24). Typically the contract will state that the guarantee provided by the ESCO, which is the value of the energy saved will be sufficient to meet the customer's debt obligations, is on the proviso that the price of energy does not go below a stipulated floor price (Bertoldi and Rezessy, 2005, p24). Table 3 summarises the features of the guaranteed and shared savings models.

\begin{tabular}{|l|l|}
\hline \multicolumn{1}{|c|}{ Guaranteed savings } & \multicolumn{1}{c|}{ Shared Savings } \\
\hline Performance related to level of energy saved & Performance related to cost of energy saved \\
\hline $\begin{array}{l}\text { Value of energy saved is guaranteed to meet debt } \\
\text { service obligations down to a floor price }\end{array}$ & $\begin{array}{l}\text { Value of payments to ESCO is linked to energy } \\
\text { price }\end{array}$ \\
\hline $\begin{array}{l}\text { ESCO carries performance risk } \\
\text { Energy-user/customer carries credit risk }\end{array}$ & $\begin{array}{l}\text { ESCO carries performance and credit risk as it } \\
\text { typically carries out the financing }\end{array}$ \\
\hline $\begin{array}{l}\text { If the energy-user/customer borrows, then debt } \\
\text { appears on its balance sheet }\end{array}$ & $\begin{array}{l}\text { Usually off the balance sheet of energy- } \\
\text { user/customer }\end{array}$ \\
\hline $\begin{array}{l}\text { Requires creditworthy customer } \\
\text { Can serve customers that do not have access to } \\
\text { financing, but still requires a creditworthy } \\
\text { customer }\end{array}$ \\
\hline $\begin{array}{l}\text { Extensive M\&V can do more projects without getting } \\
\text { highly leveraged }\end{array}$ & $\begin{array}{l}\text { Favours large ESCOs; small ESCOs become too } \\
\text { leveraged to do more projects }\end{array}$ \\
\hline $\begin{array}{l}\text { More comprehensive project scope due to lower } \\
\text { financing costs }\end{array}$ & $\begin{array}{l}\text { Favours projects with short payback ('cream } \\
\text { skimming') due to higher financing costs }\end{array}$ \\
\hline
\end{tabular}

Table 3: Guaranteed savings and shared savings: a comparison 
Increasingly ESCOs are reluctant to be the borrower of the funding as in the shared savings model. It restricts their further borrowing and, in some case, some ESCOs just can not raise the money due to their small size. However, customers or clients value the off-balance sheet treatment of the financing therefore a contract variant has emerged along the lines of a typical Project Finance structure. In this structure a Special Purpose Entity or Vehicle (SPE/V) is established whereby it contracts with the customer to provide the services and also has a contract with an ESCO to provide those services. The SPV raises the finance, protecting the ESCO from the funding risk and at the same time allowing the contract to remain off the customer's balance sheet. This type of financing can be more expensive as it relies solely on the project itself with no recourse to the ESCO or customer and therefore it requires the funder to understand the nature of the project and to be able to price the risks accordingly. Figure 14 illustrates a typical Project Finance structure using an SPV.

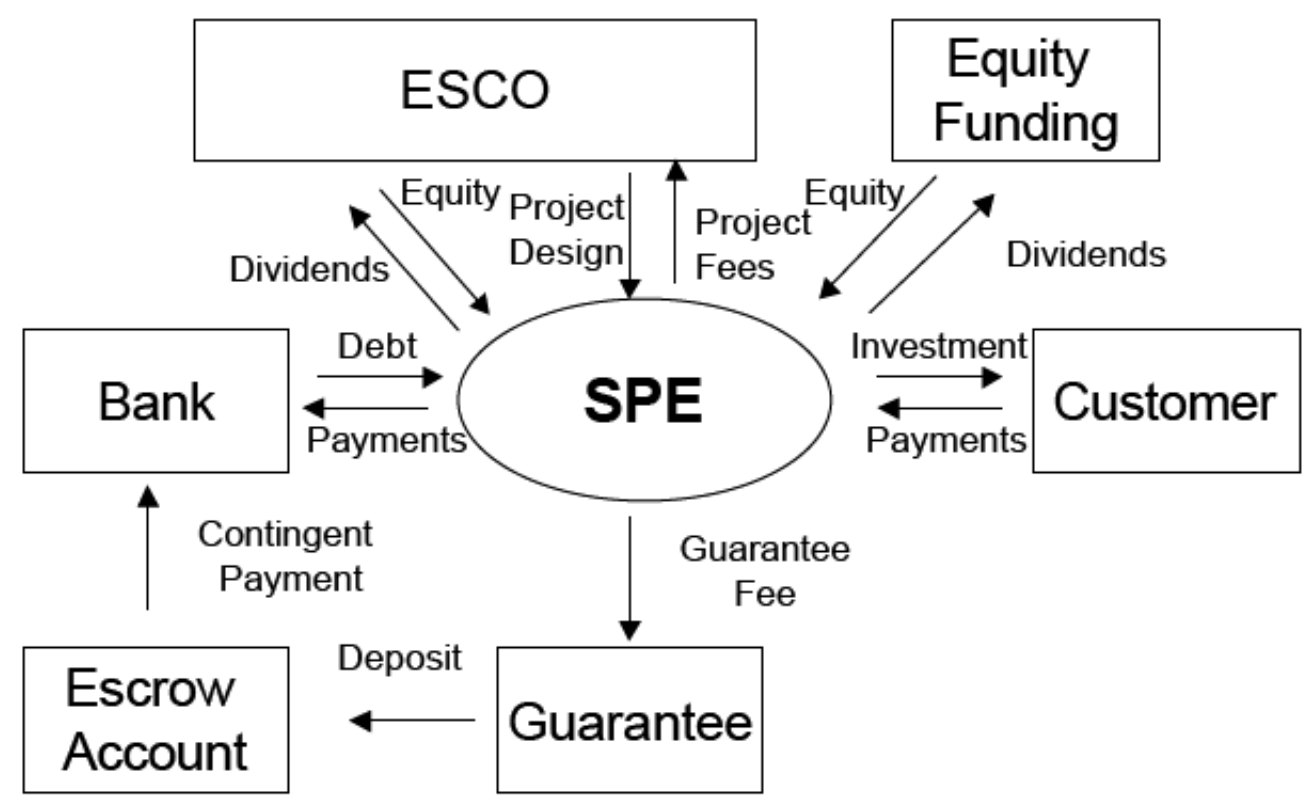

SPECIAL PURPOSE ENTITY/VEHICLE (SPE/V) MODEL

Figure 14: Special Purpose Entity/Vehicle (SPE/V) EPC financing model 


\subsubsection{Criticism of Energy Performance Contracting}

Energy Performance Contracting does not appear to have fulfilled its full potential (Fawkes, 2013a, p170, 2013d).. As we have seen, there is a need for energy efficiency improvements in buildings that could significantly contribute to the reduction in $\mathrm{CO}_{2}$ emissions if implemented on a large scale. Whilst EPC would appear to be a method of achieving that aim, this has not proved to be the case (Fawkes, 2013d). Although not implemented widely in the UK, EPC has been adopted in various forms by organisations such as The Greater London Authority, The Department of Energy and Climate Change (now part of the Department of Business, Energy and Industrial Strategy) and The Green Investment Bank. Energy Performance Contracting as a procurement method is not without disadvantages and criticism, which may go some way to explain the reason why it has not been implemented more widely.

The lack of low-cost financing for EPCs is a contributory factor of its restricted use. When the procurement method was developed in the US it was financed mainly by municipal debt, which is particularly cheap financing only available to parts of the US public sector, and is not available in other jurisdictions. The option of the ESCO itself financing projects is not popular or attractive to the ESCO, as for the larger companies it creates balance sheet restrictions while the smaller providers would have trouble raising the capital even if they had intended to (Fawkes, 2013a, p170, 2013d).

EPCs are inherently long-term and complex agreements. They are typically between seven and fifteen years long, to make sure savings exceed payments. Being over such a duration other factors then have to be taken into account such as changes in how the buildings are used or even that they could have a change in ownership. The transactions can take a long time to agree, be complex and hard to negotiate and the transaction costs can be high. A Method of M\&V needs to be agreed and put in place that may involve independent $\mathrm{M} \& \mathrm{~V}$ specialists being engaged. This all involves much time and effort on behalf of the client in order to achieve the optimum transaction, which may be further hampered by the EPC contractor looking to maximise the amount of capital expenditure within a deal, maximising its mark up on the energy conservation measures installed (Fawkes, 2013a, 2013d). 
EPC transactions are most suited to the public sector and buildings with an owner-occupier rather than the commercial rented building sector, as issues such as the split incentive between landlords and tenants can make the deal structure difficult to work effectively (Fawkes, 2013d).

If EPC is not the full answer to the need for energy efficiency investment at scale, and Fawkes (2013c) is not suggesting that it is without its merits in certain circumstances, then what is the approach that should be taken? Although EPC appears to be the model being proffered as the solution, other forms of contractual arrangement have emerged in recent years, most notably Efficiency Services Agreements (ESA). ESAs are increasingly being used in the US having been pioneered by a company called Metrus but are now being implemented more widely. However they haven't yet been used in the UK in any meaningful way, with one or two notable exceptions (Fawkes, 2013b).

Efficiency Services Agreements work per the contractual arrangement illustrated in Figure 15 which has been extracted from the Metrus Energy website.

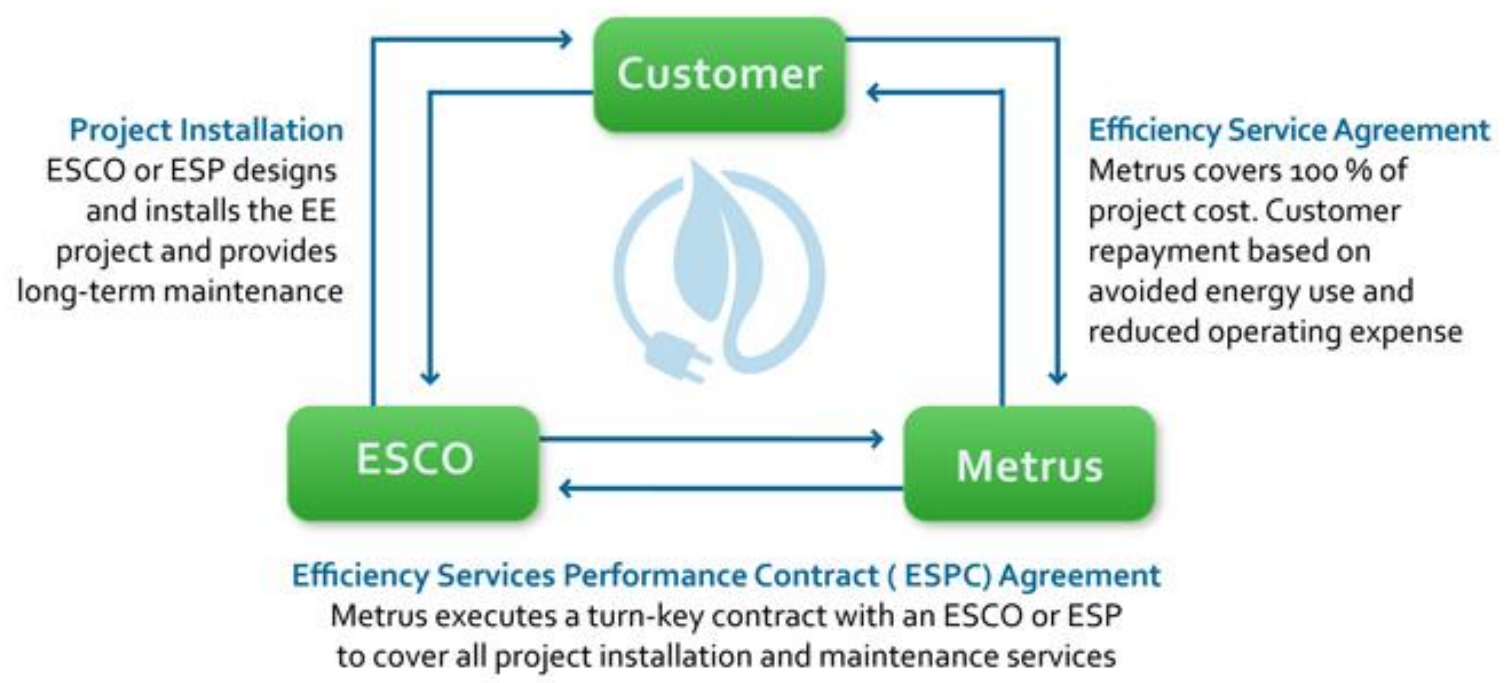

Source: Metrus Energy n.d.

Figure 15: Efficiency Services Agreement contractual structure from Metrus

The Efficiency Services Agreement (ESA) creates pay-for-performance energy efficiency financing for an energy efficiency upgrade project with no upfront cost. Through the ESA, the 
developer (and/or financier), in the Figure 15 it is Metrus, pays for $100 \%$ of development and construction costs. After the project is operational, the customer or client takes a portion of the realised savings from reduced energy consumption to make service payments to the developer. ESA service payments are based on actual energy units that are saved, avoided kilowatt hours of electricity or avoided therms of natural gas etc.

The developer enters into the ESA directly with the customer or client and pays and manages an ESCO/contractor to implement and help maintain the project. The developer retains ownership of all project-related assets for the duration of the ESA term and pays for maintenance services in order to optimise performance. As in the EPC arrangement, project performance is quantified using agreed-upon $\mathrm{M} \& \mathrm{~V}$ protocols. These verified savings provide the basis for the ESA service charge. The ESA contractual structure makes the payments made by the end user firmly operating expenses and therefore it is a fully off-balance sheet structure.

\subsection{Investments by Institutional Investors in Energy Efficiency}

The next important consideration is that of how energy efficiency investments can be made by institutional investors. Of course, investors could make direct investments in companies that carry our energy efficiency improvements as part of their equity allocation however when it comes to providing funding to individual energy efficiency projects, investors have not been forthcoming (Kaminker and Stewart, 2012, pp26-27). This is due to a number of factors not least the relatively small size of the projects (Kaminker and Stewart, 2012, pp26-27). Many of the larger energy efficiency projects can be in the range of between $£ 2 \mathrm{~m}$ to $£ 10 \mathrm{~m}$ which is small when compared to infrastructure or PFI type projects which often exceed $£ 100 \mathrm{~m}$, however they can be as small as $£ 10 \mathrm{k}$. This issue, coupled with the unfamiliarity of the sector and the use of non-standard protocols and processes underlying the deals, investors are disincentivised to invest directly. Investors would need to expend significant time and cost in fully understanding and executing the deal structure and due to the non-standard nature of the transaction they would need to repeat it again for the next bespoke project. While the issue of transaction standardisation is in the process of being addressed through initiatives such as the 
Investor Confidence Project there is currently insufficient confidence within the investor base for direct investment in energy efficiency for it to be seen in any great numbers (ICP n.d.). Investors also require familiar contractual structures to understand how the revenues will be generated and get translated into their returns. This additional need goes against direct investment on a large scale.

A further way of investing would be indirectly via a Fund structure, much the same way as investors invest funds into a Private Equity fund or an Infrastructure Fund where a fund manager is appointed to manage and invest the funds injected by the institutional investors in accordance with a prescribed fund strategy. Investors would not only need to have the confidence in the underlying investments in energy efficiency, which is increasing via initiatives such as the Investor Confidence Project, but they would also need to be convinced of the fund manager's knowledge, experience and understanding of the sector. This way of investing is more attractive to institutional investors while the sector is relatively new. If the investor can be confident in the fund manager then it will rely on it to make a investments on its behalf without having to invest time an effort to fully understand the underlying investments which it would be unlikely to do.

Limited Energy Efficiency Fund structures have emerged however even fewer that would enable institutional investors to invest their funds. A number of public funds have been created to investing to energy efficiency such as the London Energy Efficiency Fund (LEEP), the Mayors Energy Efficiency Fund (London) and the Central Energy Efficiency Fund in Scotland but these do not have the possibility for institutional investors to directly invest their funds as they are either fully funded publicly, have received some funding from European Union Structural Funds or have agreements with commercial banks or a combination of the three sources (Energy for London, 2013, London Assembly, 2018, Natural Scotland, 2004).

The Zurich based Susi Energy Efficiency Fund is a prominent private sector fund, seeking to invest in energy efficiency across Europe and has raised its capital from institutional investors in Euros (SUSI Partners, 2017). It has €200m commitments from mainly German, Swiss and Dutch institutional investors and the European Investment Bank (SUSI Partners, 2017). While this fund has been open for investors from the UK it may not have been attractive when considering the unfamiliar nature of the investments and the fund manager and the need to invest in Euros. 
The Green Investment Bank (GIB), in an effort to attract institutional investment into energy efficiency rather than attempt to encourage direct investment, decided in 2011 to make $£ 50 \mathrm{~m}$ investments into two dedicated energy efficiency funds, and launched a competition in order to select fund managers (BIS, 2012). The two successful fund managers were Equitix, which is an established fund manager specialising in social infrastructure investments, and Sustainable Development Capital LLP (SDCL) a company that had extensive energy efficiency advisory experience, if not in a fund management role, the funds were launched 2012. A requirement of the GIB was that the funds should also have a matching $£ 50 \mathrm{~m}$ invested from institutional investors (BIS, 2012). In fact, both fund managers have been able to significantly exceed the $£ 50 \mathrm{~m}$ requirement with sums of between $£ 100 \mathrm{~m}$ and $£ 150 \mathrm{~m}$ being raised in each fund. Subsequently a third energy efficiency fund was added to the GIB list of supported funds, that of Aviva Investors, which focuses specifically on NHS Energy Centres. 


\section{Literature review and positioning the research}

Investment in Energy Efficiency at scale via institutional and pension fund investment has not been widespread and indeed the objective of this research is to identify ways in which this can happen. The energy efficiency literature to date has not focused on this aspect but has concerned itself with investment in energy efficiency from an end user perspective. It examines the organisational and behavioural aspects of a firm or individual investing in a relatively small energy efficiency projects and has not as yet addressed the issue of applying large scale funds to aggregated projects. The energy efficiency gap, that is to say the difference between current energy use and optimal energy use, is discussed extensively, examining the issues and reasons why cost effective measures are not implemented in order to close the 'gap' (Jaffe et al., 2004, Jaffe and Stavins, 1994a, Allcott and Greenstone, 2012). These reasons have been translated into barriers to implementation and much has been written about the identification of what is preventing companies or individuals from undertaking energy efficiency measures, with many of the issues based in behavioural or organisational economics (Sorrell et al., 2004, Sorrell et al., 2000, Palm and Thollander, 2010, Valentová, 2010).

It is important to understand these issues if institutional investment into energy efficiency is to be encouraged. Investors need to know that there is a continuing and liquid market and there are investments to be made at scale in the future if they are to spend time and effort understanding the market (Fankhauser, 2012).

Although their characteristics are different, investment in energy efficiency is often discussed together with renewable energy, and termed collectively as low carbon investments (Usher, 2008, UNEP, 2010). Whereas renewable energy creates a return from producing energy, energy efficiency creates its cash flow from energy conservation and therefore through costs being saved. Through the linking of renewable energy and energy efficiency investments, the literature concerning institutional and pension fund investment in renewable energy is important when considering investment in energy efficiency at scale. Much of this linkage relates to energy efficiency in the commercial property and industrial sectors, however there is an increasing recognition that investment at scale is required in the domestic sector also (Carrington, 2011). 
This literature review firstly examines the energy efficiency gap and the identified barriers to energy efficiency investments and then looks at literature concerning low carbon institutional and pension fund investment, in general, and renewable energy, in particular where relevant.

\subsection{Energy Efficiency Gap}

The energy efficiency gap, the difference between current energy use and optimal energy use, is discussed in the literature with the focus on attempting to explain why the phenomenon exists. Why for example are technologies such as thermal insulations materials and energy efficient appliances not more widely used, when simple net present value calculations show them to be cost effective (Jaffe and Stavins, 1994a)? Shama (1983) describes the gap as the paradox of gradual diffusion of apparent cost effective energy efficiency technologies (Shama, 1983). Jaffe and Stavins go on to develop a framework for thinking about the 'paradox' and their analysis provides some keys to understanding why the technology diffusion process is gradual (Jaffe and Stavins, 1994b, Jaffe et al., 2004). They identify a series of market failures and other issues that create this phenomenon, which have collectively become known as barriers to energy efficiency (Sorrell et al., 2004). These barriers have typically been characterised as economic, behavioural or organisational in nature (Weber, 1997).

\subsection{Barriers to Energy Efficiency}

According to Weber (1997) the following questions need to be asked in order to determine the existence of barriers to energy efficiency:

What is the barrier? e.g. hidden costs, risk, lack of capital, lack of information, inadequate financial incentives etc.

Who or what is it an obstacle to? e.g. firms, public, organisations, departments within organisations, individuals.

What does it prevent? e.g. purchase of more efficient equipment, retrofitting insulation to a building, establishing a monitoring \& targeting scheme. 
Weber (1997) discusses barriers to energy efficiency in three broad groupings, namely neoclassical economics, behavioural perspectives and organisational perspectives. He then proceeds to state that in reality each barrier may have aspects of each. Sorrell et al. (2000) provide an illustrative example of these perspectives, provided here as Table 4.

\begin{tabular}{|c|c|c|c|}
\hline Perspective & Examples & Actors & Theory \\
\hline Economic & $\begin{array}{r}\text { imperfect information, } \\
\text { asymmetric information, } \\
\text { hidden costs, risk }\end{array}$ & $\begin{array}{r}\text { Individuals \& } \\
\text { organisations } \\
\text { conceived of as } \\
\text { rational \& utility } \\
\text { maximising }\end{array}$ & $\begin{array}{r}\text { Neo-classical } \\
\text { economics }\end{array}$ \\
\hline Behavioural & $\begin{array}{l}\text { inability to process } \\
\text { information, form of } \\
\text { information, trust, inertia }\end{array}$ & $\begin{array}{r}\text { Individuals } \\
\text { conceived of as } \\
\text { boundedly rational } \\
\text { with non-financial } \\
\text { motives and a variety } \\
\text { of social influences }\end{array}$ & $\begin{array}{r}\text { Transaction cost } \\
\text { economics, } \\
\text { psychology, decision } \\
\text { theory }\end{array}$ \\
\hline Organisational & $\begin{array}{r}\text { energy manager lacks } \\
\text { power \& influence; } \\
\text { organisational culture } \\
\text { lead to neglect of } \\
\text { energy/environmental } \\
\text { issues }\end{array}$ & $\begin{array}{r}\text { Organisations } \\
\text { conceived of as } \\
\text { social systems } \\
\text { influenced by goals, } \\
\text { routines, culture, } \\
\text { power structures etc. }\end{array}$ & $\begin{array}{r}\text { Organisational } \\
\text { theory }\end{array}$ \\
\hline
\end{tabular}

Source: Sorrell et al, 2000

Table 4: Perspectives on barriers to energy efficiency

\subsection{Economics perspective}

Much of the literature on energy efficiency barriers is based in neo-classical or orthodox economics; it assumes that consumers make decisions regarding energy efficiency measures in a fully rational way and then attempts to identify the drivers for the energy efficiency gap (Sutherland, 1996, Jaffe and Stavins, 1994a). The approach states that individuals maintain rational preferences and that they make choices through market transactions (Sanstad and Howarth, 1994b). These choices, for example to decide to accept or reject a cost-effective energy efficiency measure, reveal that additional factors are present, such as hidden costs or benefits, assuming rational consumer behaviour is correct. This approach is criticised as representing an unrealistic description of actual behaviour (Hodgson, 1988). 
Many of the early works attempting to identify market barriers to energy efficiency, which according to Sorrell's definition of a barrier is a mechanism that inhibits investment in costeffective energy efficiency technology, were criticised by neo-classical economists (Sorrell et al., 2004). They asserted that these 'market barriers' such as those proposed by Hirst \& Brown (1990), namely uncertainty in future fuel prices or the unavailability of capital, are ambiguous and may simply be benign characteristics of an efficient market (Sutherland, 1996, Hirst and Brown, 1990). For example, the unavailability of capital may only be related to low income households as they would be deemed high risk borrowers. The funding market could be working efficiently even though it may inhibit energy efficiency investment by the low income sector of society (Sutherland, 1996).

Sorrell $(2000,2004)$ states that these criticisms were useful in formulating the neo-classical approach to the issue which seeks to identify where public policy should be targeted in order to encourage energy efficiency. The argument is that this should be achieved through encouraging economic efficiency where there exists some form of market failure (Jaffe and Stavins, 1994a, Sutherland, 1996, Golove and Eto, 1996). Therefore, it is only the identifiable market failures that warrant policy intervention, however not all market barriers are market failures. Sorrell $(2000,2004)$ characterises these market failures in the following ways; as incomplete markets, imperfect competition, imperfect information and asymmetric information, however it is the last two, imperfect information and asymmetric information, that have the most impact on barriers to energy efficiency and to explain the energy efficiency gap.

\subsubsection{Imperfect information}

Markets need to produce and transmit sufficient information for market participants to undertake fully efficient transactions. This may not occur where information has public good characteristics and many people are able to benefit from it without affecting its supply. Private firms may be unwilling to supply information because they would be unable to retain all of its benefits, which is a common rationale for government intervention (Sorrell et al., 2000).

Relating this to barriers to energy efficiency investment, it is claimed that the energy services market provides insufficient information about the energy performance of different 
technologies (Huntington et al., 1994). This can take the form of information on current energy consumption, energy specific investment opportunities and specific equipment. Huntington et al (1994) state that information problems are the principal source of market failures that account for the gap in energy efficiency investments.

\subsubsection{Asymmetric information}

Asymmetric information is a form of imperfect information where one party to a transaction may know or understand more than the other. A seller may know more about the quality of a good than the buyer. The effects of asymmetric information can manifest themselves in a number of ways.

Adverse selection can relate to a situation where a seller has difficulty in communicating information that they have to potential buyers. Consumers may not be able to observe and understand the quality of the product and only select products on the basis of what is visible, such as price, making them reluctant to purchase the higher quality product due to the price premium. For example, energy efficiency and conservation management issues within a building may be controlled by a highly efficient Building Management System (BMS), but remain invisible to potential buyers who may hold more store in the quality of the finishes or the fabric of the building, and then are reluctant to pay the price premium for having the quality BMS installed (Howarth and Sanstad, 1995).

Moral hazard is a term that originated in the insurance industry to describe insurance companies' lack of ability to effectively monitor the actions of their policyholders. The policyholder may act in a way to make the insured loss more likely to occur (Sorrell et al., 2000). In the context of the energy efficiency gap, moral hazard is normally discussed in terms of principal-agent relationships. For example, construction companies, acting as agents, are employed by the client as principal. The construction company may have incentives to act and take actions in a different manner than the principal would like, perhaps to cut corners on energy efficiency measures for example in order to increase profits. This is potentially possible as the agent's actions could be largely unseen by the principal (Sorrell et al., 2000). 
'Split incentives' is a highly recognised barrier to energy efficiency and are typically seen where a landlord of a building may be unwilling to retrofit with energy efficiency measures as the resulting savings in energy use will be realised by the tenant. At the same time the tenant would be unwilling to retrofit as they may move out before benefiting from the cost savings. Jaffe and Stavins (1994) have interpreted split incentives as a market failure resulting from asymmetric information. One party may have the relevant information on the costs and benefits of an energy efficiency investment but it may be difficult to convey this to the other party. If there were no information problems landlords and tenants would be able to enter into contracts to share the costs and benefits of the investment.

\subsubsection{Jaffe \& Stavins framework}

Jaffe \& Stavins (1994) use this approach to identify a framework for characterising different types of barrier into those that are market failures and those that are not, while also classifying them as explaining the energy efficiency gap and those that do not, refer to Table 5. This framework complements the neo-classical economist's assertion that only identifiable market failures warrant government policy intervention.

\begin{tabular}{|c|c|c|}
\hline & Explains efficiency gap & Does not explain efficiency gap \\
\hline $\begin{array}{l}\text { Barriers that } \\
\text { are market } \\
\text { failures }\end{array}$ & $\begin{array}{l}\text { - Public good attributes of information } \\
\text { - Positive externalities of technology } \\
\text { adoption } \\
\text { - Split incentives in energy service } \\
\text { markets } \\
\text { - Adverse selection in energy service } \\
\text { - Moral hazard \& principal agent } \\
\text { relationships in energy service markets }\end{array}$ & $\begin{array}{l}\text { - Distortions in energy pricing } \\
\text { (e.g. departures from marginal } \\
\text { cost pricing, cross subsidies, } \\
\text { VAT differentials etc.) } \\
\text { - Environmental externalities }\end{array}$ \\
\hline $\begin{array}{l}\text { Barriers that } \\
\text { are not market } \\
\text { failures }\end{array}$ & $\begin{array}{l}\text { - Heterogeneity } \\
\text { - Hidden costs (e.g. overhead costs, } \\
\text { disruption) } \\
\text { - } \text { Risk (technical or business) } \\
\text { - } \text { Access to capital }\end{array}$ & - \\
\hline
\end{tabular}

Table 5: Barriers and market failures 


\subsection{Behavioural perspective}

The behavioural aspects of barriers to energy efficiency concern the actions and behaviour of individuals in the decision-making process. These may be influenced by the costs associated with the implications of an investment decision, the level of information that is available to inform a decision. An individual's biases can influence investment decisions that are based on past experience or the chance of gaining an assumed benefit. Decisions are influenced by the assumed level of risk being taken in the investment process and how risk adverse an individual is also a factor. These decisions are based on the concepts of transaction cost analysis, bounded rationality and ultimately cognitive bias in its different forms.

Investment decisions are made with reference to both risk and return and the biases identified by prospect theory are particularly relevant as they primarily concern loss and regret. Models of investment and the investment decision process have been formulated identifying that cognitive issues play a role in the decision process. This is demonstrated in the differentiated model of risk and return involving energy policy and investment. However, the model considered most appropriate for consideration is Clark's model of investment decision making as it specifically identifies institutional investors (pension fund trustees) as the decision makers. It includes all the aspects identified as important in other models including investors' approach to risk and return and particularly references elements of prospect theory in the framing of investment decisions.

\subsubsection{Transaction Cost Economics}

Transaction cost economics builds upon the concepts introduced by the neo-classical or orthodox economics approach. As with the orthodox approach it is concerned with the behaviour of individuals, assuming that they are fully rational. However, it also assumes that transactions are rarely costless. It focuses on costs and risks of transactions and uses these to explain organisational governance structure. The concept of transaction costs derives originally from the work of Ronald Course but transaction cost economics as a theme of organisational economics derives from Williamson (1979) and draws on the behavioural assumption of bounded rationality. 
Transaction cost economics focuses on the nature of different transactions and the costs and risks associated with those transactions (Sorrell et al., 2004). Transaction costs are assumed to include legal, administrative information gathering and other costs associated with negotiating and entering a transaction. Arrow (1969) asserted that transaction costs in general impede and in particular cases completely block the formation of markets. Golove \& Eto (1996) indicate that one of the implications of Arrow's assertion in terms of energy services may be that the slow diffusion rates of efficient technologies may be better understood in terms of transaction costs associated with the development of such markets, than by the types of neo-classical market failure discussed previously. Both Sanstad \& Howarth (1994) and Golove \& Eto (1996) argue that transaction economics has much to offer in understanding barriers to energy efficiency, with the latter particularly arguing that both neo-classical market failures and transaction cost based failures represent legitimate possible objects of government intervention.

\subsubsection{Bounded rationality}

Transaction Cost Economics not only takes into consideration costs associated with a transaction but also the behavioural assumptions to explain why a transaction takes place or the form in which it takes place. Sorrell (2000) states that Williamson introduces two important behavioural assumptions:

- bounded rationality: which implies that people make decisions subject to constraints on their attention, resources and ability to process information; and

- opportunism: which implies that self-interest seeking can take anti-social forms such as lying, stealing and cheating.

It is the concept of bounded rationality that has the most relevance to energy efficiency. The concept was first introduced by Herbert Simon in the 1950s and directly contradicts the assertion that agents make decisions in the manner prescribed by formal optimisation models followed by orthodox economists (Simon, 1955). He suggested that people make decisions subject to constraints on their attention, resources and ability to process information; therefore, 
their decisions are likely to differ significantly from the predictions of optimisation models. These constraints lead individuals and organisations, who are otherwise rational, to make decisions through imprecise routines and rules of thumb rather than full analysis with the optimum outcome. In a survey of energy information programmes it was concluded that 'it is clear that, with the exception of some energy labelling programmes, energy information programmes on their own have not to date resulted in significant energy savings' (Robinson, 1991). The provision of accurate information on costs and benefits does not necessarily improve the quality of decision making; bounded rationality comes into play.

\subsubsection{Cognitive bias - Heuristics}

The concept of bounded rationality in the context of everyday decision-making including those involving the making of investments involves individuals use of decision-making shortcuts known as heuristics (Baddeley, 2013). Investors use tools and techniques, or heuristics, based on given information and their past experience to allow them to determine which investment to make. Investors' decision-making may not be completely rational, since there are emotional and mental factors involved in the process of decision-making which the investors go through by collecting relevant evaluation of the information. Following factors are included in the heuristic decision-making process:

Representativeness: Tversky \& Kahneman (1974) describe representativeness as the heuristic that is used while making judgments regarding the probability of an event under the state of being unsure of something. Investors' tendency to make decisions established on previous experiences is known as stereotyping. Kahneman \& Tversky (1982) first proposed it by defining representativeness as; (i) the level to which an event's characteristics are similar to its parent population, and also (ii) contemplates prominent features of the procedure by which it is yielded.

Overconfidence: Dittrich, Güth \& Maciejovsky (2005) observed in their experiment that around two thirds of the participants were prone to overconfidence. They further observed that those investors who lose their money in investment, gain more confidence. Confidence might have several dimensions, giving more courage, and playing a vital role in gaining success. 
Confidence alone is not the sole factor to success but still it is usually celebrated and encouraged. Self-confidence is always considered to be a positive trait. In certain cases, investors while overestimating their skills and knowledge indulge into excessive trading (Dittrich et al., 2005).

Anchoring: Anchoring and adjustment is a heuristic that involves making an initial estimate of a probability called an anchor, and then adjusting it up or down in the light of new information (Tversky and Kahneman, 1974). This then typically results in assessments that are determined by an anchor value or reference point.

Gambler's Fallacy: Assessment of probability, when lack of understanding leads to an incorrect estimation and prediction regarding the outcome of events. The incorrect assumption or assessment is called gambler's fallacy. This fallacy arises when investors predict inappropriately and the anticipation of a favourable outcome may or may not be valid (Baddeley, 2013).

Availability bias: This heuristic involves the judging of an event to be more likely if occurrences of the event can be easily recalled, for example, more frequent classes of events are easier to recall (Tversky and Kahneman, 1974). It also leads to an effect in which the first and last events in a series have a disproportionate impact on current judgements.

These decision-making heuristics are presented by Jahanzeb et al. (2012) in their model of cogitive decision processes as one arm of cognitive bias, or cognitive illusions in their terminology, provided in Figure 23.

\subsubsection{Cognitive bias - Prospect Theory}

Kahneman and Tversky (1979) developed this theory. It is the theory which explains that people value their gains and losses differently. If two equal choices are given to an investor, one in terms of potential gains and the other one in terms of potential losses, the chances are that the investor would choose the former one. This theory is also called 'loss-aversion theory'. Key concepts of the theory as explained below: 
Framing and Loss aversion: Framing is the first part of the prospect theory which leads to outcomes and contingencies associated to a particular problem. It is the way facts are presented which influences the choice of an investor. Kahneman \& Tversky (1979) found that unlike expected utility theory, investors mark gains and losses differently. They found that the investors generally conceive the loss of $\$ 1$ twice as painfully as compared to the pleasure of a $\$ 1$ gain.

Regret aversion: This kind of aversion arises when an investor desires to avoid the pain of regret occurring from a bad investment decision or having forgone or overlooked opportunities which would have untimely been lucrative.

Mental Accounting: Thaler (1980) established this concept of Mental Accounting and further conceptualized that 'Mental Accounting Matters' (Thaler, 1980, Thaler, 1999). Mental Accounting is the tendency for people to separate their accounts and classify them on the basis of variety of subjective criteria, showing the source of money and the intention of each account, and this determines the purchasing decision. It provides the way for decision makers to set the points of references for the accounts that determine losses or gains.

Self-control: Investors are assumed to avoid the losses and shield their investments. According to the views of Thaler \& Shefrin (1981) investors should always show some sort of tolerance and should be looking to improve their self-control . Psychologically it is also known as selfregulation.

The concepts of Prospect Theory are presented by Jahanzeb et al. (2012) as the second arm of cognitive bias, or cognitive illusions in their model of cogitive decision processes, refer to Figure 16. 


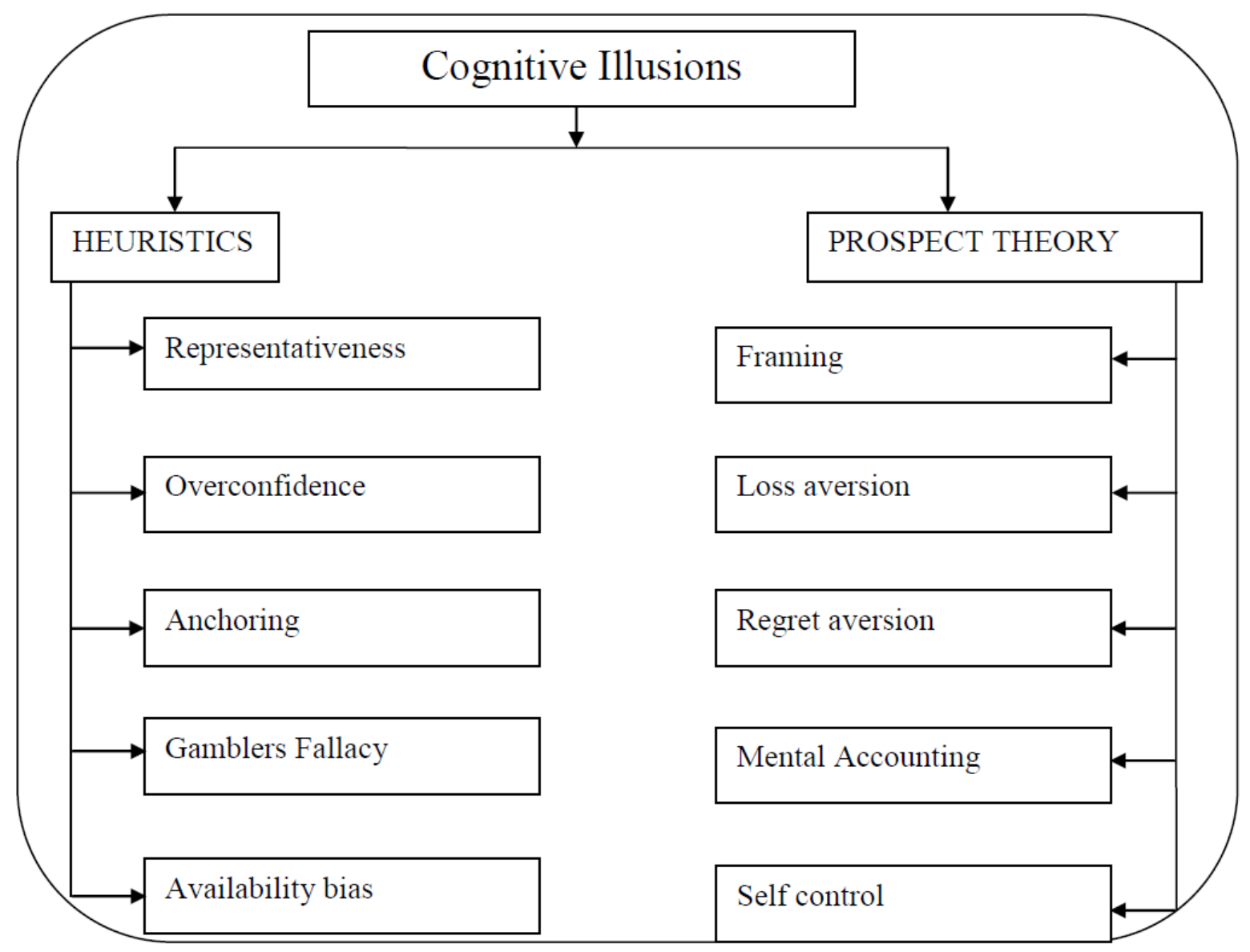

Source: (Jahanzeb et al., 2012)

Figure 16: Conceptual model of cognitive decision processes

\subsubsection{Renewable energy investment}

It is recognised that increased investment in renewable energy technology combined with energy efficiency can help meet future energy demand and minimise the risks of conventional energy supply, such as those posed by the accident in Fukushima (Wüstenhagen and Menichetti, 2012). There is significant literature dealing with investment into renewable energy but the issues surrounding attracting institutional investment into energy efficiency at scale have yet to be explored. Energy efficiency has however been discussed alongside renewable energy as an investment asset class. Usher (2008), for example, discusses the UNEP SEFI (2007) analysis of the sustainable energy sectors defined as new renewables and energy efficiency. Energy efficiency only accounted for $6 \%$ of the 2007 figure of $\$ 117.2$ billion invested in the sector. 
Important changes in the social and institutional context are required if the scaling up of sustainable energy investments is to be achieved (Krewitt et al., 2007). Grubb (1990) suggests that although technological advances and breakthroughs are required, the major change that is needed to achieve the scale required is one of attitudes. This change in attitudes is required across the spectrum of actors involved from policy makers to citizens, industry and market operators and importantly investors. Wüstenhagen et al. (2007) state that management of this social acceptance and particularly acceptance by the financial community could ultimately be an important success factor for future energy and climate policies. This issue has direct relevance to the original Green Deal initiative in the domestic arena as its failure was to some extent linked to its non-acceptance in a social and financial context (The Green Age, 2013).

The investors' basic model represents investments as a function of both risk and return. Investors rationally weigh the levels of risk and return of possible investment opportunities and will select those opportunities that provide the best return for a given level of risk, an assessment of risk adjusted return (Wüstenhagen and Menichetti, 2012). In renewable energy investment, government policies can influence the assessment of risk adjusted return for a particular investment by increasing the returns (e.g. feed-in tariffs) or reducing the risk (e.g. loan guarantees or underwriting of the risk). There would appear to be some debate as to the level of influence policy has on the investment decisions of private investors, with surveys of venture capitalists such as the one undertaken by Wüstenhagen and Teppo (2006) suggesting that the influence is not significant. However, the established view is that policy will have an influence and the basic model is represented in Figure 17.

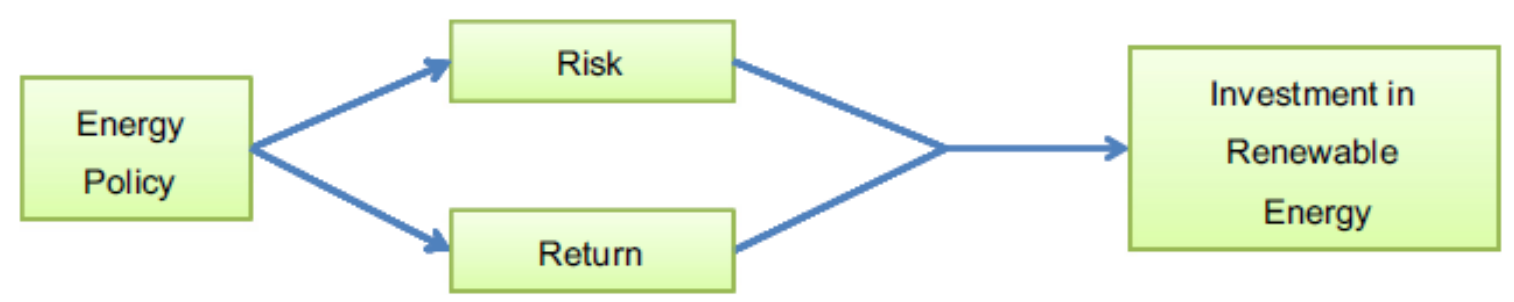

Source: Wüstenhagen and Menichetti , 2012

Figure 17: Basic model of risk and return involving energy policy and investment 
The basic model is an oversimplification of the situation and in reality, other influencing factors are present. An extension to the basic investment model of risk and return comes from portfolio theory, which was first introduced in the 1950s by Markowitz (1952). He demonstrated the concept of portfolio diversification, noting that risk can be reduced by combining different assets together in a portfolio that has different risk profiles. Therefore, there is a difference between the risk return profile of one investment and that of the portfolio of investments, essentially diversification reduces risk. As this approach is now an established tool for institutional investors, Wüstenhagen and Menichetti (2012) suggest that investments in renewable energy assets may become more attractive as a way of diversifying their portfolio. Indeed diversification among different renewable assets may also be beneficial within a portfolio (Laurikka, 2008). Assessment of the effect of a diversified renewable energy portfolio can represent a cognitive barrier to investing in the sector.

Additionally, the basic investment model is affected by the type of policies that are introduced as they tend to be targeted at certain segments of investors. Taking solar photovoltaics for example, the investor base could range from utility companies, insurance companies and pension funds through to retail investors who will require emphasis on different issues in their assessment of a worthwhile investment. This may take the form of rates of return or levels of down-payment (Wüstenhagen and Menichetti, 2012).

Further cognitive issues of risk perception are also important in the investment model. It has been previously noted that the concept of bounded rationality introduced in the 1950s by Simon (1955) is important in the decision making process when considering whether to make an investment in a cost effective energy efficiency project. The concept is just as valid in the assessments made by institutional investors and suggests that alongside objective measures of risk and return, perceptions of risk and return are important and those perceptions are influenced by cognitive factors. Cognitive factors have been identified as biases that can lead to conservatism in adjusting to new information and to decisions in which losses are weighted differently than gains (Tversky and Kahneman, 1974, Kahneman, 2003, Kahneman and Tversky, 1979). Biases that have been identified within behavioural finance include anchoringand-adjustment, availability, representativeness and status quo-biases (Pitz and Sachs, 1984, Barnes, 1984, Samuelson and Zeckhauser, 1988, Katz, 1992, Baddeley, 2013, Baddeley, 2017). In the wider financial world, behavioural economics and finance theories making use of 
cognitive factors have demonstrated how in reality financial markets deviate from orthodox economic models, in much the same way as for decision making by individuals. This has been demonstrated in areas such as investor behaviour in stock markets (Lakonishok et al., 1994, Jordan and Kaas, 2002, Chan and Lakonishok, 2004, Shefrin, 2007), and currency speculation (Froot et al., 1992, Bikhchandani et al., 1992, Bikhchandani and Sharma, 2001).

In terms of renewable energy investment, if bounded rationality and cognitive biases do indeed have an influence on investors' decision-making then policy becomes very important factor in that decision-making process. While actual risk and return certainly still matter, not all investors will have all of the information available to comprehensively judge the levels of risk and return before making an investment decision (Wüstenhagen and Menichetti, 2012). Therefore, in addition to lowering risk or increasing return, policies also need to manage expectations and perceptions. Risk return perceptions, for example, can be negatively influenced by frequent policy changes and unclear targets (ibid).

A further relevant aspect of the bounded rationality concept is that of path dependence, which is where past events have an impact on present choices (North, 1990, Goldstone, 1998). Wüstenhagen and Teppo (2006) identified evidence for path dependence in the venture capital market, slowing down the flow of venture capital investments into the renewable energy sector. Past investments in fossil fuels may influence the risk return perceptions of decision makers, leading them to see more opportunities in fossil fuel investment than in renewable energy, as it is a sector they are more familiar with (Pinkse and van den Buuse, 2012).

These cogitative issues and other influencing factors build a more refined model of risk and return, refer to Figure 18. 


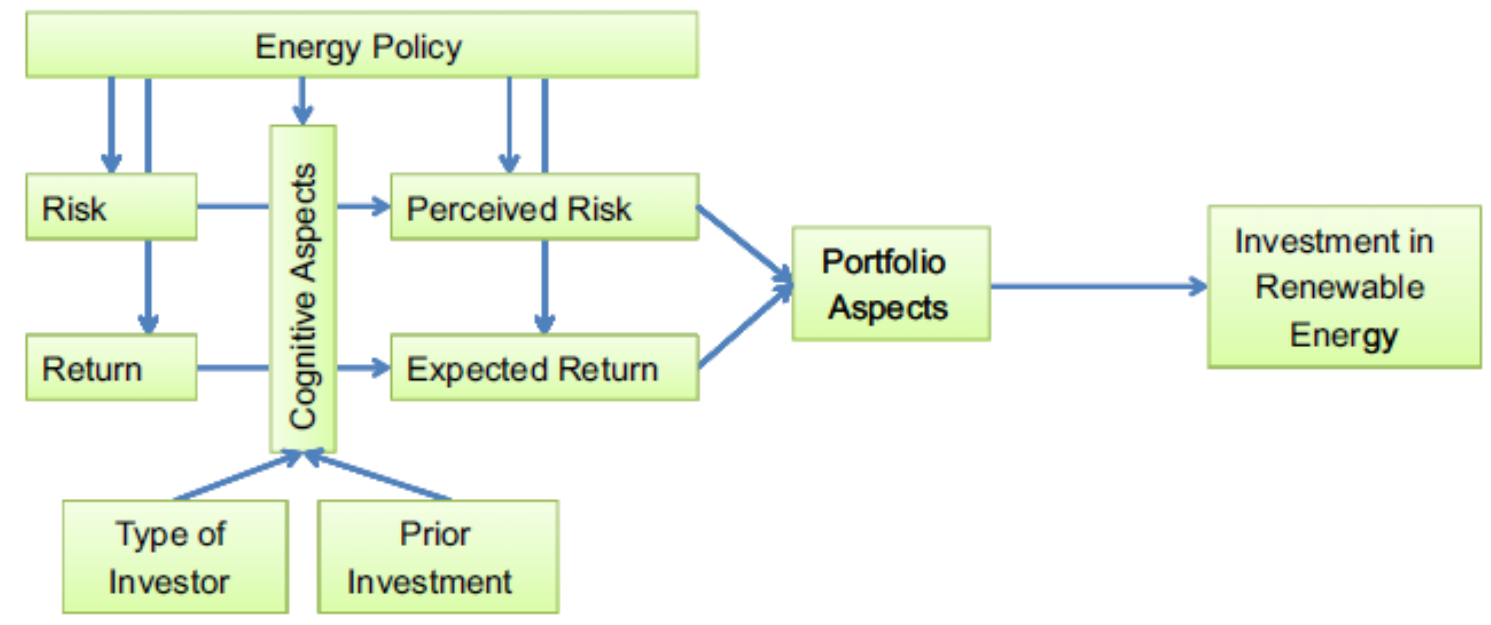

Source: Wüstenhagen and Menichetti , 2012

Figure 18: Differentiated model of risk and return involving energy policy and investment

\subsubsection{Investor preferences and trustees' fiduciary duty}

Investment decisions are made, particularly in the case of pension funds, by their trustees on behalf of their beneficiaries the pension holders. They may be advised by investment advisers but ultimately the trustees have a fiduciary duty, a legal responsibility to exercise reasonable care, skill, caution and loyalty in making these investor decisions (Viederman, 2008). The model of investment decision making formulated by Clark (1998) is considered most appropriate as it specifically identifies institutional investors (pension fund trustees) as the decision makers, it includes all the aspects identified as important in other models including investors' approach to risk and return and it particularly references elements of prospect theory in the framing of investment decisions. Clark (1998) states that trustees make three types of fundamental decisions. Firstly, they allocate assets between asset classes (stocks, bonds, property etc), secondly, they evaluate and choose between types of investment products (e.g. index fund, growth funds) and finally they evaluate and choose investment (or fund) managers (Clark, 1998). Clark (1998) goes on to suggest that trustees take those decisions in accordance with Tversky and Kahneman's prospect theory by framing them around various norms, habits and expectancies. In terms of institutional and pension fund investment there are some implied rules by which, in the case of pension funds, the trustees are governed when they make investment decisions. Rules of proprietary conduct such as the fiduciary duty mentioned above 
which can be translated into the responsibility a trustee has to the schemes pensioners to achieve the best risk weighted return possible, and the implementation of an appropriate asset allocation policy, the modern portfolio theory approach being the most developed.

Gordon Clark's model of the investment decision process, Figure 19, highlights both the rules of proprietary conduct and habits of prudence as influencing those decisions (Clark, 1998). The habits of prudence encompass those behavioural economic issues that dictate individual decision making and can be particularly applied to the financial decision-making process. With respect to habits of prudence, in his model Clark has framed the investment decision process in cognitive bias, prospect theory terms with both loss aversion and regret. Clark has also included preferences for similarity and certainty which are in fact a demonstration of path dependence where past investments influence the risk return perceptions of decision makers, leading to a bias towards similar investments. Clark's outer layer of constructs of reliance, reciprocity and respect are cited as being norms of relationships with external advisers, particularly fund managers, which have an overarching influence on investment decisions.

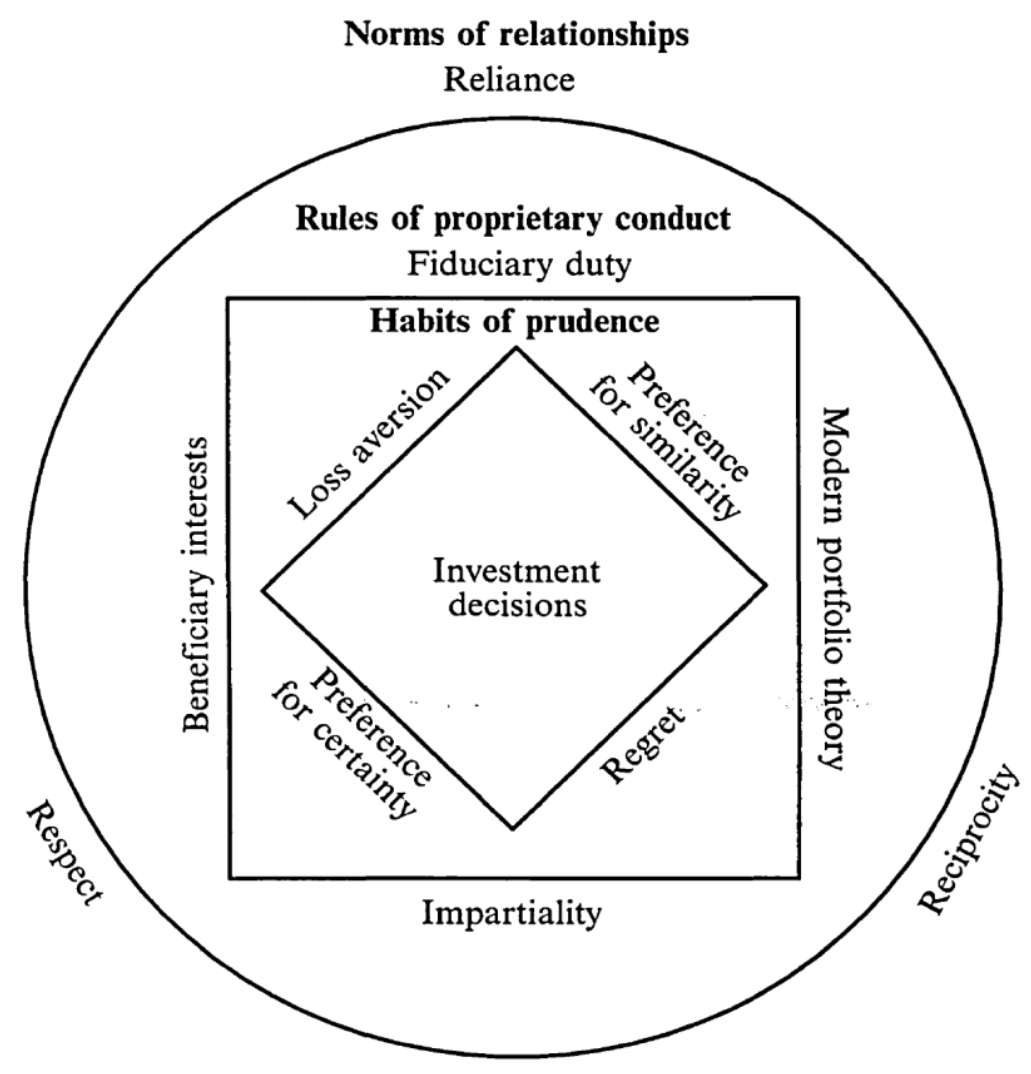

Source: Clark, 1998

Figure 19: Framing trustee decision-making 
Funds need to be managed in the best interests of the ultimate recipients of the funds, namely the pension holders. 'Best interests' have come to equate with short-term financial interests and the maximisation of financial returns and to preclude taking environmental, social and governance (ESG) issues into account in investment decisions (Viederman, 2008, Jansson et al., 2014).

However, this view of fiduciary duty has been challenged most notably in a 2005 report by law firm Freshfields Bruckhaus Deringer, commissioned by the United Nations Environment Programme's Finance Initiative (UNEP FI) which suggests that there are circumstances where ESG issues should be considered. Firstly, where investments are exactly similar on financial grounds, secondly where ESG issues can be expected to impact on a company's financial performance and finally when beneficiaries support it (Jansson et al., 2014, Freshfields Bruckhaus Deringer, 2005). This challenge to the established view has fuelled a heated debate among academics and industry practitioners concerning the extent to which institutional investors should include ESG issues in their investment decision making process and has seen some of the largest pension funds start to include such concerns (Jansson et al., 2014, BNP Paribas, 2016, BNP Paribas, 2017). Jansson et al (2014) undertook research among Swedish future beneficiaries of pension funds to try to understand how they define their 'best interests' in the investment process. They concluded that there is support for a model that includes both financial motives of risk and return together with value-based motives of integrating ESG issues.

Clearly investments into non-domestic energy efficiency would fall within a socially responsible investment (SRI) strategy making low carbon investments. It would be a useful output of the research if it establishes to what extent a desire to include ESG issues in the decision-making process influenced the decision to invest in energy efficiency.

\subsubsection{Investment initiatives}

The issue of overcoming the barriers to funding and investing in energy efficiency is gaining momentum with a number of recent industry initiatives on a wider European and global scale. In September 2015 a conference organised by the European Bank for Reconstruction and 
Development (EBRD) and the United Nations Environment Programme Finance Initiative (UNEP FI) brought together 70 financial institutions. They endorsed a declaration pledging to further engage in financing energy efficiency and further integrate energy efficiency into their business operations. Opening the conference, entitled 'Building a Global Energy Efficiency Financing Alliance', Josué Tanaka, Managing Director for Energy Efficiency and Climate Change at the EBRD said:

The financial sector is uniquely placed to channel finance to energy-saving opportunities and address the current investment gap. Our aim is to make sure the financial community can tap into this potential by forging links with the most up-todate expertise and technology

(EBRD, 2015)

The Energy Efficiency Financial Institutions Group (EEFIG) was established as a specialist expert working group by the European Commission and UNEP FI, in late 2013, to engage with financial institutions and other stakeholders to determine how to overcome the well documented challenges inherent to obtaining long-term financing for energy efficiency. The work of the EEFIG resulted in the publication in February 2015 of their report entitled 'Energy Efficiency - the first fuel for the EU Economy: How to drive new finance for energy efficiency investments'. Its conclusions, for the Buildings sector, includes, recommending that the focus of attention should be on a strong and stable regulatory framework and access to building performance and benchmarking information (EEFIG, 2015).

The Investor Confidence Project is a project of US based 'Environmental Defense Fund' that was created to consult with the Energy Efficiency community in the US to develop a series of common protocols for Energy Efficiency projects. The intention therefore is to allow investors to be confident in the knowledge that Energy Efficiency projects utilising the protocols, will have been procured, structured and will be managed in a way that they understand and can rely on without having to undertake specific due diligence on each new transaction. After gaining funding from the European Union the Investor Confidence Project has launched in Europe with the intention of finalising its European specific protocols during 2016 (ICP n.d.). 


\subsection{Conclusions}

This literature review has sought to identify that the issues around the energy efficiency gap, the difference between current energy use and optimal energy use and explain why it exists in terms of barriers to the implementation of energy efficiency. Much of the literature is based around orthodox economics and identifies market failures, as the assumption is that individuals make rational decisions. However, the concept of bounded rationality is contrary to the orthodox view and effectively states that people make decisions without the full information in their possession and therefore they are not able to make them rationally.

Additionally, investments by institutional investors in renewable energy have also been examined and although energy efficiency investments are notably different, they have been linked together as low carbon investments. The issues of bounded rationality and cognitive factors also influence investors' decisions when considering investing in renewable energy.

Cognitive factors should be considered in any analysis of energy efficiency investments made by institutional investments as they influence the decision-making process. Investors may make decisions irrationally contrary the orthodox view not only because of lack of full information but due to different biases that may be exerting varying degrees of influence. Wüstenhagen and Menichetti's model concerning renewable energy investment also considers cognitive biases as influencing decisions (Wüstenhagen and Menichetti, 2012).

Clark's model which frames institutional investor's / pension fund trustee's decision-making processes when considering investments and identifies not only the rules of proprietary conduct but also habits of prudence, those cognitive biases that are most prevalent in the decisionmaking process with those identified in prospect theory being most prevalent (Clark, 1998). It is apparent from the literature review that these issues need to be considered in the investor decision making process and Clark's model is particularly relevant as it specifically references institutional investors decisions when placing their funds across all investment classes. This is a useful starting point from which to consider investment decisions concerning energy efficiency specifically. The model also includes all the aspects identified as important in other models including investors' approach to risk and return and can therefore be considered the best amalgamation of other developed models. The review has also discussed the possibility 
that ESG issues are increasingly being considered as part of the investment decision-making process.

The gap that has been become evident is that there has been little or no research and into identifying institutional investors decision-making processes when considering energy efficiency investments in particular and whether the current move towards ESG issues influencing investment decisions have a bearing on decisions to invest in energy efficiency. Whether the current investment initiatives identified also have a bearing is also unknown. 


\section{Research questions, methodology and method}

\subsection{Introduction}

The previous chapters have sought to identify that energy efficiency of buildings and industrial processes is one area that is cost effective to approach in terms of investment and $\mathrm{CO}_{2}$ emission reduction. Buildings are a major contributor to $\mathrm{CO}_{2}$ emissions and it would appear that for the level of investment required it is one of the sectors that could have the most effect in its $\mathrm{CO}_{2}$ reduction and could contribute significantly to the UK governments emission reduction targets. However, significant investment would be required for this to become a reality.

Institutional investors hold a significant level of funds that they seek to invest in order to maximise their return. The current research seeks to analyse the investment decisions made by institutional investors and pension funds when they decide to make an investment with a view to increasing investment into energy efficiency and therefore contribute to the reduction in $\mathrm{CO}_{2}$ emissions.

\subsection{Research questions}

In analysing the literature, together with the benefits of implementing energy efficiency at scale, the following research question has been formulated together with three sub questions.

What are the barriers to attracting capital investment at scale for energy efficiency in the context of institutional and pension fund investment?

1. How do institutional investors decide whether to invest in energy efficiency?

2. Why, when environmental social and economic benefits are apparent, have institutional investors not invested in energy efficiency at scale? 


\section{What are the enabling conditions that would facilitate institutional investors investing in energy efficiency at scale?}

\subsection{Methodology}

The approach to research is driven by a philosophical epistemological position which culminates in the research design and methods employed. Ontology is the study of being, the nature of existence embodying the understanding of what is (Gray, 2009). Epistemology tries to understand what it means to know and provides a philosophical background for deciding what kinds of knowledge are legitimate and adequate (Gray, 2009). While ontology is about what you are looking at, epistemology is about how you look and find out about these events in the social world (Thomas, 2009). Depending on the researcher's epistemological stance, a theoretical perspective is taken which then in turn influences the research methodology and methods employed (Gray, 2009).

Two prominent epistemological positions that have emerged are objectivism and constructivism, which take opposing positions (Gray, 2009). Objectivism holds that reality exists independently of consciousness and that there is an objective reality (Gray, 2009). A theoretical perspective closely linked to objectivism is positivism or postpositivism where knowledge about the world can be obtained objectively, and what we see and hear is straightforwardly perceived and recordable (Thomas, 2009). The things of the social and psychological world can be observed, measured and studied scientifically, in much the same way as physicists study levers, atoms and pulleys (Thomas, 2009). Constructivism rejects this view of human knowledge. Truth and meaning do not exist in some external world but are created by the subject's interaction with the world (Gray, 2009). Meaning is constructed not discovered so subjects construct their own meaning in different ways, even in relation to the same phenomenon (Gray, 2009). A theoretical perspective closely linked to constructivism is interpretivism (Mertens, 1998, Habermas, 1970) where the social world is not straightforwardly perceivable because it is constructed by each of us in a different way. It is not simply 'out there' it is different for each of us (Thomas, 2009). It focuses on the ways that people make sense of the world, especially through sharing their experiences (Easterby-Smith et al., 2002). 
Having an epistemological perspective is important as it can help to clarify issues of research design, meaning the overarching structure of the research including the kind of evidence that is being gathered, from where, and how it is going to be interpreted (Easterby-Smith et al., 2002).

The epistemological position of the research and researcher is based in Objectivism, where there is assumed to be an objective reality. The theoretical perspectives previously mentioned dictate how the research is carried out, within a framework that Creswell (2009) suggests is a philosophical worldview or as some, such as Lincoln \& Guba (2000) and Mertens (1998) both cited by Creswell (2009), call paradigms (Creswell, 2009, Lincoln and Guba, 2000, Guba, 1990). It is how we seek knowledge and how we use it or according to Guba (1990), a basic set of beliefs that guides action. Therefore, the proposed research will follow the postpositivist worldview, which represents the view after positivism, which is typically seen as an approach to quantitative deductive research, however it can also be aligned to qualitative inductive research (Creswell, 2009). Postpositivim acknowledges that researchers are influenced by their contexts and therefore influence research (Braun and Clarke, 2013). There can be both positive and interpretive qualitative research and Guba and Lincoln (1994) state that both qualitative and quantitative methods may be used appropriately with any research paradigm (Guba and Lincoln, 1994).

\subsubsection{Qualitative approach using Case Study analysis}

The research questions and the analysis of investors' decision processes lends itself to a qualitative rather than quantitative research approach. Within qualitative research the role of the researcher is to gain a deep, intense and 'holistic' overview of the context under study, often involving interacting within the everyday lives of individuals, groups, communities and organisations (Gray, 2009). It is a naturalistic approach that seeks to understand phenomena within their own context-specific settings (Gray, 2009). Capturing data on the perceptions of actors in the field of study, means being attentive, suspending preconceptions about a subject and being empathetic to those being studied (Gray, 2009). 
The analysis of investors' decision processes again lends itself to a case study research method. Yin (2009) defines the case study in two parts as:

1. A case study is an empirical inquiry that

- Investigates a contemporary phenomenon in depth and within its real-life context, especially when

$\circ$ The boundaries between phenomenon and context are not clearly evident.

2. The case study enquiry

- Copes with the technically distinctive situation in which there will be many more variables of interest than data points, and as one result

- Relies on multiple sources of evidence, with data needing to converge in a triangulating fashion, and as another result

- Benefits from prior development of theoretical propositions to guide data collection and analysis.

The research being undertaken considers a contemporary phenomenon in its real-life context, investment decisions being made by highly capitalised institutional investors and fund managers in an extremely competitive commercial environment. The boundaries between phenomenon are not evident with many variables being present. Although the main source of data is the output from semi-structured interviews, various documentary evidence was also consulted even if a full triangulation of the research outcome was not feasible. The research starting point was identified a priori constructs which for the basis of theoretical propositions that guide the data collection.

Yin (2009) suggests that case study research is one method that can be applied to exploratory, descriptive and explanatory research, however the use of how and why questions is more explanatory and likely to lead to the use of case studies as preferred research methods. The first two sub research questions posed in this research, which are being directly addressed, are how and why questions and are explanatory in nature. The third sub research question is a what question but however it is likely to be answered in the course of addressing the first two questions. For these reasons a case study approach is deemed an appropriate method for the research being undertaken. 


\subsubsection{Thematic Analysis}

Having established that use of case studies is an appropriate research approach, the next stage is to identify an appropriate method of analysis of the qualitative data produced from, in the main, semi - structured interviews. Thematic analysis is deemed appropriate to analyse large quantities of data. Thematic analysis is a systematic approach to the analysis of qualitative data that involves identifying themes or patterns of cultural meaning; coding and classifying data, usually textural, according to themes; and interpreting the resulting thematic structures by seeking commonalities, relationships, overarching patterns, theoretical constructs or explanatory principles (Mills et al., 2010). Thematic analysis is not a research method in itself but rather an analytic approach and synthesising strategy used as part of the meaning-making process of many methods, including case study research (Mills et al., 2010).

Boyatizis (1998) describes thematic analysis in the following way: It is a process for encoding qualitative information. The encoding requires an explicit "code." This may be a list of themes; a complex model with themes, a complex model with themes, indicators, and qualifications that are causally related; or something in between these two forms. A theme is a pattern found in the information that at a minimum describes and organises the possible observations and at a maximum interprets aspects of the phenomenon. Themes may be initially generated inductively from the raw information or generated deductively from theory and prior research (Boyatzis, 1998).

According to Boyatzis (1998) thematic analysis has a number of overlapping or alternate purposes. It can be used as a means (1) of seeing, (2) of finding relationships, (3) of analysing, (4) of systematically observing a case, and (5) of quantifying qualitative data. As a sensemaking approach thematic analysis is a tactic for reducing and managing large volumes of data without losing the context, for getting close or immersing oneself in the data, for organising and summarising, and for focusing the interpretation (Mills et al., 2010).

The method of analysis employed in the research is a hybrid approach as advocated by Fereday and Muir-Cochrane (2006) and further discussed by Boyatzis (1998) and Braun and Clarke $(2006,2013)$ that uses both deductive and inductive applications of thematic analysis. As 
Boyatzis (1998) stated, themes may be generated inductively or deductively and this reflects a postpositivist worldview. In the research a deductive approach is initially taken following Crabtree and Miller's (1999) process of formulating an a priori template of codes based on the research questions, constructs and conceptual framework, outlined in the Section 5.4 Method (Crabtree and Miller, 1999). As the analysis proceeded this framework of codes developed both deductively, in that the original a priori constructs were refined and further subdivided, and inductively as other constructs, concepts and codes emerged from the data as it was being analysed.

\subsubsection{Validation and Reliability}

Validity in qualitative research is a difficult issue as the notion of validity has been formulated by a positivist, quantitative approach to research and holds a perspective that "validity," the accuracy and truthfulness of the findings, can be based on notions of "reliability" (repeatable, generalisable), or the stability of methods and findings (Altheide and Johnson, 1994). Crabtree and Miller (1999) state that in comparison to quantitative research, qualitative analytical methods rarely have the luxury of deductive universal categories, numerical proofs or statistical generalisability. Crabtree and Miller (1999) go on to assert that qualitative researchers have had to take different tacks in attempting to make assertions of validity and provide the following list of issues to be addressed:

- Reflexivity;

- Depth of description;

- Accuracy;

- Rigor;

- Intellectual honesty;

- Searching for alternative hypotheses and interpretations.

Reflexivity refers to the technique whereby the researcher focuses on themselves to evaluate their influence on the findings and interpretations (Crabtree and Miller, 1999). Depth of description is critical both in avoiding superficiality and in ensuring that the issues, concepts 
and contextual realities have been suitably explored (Crabtree and Miller, 1999). Accuracy is a primary responsibility of the investigator (Crabtree and Miller, 1999). Validity in quantitative research is inexorably tied to the notion of rigor and intellectual honesty (Crabtree and Miller, 1999). There must be certainty that the investigator has been tireless in recording, examining and interpreting the data and in searching for alternating hypotheses and interpretations (Crabtree and Miller, 1999). Crabtree and Miller (1999) assert that if the researcher understands the issues that need to be addressed then the research will be successful.

Yin (2009) suggests that to assist the qualitative case study researcher to determine that their approaches are consistent or reliable they should document the procedure of their case studies and document as many of the steps of the procedures as possible. He also recommends setting up a case study protocol. Refer to Appendix B.

An established validation strategy is the use of quasi-statistics, that is the drawing of simple quantitative data from qualitative methods, frequencies and variances for example (Sitko, 2013). This approach was advocated in the 1960s, and it has been seen as a reflection of that era (Taylor et al., 2016). In the 1950s and 1960s qualitative research was strongly influenced by positivist concepts of validity and reliability and many researchers tried to justify qualitative studies according to standards associated with quantitative research (Taylor et al., 2016). Today, few qualitative researchers would attempt to validate their research in this way, however it is still a relevant approach, particularly as the current research is being carried out from a postpositivist perspective. It enables the assessment of the evidence in the data that supports or does not support the conclusions being made and therefore an attempt to use quasistatistics in this way is made (Sitko, 2013).

\subsection{Method}

It has been established that the analysis of investors' decision processes lends itself to a qualitative case study research approach. In terms of selecting a case or cases to analyse it is not practicable to use direct investing as a basis for analyse as there is not sufficient level of investment activity in the market. As this research concerns institutional investment at scale it is more appropriate to use institutional investment into dedicated energy efficiency funds as 
the basis of the analysis. Four funds have been identified as being available for institutional investment, the Zurich based Susi fund and the three GIB invested funds run by Equitix, SDCL and Aviva.

It was decided to use the three GIB invested funds as the basis of the research and to discount the Susi fund on the grounds of pragmatism, accessibility and standardisation of the fund structure. The fact that the GIB were involved in the Equitix, SDCL and Avivia funds, investing the same amount of initial capital, intended to be invested in the UK and being based in the UK were important factors. Pragmatically speaking, gaining access to the Susi fund managers and its investors would be difficult, being based outside the UK. Therefore, it was decided to analyse the three GIB invested funds.

The GIB took the decision to invest in energy efficiency funds run by external fund managers a only viable way of increasing institutional investment into the sector at its current stage of development. The research that is being undertaken seeks to investigate and understand the decision-making process of institutional investors with regard to investment into energy efficiency via the three established energy efficiency funds. These funds all have the common characteristic of an initial $£ 50 \mathrm{~m}$ investment from the (GIB). One of the aims of the GIB is to encourage private investment into its stated areas of interest, including non-domestic energy, efficiency and due to its state funded status an investment made by the bank needs to have a matching investment made by the private sector. Therefore, in relation to the energy efficiency funds the three fund managers are obliged to secure an additional $£ 50 \mathrm{~m}$ of private sector investment in their respective funds, matching the GIB's investment. As the funds are deployed they are drawn down on a pari passu basis between the GIB and the private investors.

Although the funds are all labelled as energy efficiency funds and the GIB has made its $£ 50 \mathrm{~m}$ initial investment in each under its stated area of interest (non-domestic energy efficiency) the investment strategy for each fund is very different although there can be some cross-over in approach particularly by Equitix and SDCL. The Aviva Investors fund focuses on investments in Energy Centres situated in NHS hospitals. Its revenues are derived from government backed entities and the fund managers concentrate on low risk contractual structures and consequently generate modest returns based on the low risk of their investments. Equitix has traditionally operated in the infrastructure investment world and has applied its infrastructure contractual discipline to its energy efficiency investments model. To date they have tended to concentrate 
to date on small scale biomass transactions that attract government support in the form of Renewable Obligation Certificates (ROCs) and the Renewable Heat Incentive (RHI). These types of investment therefore rely partly on government funding and partly on the performance of a private or corporate entity. Returns will reflect the inherent risk in the transactions. The third fund run by SDCL takes an even bigger shift away from government backed income and focuses on an Energy Performance Contracting model, whereby transaction revenues are derived from the ability of an Energy Service Company (ESCO) to achieve an agreed level of energy saving from which finance repayments are made. Should the ESCO fail in achieving this then they are obliged to make up the shortfall. This type of arrangement is therefore generally reliant on private sector performance rather than any government backed revenue and the returns offered reflect this increased risk.

Table 6 summarises the transactions entered into by each of the funds. A fuller explanation of the transactions can be found in Appendix A.

\begin{tabular}{|c|c|c|c|c|}
\hline GIB Fund & Transaction & Year & Value $\mathrm{fm}$ & EE Sector \\
\hline \multirow[t]{6}{*}{ Equitix } & Roundwood Energy & 2013 & 10.00 & Biomass \\
\hline & Tomatin Distillery & 2013 & 1.20 & Biomass \\
\hline & Bernard Matthews' Turkey Farms & 2014 & 24.50 & Biomass \\
\hline & Sheffield CHP & 2015 & 30.00 & Biomass \\
\hline & Nottingham CHP & 2015 & 30.00 & Biomass \\
\hline & $\begin{array}{l}\text { Expansion of Wick district heating } \\
\text { scheme }\end{array}$ & 2016 & 10.00 & Biomass \\
\hline \multirow[t]{6}{*}{ SDCL } & Kingspan & 2014 & 5.00 & $\begin{array}{l}\text { Building } \\
\text { Retrofit }\end{array}$ \\
\hline & NCP Car Parks & 2014 & 10.00 & $\begin{array}{l}\text { Building } \\
\text { Retrofit } \\
\end{array}$ \\
\hline & Citi & 2014 & 5.2 & $\begin{array}{l}\text { Building } \\
\text { Retrofit }\end{array}$ \\
\hline & Moy Park Poultry Farms & 2014 & unknown & Biomass \\
\hline & Santander & 2015 & 17.50 & $\begin{array}{l}\text { Building } \\
\text { Retrofit } \\
\end{array}$ \\
\hline & St Bartholomew's Hospital & 2015 & 4.50 & Energy Centre \\
\hline \multirow[t]{2}{*}{ Aviva } & Addenbrooke's Hospital & 2013 & 36.00 & Energy Centre \\
\hline & Cheltenham Hospital & 2014 & 2.20 & Energy Centre \\
\hline
\end{tabular}

Table 6: Examples of transactions entered into by each GIB fund 
The research is intended to investigate the decision-making process of institutional investors in these three funds and of course the reasons for investing and the criteria investors have established for making their investments can vary widely, particularly when considering the wide range of underlying investment types that constitute energy efficiency and the varying strategies employed by the three funds. The one common denominator is the GIB and its $£ 50 \mathrm{~m}$ initial investment. For this reason it is considered appropriate to follow a single case study methodology with embedded units of analysis (Yin, 2009). In this case the single case study is the GIB fund investment with embedded units of analysis on two levels. The first level is the three funds themselves and then the second the individual institutional and pension fund investors in each of the funds, refer to Figure 20.

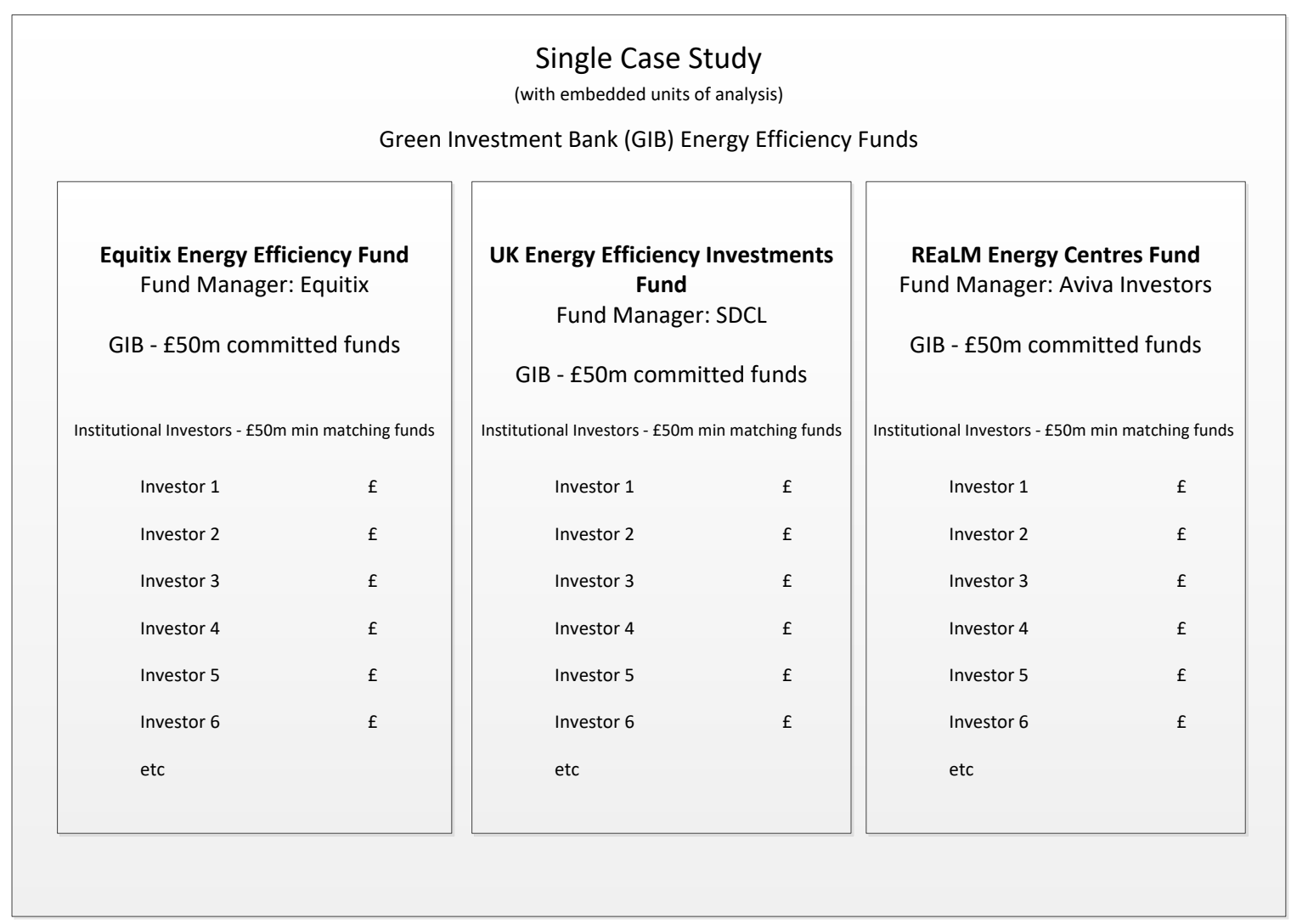

Figure 20: Single case study based on Yin, 2009 
Although the case study approach can involve a number of different data collection methods such as reviewing relevant documents or direct observation, and some confidential documents have been received from the fund managers, the most appropriate method in this case involves undertaking a series of semi structured interviews with individuals at each level of analysis, at the GIB, the fund managers and the individual investors. The original intention was that there would be up to 25 interviews overall, no less than 20 , with an increasing number of interviews as the investigation moved from the GIB to the funds and then to the investors. It was intended that there would be three interviews with GIB personnel involved in the energy efficiency sector and particularly with the investment made in the funds, six with fund managers across the three fund management companies and the remainder, between eleven and sixteen with individuals representing the investors in the funds themselves. It was also intended that of the investor interviews a proportion of them would be with investors that had considered investing in the energy efficiency funds but ultimately declined to invest.

At the end of the data collection process there had indeed been three interviews with GIB personnel and six with individual fund managers encompassing the three funds and the remaining thirteen interviews were with representatives of investors in the funds, one of which was with a declined investor. The interviews were carried out between November 2014 and January 2016. Although the main data collection process was via semi-structured interviews, a confidentiality agreement was signed with Aviva Investors enabling a certain amount of confidential papers, predominately investment committee papers that outlined the case for investment by their fund into various energy efficiency investments, to be reviewed as part of the research process. In addition, publicly available documents that outlined the various investments made by each fund, albeit in not great detail, were also reviewed. The third aspect of a case study research method of direct observation was not possible as this would entail being present at a confidential investment committee while the investment decision was being made. Table 7 outlines the semi-structured interviews that were undertaken. It illustrates which type of entity they are from, the GIB, fund manager or investor and in respect of the fund managers and investors which fund they are associated with, the Aviva, Equitix or SDCL managed fund. 


\begin{tabular}{|c|c|c|c|c|c|}
\hline $\begin{array}{l}\text { Interview } \\
\text { count }\end{array}$ & Interviewee entity & $\begin{array}{l}\text { Interview } \\
\text { No }\end{array}$ & Interview dates & Generic Role of interviewee & Investor type \\
\hline & GIB & & & & \\
\hline 1 & & 1.1 & 13th April 2015 & Senior Investment Exectutive & \\
\hline 2 & & 1.2 & 15th May 2015 & Senior Investment Exectutive & \\
\hline \multirow[t]{2}{*}{3} & & 1.3 & 9th June 2015 & Senior Investment Exectutive & \\
\hline & Fund Managers & & & & \\
\hline 4 & Aviva & 2.1 & 24th Feb 2015 & Fund Manager & \\
\hline 5 & & 2.2 & 9th June 2015 & $\begin{array}{l}\text { Managing Director } \\
\text { - Infrastructure Finance }\end{array}$ & \\
\hline 6 & Equitix & 3.1 & 13th Nov 2014 & Investment Director & \\
\hline 7 & & 3.2 & 15th Oct 2014 & Investment Manager & \\
\hline 8 & & 3.3 & 23rd Oct 2014 & Investor Relations Manager & \\
\hline \multirow[t]{2}{*}{9} & SDCL & 4.1 & 27th Feb 2015 & Partner & \\
\hline & Investors & & & & \\
\hline 10 & Aviva & 2.3 & 8th July 2015 & Head of Infrastructure Equity & $\begin{array}{l}\text { Pension/Insurance Co/Fund Manager } \\
\text { (Global Assets under management } \\
\text { of } £ 315 \mathrm{bn} \text { ) }\end{array}$ \\
\hline 11 & Equitix & 3.4 & 14th Nov 2014 & Principal & $\begin{array}{l}\text { Investment Manager } \\
\text { (Small scale investment advisor } \\
\text { of } 122 \text { employees) }\end{array}$ \\
\hline 12 & & 3.5 & 22nd April 2015 & Chief Investment Officer & $\begin{array}{l}\text { Corporate Pension Fund } \\
\text { ( } £ 1.9 \text { bn of annual revenue) }\end{array}$ \\
\hline 13 & & 3.6 & 17th July 2015 & Head of Pensions and Treasury & $\begin{array}{l}\text { Local Gov Pension Fund } \\
\text { (Market Value of Assets } £ 877 \mathrm{~m} \text { ) }\end{array}$ \\
\hline 14 & & 3.7 & 27th July 2015 & Head of Infrastructure Research & $\begin{array}{l}\text { Investment Manager } \\
\text { (Major global consulting firm with } \\
\$ 3.6 \text { bn of annual revenues) }\end{array}$ \\
\hline 15 & & 3.8 & 27th July 2015 & $\begin{array}{l}\text { Team Leader } \\
\text { - Sustainable Development \& Energy }\end{array}$ & $\begin{array}{l}\text { Local Gov Pension Fund } \\
\text { (Market Value of Assets } £ 877 \mathrm{~m} \text { ) }\end{array}$ \\
\hline 16 & & 3.9 & 23rd Nov 2015 & Head of Division & Multilateral Development Bank \\
\hline 17 & & 3.10 & 23rd Nov 2015 & Investment Officer & Multilateral Development Bank \\
\hline 18 & & 3.11 & 23rd Nov 2015 & Senior Economist & Multilateral Development Bank \\
\hline 19 & & 3.12 & 18th Jan 2016 & Alternatives Investment Manager & $\begin{array}{l}\text { Declined Investor - Local Government } \\
\text { Pension Fund } \\
\text { (Market Value of Assets } £ 11 \mathrm{bn} \text { ) }\end{array}$ \\
\hline 20 & $\mathrm{SDCL}$ & 4.2 & 9th June 2015 & Sustainable Investment Executive & $\begin{array}{l}\text { Investment Fund } \\
\text { (Small scale sustainable } \\
\text { venture capital firm) }\end{array}$ \\
\hline 21 & & 4.3 & 29th june 2015 & Sustainable Investment Executive & $\begin{array}{l}\text { Investment Fund } \\
\text { (Small scale sustainable } \\
\text { venture capital firm) }\end{array}$ \\
\hline 22 & & 4.4 & 22nd Jan 2015 & Chief Investment Officer & $\begin{array}{l}\text { Investment Fund } \\
\text { (Independent investment fund with } \\
\text { f8bn of assets under management) }\end{array}$ \\
\hline $\mathrm{n} / \mathrm{a}$ & & 4.5 & 23rd Nov 2015 & Head of Division & same interview as 3.9 \\
\hline $\mathrm{n} / \mathrm{a}$ & & 4.6 & 23rd Nov 2015 & Senior Economist & same interview as 3.11 \\
\hline
\end{tabular}

Table 7: Outline of the semi-structured interviews undertaken 
The constructs identified in Clark's model of trustee decision making, refer to Figure 19 in section 4.4.6, have formed a priori constructs to the research being conducted together with those identified relating to low carbon investments and to government intervention. Using these constructs, a model of the investment decision specifically relating to energy efficiency was formulated prior to the commencement of the research, see Figure 21. The habits of prudence remain as per Clark's general model, as they will always frame any investment decision. In particular Clark suggests that loss aversion and a preference for certainty are significant pension trustee habits. The remaining two prudential habits of prudence, a preference for similarity and regret are less so, however they collectively work to ensure that investment decisions where large sums are involved will be made on a conservative basis. The model has a series of influencing factors which have been formulated as constructs to the decision process and includes many of the assumed issues that are to be considered in the research. The habits of prudence and influencing factors are enveloped by the rules of propriety conduct that all pension fund trustees and other institutional investment decision makers are bound by. The reference to Modern Portfolio Theory in the rules of propriety conduct from Clark's model has become Strategic Asset Allocation Policy as it assumes that there are a much wider series of approaches to this issue across different investor types. Another deviation from Clark's model is that of the norms of relationships. Clark's model refers to general decision-making where institutions employ and invest with many fund managers and such decision-making processes would need to take a particular institution's relationship with these companies into account. In Clark's model these norms of relationships, reliance, respect and reciprocity, are encompassing the decision process in global sense, and their presence in the process is an established phenomenon. As this research is looking at a very specific asset type, energy efficiency, which is very new in investment terms, the issue of the fund manager has been made a specific influencing factor rather than a global consideration and the norms of relationships are part of the specific influencing factor within the energy efficiency model. 


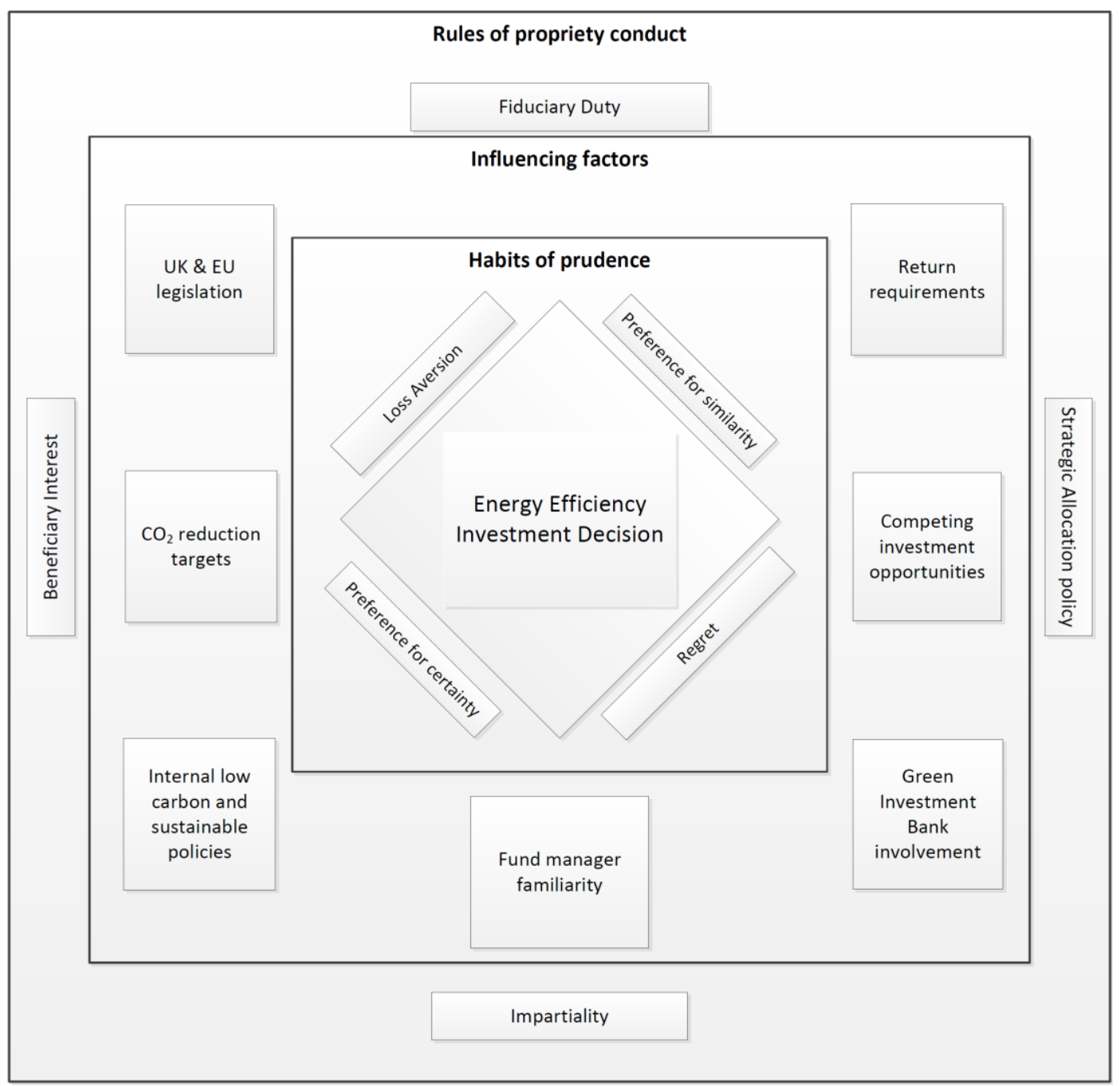

Figure 21: Energy Efficiency Investment Decision process

The starting point of the research process was to formulate a case study protocol based on the approach outlined by Yin (2009). This served as a guide to carrying out the research in a disciplined manner in order to aid the reliability of the outcome. The following quote from Yin illustrates the usefulness of developing a case study protocol as not only a guide but also in demonstrating the reliability of the research.

The protocol is a major way of increasing the reliability of the research and is intended to guide the investigator in carrying out the data collection from a single case.

Yin, 2009 
The contents page of the case study protocol formulated for the current research, which sets out the issues to consider when carrying out the research is provided in Appendix B along with two other documents, an information sheet and consent form. The information sheet was provided to each interviewee before the interview commenced and was discussed at the beginning of each meeting to set out the background, the issues and the purpose of the research. The consent form gave the interviewee an opportunity to confirm that they had read the information sheet and understood the basis of the research and among other things that they agreed to be audio-recorded and they agreed to take part in the research. It also gave them the opportunity to withdraw from the process if they so wished however, all of the interviewees signed the consent form prior to their interview. The semi-structured interviews then proceeded, and were recorded and transcribed. The transcripts were sent to each of the interviewees to review and comment on prior to being finalised.

The questions in the research have centred on a number of key topics and the semi-structured interview questions have also been categorised in this way:

- Asset allocation and return requirements

- Return requirements

○ Strategic Asset Allocation Policies

- Low carbon investments

- Return requirements

- Internal low carbon and sustainable policies

- Decision to invest/not to invest

○ Competing investment opportunities

○ Green Investment Bank involvement

○ Habits of prudence, loss aversion, preference for certainty and similarity, regret

- Fund Manager

○ Fund manager familiarity

- UK government and EU polices

○ UK and EU legislation

○ $\mathrm{CO}_{2}$ reduction targets 
The various constructs in the energy efficiency model have been identified as falling into one the topics. The rules of propriety conduct that are not identified as being part of a particular topic, namely fiduciary interest, beneficiary interest and impartiality, would fall into all of the topic areas.

The semi-structured questions based on the above topics are provided in Appendix C. As discussed previously, a form of thematic analysis in a combined deductive and inductive way was employed to analyse the data collected. The process was deductive as a priori constructs were initially identified and therefore established prior to the interview transcripts being analysed and to a lesser extent the transaction documents. The research was also inductive as new unexpected constructs, concepts and ultimately codes emerged from the data. The results from the thematic analysis process were further applied to the analysis of the investor decision making process, facilitating the identification of the enabling conditions that would need to exist for institutional investors to invest in Energy Efficiency at scale. The a priori constructs identified prior to the data analysis process were based on the constructs of the conceptual model of the energy efficiency investment decision process shown in Figure 23 and are provided below:

\section{A priori constructs:}

- Investment return requirements

- UK and EU legislation

- $\mathrm{CO}_{2}$ reduction targets

- Familiarity with fund manager

- Strategic asset allocation, use of Modern Portfolio Theory

- Competing investment opportunities

- Internal low carbon and sustainability policies

- Green Investment Bank (GIB) involvement

- Behavioural Finance, habits of prudence:

Loss aversion

Preference for certainty

Preference for similarity

Regret 
- Behavioural Finance, norms of relationships: (with Fund Manager)
Reliance

Reciprocity

Respect

There are two are issues to note. The construct 'Strategic asset allocation, use of Modern Portfolio Theory' refers to the use of Modern Portfolio Theory. Although reference to Modern Portfolio Theory in Clarks original model has become Strategic Asset Allocation Policy in the energy efficiency investment decision model as it assumes that there are a much wider series of approaches to this issue across different investor types, it is left in as part of the particular $a$ priori construct in order to test this assumption. Secondly the norms of relationships with respect to the fund manager, of reliance, respect and reciprocity are not specifically referenced in the energy efficiency investment decision model. As discussed previously they are intrinsic to the fund manager familiarity influencing factor and not a general encompassing 'given' in the investment decision process as in Clarks model. Again, it was felt worth testing this in the research and they were included as separate behavioural finance constructs.

The a priori constructs were firstly mapped to the research questions to allow a reference back to the constructs when responding to the research questions at the conclusion of the process. The constructs and the research questions were also mapped to the individual semi-structured interview questions that were grouped into the key categories identified above. This mapping process involving the a priori constructs, research questions and the semi-structured interview questions is provided in Appendix D.

The a priori constructs formed the initial set of codes and sub codes to be used to analyse the semi-structured interview transcripts. These can be seen in Appendix E highlighted in blue in the code system. As the data analysis progressed further codes were identified inductively as unanticipated issues and concepts arose during the process, and these are highlighted in yellow in code system in Appendix E. The transcripts and the codes were inputted into MAXQDA which is an established Computer Assisted Qualitative Data Analysis Software (CAQDAS) within which various passages and quotes within the transcripts can be assigned a code or codes from the original set of identified codes or a new code as appropriate. Finally, once the transcripts had been fully coded, the codes were mapped to each semi-structured interview 
question and this can be seen in Appendix F. This mapping allowed the data analysis to be carried out and a narrative to be produced for each key category listed above. It also enabled a response to the individual research questions and a final conceptual model of the energy efficiency investment decision process to be formulated. 


\section{Data Analysis}

\subsection{Research outcomes}

As outlined in section 5.4 Method, the data collection via semi-structured interviews encompasses twenty-two interviews, summarised in table 5 in section 5.4 Method. Of the twenty-two interviewees three were conducted with personnel from the European Investment Bank either current or previous employees, six were from the fund manager organisations and thirteen from investors. Of the investors interviewed, all but one had considered the investment into one of the energy efficiency funds and ultimately made an investment. The one investor that considered the opportunity and declined to make an investment provides an alternative perspective on the decision to invest in energy efficiency. In addition, a further investor that considered investing but ultimately decided not to investment that was approached to participate in the research and declined, did in fact provide some insights into their decision informally via discussion and email. The results of the analysis of the interviews are provided in this chapter. The sample of participants is based on a theoretical sample rather than a statistically significant one where the research is looking to draw out insights and conclusions in a qualitative approach (Eisenhardt, 1989, Yin, 2009).

The interview questions were orientated around the five broad topics identified in section 5.4, within which a number of questions were asked of the research participants. The data collected is analysed in this chapter and more specifically each of the five topics are analysed in sections 6.2 to 6.6. To recap, the five topics are:

- Asset allocation and return requirements

- Low carbon investments

- Decision to invest/not to invest

- Fund Manager

- UK government and EU polices 


\subsection{Asset allocation and return requirements}

Asset allocation is important in the context of institutional investment, as investors are primarily risk averse and will tend towards their traditional investment classes of equities and bonds (Bekkers et al., 2009). It is useful to understand in practice how the investment made in energy efficiency is classified. Is it viewed as an infrastructure investment or as renewable energy, even though in reality it does not concern energy generation? However it is classified, it is hard to see energy efficiency sitting anywhere but in the wider 'Alternatives' classification which has traditionally attracted only about $5 \%$ of investors allocation of funds, although its recently increased up to $9 \%$ and in some specific cases even higher and is typically used in order to diversify an investor's portfolio. It would be interesting to gauge whether investors are willing to increase that percentage if they view energy efficiency as a new sub-sector of 'Alternatives' that could prove profitable for them potentially increasing the funds available for investment in the sector, or whether it just fits into one of their current classifications where it competes with other conventional investment opportunities.

\subsubsection{Investment Correlation and Asset Allocation Strategy}

A main driver of diversification is to de-risk the investment portfolio and seek out investments that, while providing the required level of return, are not correlated with the more conventional investments in equities and bonds. Therefore, when adverse market events occur that negatively affect more conventional investments, a fully diversified portfolio is not affected in the same way protecting returns from those adverse market returns. One interviewee from the GIB noted:

It's a small portion of their funds, so they'll probably take the view that it's uncorrelated. So, it's not negatively correlated, it's completely uncorrelated. So, they're just looking for some uncorrelated yield.

So, it's not even diversification, it's just non-correlated. So, in the case you have a black sort of event in the market, this stuff should be completely uncorrelated. Which for the 
most part is true. You know, health sector returns that you're getting paid on energy efficiency should be completely unrelated to the market's return. ${ }^{1}$

This response indicates that energy efficiency investments are considered to be a good diversification with a low-level correlation to mainstream investments which therefore should make it an attractive proposition in a strategy that aims to create a balanced, diversified portfolio. For investors or their investment managers to fully assess investments, information about the risk and return of a particular asset type is required.

The investors in the study all appear to employ an asset allocation strategy to varying degrees. An asset allocation strategy in its most sophisticated form uses a Modern Portfolio Theory approach that attempts to maximize portfolio expected return for a given amount of portfolio risk, or to minimise risk for a given level of expected return by selecting the proportions of various assets. It uses a mathematical approach to model diversification of investment, with the aim of identifying a collection of investment assets that has collectively lower risk than any individual asset, and was developed in the early 1950s (Markowitz, 1952). There has since been an acknowledgement that behavioural issues play a part in investment decisions and investment strategies now tend to reflect this (Kahneman and Tversky, 1979).

The interview outcomes bear out that, as would be expected, some form of strategic asset allocation policy is being used with some interesting issues arising. A wide range of approaches is taken. Many pension funds and institutional investors use investment consultants to assist them in placing investments and in some cases, assist in their asset allocation strategy.

Yes, we do [have a strategic asset allocation policy]. I mean the advisors play a big part in that and we have a range, a target asset allocation, for each of the constituents and that is monitored. ${ }^{2}$

It is these investment consultants that appear to employ the more sophisticated approach with the investors themselves using a more limited methodology. The following quote is from an

\footnotetext{
${ }^{1}$ Interview 1.1, Investor (GIB), $13^{\text {th }}$ April 2015.

2 Interview 3.12, Declined Investor, $18^{\text {th }}$ January 2016.
} 
investment manager confirming that they apply a sophisticated strategic asset allocation approach based on Modern Portfolio Theory (MPT).

For many of our clients, we help them with their strategic asset allocation in general. It's based on Modern Portfolio Theory approach with usually stochastic modelling and that type of thing.

It's a pretty sophisticated approach, yes. I mean, it wouldn't be consistent with most consultant approaches in the marketplace. ${ }^{3}$

However, the investment manager appears to believe that the level of sophistication that they employ is not consistently used among their peers. A further quote from a second investment manager confirms that their involvement in establishing their clients' (institutional investors) strategic asset allocation strategy is variable however when they are fully involved then their process does involve MPT. The quote also confirms the lack of data around energy efficiency investments required to fully inform their strategic asset allocation approach.

For all mandates, there will be a strategic allocation. Now, sometimes, [name of investor] gets involved in that decision. Sometimes, that is handed to us as a "Basically, go and fill it, please" mandate.

In terms of the way we make recommendations, yes, we do use tools like Modern Portfolio Theory. Data is always difficult in infrastructure, generally, let alone energy efficiency. ${ }^{4}$

The fund manager interviewees felt that although the investors had strategic asset allocation strategies they were most likely assisted by investment managers who formulated them and managed them on their behalf:

Again, it's speaking generally, but the investors that we work with tend to be very large institutional investors, and because of that, tend to have quite sophisticated asset allocation processes and policies in place.

\footnotetext{
${ }^{3}$ Interview 3.7, Investor (Investment Manager), $27^{\text {th }}$ July 2015.

${ }^{4}$ Interview 3.4, Investor (Investment Manager), 14 ${ }^{\text {th }}$ November 2014.
} 
In the UK, at least, and I think it's quite common globally but in the UK certainly, many investors rely on pension fund consultants to manage their exposures and to do the allocation processes or support the allocation processes for them. ${ }^{5}$

'I think, my sense is that there is not a [strategy] - maybe there is, I haven't seen any internal [investors] documents - but my sense is that there isn't a clearly-defined strategy. ${ }^{6}$

The research findings bear out that, as would be expected, some form of strategic asset allocation policy is being used with some interesting issues arising. One of the investors, a typical large corporate pension fund, discussed the fact that they had a strategic asset allocation approach that was risk rather than return based.

We did have a strategic asset allocation...

We didn't have so much a fixed return target. We knew what returns we would have to need as a minimum, but we were only at the very early stages of the de-risking journey in saying, "Well actually shall we just fix that as a target?" It was still maximised returns with minimum risk. It was a risk driven thing rather than a return driven thing.

We had quite a large alternatives exposure. Clearly it depends how you define the buckets, but we had probably about $30 \%$ allocation to alternatives including real estate, private equity, hedge funds, infrastructure. We didn't have anything specifically on renewable energy. ${ }^{7}$

Their assessment of investments was based on investment risk and they did not focus on achieving particular returns per investment type although they did work to a minimum. With this approach they had increased the 'Alternatives' exposure to around $30 \%$ which is significantly higher than the more usual allocation of $5 \%-9 \%$. The $30 \%$ of 'Alternatives' did include real estate, which in some cases is a classification on its own however it still represents an increase in allocated funds. The other investment classifications within alternatives were private equity, hedge funds, and infrastructure which included renewable energy. The

\footnotetext{
${ }^{5}$ Interview 2.1, Fund Manager, $24^{\text {th }}$ February 2015

${ }^{6}$ Interview 3.2, Fund Manager, $15^{\text {th }}$ October 2014.

${ }^{7}$ Interview 3.5, Investor, $22^{\text {nd }}$ April 2015.
} 
investment in energy efficiency was deemed an infrastructure investment and this was generally but not universally the case.

\subsubsection{Asset classification}

Asset classification is an important issue as it is an integral component of an investor's asset allocation strategy. Investors will need to understand fully the risk and return characteristics of an investment in energy efficiency if they are to see a value in increasing fund allocation within their asset allocation strategy.

It is apparent from the interviews that energy efficiency is firmly seen as part of the 'Alternatives' classification but it cannot be easily defined and it is unlikely to become a separate 'Alternatives' sub class. This is because it is little understood with currently low numbers of investments available. This has resulted in investors to date tending to classify such investments in other 'Alternatives' sub classes such as Infrastructure or even Private Equity.

Perhaps more typical would be a limited allocation to what might be called Alternatives; and Alternatives might get 3\%, 5\%. Alternatives that covers half a dozen sub-sectors like Real Estate, Hedge Funds, Commodities, Private Equity and Infrastructure. ${ }^{8}$

I think they would probably all regard energy efficiency to sit within an infrastructure bucket of some sort [...].

Generally, they fall within an alternative assets part of their portfolio [...].

It depends on the size of them as to really how granular they are in terms of asset allocation between sectors; so, some will just look at alternatives, some will look at infrastructure, and some will subdivide infrastructure into core infrastructure and renewables. ${ }^{9}$

\footnotetext{
${ }^{8}$ Interview 2.3 , Investor, $8^{\text {th }}$ July 2015.

9 Interview 3.1, Fund Manager, $13^{\text {th }}$ November 2014.
} 
Although energy efficiency is most often viewed as an Infrastructure investment, the issue is further complicated in terms of asset allocation by how the investment is structured. If it is 'packaged' in a certain way then investments can be viewed very differently.

[The] majority of our funds under management to date are infrastructure funds. We have three funds, excitingly named Equitix I, II and III, that all invest into core infrastructure.

Our investors within those funds have tended to make the investment via their alternatives pot. So, a lot of them will have real estate, private equity, government bonds etc., and then they will have a smaller allocation to alternatives, and infrastructure typically falls under the alternatives bracket. A lot of pension funds do have an alternatives bucket, but some are only coming up to speed and actually starting to allocate money to alternatives.

With regards to the energy efficiency funds, it is seen by investors both as an alternatives investment or as a private equity style investment, due to the structure of our fund. Our core infrastructure funds are 25 years, so we invest into solid social infrastructure, like schools and hospitals, social housing. Whereas our energy efficiency fund is a 10-year fund, we intend to sell the assets at some stage during the life of the fund, which is more akin to a private equity style structure. So, it has been viewed by investors in different ways, so some have invested via their private equity bucket, some have invested still through their infrastructure alternatives asset allocation... ${ }^{10}$

The above quote is by a fund manager and this particular fund manager has packaged its energy efficiency fund in such a way that it resembles and acts like a private equity investment. It is a 10-year fund rather than a 25-year fund more typically associated with infrastructure investment, with the fund strategy of selling assets during the life of the fund.

An investor in that fund manager's funds bears out that its investment was, in the first instance at least, regarded as a private equity investment.

The history of this is a little bit different, in that we initially invested in Equitix as a private equity firm [...]. We've only, in the last couple of years, reclassified the Equitix piece as infrastructure. ${ }^{11}$

\footnotetext{
10 Interview 3.3, Fund Manager, $24^{\text {th }}$ October 2014.

11 Interview 3.6, Investor, $17^{\text {th }}$ July 2015.
} 
If the investments are to be viewed as private equity then investors would probably require higher returns.

In terms of private equity investments, the pension funds are looking for higher returns, generally a shorter life of an investment. Infrastructure typically yielding lower returns but matching long term liabilities for pension funds.

So, it depends on the returns expected from each investment. Private equity tends to be higher than alternatives, more in the $8 \%$ to $10 \%$ bracket. ${ }^{12}$

This view of energy efficiency projects and the way that they are presented can also have a counter-productive effect in that they do not meet the return expectations of private equity while also not meeting the risk expectations of infrastructure.

[Investors] might have a separate private equity type bucket, and might perceive the risk of investing in energy efficiency as being higher than core infrastructure but the returns are not high enough to warrant it being it in a private equity bucket.

A risk-adjusted return, probably, would fit quite nicely in their portfolio, but it might sit in a gap between infrastructure and private equity, for example. ${ }^{13}$

The shorter investment period for energy efficiency also presents an issue with some investors when looking to make investments as infrastructure.

Yes, for us we only do infrastructure so it would have to be infrastructure like [...].

I think there is a strong case that some of the things that people are investing in as energy efficiency aren't infrastructure; because they are simply not long enough term. And an obvious example might be replacing light bulbs with LEDs. Is it really infrastructure and you have got a payback of five years or even at the end of cash flow it will be five years. It depends on your definition of infrastructure. ${ }^{14}$

Additionally, investors do not always understand the characteristics of the type of investment itself and confusingly see energy efficiency as a renewable energy investment which it is not.

\footnotetext{
12 Interview 3.3, Fund Manager, $24^{\text {th }}$ October 2014.

13 Interview 3.1, Fund Manager, $13^{\text {th }}$ November 2014.

${ }^{14}$ Interview 2.3, Investor, $8^{\text {th }}$ July 2015.
} 
One fund manager even experienced a situation where some investors did not know how to classify a potential energy efficiency investment, seeing it falling somewhere between infrastructure and renewable energy and as a result declining to invest as it did not match their allocation policy.

In terms of where they sit, most investors tend to see them in an infrastructure class. Some might put them in a renewable energy sub-class of that or perhaps they might have renewable energy and infrastructure onside.

I think, it is, between the two, probably more infrastructure than renewable energy if there were two classes separately, but when renewable energy falls under infrastructure, they'd probably say [...].

Sometimes, it's across the two. We've seen some investors who don't quite know what pool to put it in, but they like it and so "we'll do it", but, equally, we've seen investors who don't know which pool to put it in and so don't proceed because it doesn 't fit within their asset allocation policy. ${ }^{15}$

A definition of infrastructure itself is hard to pin down with a distinction being made between liquid investments such as tradable equities in infrastructure companies, which will just as well be classified in the equities pot or listed funds and illiquid investments, such as those in nonlisted funds similar to the funds in question.

Right, well in terms of the infrastructure, we have a $2 \%$ target. I think we're currently $1.4 \%$ of portfolio. But that $1.4 \%$ doesn't include other infrastructure asset classes that maybe a liquid or on a listed market. So, there's probably, I'd say, about another 11/2, $2 \%$ there, I don't think we've gone above, 3 to 31/2, you know.

And in terms of energy efficiency or renewables perhaps they have that kind of spin on it that I suppose, as we stand today, that's probably $20 \%$ of the infrastructure portfolio. 16

One investor viewed 'Alternatives' investments, including those it had made in energy efficiency, as part of a strategy of enhancing its returns to close a funding gap, a deficiency in the assets it needs to meet its future liabilities and allocated at least $25 \%$ of its assets to the asset class.

\footnotetext{
15 Interview 3.1, Fund Manager, 13 ${ }^{\text {th }}$ November 2014.

${ }^{16}$ Interview 3.12, Declined Investor, $18^{\text {th }}$ January 2016.
} 
Broadly, we've got three asset classes. We've got equities and, at the moment, equities are a shade over half of the portfolio and that's because, well, basic portfolio theory, isn't it? We believe that over long-term equities will generate returns and that kind of ticks that box in terms of growing the portfolio. The second bucket is fixed interest bonds and that's about a quarter of the portfolio [...].

We have the added complication of, due to historical reasons, we have a funding gap. That's to say that we only have somewhere around $70 \%$ of the assets that we need. We also have to generate an enhanced return to close that gap and we've got an allocated period of 20 years in which to close that gap. So that's what we're looking in the fund to do.

The alternatives are running at about a quarter and they are there, by and large, to give you that uptick that added return, which will drive the portfolio to close that gap. ${ }^{17}$

A positive view of the way one of the funds had contractually structured their energy efficiency investments was particularly helpful to one investment manager acting on behalf of a major pension fund.

For us, the key for it to be an appropriate asset class is the project finance wrapper around the investment. That's something you don't always see.

This particular fund is bringing that project finance discipline to areas where it traditionally hasn't been. For us, given that, and then all of the government subsidies, etc, and the contractual structures, that becomes an infrastructure investment at that point. ${ }^{18}$

This is attractive to the investment manager as it was contractually structured in the same way as infrastructure transactions they had been used to with cash flows for performing assets being made in a familiar way, though a 'Special Purpose Vehicle' structure. To them this represented a disciplined way of structuring the transaction which went a long way to helping them to decide on investing.

\footnotetext{
${ }^{17}$ Interview 3.6, Investor, $17^{\text {th }}$ July 2017.

18 Interview 3.4, Investor (Investment Manager), 14 ${ }^{\text {th }}$ November 2014.
} 


\subsubsection{Investment Return}

An important aspect of any investment is the return it generates and an investor will make investment decisions, as discussed, by assessing both risk and return. Investors may initially be sensitive to the return that will be achieved in an investment, particularly a new type of investment and one firmly in the 'Alternatives' classification that may be part of a strategy to enhance the overall portfolio return.

Yes, so [8\% return] that's the minimum return you could accept from an equity-based product in energy efficiency. You'd probably even want higher than that, but that's where they start earning their fee. That's where you incentivise them.

Yes, [12\% return] that's what you model the portfolio on. ${ }^{19}$

[The fund] Absolutely does [meet our] minimum return requirements. The fund, I believe, is expected to do something like a $12 \%$ return. Very comfortable in terms of what we would require as a minimum spread. ${ }^{20}$

Yes, it did [meet our return requirements]. And actually, in general both funds have been well above the minimum threshold that we had. And actually, we are seeing that there is always a promise to deliver a return at this time. But it is higher than what we have seen in other sectors. ${ }^{21}$

The previous investor quotes demonstrate that the absolute return achieved from their energy efficiency investments was comfortably within what they expected and were required to achieve from such an investment. However, return is only one element of the investment that will concern them and the second issue is that of risk. Energy efficiency is in the main a new and unknown sector for most investors and they would want to understand as much about the underlying investment as possible, from the technology and processes used to the expected performance of the investment and the security of the project revenues, in order to assess the risk of actually realising the stated return.

\footnotetext{
19 Interview 1.1, Investor (GIB), $13^{\text {th }}$ April 2015.

20 Interview 3.4, Investor (Investment Manager), 14 ${ }^{\text {th }}$ November 2014.

${ }^{21}$ Interview $3.9 \& 4.5$, Investor, $23^{\text {rd }}$ November 2015.
} 
The level of perceived risk will dictate how much actual return they would require in order to take that risk. Many investors have no way of assessing the level of risk with energy efficiency investments as they are a relatively new investment type, with new and unfamiliar technology and with little or no investment history to call upon. Investors will therefore rely on their advisers in the form of investment managers and the fund managers they have relied on in the past to provide the returns they require in related sectors.

So, if we felt it was a good level of return for the level of risk and it was hopefully above our overall return requirement, or if it wasn't, it was very safe, then we would invest, so it's a kind of portfolio diversification type approach that we take. We try and find the best return per year risk across all asset classes. ${ }^{22}$

So, across their entire portfolio I imagine they have expectations as to what they need to deliver to their clients, being their pensioners, and within that bucket, within that overall umbrella portfolio they will have different exposures to different asset classes depending on the risk return basis, to get that blended overall return that they need to deliver.

I imagine that as part of their asset allocation and looking to invest capital, they will have ' $x$ ' millions or billions to invest per year. They will have to find funds that meet some of the higher end targets, which possibly is why they looked at the Equitix Energy Efficiency Fund and would have made an investment based on our risk return profile, which then has to sit within their bucket. ${ }^{23}$

Yes, it has delivered the returns that we had expected. It has been managed within the context of constrained risk, and therefore, we have had a tick, both in terms of the absolute riskiness, but also the co-movement with other assets. And it has delivered cash flow on budgets, so we have been able to disperse distributions to end investors. ${ }^{24}$

The investor and fund manager quotes clearly demonstrate that investors view potential investments in terms of both risk and return. The nuances to those risks mentioned above which the investors will have no information about and no resources at hand to investigate will form part of their risk assessment and they will rely on their advisers and fund managers to educate them and to inform their risk assessment and ultimately their return requirement. In the case below the fund manager is stating that his investor will require a higher return as some of the

\footnotetext{
22 Interview 3.12 Declined Investor, $18^{\text {th }}$ January 2016.

23 Interview 3.3, Fund Manager, $24^{\text {th }}$ October 2014.

24 Interview 4.4, Investor (Investment Fund), 22 ${ }^{\text {nd }}$ January 2016.
} 
energy efficiency investments do not have a government backed income stream as per the usual infrastructure PFI and PPP investments they were used to participating in. He is therefore suggesting that a higher return will be required, but takes comfort that the energy efficiency fund is being managed by the familiar fund manager.

Yes, I get a sense that lots of our investors do have a, certainly a higher return allocation for energy efficiency projects, mainly because, as I've stated, the fact that there is more exposure to non-Government income streams. ${ }^{25}$

So, a good example is the [..] Pension Fund, which has invested in the Equitix core funds, so obviously has an exposure to 100\% Government-backed income streams through the PFI and PPP assets which we have through the core funds. But also, they are looking to invest in the EEEF, the Energy Efficiency Fund, and have made an allocation to date.

Clearly the difference with the EEEF projects is that there will be a number of projects which will have a mix of income streams, whether they'll be Government backed through the Renewable Heat Incentive or the Renewable Obligations Certificates, or then through, for example, wholesale power price or heat sales price, which will give them some exposure to hosts, whether it's the heat user, or wholesale power, whether it's through a PPA-type structure. So, it gives them more of a blend of assets within the asset class that they invest in. ${ }^{26}$

A further reason why investor return may need to be higher is that the funds on offer are illiquid and not easily tradable as in equities or able to be sold quickly. It is accepted that this issue would also apply to conventional infrastructure investments within an unlisted fund however, infrastructure investments in such funds are much more mainstream and other investors and funds would be more willing to buy assets on a secondary basis lowering the premium for illiquidity.

No, we don't [require a minimum return percentage from investments]. The caveat to that is that, obviously, for illiquid investments, we require a premium for illiquidity, and generally that's in the region of anywhere from $1 \%$ to $4 \% .27$

\footnotetext{
25 Interview 3.2, Fund Manager, $15^{\text {th }}$ October 2014.

${ }^{26}$ Interview 3.2, Fund Manager, $15^{\text {th }}$ October 2014.

27 Interview 3.7, Investor (Investment Manager), $27^{\text {th }}$ July 2015.
} 
The research has highlighted instances where the energy efficiency fund investment opportunity offered was declined due to an assessment of the perceived risks associated with the underlying investment, even though the level of return predicted more than achieved the levels that were required by the potential investors.

Yes, so I wouldn't say for the investors that haven't invested in our fund that the return was the primary driver for them not doing so. ${ }^{28}$

[The] target returns were $12 \%$ net so at face value it probably would [meet return requirements], but then when you look at the risk I noticed there are some small investments. And, as I said before, an element of anaerobic digestion and biomass type class assets. [...] I probably didn't like the sound of it.

[...] it's the likelihood of them meeting that return and then the level of risk that they're taking to get there. ${ }^{29}$

The declined investor clearly didn't like the profile of some of the target investments in terms of size and technology, even though the returns potentially on offer met their requirements and in comparison to other infrastructure investments are at the high end. One of the fund managers has even stated that when investing in the sector, investors don't understand it and rely on them to advise them on the risk profile.

[...] that comes back to Equitix's role in this, I think. They probably don't understand the real detail of what an energy efficiency project looks like and what the risk profile looks like, but they rely on a fund manager's judgement to say, "On balance, it's like this, but with a bit more risk here."

If you try to take institutional investors from a bottom-up analysis of all the risks in a project, you [would need an inordinate amount of time to do so]. ${ }^{30}$

A further issue that has arisen through the research that has a bearing on investors view of risk is that of speed of deployment. This concerns the amount of time taken to source, structure and place the investment by the fund managers. Interestingly, there is divergence of opinion on this

\footnotetext{
28 Interview 3.1, Fund Manager, $13^{\text {th }}$ November 2014.

${ }^{29}$ Interview 3.12 Declined Investor, $18^{\text {th }}$ January 2016.

${ }^{30}$ Interview 3.1, Fund Manager, $13^{\text {th }}$ November 2014.
} 
issue. A fund manager states that he believes speed of deployment is a reason some investors may not invest in an energy efficiency fund. In contrast an investor discusses that they were very happy with the speed of deployment in comparison with other infrastructure investments, albeit with an investment in a different energy efficiency fund.

I think, if anything, it's [the reason for not investing] perhaps a slight nervousness about it in asset class, questions about speed of deployment of capital in the context, something we might come on to, and the size of projects, and how many projects you have to do to get capital deployed at scale. ${ }^{31}$

The commitment we have to SDCL in the context of the overall portfolio is very small. So, we would like the disbursement to be more rapid, as always, but I would suggest that in the context of our overall experience of infrastructure, deployment of cash has been fine.

Perhaps, just by way of background, I should explain that we began investing in infrastructure in 2007. We have experienced relatively slow deployment of cash overall, and relatively poor returns from a number of projects. In that context, we think SDCL has done very well. ${ }^{32}$

\subsubsection{Inflation linked income matching liabilities}

Investors are looking for inflation linked returns, in order to match their inflation linked obligations, that are not correlated to their core investments of inflation linked equity and bond investments.

[With] the nature of the investments, because our investors typically have long-term liabilities that are inflation-indexed that they're trying to match [...].

They have substantial exposures in their portfolios to long-term inflation-indexed investments, whether they're debt, equity or something else, so the general needs of the liabilities are driving investment decisions, which make infrastructure generally quite attractive.

\footnotetext{
31 Interview 3.1, Fund Manager, $13^{\text {th }}$ November 2014.

32 Interview 4.4, Investor (Investment Fund), $22^{\text {nd }}$ January 2016.
} 
Energy efficiency would be a small sub-sector of the much larger infrastructure space $[\ldots] .{ }^{33}$

...I think, generally, you will see investors who invest in these sorts of asset classes being attracted by things such as inflation linkage.

Infrastructure is, to a certain extent, less correlated to equity markets, bond markets or whatever they may be, and enhanced returns.

[Their] approach to investing in infrastructure and renewable energy will tend to be looking for index-linked returns for projects that offer an enhanced return compared to other index-linked classes, risk-diversification away from index-linked gilts, or indexlinked corporate bonds. ${ }^{34}$

I'd say for the clients where we make energy efficiency investments, they tend to have an inflation-linked objective, so it would be something like a $4 \%$ to $5 \%$ outperformance of inflation, which translates to a, roughly, 7\% to 8\% nominal return as a minimum. ${ }^{35}$

Yes. It [required return] was not set in stone but what we were driven by, is knowing that our liabilities went up every year by the lower of RPI or $41 \frac{12 \%}{2}$. It's just the rules of the scheme. So as part of thinking about a de-risking flight plan and fully funding strategy or whatever, we knew that, that would be the minimum we'd need to cover the ongoing increasing liabilities, the lower of RPI or $41 / 2 \%$. So effectively that was our minimum band. It applied to everything. Nothing had any special treatment. ${ }^{36}$

From the research the matching of index-linked liabilities to index-linked returns is seen as an essential requirement across the spectrum of interviewees from fund managers, investors and their investment managers and is perhaps unsurprising given the nature of the investors' obligations and, of course, it is to be expected as it mirrors the investors stated investment strategies.

\footnotetext{
33 Interview 2.1, Investor, $24^{\text {th }}$ February 2015.

${ }^{34}$ Interview 3.1, Fund Manager, $13^{\text {th }}$ November 2014.

35 Interview 3.4, Investor (Investment Manager), 14 ${ }^{\text {th }}$ November 2014.

${ }^{36}$ Interview 3.5, Investor, $22^{\text {nd }}$ April 2015.
} 


\subsection{Low Carbon Investments}

There is a continual move by investors towards taking ESG issues into account when making investments with wide ranging SRI strategies being developed (Freshfields Bruckhaus Deringer, 2005, Jansson et al., 2014, BNP Paribas, 2016, BNP Paribas, 2017). Low carbon investments, of which investments in energy efficiency are an example, would sit very well within that approach. An objective of the study is to understand whether investors positively discriminate in favour of these types of investments at the expense of alternative investment opportunities, perhaps even compromising on the level of return that is achieved.

\subsubsection{Low carbon strategies}

There is a general understanding by the fund managers that investors are focusing on low carbon strategies and that they are increasingly looking for low carbon investments in order to fulfil these strategies.

I think, investors generally, and certainly in Europe, are looking increasingly to understand and manage their investments in terms of a more holistic, green, double-bottom-line approach, let's say. ${ }^{37}$

Yes, I think increasingly they are. I think also the fact that the - I think there's two things happening. One is that the PFI / PPP [Infrastructure investments] market's becoming slightly more saturated, so there's less projects for them to invest in within that space.

And secondly, within the energy efficiency space, if they're looking for potentially higher returns as well as having a good green story and energy efficiency story, that this is an asset class which offers them more attractive returns as well as hitting, you know, carbonsaving and renewable targets. ${ }^{38}$

\footnotetext{
${ }^{37}$ Interview 2.1, Fund Manager, $24^{\text {th }}$ February 2015.

38 Interview 3.2, Fund Manager, $15^{\text {th }}$ October 2015.
} 
The fund managers themselves are also moving towards implementing low carbon investment strategies and on the part of Aviva, one of the world's largest investors and fund managers, it is part of a wider ESG initiative.

So, Aviva, right through Aviva, there is a low carbon agenda anyway, not just from an investment perspective, but just in terms of, as a good corporate citizen, so the low carbon agenda is quite important at the Aviva level. Within the investment space, we actually have been working with our ESG team [...] to look at the low carbon environment specifically [...]. ${ }^{39}$

There is also an indication that some of the smaller more niche find managers are also taking this on board and implementing low carbon investment strategies.

Yes, so we take it very seriously, and we have a number of clients for whom it's a very serious matter.

We represent a lot of public sector entities, including the [XYZ] Pension Fund, who, naturally, have a pretty big focus on this area. ${ }^{40}$

Although the view of the fund manager participants that the investors will have low carbon strategies is generally true, it was not exclusively the case. The following two quotes are from large institutional investors, which demonstrates that this is indeed the case and they are taking it very seriously.

[We are] very advanced, is probably the word I am sort of hesitating on but it doesn't quite capture it. But we are at the forefront of investment thinking from a sustainable perspective. And we have got a separate team entirely focussed on this. ${ }^{41}$

So organisationally we have a kind of three-year planning window and we have targets within that planning window for different sectors and technologies. Mostly sectors in fact but technologies are its role beyond this point and the key metric is what we call climate action. So, $25 \%$ of our lending volumes should be climate action and then clearly energy

\footnotetext{
39 Interview 2.2, Fund Manager, $17^{\text {th }}$ March 2015.

${ }^{40}$ Interview 3.4, Investor (Investment Manager), 14 ${ }^{\text {th }}$ November 2014.

${ }^{41}$ Interview 2.3, Investor, $8^{\text {th }}$ July 2015.
} 
efficiency falls within that climate action. So, anything that can contribute to the $25 \%$ target is a high priority for the Bank. ${ }^{42}$

The quote below is from a very small investor who has also embraced the carbon reduction initiative and has implemented a quite sophisticated approach to assessing low carbon investments to the extent that it will not invest if an investment does not meet their strict criteria.

We take a sustainable approach for a start. I could take you through what we have here, this is Earth Capital. We've won awards for what we call the Earth Dividend and it's a calculation of whether or not you're positively contributing to $\mathrm{CO}_{2}$ reduction through a business. You rate it and you calculate it. The idea is that when we invest, we can look at the business forecast and say, "Well, what's it going to do, will we make a positive contribution to $\mathrm{CO}_{2}$ reduction?" and if we do then it meets that criteria and then we'll do it for financial reasons. The answer is yes. ${ }^{43}$

In contrast the following quote is from a pension fund investor representing the pensioners of a major media organisation, which clearly has no low carbon or sustainability strategy when considering its investments. In the research this was the exception, however the fact that the pension fund of such a company makes no allowance for low carbon in their investment decisions suggests that a significant, albeit minority, proportion of other company pension funds are likely to take the same approach.

There wasn't really one. No specific targeting. There are sustainability initiatives within the wider business, but in terms of a definitive impact or strategy exposure within the pension scheme, no. ${ }^{44}$

\subsubsection{Pressure to show investing responsibly}

Despite the fact that some pension funds are not implementing a responsible investment strategy including lowering carbon emissions, there is clearly an imperative for pension funds to do so. The following quote is from a fund manager that is seeing this trend in its investors.

\footnotetext{
42 Interview 3.11 \& 4.7, Investor, 23 ${ }^{\text {rd }}$ November 2015.

${ }^{43}$ Interview 4.3, Investor (Investment Fund), $29^{\text {th }}$ June 2015.

${ }^{44}$ Interview 3.5, Investor, $22^{\text {nd }}$ April 2015.
} 
There is increasing pressure on pension funds now to certainly show that they are investing responsibly and there are different organisations that they can sign up to, to declare the ways in which they are investing their capital and how it is being (a) delivering returns to their pensions. But also investing in a responsible way that will see the growth of the U.K. sustainably, economically, environmentally and all under a robust governance structure. ${ }^{45}$

Although this may be more evident in public sector pension funds, as the government will have more influence over them than over private sector pension funds and investors, there are other influences that may encourage the private sector to follow suit. The quote below is an observation by an investor representing the GIB.

So, there's greater press coverage of people investing into carbon intensive industries, then there's a risk in the future that they will be at a discount because they're going to be more penalised by other investors, because there's going to be less traction for them. ${ }^{46}$

What he is suggesting is that as time goes on, carbon intensive investments will become less attractive and the value of the investments made today may not be realised in the future when the time comes to sell them. Therefore, there is pressure now to make sustainable or carbon reduction investments as a commercial decision, in order to maximise returns when the investment or investments are sold on. This may be the imperative for investors to start to implement a responsible investment strategy, even if they are not doing it necessarily because they believe in a green agenda.

Investors' desire for responsible investing is often reflected in their choice of fund manager. The following quote from an investor demonstrates that even though the primary reason for its selection is that of performance and investment philosophy, responsible investment practices would then have an influence.

When choosing fund managers, it wouldn't be a prime concern that one is greener than another. You'd have to look at aspects like past performance, structures, fit with your investment philosophy. But once you get that list of people that meet those criteria, then those aspects take on more importance. ${ }^{47}$

\footnotetext{
45 Interview 3.3, Fund Manager, $23^{\text {rd }}$ October 2014.

${ }^{46}$ Interview 1.2, Investor (GIB), $15^{\text {th }}$ May 2015.

${ }^{47}$ Interview 3.6, Investor, $17^{\text {th }}$ July 2015.
} 
The following is a quote from a fund manager demonstrating investors' desire to use fund managers that are fully committed to ESG issues and low carbon investing.

More and more often we are seeing as a manager, we are seeing more and more pension funds who want to understand our commitments to ESG and how we demonstrate, not just investing for the environment but investing for economic, social, adding to the ESG as a whole, in benefiting the country as a whole.

There is an increased pressure from pension funds to demonstrate this. ${ }^{48}$

The following quote is from an investor into the energy efficiency fund that is itself operating as a fund manager, managing funds for institutional investors. They make responsible investing an integral part of their investment process, which again appears to flow from the mandates that they have from investors to take environment factors very directly into account. This again demonstrates the commercial pressures to move to a responsible investment agenda.

Well, we have some investors who have mandated us to take environment factors very directly into consideration. But as a house overall, we are signatories to the UN PRI, and therefore, we do have a responsibility agenda. The responsibility agenda, from our point of view, requires us to consider, for all investors, unpriced risk that may impact, over time, on the financial returns they achieve. ${ }^{49}$

\subsubsection{Low carbon strategy taken into account in investment decision}

As responsible investment strategies are becoming more prevalent among investors, the research investigated whether these strategic considerations are taken into account when investors considered investing in the energy efficiency funds. The research participants were asked whether investors would perhaps compromise on investment return in order to achieve their strategic responsible investment objectives. Pension funds and other institutional investors do of course have a fiduciary duty to maximise the return of investments for the

\footnotetext{
48 Interview 3.3, Fund Manager, $23^{\text {rd }}$ October 2014.

49 Interview 4.4, Investor (Investment Fund), 22 ${ }^{\text {nd }}$ January 2016.
} 
benefit of pension holders and other beneficiaries. However, there is a growing view among the investment and academic community that ESG issues can be considered in the investment decision and can be considered equally alongside return maximisation as a benefit to the beneficiaries of the fund as it provides them with a positive investment impact which they may value at the expense of monetary value maximisation.

There does not appear to be any evidence from the research that indicates that ESG issues in the form of a responsible investment or low carbon investment strategy have any bearing on the decision-making process apart from on a secondary basis. Value maximisation appears to remain as the primary objective related to fiduciary duty. There is a consensus among the majority of investors that monetary value maximisation is the primary consideration. The following investor quotes demonstrate this.

No, definitely not. It has to be green and profitable, it can't be green or profitable. 50

Probably we do [have a low carbon investment strategy] and, in all honesty, I know we're in favour of it, but at the end of the day we would always look for the return, you know. The return versus risk is paramount and these kinds of things are secondary.

Nice to have [a low carbon investment strategy] but our immediate fiduciary duty is to those with our pensions. No, no, we wouldn't [accept a low return for an energy efficiency investment], no. ${ }^{51}$

[If] we went to a client and said, "This is a great idea. It doesn't fit on a risk-return basis, but you're doing some good for the environment," we would get laughed out of the room. I mean, they have a fiduciary duty.

It needs to work on a risk-return basis, and the green, feel-good basis [...] ${ }^{52}$

But each sector and each risk profile would justify a different return, well back to your words different minimum return. You obviously go out of your way to get as big a return as possible. But just, the last bit of the sentence is just because it met your low carbon investment criteria, no. ${ }^{53}$

\footnotetext{
50 Interview 1.1, Investor (GIB), $13^{\text {th }}$ April 2015.

51 Interview 3.12, Declined Investor, $18^{\text {th }}$ January 2016.

52 Interview 3.7, Investor (Investment Manager), $27^{\text {th }}$ July 2015.

53 Interview 2.3, Investor, $8^{\text {th }}$ July 2015.
} 
No, we didn't have one [a low carbon investment strategy] but even if we did, no [we would not accept a lower return]. ${ }^{54}$

People will do a green investment if it gives the same return, but they won't take a $200 \mathrm{bp}$ haircut or anything.

For us, I think the answer is "no" and I think for the wider market, the answer is "no" as well. ${ }^{55}$

We categorically, from a sustainable point of view, start from the premise it's got to make money and if it makes money, then fine we'll do everything we can to make the sustainability work better. ${ }^{56}$

One of the fund managers did at least suggest that, should investors be faced with two infrastructure investments providing similar return for a similar level of risk, some may be inclined to invest in the one that can demonstrate the added benefit of carbon savings. His opinion was not that the majority would go for the carbon saving investment and he did also emphasis that the added carbon saving benefit would not be at the expense of return.

I would say the answer to that is "No" but I think to put the question in a slightly different way, if they were weighing up two infrastructure investments where all the other parameters were the same, then, I suspect maybe not all but some may be inclined to go for something that they can demonstrate also has the added benefit of carbon savings.

I think that added benefit probably does help in the allocation of capital to the sector, but not at the expense of return [...]. ${ }^{57}$

There were however some positive comments but generally they do not provide any evidence that ESG considerations are being taken into account alongside financial return or indeed being considered as the primary criteria. The following quote from a fund manager suggests that a

\footnotetext{
54 Interview 3.5, Investor, $22^{\text {nd }}$ April 2015.

55 Interview 4.2, Investor (Investment Fund), $9^{\text {th }}$ June 2015.

${ }^{56}$ Interview 4.3, Investor (Investment Fund), 29 ${ }^{\text {th }}$ June 2015.

57 Interview 3.1, Fund Manager, $13^{\text {th }}$ November 2014.
} 
lower return may be acceptable in the circumstances where a blended portfolio is the objective and the investment would be used to achieve that objective, even if the investment has a low return.

I imagine there's probably, as you say, competing demands between the risk profile of an energy efficiency type project, which I think at the moment is relatively high, but will come down as people get more comfortable with the asset class. And I think there is, again, a strong push to make sure there's a blended portfolio, and hence in some cases there may be some acceptance of a lower hurdle [return rate]. ${ }^{58}$

The following quote from an investor who is an investment manager representing institutional investors is quite positive but does not quite endorse the situation where an investment with a low carbon objective is prioritised over financial return. He can envisage a situation where this could happen but also states that investments have to stand up, meaning financially.

I think we possibly would [accept a lower return]. I think, for us, investments have to stand up [financially].

We don't have a mandate today where sustainability overrides performance, but that could conceivably happen and I think on the margin, we could do that. Generally, not, but I can see situations where we would be fairly relaxed. ${ }^{59}$

The following investor quote is encouraging in that it does state that other factors can be taken into consideration and that financial maximisation is not the only consideration but then states as long as they do not prejudice the effectiveness of the investments, meaning presumably financial value maximisation.

The fiduciary duty to maximise isn't the be all and end all. You are allowed to take these other factors into consideration, but only where they don't prejudice the effectiveness of the investments. 60

\footnotetext{
58 Interview 3.2, Fund Manager, $15^{\text {th }}$ October 2014.

59 Interview 3.4, Investor (Investment Manager), 14 ${ }^{\text {th }}$ November 2014.

${ }^{60}$ Interview 3.6, Investor, $17^{\text {th }}$ July 2015.
} 
Finally, an investor did say that he would accept a lower return when deciding between investments. This is a result of the effect previously mentioned where investors are concerned about the profitability of investments that offer higher returns now but there is uncertainty about whether those returns can be realised in the future. However, this is in a situation where low carbon investment is part of their investment mandate. This is the most positive of the responses but it does not represent a trend towards low carbon considerations taking precedence over monetary return in investment decision making.

Simply, yes, in so far as we worry that there are higher returns immediately available in exchange for significant risk participation. We worry that the downside risks associated with climate are sufficient that they cannot be addressed through a normal probabilitiesbased distribution that would otherwise create transparency on forward returns. In these much more dramatic risks, we are happy to accept a lower return, if it gives us high confidence that we will be able to deliver to end investors, where that is part of the mandate. 61

\subsection{Decision to invest / not invest}

This section of the research seeks to identify the factors and influences that lead investors to make the decision to invest in energy efficiency opportunities and in the GIB Funds in particular. Of course, some investors may have decided not to invest after having been presented with the investment opportunity and making their assessment of the risk and rewards, and these insights are just as valuable.

There are many factors that influence the decision by investors to invest in a particular asset or investment type. By far the most commonly quoted issue that influenced investors was the experience and familiarity of the fund manager itself. This issue is in fact an individual category of inquiry being pursued in the research and will be expanded in a further section however it is worth stating that this appears to be a major influencing factor in the decision to invest.

${ }^{61}$ Interview 4.4, Investor (Investment Fund), 22 ${ }^{\text {nd }}$ January 2016. 


\subsubsection{Influence of the Green Investment Bank}

The influence of the GIB on an investor's decision to invest in the energy efficiency funds is key issue as it is unknown whether the GIB will in fact repeat their investment to increase activity in the sector or whether the exercise of investing and creating the three funds was purely an attempt to 'kick start' the market and their intention is not to invest further. This is particularly uncertain since the announcement by the UK government of its intention to sell the GIB and its eventual sale in 2017 (Pickard, 2015, Plimmer and Pickard, 2017). If it could be established whether the GIB or UK government's presence is essential for further funds to be successful, at least in the short term, or whether investors will find other newly created funds that do not have the GIB on board attractive enough to commit funds to, this will provide a valuable insight to future success of energy efficiency funds.

It is useful understand the views of the GIB themselves regarding their involvement in the energy efficiency sector. A stated aim was to encourage investment but it would appear that by no means were they convinced that this objective could be fully achieved. The following interview quotes are from an interviewee who was involved in the energy efficiency offering from the early days of the GIB and was instrumental in shaping its energy efficiency strategy.

So, my guess is, well the GIB involvement could be a plus or a minus and this was one of the big issues we had in setting up the GIB. If the GIB is perceived as a pot of dumb publicsector money that is investing without due consideration of returns, then actually for a private investor, investing alongside the GIB would be a negative.

The worry would be that the investments would not be made on a commercial basis and they would be made for policy reasons and not commercial reasons and therefore why would you put good private money, wanting a reasonable private return alongside public money? 62

A clear concern was that the GIB would not be seen as commercial enough with due cognisance of the risks and rewards of a commercial investment which would subsequently dis-incentivise private investment.

${ }^{62}$ Interview 1.3, Investor (GIB), 9 ${ }^{\text {th }}$ June 2015. 
One of the key concerns we had in setting up the GIB was to make sure that the GIB evolved as a respected investor in the market and that is something that you earn over time and I guess the case is still not proven.

The way the GIB has got to attract capital into these markets is by being seen to be a real expert, investing commercially, perhaps investing more than a commercial bank would or investor would do in the due diligence and the expertise around the technology on the contractual side of things. So, you are then encouraging people to come in and invest alongside. ${ }^{63}$

There was a real recognition that the GIB had to demonstrate that they were not only a UK public sector sovereign entity but they needed to be a well-respected and knowledgeable investor able to exercise sound investment discipline. It is interesting to note that at the time of the interview the interviewee was not convinced that the GIB had achieved this. The way that they chose to demonstrate technical knowledge to the market was to invest via the three funds in question.

The positives of the GIB is not a given. For these funds what the GIB did was encourage dedicated energy efficiency investment teams into the market that didn't exist beforehand by giving them a bit of a platform or giving the opportunity to create a platform which would have higher profile.

You had Equitix they were infrastructure to come out of PFI. So, without the GIB fund they would not have created an energy efficiency labelled fund and therefore there wouldn't be anything to invest alongside.

SDLC again, Jonathan [Maxwell, CEO] had been struggling for a number of years to get it going and this was a catalyst to potentially to get it going.

Presumably it made it more attractive for the pension funds that Equitix had been able to get into its fund. It happened with GIB though, it is probably an attraction [...]. ${ }^{64}$

However, this early uncertainty on behalf of the GIB was not universally shared by the GIB interviewees with the following being a quote from a senior executive at the GIB once the bank had been fully set and operating. When asked whether the GIB's presence influenced the private investors decision to invest his response was:

\footnotetext{
63 Interview 1.3, Investor (GIB), $9^{\text {th }}$ June 2015.

${ }^{64}$ Interview 1.3, Investor (GIB), $9^{\text {th }}$ June 2015.
} 
I think it's the fact the GIB's involved. ${ }^{65}$

Once its strategy was in place then the GIB felt that its involvement did encourage further investment by institutional investors. This has been echoed by all the fund managers responses to this issue in the study. The first two quotes strongly endorse the GIB's involvement and see it as a strong brand that can be used to sell the investment proposition including on the second case to sell it as if the investment is actually in the GIB.

I guess, from my perspective, it can't be a bad thing. They've got a great brand. Pretty much anyone in the UK will know who they are and what they're doing, and it's, from my perspective, an immediate stamp of approval: that, if the GIB is doing it, it should be at least worth a look.

We think it's a very good relationship from that perspective, yes. ${ }^{66}$

I would say it was important to most investors.

Obviously, that's the way we told them the story, so it's difficult to know whether they would still have invested if GIB weren't there. The whole investment proposition is to invest in GIB. The commitment from the government and the expertise and the endorsement of the asset class, if you like, that a Green Investment Bank investment brings has been important to them. ${ }^{67}$

The fund managers definitely saw the GIB involvement as a positive factor influencing institutional investment in the funds.

[The] GIB has also been a key driver for a number of investors, seeing the GIB pretty much 50/50 in all the investments which we make, and having them sat on the other side, and giving the endorsement to Equitix as a fund manager, that's another strong driver, which facilitates a lot of investment.

Yes, I think in pretty much all cases, it was, or it is a positive factor. I think, given the quantum they've invested, that's a big, strong driver. And also, the fact that people would look at ticket sizes and measure against the amount the GIB have committed.

\footnotetext{
${ }^{65}$ Interview 1.1, Investor (GIB), $13^{\text {th }}$ April 2015.

66 Interview 2.1, Fund Manager, $24^{\text {th }}$ February 2015.

67 Interview 3.1, Fund Manager, 13 ${ }^{\text {th }}$ November 2014.
} 
And that's, in a number of cases, increased the amount that they've been prepared to commit to the sister fund. ${ }^{68}$

Yes, no, absolutely, and I think it does certainly carry some weight, to say that our fund has got the Green Investment Bank as the cornerstone investor in the fund. It certainly carries quite a bit of weight clearly, with the investors. So, no, absolutely, I think that it does have an influence on the decision, yes. ${ }^{69}$

I think it helps. It was created and is managed by the UK government so I think it helps in terms of being an anchor, in terms of the capacity and the ability to continue raising further funds. Then it's just a question of how you can deploy that, how successful you are in deploying and mitigating the risk. ${ }^{70}$

In some cases the fund managers introduced their potential investors to the GIB which then further convinced the investors to decide to invest in the funds.

So, our investors have spoken to GIB, just in terms of GIBs outlook and their foresight into what the market has to offer. So, I think that the GIB have been very useful and are very supportive obviously in our fundraising process. Because the more capital that we get from the private sector side, the more we can invest of the Green Investment Bank capital, so it goes hand in hand. ${ }^{71}$

In the main the investors interviewed also affirmed the view that the GIB presence was a positive influence on their decision to invest. One investor actively worked with the GIB, comparing and sharing their due diligence outcomes and a second stated that they respected the quality of their research. Therefore, not only were the GIB a positive factor because they were seen as a UK sovereign entity, they also provided valuable expertise in the evaluation of the market, which enabled some investors to get comfortable and commit to an investment.

If we had GIB not there, we wouldn't have invested solo in this fund [...]. ${ }^{72}$

\footnotetext{
68 Interview 3.2, Fund Manager, $15^{\text {th }}$ October 2014.

69 Interview 2.2, Fund Manager, $17^{\text {th }}$ March 2015.

70 Interview 4.1, Fund Manager, $27^{\text {th }}$ February 2015.

${ }^{71}$ Interview 3.3, Fund Manager, $23^{\text {rd }}$ October 2014.

72 Interview 4.2, Investor (Investment Fund), $9^{\text {th }}$ June 2015.
} 
It was very helpful, obviously. It obviously provided the Management team with a bedrock of capital to start to show proof of concept in the early stage.

We were a pretty early-stage investor. I think we were the second investor in the institutional parallel vehicle. I think, for us, on the due diligence side, it helped to know that they had been through a process, and we actually directly compared due diligence notes and findings with the Green Investment Bank to help with our process, so having that second opinion, which is, for us, quite unique in that, typically, other investors alongside us are, in effect, competitors. Here, you had someone who was just pretty aligned with you without any competitive issues.

It was helpful but I wouldn't say it was absolutely fundamental to the decision. ${ }^{73}$

With both Funds we are together with the Green Investment Bank, I think they were there at the same time. I think it was important in terms of, I mean EIB is a new pan-European institution the forum where we know individual markets. I mean we take comfort of people which are more into the markets to be involved in the projects that we finance. And clearly in this case I mean having the involvement of the Green Investment Bank, knowing them and having in mind what the requirements in terms of due diligence and objectives were, I think we felt comfortable having them in the Fund.

We run through the due diligence process of someone who we consider a reputable player. It is positive, yes. ${ }^{74}$

Yes, absolutely. No, I mean, the GIB cornerstone was absolutely critical to getting this thing off the ground. ${ }^{75}$

Absolutely, 100\%. Let's be clear about it, they backed a very young team in SDCL. Lots and lots of knowledge but no real provability of what they were able to do and so there is a double benefit here for Green Investment Bank. Lots of diversity and all that stuff, but if they want to go into energy efficiency who would they go to on that basis, because there was a very, very limited number of investment management teams? An awful lot of them have started to add energy efficiency into their mandates with limited expertise, energy efficiency is what we do. I don't think any of them really know what they're doing in quite the same way. ${ }^{76}$

\footnotetext{
73 Interview 3.4, Investor (Investment Manager), 14 ${ }^{\text {th }}$ November 2014.

${ }^{74}$ Interview 3.9 \& 4.5, Investor, $23^{\text {rd }}$ November 2015.

75 Interview 4.2, investor (Investment Fund), $9^{\text {th }}$ June 2015.

${ }^{76}$ Interview 4.3, Investor (Investment Fund), 29 ${ }^{\text {th }}$ June 2015.
} 
A significant factor, because we respect the quality of their research. They are a far larger entity than ourselves. Realistically, we like to work with third parties who undertake rigorous and detailed due diligence, and with whom we can pool our insights and our information.

The Green Investment Bank is a classic entity, where there is a confluence of interest between ourselves and themselves, so they are not trying to structure the agreement where they get more than we. Yet, at the same time, there is an absolute requirement from all of our point of view to approach this robustly and with rigour, to maximise the probability that the outcomes are as we all expect. ${ }^{77}$

Although the investor comments regarding the GIB presence being a positive influence on their decision to invest were mostly positive, there were some dissenting voices and when asked directly about whether the GIB had an influence the following two responses were also received along with the many positive comments. The first very short response is clear and unequivocal, the particular investor was not influenced at all by the GIB involvement and his assessment was based solely on the fundamentals of the fund in terms of risk return and strategy. The second investor dismissed the GIB as an influencing factor as they valued the fund manager as a positive due to having invested in its two previous funds.

Not. ${ }^{78}$

Well, actually, to be frank, it wasn't because by then we'd already made investments into funds one and two. I don't think they got involved until about fund three. ${ }^{79}$

The intention of the GIB was always to stimulate the market and encourage institutional investors into the sector be they public sector pension fund or from the private sector. Whether they intended to make further investments in similar funds once the initial three were fully committed was unclear, although some of the fund managers felt that this had been the intention. Now that the GIB had been sold, the situation regarding energy efficiency is even more unclear. However, one avenue of enquiry has sought to establish whether the institutional

\footnotetext{
77 Interview 4.4, Investor (Investment Fund), $22^{\text {nd }}$ January 2016.

${ }^{78}$ Interview 3.5, Investor, $22^{\text {nd }} A$ April 2015.

${ }^{79}$ Interview 3.6, Investor, $17^{\text {th }}$ July 2015.
} 
investors in the funds would invest in further energy efficiency funds that did not have the GIB involved, assuming of course that all other aspects of the fund investments had met their investment criteria. If this was positive then this could indicate that other similar energy efficiency funds could also be successful in the market attracting institutional investors, perhaps with the current institutional investors as cornerstone investors that would attract others that were new to the sector, again of course subject to the existing funds being seen as a success.

In terms of the study, the responses from the GIB themselves as to whether they felt institutional investors would invest in further funds that did not have the GIB involved was a little mixed.

It depends on the institution, I would have thought they would prefer to have us in anyway. 80

I think they probably would. I am probably jumping ahead but the big challenge is the volume of investment opportunity and the track record, so you don't have to have the GIB there. ${ }^{81}$

The interviewee providing the first comment didn't think so, but the second was a little more positive about the how investors consider investments generally and as long as the volume of investment opportunity was present and the fund managers had a track record, then the GIB did not need to be involved.

The fund managers were again mixed in their views. The first comment below suggests that investors would query why the GIB was not investing further, which would subsequently raise questions about the energy efficiency proposition. The second fund manager comment warns that although their fund has been successful, if the GIB then did not invest further perhaps due to government changing its focus or policy, then it could create investor uncertainty which the GIB needs to manage.

\footnotetext{
80 Interview 1.2, Investor (GIB), 15 $5^{\text {th }}$ May 2015.

81 Interview 1.3, Investor (GIB), $9^{\text {th }}$ June 2015.
} 
Whether those investors would invest in future funds if the GIB wasn't invested, I think as an LP [Limited Partner] investor coming in I would be querying why the GIB would not be reinvesting or investing further if they were truly committed. In other words, is there something wrong with the proposition or the team or the current investments? It would be a factor. ${ }^{82}$

GIB and Equitix have done a very good job with the first fund in saying, "We have deployed GIB's capital and private sector capital. We have generated a good return and proven and stable cash flows. It's been a success. It's demonstrated to the market that this is a valid asset class and it's been a success."

Then, I do think that us raising a follow-on fund or others raising funds is a good possibility and I think people will invest in them. I think if the GIB were to not invest in the next fund because of other reasons, because investment in the sector hasn't been a success, and then, I guess, it doesn't really matter, or perhaps even because of a change in political [climate]...If the GIB were to [not invest further], because of a change of government or a change of government policy or whatever it may be, change their focus that caused uncertainty in the investor community about the commitment of the government to the sector, then, I think that would potentially be different, but I think that's part of the way the GIB need to manage themselves going forward, and they're well aware of that. ${ }^{83}$

There were also views from fund managers that investors would indeed invest in further funds without the GIB based on the track record of the existing funds and the opportunities presented by a further fund.

I would like to think so. I think that due to, you know, the strength of the investments made, I would like to think, and the returns coming back to investors, I would like to think that yes. A number of the projects, particularly the small-scale biomass for example, start yielding very quickly, which I think is hopefully very attractive to a number of investors.

And I also think that because there's the Equitix relationship, and it's been proven through the core funds, that when further rounds of fundraising have taken place, people have committed additional funds, whether it's fund 2 or fund 3, based on the track record of the fund manager. So, whether or not GIB is involved, I would like to think that there would be strong appetite if we were to raise an independent fund that could invest $100 \%$ in projects. ${ }^{84}$

\footnotetext{
82 Interview 4.1, Fund Manager, 27 $7^{\text {th }}$ February 2015.

83 Interview 3.1, Fund Manager, $13^{\text {th }}$ November 2014.

84 Interview 3.2, Fund Manager, $15^{\text {th }}$ October 2014.
} 
I think that if Equitix was indeed to deliver what we have said we will deliver to our investors, then there might be the potential in the future to raise further capital without GIB. ${ }^{85}$

When discussing the issue directly with investors, they all responded positively that they would consider investing in other funds that did not have the GIB also invested and some stated that they have already done so or are actively looking for such investments. Certain investors stated that they would reinvest in other funds as a direct result of the experience they had with the GIB funds and based on the knowledge and information that they had gleaned from the experience. However, they still didn't feel that it was essential for them to be involved but merely helped them into the sector.

Yes, and we have looked. I think we're going to do one where it's not the central strategy but they will do similar energy efficiency type projects as part of their portfolio.

[as a result of the experience you've had with the Equitix fund?] Well, I think so because, clearly for us, it's a pretty niche area of infrastructure. We definitely garnered a lot of knowledge which we didn't have before from doing it. ${ }^{86}$

Yes. Based on the experience we've had with Equitix, as well as the experience we've had with GIB, to be honest. They're quality investors, but they're not any better or any worse than other [...]. ${ }^{87}$

Will we. Yes, no definitely I mean we are actively looking to invest in energy efficiency funds all across Europe. I think, let's put it this way I mean the initiative launches because both Equitix and SDCL follow a call for investments made by GIB and the forum. So now this has opened up the market for us as well.

But we are looking after other investments all across Europe. ${ }^{88}$

\footnotetext{
${ }^{85}$ Interview 3.3, Fund Manager, $23^{\text {rd }}$ October 2014.

86 Interview 3.4, Investor (Investment Manager), 14 ${ }^{\text {th }}$ November 2014.

${ }^{87}$ Interview 3.7, Investor (Investment Manager), $27^{\text {th }}$ July 2015.

88 Interview $3.9 \& 4.5$, Investor, $23^{\text {rd }}$ November 2015.
} 
There were clearly other investors where the GIB presence was not an issue and as long as the fund and investment fundamentals such as financial return, level of risk, quality of management etc were indicating that the investment made sense, then they would invest again.

Yes, we would. So GIB involvement not really an issue, much more on the fundamentals of the fund, so yes. ${ }^{89}$

The answer is yes, in so far as, as long as we were dealing with a set of proposals where we could clearly analyse, understand and consider the risk characteristics, including management, then we would be happy to invest. It is, in my experience, hard to find propositions which have full transparency, low technology risks, and strong management at a fair price. ${ }^{90}$

Some investors were less illuminating and just happy to invest again without the GIB but not expanding on their reasons.

Yes. I think the key issue; my colleagues probably don't think about it but is if we had two equal Funds and we had to choose between two equal Funds would the GIB influence? I think my colleagues would struggle to say it did, frankly.

They might say it did but I think... [they wouldn't be able to justify it] ${ }^{91}$

Yes. ${ }^{92}$

\subsubsection{Transaction contractual structure}

Each individual transaction's contractual structure is important, as investors will need to be as certain as possible that the required returns will be made and that the investments can deliver them. If it is too unclear or unfamiliar then investors will not feel comfortable investing, even if all other indicators are positive, particularly if there are other competing investments that

\footnotetext{
89 Interview 3.5, Investor, $22^{\text {nd }}$ April 2015.

90 Interview 4.4, Investor (Investment Fund), $22^{\text {nd }}$ January 2016.

${ }^{91}$ Interview 3.11 \& 4.7, Investor, $23^{\text {rd }}$ November 2014.

92 Interview 3.6, Investor, $17^{\text {th }}$ July 2015.
} 
could be made. This issue has come across strongly as an important factor across the spectrum of investors. One investor made the point that a familiar project finance structure was a key driver allowing them to invest and that they attributed significant value to this issue when making their investment decisions. They emphasised it a number of times in the same interview as demonstrated by the following four extracted comments.

Actually, energy efficiency for us has got two aspects. The first is infrastructure-type projects; so, whether that's things like biomass boilers, CHPs, heat capture or fit-outs of buildings into more energy-efficient assets. All of that in infrastructure would have, if you like, a traditional project finance wrap around it. ${ }^{93}$

For us, the key for it to be an appropriate asset class is the project finance wrapper around the investment. That's something you don't always see.

This particular fund is bringing that project finance discipline to areas where it traditionally hasn't been. For us, given that, and then all of the government subsidies, etc, and the contractual structures, that becomes an infrastructure investment at that point. ${ }^{94}$

I think I've mentioned before the application of traditional project finance contractual architecture to areas where it hasn't been before. ${ }^{95}$

I think I've mentioned it several times. That project finance wrap being there for the first time made a huge difference. A huge difference.

What we were able to do, and I don't think we would have done it [invest] if we couldn't, was actually have legal reviews of all the contractual set-ups. We were actually able to use a typical renewable/infrastructure lawyer. It was just like a wind project or a bridge. It had all the same types of contracts, arrangements, etc.

In terms of due diligence, it could be done in a very clear, well-trodden path. ${ }^{96}$

In this last comment the investor actually states that the familiar structure allowed them to use an infrastructure lawyer as it had essentially become an infrastructure investment rather than

\footnotetext{
93 Interview 3.4, Investor (Investment Manager), 14 ${ }^{\text {th }}$ November 2014.

${ }^{94}$ Interview 3.4, Investor (Investment Manager), 14 ${ }^{\text {th }}$ November 2014.

95 Interview 3.4, Investor (Investment Manager), 14 ${ }^{\text {th }}$ November 2014.

96 Interview 3.4, Investor (Investment Manager), 14 ${ }^{\text {th }}$ November 2014.
} 
an energy efficiency investment, which had allowed them to satisfactorily review the transaction legally and without which they would not have made the investment. This is significant if investors are to be positively influence to make further energy efficiency investments.

Contractual structure was raised by a number of investors throughout the study and a strong theme emerged.

No but I think Equitix is targeting a lot of renewable heat incentive stuff which is much easier business case. From a private investment perspective that is much easier to do because they understand it, right, you can do the cash flows and it is much closer to traditional project finance type approaches, right. ${ }^{97}$

Well essentially this was the first type of fund like this that I'd seen. So, we'd been an investor in the Equitix PPP Fund, so I was familiar with the sorts of long-term contractual infrastructure investments that sit in those funds. ${ }^{98}$

I think, on the positive side, the project finance type of approach that Equitix was very attractive. I think we talked to a number of other people in this area and they were running it more on a developer model, but the long-term project finance made a lot of sense for managing the risks. ${ }^{99}$

The following comment was made by a declined investor and although it wasn't related to the investment's project finance structure, it does demonstrate the issue around confidence of fund structure or strategy for an investment to be able to achieve the required and promised returns.

So, the manager risk I've touched on is the complexity of the opportunity and how visible or plausible that is. There's a term so it may be that there's a good opportunity but it's structured in not a suitable way, you know, in an unsuitable way, meaning it may be in an onshore, offshore fund or it may have certain elements of it that aren't tax efficient or it may be that the manager is charging too high an incentive for your base management fee. ${ }^{100}$

\footnotetext{
97 Interview 3.11 \& 4.7, Investor, $23^{\text {rd }}$ November 2015.

98 Interview 3.5, Investor, $22^{\text {nd }}$ April 2015.

99 Interview 3.7, Investor (Investment Manager), $27^{\text {th }}$ July 2015.

100 Interview 3.12 Declined Investor, 18th January 2016.
} 


\subsubsection{Risk, reward and opportunity}

Investors' decision to invest will be influenced by their assessment of risk, reward and their propensity to exploit a potentially advantageous opportunity within the market.

\subsubsection{Security of income and level of return}

As already discussed, investors assess potential investments through the lens of risk and return. In the responses to questions about what factors influenced investors decisions to invest in energy efficiency, government revenue incentives were mentioned as a positive factor.

The Green Investment Bank are publicly owned, so the Green Investment Bank and EEEF together are gaining returns and a lot of these returns are driven by responsible heat incentives, the RHIs, the ROCs, FiTs if applicable. ${ }^{101}$

One of the features of the fund, in fact, of Equitix as a house [financial institution], is that they have been very canny in tapping into quasi-guaranteed investments underwritten by government and that bond-like aspect of it has been quite attractive. ${ }^{102}$

However, they were also mentioned in the context of being a risk in that the government could discontinue their use and, more problematically, the risk of a retrospective discontinuance. Once the income from these instruments has been factored in to the transactions return the investors want to be totally confident that they will realise that return which would not be the case if the government retrospectively discontinued providing the enhanced revenues achieved.

As I said, the things that we spent a lot of time on and tried to get our investment committees comfortable with [...] was just around the government's continued use of the RHI and not changing things retrospectively. ${ }^{103}$

\footnotetext{
101 Interview 3.3, Fund Manager, $23^{\text {rd }}$ October 2014.

102 Interview 3.6, Investor, $17^{\text {th }}$ July 2015.

103 Interview 3.7, Investor (Investment Manager), $27^{\text {th }}$ July 2015.
} 
In general, the investors were attracted by the returns offered and the risk-return profile.

I think, then, for us, there are just some characteristics of the return, being predominantly income-focused, for example, which just suit our client mandates very well.' 104

'Actually, the returns were really quite attractive for what was quite a low risk thing. Sticking a new big boiler in a hospital actually - and if you secured your feed stock supplies and your off take actually it's very low risk. ${ }^{105}$

It's very much the risk-returns, being in a new institutional investment asset class offering you reasonably strong returns for the risk that we thought we were taking. ${ }^{106}$

If the risk adjusted return, at the fund level, let's say, is 10\%, there or thereabouts net of fees and costs, that is a pretty sensible return in the current environment when you look at what all the risk-free asset classes might deliver you. Right now, a 10\% RAR looks quite strong. ${ }^{107}$

Risk return coupled with strong investment case and investment partners including the fund manager was also a feature of the responses.

Yes. If I were to summarise it in a sentence, I would say probable forward net returns over time. But that simple sentence includes a great deal of luggage. If I were to unpack the luggage, the probable forward returns are a set of expectations about the reliability that this investment will deliver the cash flow that we believe is appropriate at outset. We think that because this is proven technology, with clear benefits to all parties, that actually, this is a relatively safe and secure investment to make.

That is coupled with the challenge that over time, this will be dependent on the parties to the agreement and the delivery. So SDCL itself, but also its industrial partners. We consider them to be robust and capable, and therefore able to deliver to us. ${ }^{108}$

\footnotetext{
104 Interview 3.4, Investor (Investment Manager), 14 ${ }^{\text {th }}$ November 2014.

105 Interview 3.5, Investor, $22^{\text {nd }}$ April 2015.

106 Interview 3.7, Investor (Investment Manager), $27^{\text {th }}$ July 2015.

107 Interview 4.2, Investor (Investment Fund), $9^{\text {th }}$ June 2015.

108 Interview 4.4, Investor (Investment Fund), $22^{\text {nd }}$ January 2016.
} 
Yes. I think it's all about fundamentals. That was the benefit of us having an internal team. That we would look at things that I think pretty much - [XYZ - investment managers] looked at this because we asked them to. As well as the fact that they knew Equitix, so they knew we were a potential client of this fund. So, having an in-house team, gives you the ability to do interesting things that are slightly less mainstream. So, when we see them it's all about the strength of the investment case, the clarity, the approach, the expertise of the team, the fees, the net returns you're going to get, the risk that's [...]. There's no rocket science here. It's basic investment appraisal, going through all the elements of the fund. ${ }^{109}$

In terms of technology, we want to be involved in proven technology, so they should not have significant technology risk. We want there to be immediate cash flow, because in our experience, investments not untypically unravel if there is a delay in implementation, with long periods of negative cash flow. At which point, the whole structure can become unviable. ${ }^{110}$

Investors, depending on their risk appetite, have a propensity to exploit a potentially advantageous opportunity within the market to varying degrees. As energy efficiency is a new area of investment, which may become its own asset class or a distinct and established sub class of infrastructure, the risks are initially perceived as higher than more established asset classes. The period of highest risk is always during the initial construction phase, certainly in infrastructure, and should a potential investor take the risk to invest during the construction phase of an investment with no operating history then it would expect a premium on its return. Once the class is proven and satisfactory operational data is available then the potential investor would expect to see the returns or yield to lower and would be able to exit its investments for a higher value. This is known as Yield Compression and investors who see the success of energy efficiency in the long term and are happy to take the risk would be seeking to take advantage of Yield Compression in the sector by investing early. A number of investors made this point.

If you are a pension fund, this is a new asset class. I mean I think part of the selling story has got to be around potentially yield compression. If you are investing in, I suspect PFI assets and infrastructure assets, I mean they are being bid ever more aggressively, because there is a shortage of income assets out there. So, you come to the energy efficiency, get in early in the asset class and then benefit from the yield compression ride, would be the key sell here would be my guess. ${ }^{111}$

\footnotetext{
${ }^{109}$ Interview 3.5, Investor, $22^{\text {nd }}$ April 2015.

110 Interview 4.4, Investor (Investment Fund), $22^{\text {nd }}$ January 2016.

111 Interview 1.3, Investor (GIB), $9^{\text {th }}$ June 2015.
} 
As investors in this fund, if you take construction risk, you expect to earn a premium for taking the construction risk. Post-construction, or particularly a year or two postconstruction, when the asset is performing and you can get to 'kick the tyres' as operational data, you would expect to exit at a lower yield and gain a bit of an uptick in terms of overall investment performance because of that yield compression.

Now, at the moment, none of the fund managers, I think, have approved it on a large portfolio basis, but that's certainly part of the investment thesis in the market, and we will see over time as to what yields are exited. ${ }^{112}$

\subsubsection{Feedstock}

Aspects of certain energy efficiency transactions, particularly those involving biomass boilers that have attracted government subsidies, require a secure fuel source. This is also a concern for investors and is viewed as a risk that they need to fully understand.

There may be things like fuel risk, which on more conventional investments may not have any requirement to source biomass or waste, or any such sort of fuel to ensure that the project works. So, it's weighing up, to the extent that those contracts are robust, and there's parties in place which can meet any obligations within those contracts. ${ }^{113}$

As I said, the things that we spent a lot of time on and tried to get our investment committees comfortable with were, first of all, the feedstock issue and how that was going to work over time, given that we hadn't been involved in investments that had had those issues over time. We needed to spend a bit of time getting our heads around that. ${ }^{114}$

If you've got a solid set of counterparties, a solid set of technologies deployed, and, in the case of biomass, also a solid on the feedstock side, that's a good set of risk parameters. ${ }^{115}$

\footnotetext{
112 Interview 4.2, Investor (Investment Fund), $9^{\text {th }}$ June 2015.

113 Interview 3.2, Fund Manager, $15^{\text {th }}$ October 2015.

114 Interview 3.7, Investor (Investment Manager), $27^{\text {th }}$ July 2015.

115 Interview 4.2, Investor (Investment Fund), 9 ${ }^{\text {th }}$ June 2015.
} 


\subsubsection{Small projects, volume of investment opportunity and deployment}

One of the established barriers to investment in energy efficiency projects is scale and the small size of the projects involved. This is one of the reasons why the GIB elected to use fund investment to attract matching investment from institutional investors, as the individual transactions were deemed too small to interest most pension funds etc. Alongside this is the concern that the investment opportunities are not readily available. Although it is recognised that investment into energy efficiency is needed and can have a significant effect in the reduction of $\mathrm{CO}_{2}$ emissions, opportunities to invest in energy efficiency are still scarce. The following quote from a GIB representative illustrates that the GIB recognised this issue and although they set up the investment vehicles, they were still concerned about there being sufficient investment opportunities.

I am probably jumping ahead but the big challenge is the volume of investment opportunity $[\ldots]$.

There is a real suspicion of investors investing in funds where they can't demonstrate deal flow, which is again one of the GIB's challenges. It has been set up by government perfect bureaucracy, but actually what are the investment opportunities out there? And they are not that great. ${ }^{116}$

One of the fund managers approached the issue of energy efficiency projects being small in value by actively structuring them as typical infrastructure assets and we have seen that this has been well received by investors in their fund. The fund manager had actively sought to market their fund as just another infrastructure fund in order to appeal to investors.

I think the key one is deployment of capital, and investors are very aware that if we have historically gone to them with PFI projects that said [...]. The average PFI project is $£ 50$ million, let's say, and 10\% of that is equity. Roughly speaking, your average ticket size is $£ 5$ million a project. If you're looking at LED lighting schemes, your average project is $£ 50,000$ or whatever it is.

I think that one of the real things that investors have had to get their minds around is how to, this is the thing we've had to do. We've helped with how you structure a portfolio of what can be relatively small assets in an efficient way and deploy capital at scale in an efficient way, in a way that makes it, in aggregate, look and feel like an infrastructure investment, because that's really what they want it to look like. Actually, when you do all

${ }^{116}$ Interview 1.3, Investor (GIB), 9 $9^{\text {th }}$ June 2015. 
that right, it's perhaps innovative in some ways, but the outcome is something that looks, in a lot of ways, like a very boring infrastructure fund. That's part of the strategy, to try and set it up in that way. ${ }^{117}$

Investors were concerned about the small scale of the investments.

...clearly scale is an issue. So, there are so many small transactions; changing the windows in your house, changing the boiler in your home, putting some insulation in the attic. I mean like a Pension Fund that has to deploy a billion Euros in every transaction, how does he deploy a billion Euros in a single transaction? It is not easy. ${ }^{118}$

However the following investor, although expressing concern about the size of the transactions, clearly got comfortable that there was sufficient deal flow and that the capital would be deployed in a reasonable timescale. He went on to state that deployment had been slower than they would have ideally liked perhaps indicting that the opportunities were not readily available to the fund as they had previously understood.

At first, we were [concerned about the size of the transactions], but ultimately, you then get comfortable with the fact that there are, individually, very small projects but, actually, there are pipelines of portfolios.

It's gone a little bit slower than we would have probably ideally liked in practice, but we like the fact the guys are being a bit cautious at times.

I think it's an area which can accept more capital quite comfortably and I know that Equitix have got a lot of the capital wrapped up; so, a concern, yes, but I think one we're relatively relaxed about. ${ }^{119}$

One of the fund managers felt that the small scale of the investments was in fact an advantage, in that they would yield or produce returns quickly however this would only really be beneficial if a sufficient number of investments had been made in order for the return to be of sufficient size to have an impact.

\footnotetext{
117 Interview 3.1, Fund Manager, $13^{\text {th }}$ November 2014.

118 Interview 3.11 \& 4.7, Investor, $23^{\text {rd }}$ November 2015.

119 Interview 3.4, Investor (Investment Manager), 14 ${ }^{\text {th }}$ November 2014.
} 
I think that due to, you know, the strength of the investments made, I would like to think, and the returns coming back to investors, I would like to think that yes. A number of the projects, particularly the small-scale biomass for example, start yielding very quickly, which I think is hopefully very attractive to a number of investors. ${ }^{120}$

Interestingly one investor did view the small scale of the investments as a positive factor, seeing the investments as big enough to make economic sense with sufficient return while also being too small individually for most investors to take notice.

So, when this fund came along and said, "Well this is all we're going to do." and went through some of the opportunities that are found, you could actually see that they were big enough to make sense as investments, but not so big that people are going to be doing them. So, there's a nice little niche there. ${ }^{121}$

There were also some responses positively advocating the use of the fund structure among investors. This reflected the view that small scale direct investing in energy efficiency is impractical and unfeasible to undertake for institutional investors.

[So], the first issue is why Funds? Because why are we even doing Funds in energy efficiency? And I think the answer is given the challenges of lending at scale to energy efficiency Funds are actually a reasonable business model to do that.

And we will see how successful that is when they have closed, when they are through their investment period [...]. But at this point it is very difficult to finance energy efficiency so that is important. ${ }^{122}$

We did look at energy efficiency direct investment for [XYZ]. We found it almost impossible to structure an agreement. Because, for example, in [example building], if you were to introduce energy efficiency with a premise that you would receive your return as a portion of the cost saving, quite often, they will want to spend the same amount on energy, and just be more comfortable.

So, they will allow the building to be warmer. They will be less effective at managing temperature and lighting, because they are not so incentivised. Whereas the counterparts in the SDCL agreement are first-class entities who wholly understand what the agenda is. There is absolute transparency and clarity on how this will be measured and the returns. ${ }^{123}$

\footnotetext{
120 Interview 3.2, Fund Manager, $15^{\text {th }}$ October 2014.

121 Interview 3.5, Investor, $22^{\text {nd }}$ April 2015.

122 Interview 3.11 \& 4.7, Investor, $23^{\text {rd }}$ November 2015.

123 Interview 4.4, Investor (Investment Fund), $22^{\text {nd }}$ January 2016.
} 


\subsubsection{Access to long-term stable index linked cashflows}

it has been explained previously that long-term stable index linked cashflows are important to investors in order that returns match their index-linked liabilities. This is a key issue recognised by the fund managers when responding to the question of what are the factors that have influenced investors to invest in their funds.

I've touched on access to long-term, relatively stable index-linked cash flow projects that fall within in it or an investment that falls within a recognised asset class of infrastructure or renewables, wherever you might want to put it. ${ }^{124}$

We may have talked about it before, but it's worth mentioning that REaLM, actually, is a trademarked name, and it stands for 'Return Enhancing and Liability Matching'.

That's the tin. We're trying to do what it says on the tin, which is we're using illiquid investments and we're using real assets to help liability matchers produce a very defined, transparent indexed cash flow, but at materially higher rates of return than they were getting in traditional liquid investments.

That's the raison d'être for the fund and what we do. ${ }^{125}$

Investors also state this in their response to this issue.

Another aspect of this asset class, and not just our fund but the asset class in general, is elements of indexation built into it. Not across the piece, but things like biomass, for instance, the main revenue streams, the Renewable Heat Incentive, and the 20-year indexation. ${ }^{126}$

\footnotetext{
124 Interview 3.1, Fund Manager, $13^{\text {th }}$ November 2014.

125 Interview 2.1, Fund Manager, 24 ${ }^{\text {th }}$ February 2015.

126 Interview 4.2, Investor (Investment Fund), $9^{\text {th }}$ June 2015.
} 


\subsubsection{Regulations influencing transactions}

Regulation also featured as an influencing feature for investors when considering whether or not to invest in energy efficiency. This issue is perhaps one that would have been expected to be a consideration.

We look at the sensitivities. If, for example, they are investing in investments which are really skewed towards regulation so there's a big risk on that, so we need to understand, if there's a change in regulation, how does that reflect on the investment? We look at all these key components of the assessments. ${ }^{127}$

We then want low policy risk, by which I mean we don't want a high dependency on governments or other third parties making statements about their preferences, which may ebb and flow according to the political cycle. Energy efficiency, because it is rooted in hard economics, is much more reliable than some of the forms of participation in low hydrocarbon economics. ${ }^{128}$

\subsubsection{Alternative Investment Opportunities}

The issue of whether investors decided to invest the energy efficiency funds at the expense of alternative investment opportunities is an important one. If investors do invest at the expense of alternative investments, then energy efficiency has investment attributes that encourage this and they could perhaps be further emphasised or developed in a strategy to encourage wider investment. Below are a number of positive responses but perhaps the most surprising of them is the first, where it appears that the investment funds to make the investment into the energy efficiency fund came direct from the 'pot of money' allocation to mainstream equities.

Yes, on the basis that in the general sense the pension scheme is a closed pot of money. So, the state we were at we were closed to new entrants. The scheme was just about cash neutral. So, there was no wall of money coming in that we just had to deploy. If we wanted to put something into a new investment, we'd have to extract that money from somewhere else. At the time we were looking at the asset allocation. The allocation into this actually came out of mainstream equities. ${ }^{129}$

\footnotetext{
127 Interview 3.10 \& 4.6, Investor, $23^{\text {rd }}$ November 2015.

128 Interview 4.4, Investor (Investment Fund), $22^{\text {nd }}$ January 2016.

${ }^{129}$ Interview 3.5, Investor, $22^{\text {nd }}$ April 2015.
} 
I'm guessing that that was the case, yes. Yes, we did. I mean, you know, we set a guide amount that we'd look to commit, in both infrastructure and private equity and, you know, we try and look at it as much as we can and take the best opportunities, so given that we didn't invest that would have been a factor.

There were other things that were taking our time and getting our attention in a more positive way. ${ }^{130}$

We did invest in the Equitix Energy Efficiency Fund at the expense of alternative opportunities, and two reasons, really.

One is just from a very, if you like, hard-nosed risk-return consideration. We just felt that it stacked up, at this point in time, very well against other opportunities.

I guess, secondly, the investment was made primarily on behalf of one client, [..]. For them, it fitted their criteria extremely well, as you can appreciate, and it is one that they're going to put up in bright lights themselves.

It suited us. As I say, risk-return, and we are recommending it to other clients, but, in particular, it was done at least initially for one client with a very particular sustainability requirement. ${ }^{131}$

Yes. There's always options. The universe is huge. ${ }^{132}$

There wasn't any specific that was the alternative. We didn't consider the other Energy Efficiency Fund that was being offered.

Not directly. We researched it as part of our market understanding of what the market was in ... ${ }^{133}$

Well, in so far as there is a limited pool of capital, and we must deploy wisely to achieve our customers' objectives, it would be correct to say that SDCL's proposition competed and won capital that could've been deployed elsewhere. I would not, however, argue that we have considered SDCL's investment in the context of there being a high opportunity cost.

\footnotetext{
130 Interview 3.12, Declined Investor, $18^{\text {th }}$ January 2016.

131 Interview 3.4, Investor (Investment Manager), 14 ${ }^{\text {th }}$ November 2015.

132 Interview 3.6, Investor, $17^{\text {th }}$ July 2015.

133 Interview 3.7, Investor (Investment Manager), $27^{\text {th }}$ July 2015.
} 
Because the characteristics of the investment are, on our expectation, relatively high return and low risk in absolute space, and highly diversifying in the context of other material asset classes. So not bearing the same characteristics as quoted equities, conventional real estate or bonds. ${ }^{134}$

\subsection{Fund Manager}

The selection of a fund manager is likely to be a key factor in an investor's decision to invest in energy efficiency via a fund structure. This section of the research seeks to establish the various attributes that investors are seeking when choosing a fund manager or deciding to invest in an opportunity presented by a fund manager. It also attempts to establish whether investors would consider investing in a wider number of funds managed by different fund managers once they had a level of understanding of the underlying asset and had a level of expertise in the sector. In this way investment in energy efficiency could be expanded.

\subsubsection{Investment Strategy}

The fund manager's investment strategy is of key importance as it can determine how likely the projected returns are achieved. Questions can be asked about the correct level of risk being taken for the likely return, what volume of investment opportunities are there for deploying funds, is the strategy focused enough etc. The following comments are by investors who have identified the investment strategy followed by a fund manager as a key consideration.

Yes, what we are looking at particularly in energy efficiency, in terms of investment in the private equity funds we look to two things basically; the quality of the team and the plausibility of the investment strategy, right as to whether or not we consider the investment strategy credible and commensurate to the risk that we have taken [...]. ${ }^{135}$

\footnotetext{
134 Interview 4.4, Investor (Investment Fund), $22^{\text {nd }}$ January 2016.

135 Interview 3.9 \& 4.5, Investor, $23^{\text {rd }}$ November 2015.
} 
The reason that they invest in the fund, it's probably three main reasons which are typical to the market. One [reason] is [that they are] comfortable with the strategy and its potential. ${ }^{136}$

Talk to your fund manager, then the strategy. The pipeline must be a reflection on the investment strategy. Their strategy track record, the investment strategy and the pipeline, they all must be aligned. ${ }^{137}$

The issue of strategy was also recognised by a declined investor and a fund manager respectively in the following two quotes.

You know, I mean, we didn't invest in this case. If we had have invested, the things we're looking for are a kind of strategy that's perhaps transparent, visible. And when I say visible I mean have some confidence in the... you know, the future returns. ${ }^{138}$

[If] you buy into the strategy or you have an allocation in your portfolio to a given strategy, that's the first big thing. ${ }^{139}$

Concern was expressed by one investor that there are fund managers that are too diversified in their proposed strategy and needs them to be more focused. This of course can be difficult in a market with few opportunities.

We want businesses that are really clear on what they're going to do and the delivery of what they're going to do. We find that there a surprisingly large number of people calling for capital, who have overly diversified business plans, who have a lack of understanding of the key requirements for them to be able to deliver, and who therefore maximise the probability of failing by being overly diversified and less focused. ${ }^{140}$

Another investor stated that they were willing to give more weight to a fund manager's strategy over their experience in structuring energy efficiency investments previously, which is not

\footnotetext{
${ }^{136}$ Interview 4.1, Fund Manager, $27^{\text {th }}$ February 2015.

${ }^{137}$ Interview 3.10 \& 4.6, Investor, $23^{\text {rd }}$ November 2015.

138 Interview 3.12, Declined Investor, $18^{\text {th }}$ January 2016.

139 Interview 2.1, Fund Manager, $24^{\text {th }}$ February 2015.

140 Interview 4.4, Investor (Investment Fund), $22^{\text {nd }}$ January 2016.
} 
always the case among investors. This indicates a recognition that energy efficiency may be a relatively new type of investment with few experienced teams, however a potential fund manager must have a well thought out investment strategy for it to be considered for investment.

What we always look for in Managers is that they have clear ideas what would work right and a well-defined idea on what is their route to the markets [...].

Somehow for energy efficiency we are willing more to give more weight a little bit to the idea of what are the investments that they want to tackle rather than to having vast experience behind showing they can do it. ${ }^{141}$

\subsubsection{Knowledge of the market and pipeline}

Another key issue is the fund manager's knowledge of the market, which in turn allows it to identify a credible pipeline of investment opportunities. This was recognised early on by the GIB.

Well they've got to demonstrate a knowledge of the market, obviously. Very importantly they've got to have a credible pipeline. ${ }^{142}$

The fund managers themselves also realise this and know from direct experience what it takes to identify sufficient opportunities that match the stated investment strategy they marketed to their investors. This includes exploiting their existing partners in their established mainstream infrastructure funds who may be able to provide energy efficiency opportunities for investment. This could also be a selling point.

[...] this isn't a commoditised mainstream business where you just evaluate deals and pick the best, it's actually going out there, building the market. It's a service-oriented approach therefore being able to build that pipeline, maintain it and manage those relationships, it's quite an involved process. ${ }^{143}$

\footnotetext{
141 Interview 3.9 \& 4.5, Investor, $23^{\text {rd }}$ November 2015.

142 Interview 1.1, Investor (GIB), $13^{\text {th }}$ April 2015.

143 Interview 4.1, Fund Manager, 27 $7^{\text {th }}$ February 2015.
} 
I guess the other factor is having a pipeline of opportunities, so being able to demonstrate that once funds have been invested, have been committed, that there's a series of projects which, you know, the fund manager can then invest in. ${ }^{144}$

There are a lot of opportunities that come from our connections through all our big infrastructure partners that have brought us opportunities that are in our pipeline for the energy efficiency fund. ${ }^{145}$

\subsubsection{Track record and ability to deploy funds}

The fund managers interviewed, as would be expected, felt that track record is an important factor when evaluating a fund manager. The second of the following two quotes from fund managers focuses on its track record of meeting target returns and identifies energy efficiency as a niche sector, thus intimating that there are not many fund managers who operate in the sector and can produce the required returns.

I mean in terms of evaluating whether to invest in a fund manager or not, the importance is, I would suggest, having a track record in investing as a starting point... ${ }^{146}$

I think the key things that would be assessed would be the track record of the fund manager, in terms of obviously delivery against target returns, and ability to meet hurdle rates, target hurdle rates. Particularly in this sector, it's quite a niche sector and there's not many investment professionals who focus on energy efficiency, particularly in non-domestic energy efficiency. ${ }^{147}$

The next two fund manager quotes emphasise that they have a well-established track record in an alternative, albeit related, sector and have deployed capital successfully and delivered the

\footnotetext{
144 Interview 3.2, Fund Manager, $15^{\text {th }}$ October 2014.

145 Interview 3.3, Fund Manager, $23^{\text {rd }}$ October 2014.

146 Interview 4.1, Fund Manager, $27^{\text {th }}$ February 2015.

147 Interview 3.2, Fund Manager, $15^{\text {th }}$ October 2014.
} 
returns to investors successfully. Therefore, they believe that they are able to demonstrate that they would be able to do the same for energy efficiency investments.

Obviously Equitix is a well-established developer and manager of core infrastructure assets and has been around for seven to eight years. We have a strong track record with our core infrastructure funds which investors I think do like to see. ${ }^{148}$

Maybe I would say this, wouldn't I, but 'Track Record'. I think, for us, to be able to demonstrate to investors that we have raised three PFI funds, deployed capital successfully to time in good quality assets within those funds, are delivering the returns to investors that we said we would deliver, continue to be successful in that sector, and to be able to say, "What we're doing is taking that expertise and just deploying it in a slightly different asset class, ${ }^{\prime \prime . . . ~}{ }^{149}$

The investors interviewed have confirmed that track record is a key issue for them in their investment decision looking at all aspects of the fund managers previous experience and knowledge if the market. The investors realise that they are looking not only for experience of energy efficiency but also a successful investment history of financial return and investment exit, ideally in related fields such as infrastructure and property.

We look at the fund manager's track record, the experience. We look at the investments they've made in the past. We look at the way the market received them. We look at the proposed exits. We look at who they partnered before. ${ }^{150}$

We look at the strength of the team, we look at the resources, we look at the track record and we look at their experience and knowledge of the sector, especially if it's a new thing like energy efficiency, for instance. ${ }^{151}$

I think track record is important. ${ }^{152}$

\footnotetext{
148 Interview 3.3, Fund Manager, $23^{\text {rd }}$ October 2014.

149 Interview 3.1, Fund Manager, $13^{\text {th }}$ November 2014.

150 Interview 3.9 \& 4.5, Investor, $23^{\text {rd }}$ November 2015.

151 Interview 3.10 \& 4.6, Investor, $23^{\text {rd }}$ November 2015.

152 Interview 3.6, Investor, $17^{\text {th }}$ July 2015.
} 
One investor identified the sector currently as very inflexible and therefore choosing a fund manager is important for the very reason that investors will not be able to exit investments very easily or not at all as there is no liquid market to do so. There are no ready investors to sell to therefore investors will most likely be stuck with the initial fund manager.

I think the answer to the first one is "track record". This is an asset class which is longonly, illiquid and the classic fund structure is a 10-year closed-end fund structure. This is an asset class where you want to choose your manager particularly carefully upfront because jumping horse halfway through is not trivial. In fact, it's almost impossible. The track record of the fund manager and particularly in this sector is a key component. ${ }^{153}$

\subsubsection{Past relationship and familiarity with the fund manager}

A past relationship and subsequent familiarity with a fund manager is an important issue and factor in deciding to invest further for investors, as there is an element of trust between them which reflects a predictable behavioural issue. The following two quotes are from fund managers when asked if familiarity is a factor in investor's decision to invest in their energy efficiency fund. Certainly it appears from their perspective that familiarity is a significant factor in the decision process although it was a little contradictory in that, according to the second quote, some investors were happy to sign up purely on the basis of their participation in its other core infrastructure funds which have presumably performed well but also surprise was expressed that more of the core funds investors hadn't signed up for the energy efficiency fund.

I think greatly, and I think it's either familiarity because they've invested in our other funds; familiarity because we'd spoken to them about our other funds, and maybe they didn't invest in those because the timing was right or whatever it may be; or they were just able to look us up.

I think it would be much harder if we weren't a, I wouldn't say we were a household name, but you know what I mean: a recognised name in infrastructure. ${ }^{154}$

I think, looking at our investor pool, it's really varied. There's some investors who that relationship, and the experience they've had with Equitix on the core funds, means it's

153 Interview 4.2, Investor (Investment Fund), $9^{\text {th }}$ June 2015.

154 Interview 3.1, Fund Manager, 13 ${ }^{\text {th }}$ November 2014. 
almost a no-brainer. "Where's the documents, we'll sign tomorrow." And that's been the case with a couple of our investors.

So, the role of the fund manager, and the familiarity of the fund manager, I think it's kind of split, and it's mixed across the [investors]. But I guess, from my perspective, I was surprised that there weren't more of the investors in the core funds which have invested in this space. ${ }^{155}$

Generally, the investors' responses, perhaps unsurprisingly, confirmed that familiarity was a strong factor in their investment decision.

It's very unlikely that we would have done this without having a relationship with Equitix. ${ }^{156}$

Yes, it did, in the sense that we had a lot of trust in them as an organisation, and their ability to deliver was key. ${ }^{157}$

Oh, it definitely has a weight. I mean when you know the Manager, where you know that they are professional, you know that their due diligence processes are good so it is much better than a poor Manager which you don't have any experience on it. In the end due diligence processes are limited in time than in depth so it is much better, you really have the experience of having worked with them on other projects. ${ }^{158}$

It was a highly significant factor. We had worked, we'd studied, monitored, followed SDCL for an extended period before electing to commit capital. That period allowed us to build a record of their track record as an entity, but also as individuals.

We have discussed investing with them over a number of years and a considerable period, before we ended up committing capital. So, they were not an entity that turned up saying, "We think we can make a lot of money. May we have some capital. This week, the idea is delivery of garden ponds." This is something they have done all the time, and they have demonstrated considerable competency. Even in the difficult periods, they have not forsaken the targets and their points of focus. ${ }^{159}$

\footnotetext{
155 Interview 3.2, Fund Manager, $15^{\text {th }}$ October 2014.

156 Interview 3.7, Investor (Investment Manager), $27^{\text {th }}$ July 2015.

157 Interview 3.7, Investor (Investment Manager), $27^{\text {th }}$ July 2015.

158 Interview 3.9 \& 4.5, Investor, $23^{\text {rd }}$ November 2015.

159 Interview 4.4, Investor (Investment Fund), $22^{\text {nd }}$ January 2016.
} 
One investor who recognised familiarity as a positive, having invested in all three of the fund manager's previous infrastructure funds, then started to get concerned about concentration risk.

It helped. It was a really positive factor as I say because we knew them. It took one of the elements of risk away.

We were investors in all three of their PPP [Infrastructure] funds. Actually, that was almost a negative, because as we had investments in three funds already we were saying, "Well actually do we want the concentration risk of investing in another one?" So, it almost tipped it the other way. ${ }^{160}$

\subsubsection{Quality of the team, depth of resource, trust and integrity}

Perhaps understandably, the quality of the team involved in placing investment in the fund manager is paramount and this goes hand in hand with the trust placed in them and the level of integrity expected. This issue runs through the various parties involved. The GIB when selecting find managers obviously needed to select teams with credible individuals in not only the energy efficiency sector but in raising further capital also. The second criteria may have been reasonably straightforward as there are many fund managers with a track record of fundraising but fund managers who are able to manage and source projects in the niche sector are much more difficult to identify. The following is from the GIB.

[...] credibility of the individuals, do they have the skills to source projects and to manage projects? Do they pass the smell test? So certainly, when we were selecting at the GIB Fund Managers, the proven ability to raise money was important. ${ }^{161}$

The fund managers also recognise this and the two quotes below from fund managers discuss this requirement and the fact that they have it.

The quality of the investment team, and in quality, meaning the depth and breadth of experience, the extent to which you've got a depth of resource, and the third component I suppose is also the quality of the organisation around those individuals... ${ }^{162}$

\footnotetext{
160 Interview 3.5, Investor, $22^{\text {nd }}$ April 2015.

161 Interview 1.3, Investor (GIB), $9^{\text {th }}$ June 2015.

162 Interview 2.2, Fund Manager, $17^{\text {th }}$ March 2015.
} 
Obviously Equitix is a well-established developer and manager of core infrastructure assets and has been around for seven to eight years. We have a strong track record with our core infrastructure funds which investors I think do like to see.

We have a big team, a strong team with very varied disciplines and varied backgrounds who add value to the team. Across all backgrounds we have got people who have worked in the construction world, in the financial world. People who have worked on infrastructure deals, energy efficiency deals, across the U.K. and abroad. So, there is a strong team ..., there is a dedicated Energy Efficiency team with expertise and knowledge in the technologies that they are implementing. ${ }^{163}$

The investors also identified the individuals in the investment team as a key investment consideration. At times investors devote significant time and resources to investigate the individual's capabilities even to the extent of undergoing individual interviews, per the second investor quote below.

So, it's key. The people in the organisation that understand what they're doing. ${ }^{164}$

We look at the strength of the team, we look at the resources...

To come back on the fund manager, we spend a lot of time also doing due diligence with them. Sometimes we have individual interviews with people really to assess their capacity and their capability of doing the business. ${ }^{165}$

Some investors, when investigating a fund manager's teams expertise, recognised that experience and direct knowledge of energy efficiency investments would be difficult to achieve and looked at similar type investments in their background. The first quoted below also identified that one particular individual in the team had a high level of technical experience and did have relevant experience.

There were two factors for us which were important with them. One was the fund manager hadn't been involved in energy efficiency before, but he had been involved in very small-

\footnotetext{
163 Interview 3.3, Fund Manager, $24^{\text {th }}$ October 2014.

164 Interview 4.3, Investor (Investment Fund), $29^{\text {th }}$ June 2015.

165 Interview 3.10 \& 4.6, Investor, $23^{\text {rd }}$ November 2015.
} 
scale infrastructure projects, which were small schools; so, a lot of lessons learned in the way the contracts and other things were put together.

Secondly, they had internal technical expertise. One of the guys who was assigned to the fund for $100 \%$ of his time, who had undertaken energy efficiency in other more technical infrastructure type projects and had done due diligence with big investors on an outsourced basis. ${ }^{166}$

Experience of the team [is a factor that is important when placing an investment with a fund manager], as I mentioned. They don't have a track record per se, but having experience of investing in similar types of investments...

It's very unlikely that we would have done this without having a relationship with Equitix. ${ }^{167}$

Often investors are wary of established finance professionals offering a fund management service in energy efficiency. They recognise that the personnel may be very experienced in their field, however they are not able to trust them when it comes to knowledge of the more specific issues in energy efficiency.

But when we look at any Fund there is obviously a whole series of things we look at but from my side one of the things we think is very important is that they have some experience or knowledge of what they are talking about. Frequently, Funds are opportunistic. There are some very smart finance guys, I mean that is great, very smart finance guys trading financial products probably do really well. But very smart financial guys doing infrastructure or doing energy specific investments I am less convinced. So that is one of the things we would like to see in the technical side is that they have some understanding of what they are trying to address. ${ }^{168}$

Yes. We put a significant first hurdle on raw competency. I would suggest that as a result of the global financial crisis and the reduction in investment bank activity, there have been a relatively large number of what one might describe as "refugees" from banking, who have decided it would be quite smart to see if they can make lots of money out of clean tech, one way or another. They may be fine at financial transactions and structuring, but know nothing about the underlying business, and we don't touch any of them.

\footnotetext{
166 Interview 3.4, Investor (Investment Manager), 14 ${ }^{\text {th }}$ November 2014.

167 Interview 3.7, Investor (Investment Manager), $27^{\text {th }}$ July 2015.

168 Interview 3.11 \& 4.7, Investor, $23^{\text {rd }}$ November 2015.
} 
So, they're silver-tongued, they produce fantastic spreadsheets and economic models, but our capacity to trust in them being able to manage the underlying business is not there. So, competence is number one. ${ }^{169}$

\subsubsection{Robust processes and risk management}

Another consideration is that of the sophistication of the fund managers' processes and controls that any fund manager would require.

[The] process around risk management, control the environment, to ensure that the investments are actually conducted in a risk aware environment. ${ }^{170}$

If I'm giving these guys pension scheme money, you have to be comfortable they've got the right controls and processes and compliance, and regulatory stuff in place. ${ }^{171}$

Additionally, the understanding of the specific risks associated with the energy efficiency sector is identified as another key factor.

I think, again, you've got to also have people who understand the risk analysis. At the end of the day, our business is all about understanding risks. Anyone can build a spreadsheet that calculates an IRR or a return calculation, but to actually understand the risks is the value-add.

There are a number of areas of risks in energy efficiency. Counterparty risk and technology risk are the two general big ones, but if we move to biomass, there are also feedstock and supply chain risks as well. Understanding those risks, understanding when to take them, when not to take them and how to understand them is critical.

We spend a lot of time fussing about counterparty risk and looking at enhancements. We spend a lot of time worrying about technology risks and laying off that risk contractually and how we do that, and ditto on biomass. The last deal we did with this fund was a biomass deal. There, we did have feedstock risk and a lot of wood pellets to feed the biomass boilers. Laying off the risks there on the supply side was a very key component of the transaction.

\footnotetext{
169 Interview 4.4, Investor (Investment Fund), 22 ${ }^{\text {nd }}$ January 2016.

170 Interview 2.2, Fund Manager, $17^{\text {th }}$ March 2015.

${ }^{171}$ Interview 3.5, Investor, $22^{\text {nd }}$ April 2015.
} 
I think that 'Risk' piece and the manager's understanding of where the pitfalls are and what the risk analysis is are absolutely crucial. The 'Returns' bit is easy after that. ${ }^{172}$

\subsubsection{Using other fund managers}

It is recognised that there are relatively few fund managers that are specifically experienced in energy efficiency albeit there are more with relevant backgrounds. In order to assess whether the market for energy efficiency investments via funds can be expanded successfully, the respondents were asked whether if they have had a good experience with their investment in the GIB funds, and with their capital being deployed at a reasonable rate and required returns being realised, they would consider investing in other energy efficiency funds run by other fund managers that were perhaps less experienced in the sector.

When asked the fund managers were all very positive and feel that there is room to expand the number of fund managers operating in the market and that investors would expand their investment base to include other fund managers. However, one fund manager did comment that some investors may be reluctant only because it could mean yet a further fund manager to report on internally and this could be a negative factor.

If you've gone down the road and made a decision that "Actually, this is an interesting fund because what it says it's going to do is very helpful to the goals or challenges I have as a portfolio manager," and then that fund delivers, why wouldn't you be more predisposed to try to replicate that in other regions or with other managers, potentially? ${ }^{173}$

Investors: I can't pretend to understand them completely, but I think they have a number of things that they will consider. One is the asset class and the number of asset classes that they're investing in. The other is the number of fund managers they work with.

I'm sure they would consider it if the asset class was right because, obviously, one of the things is if they're investing in a new area, they will never need to become, because that's what they pay us to do, a true expert in the asset class, but they need to understand enough about the investment they've made to be able to value it in their portfolio. Somebody in their team has to understand a little bit about energy efficiency, and obviously, we help

\footnotetext{
172 Interview 4.2, Investor (Investment Fund), $9^{\text {th }}$ June 2015.

173 Interview 2.1, Fund Manager, 24 ${ }^{\text {th }}$ February 2015.
} 
them with that. Going forward, after somebody has spent all the time understanding it as an asset class, then, if they like it, I'm sure they will invest in it again.

Equally, some are not necessarily constrained, but some do constrain themselves on the number of fund managers they work with because, in the same way they have to report on asset class, they want to report on fund managers. For a large investor, it might not be that attractive an opportunity to invest another small amount of money with another fund manager if that means bringing in another set of reporting processes and that sort of stuff. ${ }^{174}$

Well absolutely. I mean can this market expand? Yes. Is it expanding? Yes. I mean when we started this there were no energy efficiency funds out there. That's seven years ago. Now, there are at least, I would say, five to seven funds in each country. My personal view is that we call this a niche market but really energy efficiency has been around for a very long time. ${ }^{175}$

The investors' responses were also very positive as they looked at the performance of the investments rather than the focus solely on the attributes of the fund managers. Of course, they would still need to see that the fund manager had all of its processes in place and they would like some related experience but there would be less emphasis on experience of energy efficiency specifically.

... if Equitix failed would that stop us investing in energy efficiency funds? I would think at this point no because we still see plenty of potential. There is plenty of opportunity to further develop the market... ${ }^{176}$

Absolutely, as long as they have that internal technical expertise. ${ }^{177}$

Yes, we would. We are extremely open-minded as to with whom we work. But I go back to my earlier comment that we do not want to work with refugees from investment banks who lack technical competency. ${ }^{178}$

\footnotetext{
174 Interview 3.1, Fund Manager, $13^{\text {th }}$ November 2014.

175 Interview 4.1, Fund Manager, $27^{\text {th }}$ February 2015.

176 Interview 3.11 \& 4.7, Investor, $23^{\text {rd }}$ November 2015.

177 Interview 3.4, Investor (Investment Manager), 14 ${ }^{\text {th }}$ November 2014.

178 Interview 4.4, Investor (Investment Fund), $22^{\text {nd }}$ January 2016.
} 
Some investors did provide some more interesting answers. The following quote from an investor respondent at first suggests that they would absolutely invest in further funds run by other fund managers as long as the strategy works, as this provides diversification benefits which is good practice for investors to achieve. However, he then goes on to state that by doing so it would encourage more funds into the market which would, in turn, lower the returns. He is focused on maximising returns but of course if the market expands then he would have more opportunities to invest in.

So yes, is the answer. If the strategy works and you see good execution delivering returns on a strategy, then absolutely. If you invested in another fund that was doing similar then you get a bit of diversification benefits. You lose some idiosyncratic manager risk.

The down side on that is are you encouraging more people into the space, and competing overall returns down? So, there's a delicate balance. In some new and innovative areas, it's often better to have more than one manager there, because it just develops the market. It becomes less niche and more mainstream. ${ }^{179}$

Well, I guess the answer is, "Yes." We're not tied into Equitix, so the answer is, "Yes." The irony is, though, if Equitix does what they say they're going to do, we're probably more likely just to invest with Equitix again.

Yes, we would consider [other fund managers], but the practical issue is probably more that we won't. I think the reality is, "Are we more likely to invest in someone else?" We're more likely to invest with someone else if Equitix doesn't do well. If Equitix doesn't do well through their own fault rather than, obviously, the market, then, well... ${ }^{180}$

There are also some investors that don't see an expansion of the market with investors willing to invest in other funds, however this appears to be the exception rather than the rule.

No, I don't. I think it is too small a niche and they will choose something and decide that is my choice. Now I don't make that decision but having seen, I haven't done a detailed analysis but having seen who has invested in similar funds I don't think, with the exception of the Green Investment Bank and the European Investment Bank that I have ever seen the same name twice. ${ }^{181}$

\footnotetext{
179 Interview 3.5, Investor, $22^{\text {nd }}$ April 2015.

180 Interview 3.7, Investor (Investment Manager), $27^{\text {th }}$ July 2015.

181 Interview 2.3 , Investor, $8^{\text {th }}$ July 2015.
} 


\subsection{UK government and EU polices}

It is important to gauge investors' attitudes to government policy as in the main they require a clear, stable and consistent regulatory environment. The application of the RHI and ROCs, prior to them being phased out, had gone some way towards satisfying this requirement allowing some degree of security of revenues on qualifying transactions. It would be useful to understand the extent to which the UK government's and the EU's aims of reducing $\mathrm{CO}_{2}$ emissions has an influence over investors' decision to invest in energy efficiency or whether they are merely affected by government incentives that make the investment more lucrative or certain.

\subsubsection{Were carbon reduction policies influential in the investment decision?}

It is, perhaps, unsurprising given the traditional view of fiduciary duty of pension fund trustees, that they have an obligation to maximise return for a given level of risk, that investors are not actively going to invest into energy efficiency just because of the government's stated aims of reducing $\mathrm{CO}_{2}$ emissions. The GIB themselves recognised this fact.

So yes, there is a strong policy desire and drive to improve energy efficiency and reduce carbon emissions. That is probably on its own not going to induce investors to take the market too seriously. ${ }^{182}$

The following quotes are from fund managers, the first recognises that the legislation and incentives around income security are there to incentivise investors, it being the way it sells its fund. The second recognises that they are clearly driving investment and providing security.

[...] that's certainly a key anchor to our story, and certainly, even beyond energy efficiency, but some of the investments that we do in the renewable energy space are absolutely [due to policy]... we emphasise all the regimes that are in place around feed-in tariffs, and differences of contract, so we do certainly, and the ROC regimes, and we do educate the investors into those various regimes that are in place, to capitalise the investment in renewable energy and energy efficiency. ${ }^{183}$

182 Interview 1.3, Investor (GIB), $9^{\text {th }}$ June 2015.

183 Interview 2.2, Fund Manager, $17^{\text {th }}$ March 2015. 
I think at the macro level, the 2025, 2020 targets, the $80 \%$ reduction by 2050 certainly is a driver. Sort of linked to that are our own institutions' CRC targets.

And also, things that have stimulated the market that we've seen and experienced have been the Renewable Heat Incentive, for example, which has really driven investments within particularly - well, the RHI covers a whole range of technologies, but particularly within the biomass to heat space, and that has certainly driven significant investment, in particular the non-domestic energy efficiency area.

But more wider things like the Renewable Obligations Certificates have driven significant investment in solar, onshore and offshore wind, which are obviously flowing down, or flowed down from the macro level, from the EU targets down to the UK targets, down to individual policies within different technology areas.

So that certainly has stimulated attractive, I guess, mechanisms and subsidies, which is then filtered down to the investor level, where they can see there's a relatively long-term, stable subsidy regime for 20+ years across a number of these technologies, which has been attractive, and has stimulated and I believe influenced a number of investors into investing into this space. ${ }^{184}$

There is an interesting perspective from one investor where he feels that the government policies have increased the likelihood of investors even bothering to look at the sector. It is a rather cynical view as the polices do offer some income security, however in his view they are at least making the sector worth a look.

...the policies and the implementation of those policies rather has driven, has increased the likelihood of scale. It hasn't increased the economics but it has increased the likelihood of anyone bothering. ${ }^{185}$

Other investors have recognised that the government incentives are a big driver but the underlying economics are also an important factor in the decision, and in some cases the investment may have attracted investment without the incentives.

Yes. There's, kind of, two sides to this. One would prefer the opportunity to have legs and to be able to stand on its own and be market driven. That would be the ultimate. But when

\footnotetext{
184 Interview 3.2, Fund Manager, $15^{\text {th }}$ October 2014.

185 Interview 2.3, Investor, $8^{\text {th }}$ July 2015.
} 
the Government stands behind something and says, "We're going to guarantee it to pay you this, " it's hard not to. ${ }^{186}$

I think they're a big factor. I've mentioned before this bond-like quality. Clearly, they're not bonds and clearly you look at examples of Spain and most latterly in the UK with wind farms. You have to recognise that there is a certain element of risk there and governments do irrational things or are driven by other factors. But, you can only work with what you've got and at the moment, that does count as quite a consideration. ${ }^{187}$

Massively [investment decisions are affected by UK government and EU policies].

Well, being hard-nosed, knowing that half of your revenue comes from a government grandfathered subsidy with price flaws and RPI linkage, makes assessing these investments a hell of a lot easier.

Frankly, if some of those subsidies were cut, we'd still be very comfortable investing. Let's say 12\% is the target on Equitix. If someone said 8 or 9, purely because of a reduced subsidy, we would feel fairly comfortable about that, but having that policy support in the $U K$, and in particular the RHI policy, which is just that little tiny bit more robust than, say, the ROC regimes, because we are dealing with smaller-scale stuff on Equitix, helped a lot.

Knowing that the EU carbon reduction targets are there lurking in the background, as well as, as we know, the decommissioning going on in things like coal and the problems that are never addressed with nuclear, we think that is a good backdrop for renewable investing generally let alone energy efficiency.

Energy efficiency, we think, has some particularly accretive policies which help it on a relative basis at the moment. ${ }^{188}$

One of the fund managers did have an investment from one investor that was primarily driven by its ESG policy but any investment that did meet it needed also to meet returns that matched its long-term liabilities as other investors need to do. It was unusual in that the first criteria was its desire to match its ESG policy and then to see if the required returns were achieved rather than the return first and if it met the ESG policy it was a bonus.

\footnotetext{
186 Interview 3.12, Declined Investor, $18^{\text {th }}$ January 2016.

187 Interview 3.6, Investor, $17^{\text {th }}$ July 2015.

188 Interview 3.4, Investor (Investment Manager), 14 ${ }^{\text {th }}$ November 2014.
} 
I think that they like to tick that sustainability box, that environmental box. I think they like to be able to say, "Yes, we are meeting our target returns." Sorry, "This is going to deliver our target returns, this is going to help us to contribute to our ESG policy."

One of our current investors, the [XYZ] Pension Fund, they were looking for an environmental investment, which is what we are delivering to them. So, they came to us on that basis, that they were looking for investment that addressed ESG policy. But then on top of that, they are looking to match their long-term liabilities as a pension fund.

They have got to do both, but they came to us on the basis that it was an environmental investment. An investor who is looking to make an investment, in fact two, including the [...]. [XYZ] was pretty focused on the environmental side and have many restrictions within their own investment criteria, as to what is energy efficient, etc., etc., and what investments they can and can't make. So, they are also partially driven by environmental targets. As is another investor, they came to us and haven't made an investment yet but are almost there. Based on they were looking for a sustainable investment opportunity.

So yes, I think that that all has affected, to a lesser extent some of our investors, but to a quite high extent other investors. It is certainly a factor that they have considered and has made them interested in the opportunity. ${ }^{189}$

There were some investors that were negative about the government targets and took a totally commercial view of the investments and were solely concerned with fiduciary duty of matching liabilities with returns achieved.

Not really. It wasn't a major factor.

Ultimately as a pension fund you have very singular fiduciary responsibility, to generate the returns that enable you to meet the liability of the pension scheme. So, these things can be supportive in the round because you could argue, well without government support the economic case for doing these energy efficiencies wouldn't be there. So, they wouldn't be able to deliver the investment return, so there would be no fund for us to invest in, de, de, de, but it's that kind of thing. 190

No. Our clients aren't here to help the government out around meeting their commitments. The fact that the government has made that commitment offers a bit more comfort around the long-term sustainability of that incentive regime $[\ldots]^{191}$

\footnotetext{
189 Interview 3.3, Fund Manager, 24 ${ }^{\text {th }}$ October 2014.

190 Interview 3.5, Investor, $22^{\text {nd }}$ April 2015.

191 Interview 3.7, Investor (Investment Manager), $27^{\text {th }}$ July 2015.
} 
The following investor again was negative on whether the government incentives have affected their investment decision but went on to express how he could not understand why, while there are incentives for generating clean energy, there are no incentives for saving energy in Building retrofit type transactions.

I think they've given me no encouragement whatsoever. It's had no influence whatsoever. Where's my tax break? I didn't get one.

Well, you know, you go and put a load of nasty looking things up in the country up north, people get really irritated and you give them a feed-in tariff or a ROC, whereas if you actually went to the factories two roads down and you said, "Well, let's go look at another power generation that saves you $40 \%$ of your energy efficiency bill”, you may not need to put it in the field next door that nobody wants to see. It just seems really odd that there's no incentive to these guys to go save money. Lots of incentive to go and generate it. Hence the reason why we're in both. ${ }^{192}$

\subsubsection{Policies that could ensure or incentivise energy efficiency investment}

In the discussions on what policies that force energy efficiency upgrade or incentivise it that are in place or could be there were a range of responses. Many references to 'carrots' and 'sticks' were made. The GIB representatives interviewed held the strongest opinions on polices to force investment, the so called 'sticks'.

I think what would help more, though, is a combination of a carrot and a stick, where you say that a certain energy efficiency target within the sector within technology has to be met. For example, the building regulations that are coming in 2018, no new-builds without a certain level of installation or energy performance certificate. Rigorously applied but then at the same time you give incentives somehow for those who have met them early. ${ }^{193}$

I think one of the positive elements has been the introduction of the European directive on energy efficiency from 2012, which includes the obligation to all companies above 250 employees to do an energy audit every 4 years, the first one has to be finished by the $5^{\text {th }}$ of December this year. For companies which have got a €50m of turnover or more, or net assets of $€ 40 m$ and above, those companies have to do it.

The ones which are smaller than that don't have to do the energy audit, but obviously if you can see companies who are quite similar to your size are actually getting a competitive

192 Interview 4.3, Investor (Investment Fund), $29^{\text {th }}$ June 2015.

193 Interview 1.1, Investor (GIB), 13 ${ }^{\text {th }}$ April 2015. 
advantage because they're cutting their costs then you're going to want to replicate that as well. So, I think that's going to be a positive move to stimulate energy efficiency because all of the companies who do have to do the energy audit have to get a director to sign off on it. That means it gives the opportunity for shareholders to then say, "Let's see that report, let's see what the savings are and I want to have higher dividends on the back of it." 194

Regulation forcing investment has to be a fine line, the point was made again by a GIB representative that imposing too much regulation by the UK government could force energy intensive industries offshore.

Well I suppose forcing people to invest. So, you have got your domestic energy efficiency, the rules on retrofit will drive investment. I guess with industrial equivalents the problem is that UK government has to be very careful about driving energy intensive industries offshore. How much regulation can you really impose upon people?

Yes, so policy does have a part to play. ${ }^{195}$

The same GIB representative advocated more subsidies or incentives in the market, the so called 'carrots', and again mentioned the lack of incentives for pure energy efficiency transactions. There is no obvious subsidy that can be made. In his view there is no appetite in government for introducing more incentivisation, rather the opposite. The interview was conducted in 2015 however the political climate has not changed in this respect.

What does make them take the market seriously is the subsidies in the system that make investments as attractive, if not more attractive than investments that might be made elsewhere. That is why FIT based projects are attractive. Renewable ROCs and stuff, and the challenge with energy efficiency is that actually there is no obvious subsidy, which is one of the reasons why it is the least subsidised of all the GIB's asset classes.

What you have got to do is, you have got to introduce some subsidies for demand reduction. When I was involved there was no appetite in DECC to do that and I can't believe the current administration has any increasing appetite.

I think the whole thinking will be about reducing incentives to stop distorting the market... 196

\footnotetext{
194 Interview 1.2, Investor (GIB), 15 $5^{\text {th }}$ May 2015.

195 Interview 1.3, Investor (GIB), $9^{\text {th }}$ June 2015.

196 Interview 1.3, Investor (GIB), 9 $9^{\text {th }}$ June 2015.
} 
When asked what further policies could be introduced, one of the fund managers offered the following opinion. He is again suggesting that there is no subsidy regime for building energy efficiency retrofits and it would be a positive should incentives in this area be introduced. He is also suggesting that companies do not take seriously the regulations or 'sticks' designed to encourage investment in energy efficiency whereas subsidies and incentives in other sectors are a real driver for investment.

...but also having, I guess, incentives in certain areas which would facilitate and attract investment. So, for example, in the building retrofit area, there's no real subsidy regime, and I think it's a market where, or certainly a sector within the industry which isn't attracting as much investment as one would hope. And in that space, it seems to be there's more sticks rather than carrots.

So, in terms of companies having to meet CRC targets, and carbon reduction targets, as opposed to there being stimulants and incentives to, and subsidies to really boost their investment in certain - whether it's technologies, or you know, energy efficiency measures. It seems to be that there's not those drivers, it seems to be there's more sticks and things happening in the future to try to - which just doesn't seem to be, people don't, or companies, entities don't seem to be taking those seriously. Whereas the other subsidies and incentives seem to be really driving investment, whereas the sticks don't seem to be working as much. 197

There were some surprising responses regarding regulation and in particular incentives and subsidies. The following quote from a fund manager confirms that he is against any kind of subsidy and liked the energy efficiency sector because of the lack of subsidies.

I have to say, and I'm probably unusual as an infrastructure manager, I don't like, as a general rule, regulated businesses and I don't like subsidies particularly much.

I understand why they exist and I invest in loads of businesses that are regulated and have subsidies, so I can certainly get over those issues, but one of the very attractive features of energy efficiency, for me, is that generally, not completely, it's just totally devoid of government support and subsidies. ${ }^{198}$

An interesting comment was made by an investor who suggested that investment in energy efficiency could be incentivised by having favourable tax treatment, effectively making

197 Interview 3.2, Fund Manager, $15^{\text {th }}$ October 2014.

198 Interview 2.1, Fund Manager, 24 ${ }^{\text {th }}$ February 2015. 
investment in an energy efficiency transaction 'off balance sheet'. He suggested that the government should be supporting this view. If it was treated in this way then companies would not be dis-incentivised to invest in energy efficiency, adding it to their balance sheet and thereby restricting further borrowing.

The other thing that they could do, actually that might change, is put some influence upon the way in which people are having to account for this stuff too. If people would like to be off balance sheet by having an energy saving structure, then actually endorse it rather than say, "We're going to change the rules over here", i.e. give it or influence the accountants or what have you to make those sorts of decisions more strongly, ie. yes, you will get the benefit of this approach if you did this type of stuff. I think that would certainly help. ${ }^{199}$

\subsubsection{Stable policy framework}

A very strong, clear and consistent message that came through the interviews from fund managers and investors was the need to have a stable policy framework. If the government makes a policy with subsidies and incentives, investors want to be able to rely on it without the threat that policy could change unduly, affecting the economics of a transaction. The following three interview quotes were from fund managers.

I think frankly, having a clearer energy policy would actually [be] a good start.

I think from a UK perspective, I think that's been... well, that's a well-rehearsed argument, that the UK doesn't have a clear UK energy policy, and the consequence of that somehow therefore hasn't really driven the investment perhaps, that it could have done, over the years. Because there's been a little bit of uncertainly as to where the policy would go.

So, I think some sort of stability... some sort of clear policy, and stability in that policy, regardless of what the political agenda of the respective parties might be, actually, would probably go a long way. ${ }^{200}$

I'm not sure investors would be able to focus on individual policy areas, but I think as a general thing, just 'stability of policy'. That's the thing that is absolutely key.

199 Interview 4.3, Investor (Investment Fund), $29^{\text {th }}$ June 2015.

200 Interview 2.2, Fund Manager, $17^{\text {th }}$ March 2015. 
No retrospective subsidy cuts and no changes in subsidy regimes, even future-looking, halfway through a process without a clear strategy for why it's... All that sort of stuff that's not unique to energy efficiency by any means, but just a clear and stable regime. ${ }^{201}$

I think that having been in the renewables space for the past four or five years, the key thing [...] which hinders investment is an unstable regulatory environment. And having experienced it through the ROC regime, and leading on now to the CFDs, by not having a clear framework under which investors can invest in a range of projects which rely on Renewable Obligations support, that has hindered the market and essentially led to delays in projects. And a lot, so not just the incentive support mechanism, but also then the quantum of support, and the budget which has been allocated to particular technologies.

So, I guess it's having a clear and stable framework, which remains in place over, you know, a significant period of time. The Government's learned a little bit, in terms of the Renewable Heat Incentive, by having a relatively stable framework, and having mechanisms whereby subsidies can be reduced if certain budgets and targets are hit. And that's actually worked relatively successfully, because investors can see where potential reductions would occur. ${ }^{202}$

There were equally strong opinions from investors about the need for a stable policy environment.

For us this is all about policy should create a consistent, stable, environment because you need that for funds to develop, and investment propositions to develop. If people are worried that there's a support package there this year but it won't be there next year, well they won't be able to deploy the capital in time, or they won't have enough projects coming forward. So, it's stability and consistency of policy is key because people can then develop businesses. Pension schemes are long-term thinkers or long-term investors, so you need long-term policy framework to operate in. You don't want a flip-flop. ${ }^{203}$

[...] changes are terrible. Retrospective is obviously the worst, but even these changes that are announced and happen reasonably quickly, despite having grandfathering periods, are difficult.

I mean, it's probably the same thing that everyone always tells the government. Just have a long-term framework in which we can make our investment decisions in that lasts a long period of time and have a lot of transparency around when those are going to change and timeframes over which they're going to change. ${ }^{204}$

\footnotetext{
201 Interview 3.1, Fund Manager, $13^{\text {th }}$ November 2014.

202 Interview 3.2, Fund Manager, $15^{\text {th }}$ October 2014.

203 Interview 3.5, Investor, $22^{\text {nd }}$ April 2015.

204 Interview 3.7, Investor (Investment Manager), $27^{\text {th }}$ July 2015.
} 
Okay apart from the obvious thing that there is the support of the policies and maybe as they did for renewables to contribute a little bit with subsidies just to kick-start the market. I think the most important thing is that we see the stability. ${ }^{205}$

We think the policy framework is a critical component that assists decision taking. But we would distinguish between the direction of policy towards a lower hydrocarbon economy, which we consider, now, to be an irreversible commitment, and the actual detail of policy, which we think is unclear, uncertain, and therefore, not to be relied upon.

From our point of view, energy efficiency, because it is based on hard economics, is far more likely to be reliable than some of the new technologies and processes designed to shift us towards a low carbon future. ${ }^{206}$

205 Interview 3.9 \& 4.5, Investor, $23^{\text {rd }}$ November 2015.

206 Interview 4.4, Investor (Investment Fund), $22^{\text {nd }}$ January 2016. 


\section{Findings and Conclusions}

As an output of the research each of the research questions needs to be addressed in the context of the research findings, provided again below.

What are the barriers to attracting capital investment at scale for energy efficiency in the context of institutional and pension fund investment?

1. How do institutional investors decide whether to invest in energy efficiency?

2. Why, when environmental social and economic benefits are apparent, have institutional investors not invested in energy efficiency at scale?

3. What are the enabling conditions that would facilitate institutional investors investing in energy efficiency at scale?

Additionally, the research should be able to inform a refined conceptual model of the investment decision making process based on the data analysis so that it can be better understood an acted upon. Figure 22 is the conceptual model of the energy efficiency investment decision process developed from Clark's general model of the investment decision process, as provided out earlier as Figure 21. 


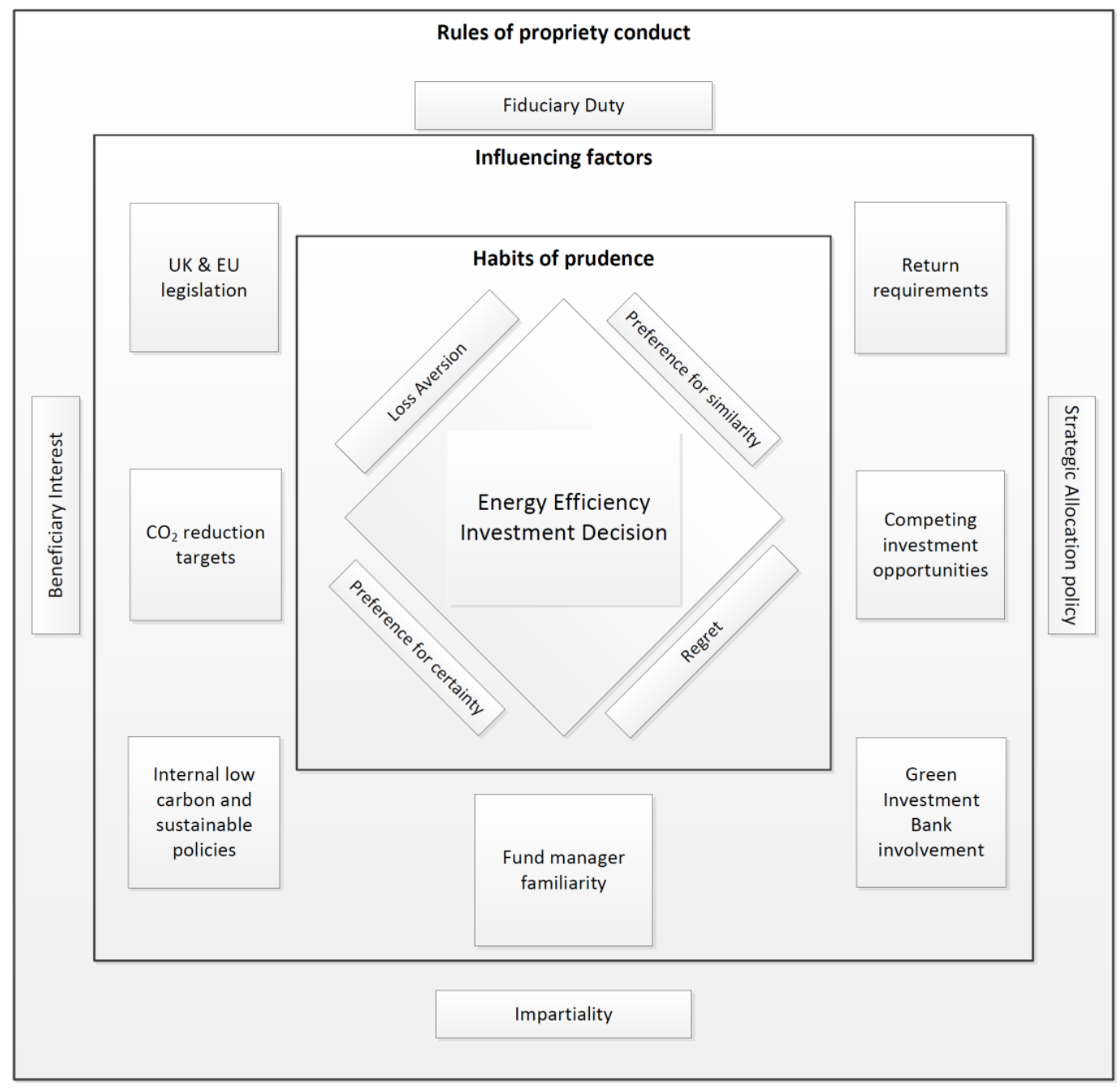

Figure 22: Energy Efficiency Investment Decision process

After commencing the interviewing process in October 2014, the early findings of the research, based on the first six of the semi structured interviews, four being with fund managers and two with institutional investors in one of the funds in the study were published (Parker and Guthrie, 2016). Of the two institutional investor interviews, one was with an advisory firm that invests funds on behalf of its client on a discretionary basis. The output was assessed prior to the full coding system was developed ,however some emerging trends were apparent.

How energy efficiency projects are classified in investment terms was seen as being important. Ambiguity over whether they should be classified as infrastructure, renewable energy or some other type of investment in a conservative world of prescribed investment asset classes caused at least one investor to decline an investment in the sector and this emerged in the early 
findings. In 'an ideal world' energy efficiency would be viewed as an individual asset class on its own account. This is important as the 'Alternatives' classification is viewed increasingly as a lower risk for the reward gained and higher percentages of funds are allocated to it

Contractual structure of the individual transactions was also seen as an important issue emerging from the research at that stage as it provides a level of familiarity to investors. The issue of fund manager familiarity was also a very strong theme and at that stage it was considered that it may restrict the expansion of the sector. Until the investors understand the underlying transactions better themselves, based on them having a greater number successful investments, they won't be able to place less reliance on familiarity of fund managers and widen out the number of fund managers able to operate in the sector. Within the first six interviewees it appeared that although the Green Investment Bank presence was generally a positive incentive for investment by institutional investors, it was by no means universally the case and at that stage it was deemed interesting to see whether this theme was continued in the wider study.

Figure 23 is an amendment to the original conceptual model of the energy efficiency investment decision process provided in Figure 22 and was formulated after the first six interviews were analysed. The three main emerging themes have been given prominence, the influence of the fund manager which was an originally assumed construct and the two new emerging constructs of investment asset class and transaction structure. The other original influencing factors remained in the model as it was too early to discount them, however some of them were deemed likely to be seen as less important or disappear altogether once the full research analysis had been concluded. 


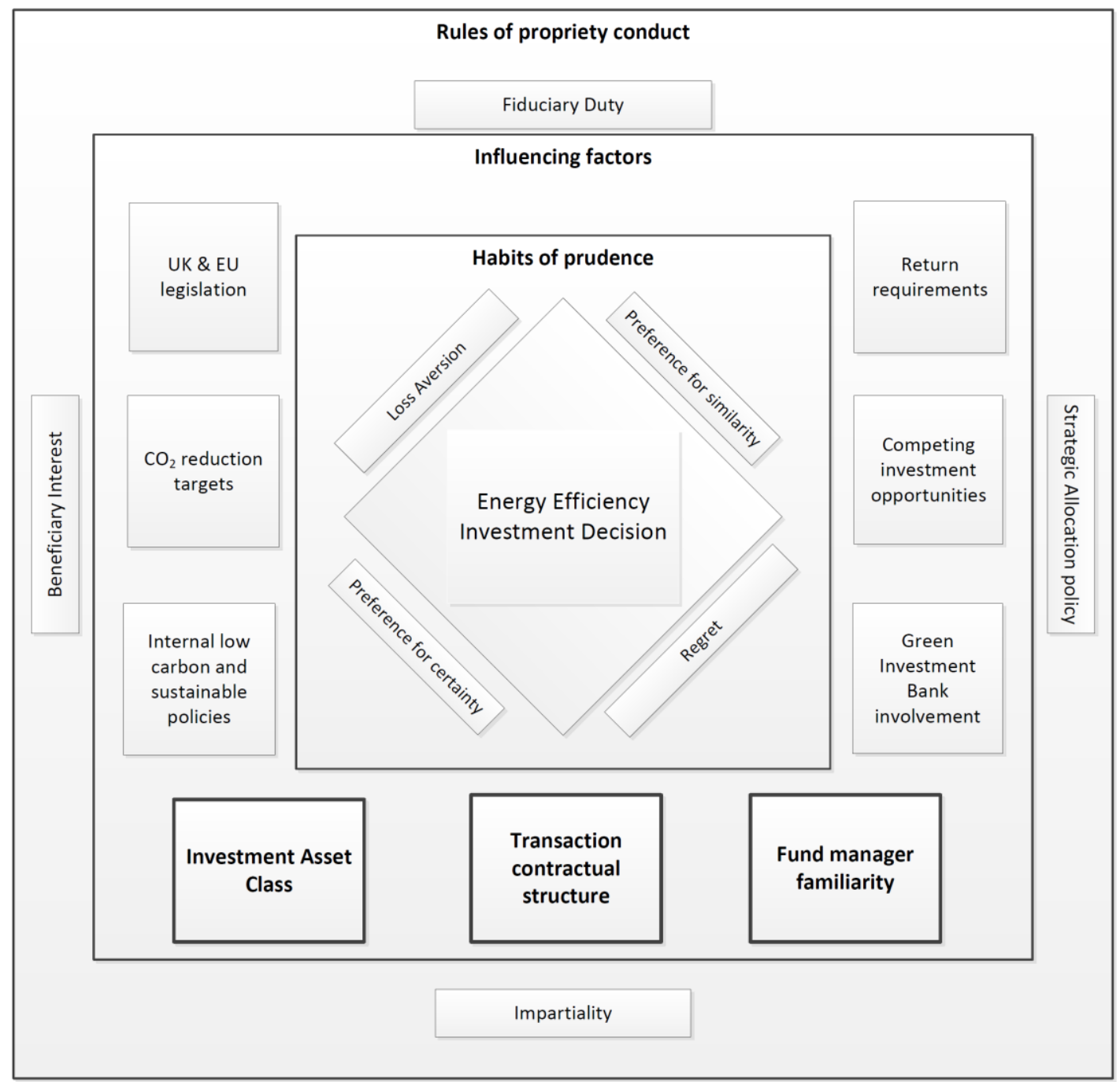

Figure 23: Energy Efficiency Investment Decision process - early findings

\subsection{Research findings}

The research has been focused on five topics into which specific questions have been asked and the data has been analysed. Conclusions can be drawn from the outcomes of the data analysis undertaken for each topic. 


\subsubsection{Asset allocation and return requirements}

This section investigated asset allocation and return requirements of investors in the energy efficiency funds under investigation. Energy efficiency investments are not correlated with investors' core investments in equities and bonds, which matches their enhancement strategy of investing in non-correlated investments that can enhance the return of the portfolio. However, little is known about the performance of energy efficiency investments, which hinders the analysis of the investment class by investors and their investment managers when or if they were to consider an energy efficiency investment within their asset allocation strategy, which vary in sophistication. A degree of performance information would be required with even the most basic allocation strategy. Investors to date appear to have been relying on their investment managers or fund managers to educate and advise them on the risks associated with such an investment.

Ideally, for energy efficiency investments to thrive they would ideally need to become an asset class of their own within the 'Alternatives' asset classification. Investors and their advisers would be familiar with the underlying technology and potential investments are contractually packaged in a consistent manner preferably in a standard contractual framework with standard approaches, with a ready secondary market. If they continue to match investors' inflationlinking requirement to match their obligations then the market for energy efficiency project would be sustained and the sectors potential for $\mathrm{CO}_{2}$ emission reduction may have a chance of being realised.

However, this situation is a long way from being a reality. Although investors are confused about the nature of energy efficiency projects, the prevailing asset classification appears to be as a sub class of infrastructure, although some investors mis-classify them as renewable energy and some in the study as private equity due to the similarity of one of the funds in question to private equity funds. This leads to investors requiring private equity level returns whereas the risk return approach to assessing these investments should over time result in a lower return being required when more information is known about the technology and investment performance, once a history of performance is established. 
The diverse nature of the underlying investment would appear to be hindering the development of a homogeneous asset class. One of the investment managers was very clear that he valued the contractual structuring of the investments within the fund as having a 'project finance wrap'. This was very familiar to him with all the contractual protections that he was used to, with cash flows for performing assets being made in a familiar way, though a 'Special Purpose Vehicle' structure when investing in infrastructure. This represented a very disciplined way of structuring a transaction. One of the other funds takes a similar approach when financing an ESCO through Energy Performance Contracting.

The return from energy efficiency projects is more than adequate to satisfy investors, however it would appear that the risks remain an issue when assessing investments on a risk return basis. A number of risks remain that need to be addressed, such as lack of understanding of the underlying technology, the reliance on non-governmental cash flows and speed of deployment or perceived speed of deployment which may be an issue for new entrants that do not have a history of investing in infrastructure.

If we can conclude that 'Alternatives' are becoming a 'safer' investment in risk terms or at least more investors are seeking to invest in 'Alternatives', a higher allocation of funds will be made available and this trend can only increase for energy efficiency investments once there is a track record and the expected returns have been realised over a period of time.

\subsubsection{Low carbon investments}

The research demonstrates that, in general investors have formulated and implemented low carbon or (SRI) strategies, with one or two exceptions, and that is likely to be reflected in the wider investor population as a whole. However, there has been no acceptance of SRI strategies as the primary driver in the decision-making process when considering alternative investments. The maximisation of financial return will always be the primary consideration. There was no significant evidence of the wider social and environmental benefits to the pension holders and other ultimate beneficiaries of the investments being considered equally alongside financial value maximisation, as they can provide positive investment impacts other than the purely financial. There has, however, been a growing view among the investment and academic 
community that ESG issues should be considered in the investment decision-making process in this way.

Where energy efficiency investments can gain some advantage is where they are one of a number of competing investment opportunities in a similar asset class, be it infrastructure, renewable energy or private equity. Investors would tend to stick with what is familiar. When faced with choosing between, say, two infrastructure investments with the same returns and risk/reward characteristics, one being with the same fund manager they have previously invested with in a familiar sector and the other being in energy efficiency, then the investment in energy efficiency may be chosen due to its carbon reduction potential.

It appears that some fund managers are increasingly being asked to demonstrate the full spectrum of (ESG) aspects to their investments, indicating that these issues are increasingly finding their way into the policies of pension funds of large corporates and public entities. Energy efficiency investments can be presented in a favourable way in this respect.

\subsubsection{Decision to invest/not to invest}

There are many factors that influence the decision by investors to invest in a particular asset or investment type. This category of inquiry investigates specific issues that led investors to commit to investing in the GIB energy efficiency funds. By far the most commonly quoted issue that influenced investors was the experience and familiarity of the fund manager. This issue is in fact an individual category of inquiry being pursued in the research, however it is worth stating that this appears to be a major influencing factor in the decision to invest.

Interestingly, the involvement of the GIB was not universally seen as an influencing factor in the decision to invest in the funds. Again, the fund management team members felt that the GIB did attract investors into the funds but it was the investors and those representing investors that were not so reliant on their involvement. It was seen as important for some investors as they viewed the GIB as UK sovereign involvement and they were able to demonstrate 'proof of concept'. This will be less of an influence going forward with the recent sale of the GIB by the UK government. Additionally, it appears that some investors were able to discuss their 
potential investment with the GIB and gain additional comfort from that process. However, there was also a strong opinion that the GIB involvement did not necessarily influence investment decision making but it was the other factors involving the fund manager's team, the risk/reward assessment of the investment and the contractual structure of the transactions that were far more important.

The issue of contractual structure of the transactions was raised by a number of participants. Where a fund manager has traditionally operated in the infrastructure world they are used to contractually structuring transactions in a prescribed manner. This gives investors comfort as they can understand very well the cash flow of the projects and risk associated with achieving their financial returns. These fund managers had tended to contractually package their energy efficiency projects in the same way, enabling investors to gain some comfort from this, and in one particular case the interviewee said that they were more comfortable as they could use the same lawyer that they use on infrastructure transactions to undertake the legal due diligence. Structuring transactions in this way is more straightforward on the ESCO EPC model, as these lend themselves to the infrastructure type contractual structure with setting up of a Special Purpose Vehicle company; however, those fund managers who have concentrated on the biomass type of deals have also actively created a familiar contractual arrangement in their deals which has appealed to investors.

The level of financial return made was certainly a factor that attracted investors and it was the government incentives that drove the higher level of returns that could be made. Investors will view investments in terms of perceived risk and potential return. As a new sector, investment in energy efficiency will most certainly represent a risk, but for the reasons outlined previously, investing in a fund run by an experienced or familiar fund manager reduces or manages that risk, certainly until the investors become more familiar with the sector themselves. Matched with this the potential returns are considered high and in particular when the investments utilise certain technologies, biomass for example, that attract government subsidies such as the Renewable Heat Incentive and Renewable Obligation Certificates (ROCs) that provide a significant proportion of a project's revenues in a secure way, making the risk reward profile more attractive. ROCs are being replaced by an alternative government incentive scheme 'Contracts for Difference' (CfDs) and it is yet to be seen whether this will prove as attractive to the sector. However, there is also the possibility of taking advantage of Yield Compression for the adventurous investor as it is new and untested. 
The investment appeared so attractive to at least one investor divested from mainstream equities to invest in one of the energy efficiency funds in what they viewed as a relatively low risk due to the profile of the fund manager and a part ring fenced revenue stream by virtue of the government subsidies securing index linked cash flows. This need for stable index linked cash flows was shared by other participants in the research. When asked if they would invest again in future funds that didn't necessarily have a GIB involvement, all the responses were positive. It was the fundamentals of the fund and the risk/reward assessment of the investment that was important although one fund manager thought the absence of the GIB in future funds may in itself lead investors to question why this would be the case in their investment appraisal process. There were concerns by some investors over feedstock supply and the small scale of transactions.

\subsubsection{Fund Manager}

Issues relating to the fund manager as a factor of the investment decision making process form a separate category of inquiry within the research and it seems that there is some justification for this which is reflected in the findings of the research.

The investment strategy being offered by the fund manager is key, as it needs to be able to match the investor's own investment aspirations and links clearly into another major area of concern, whether the correct level of risk is being taken for the amount of return being realised. There has been a concern expressed that some fund managers are too diversified and need to be more focused in their approach to energy efficiency investments. This may be difficult if there are few market opportunities and fund managers are looking to raise significant funds from institutional investors. They may feel that they would have difficulty investing the funds promptly if it was focused on energy efficiency and may struggle to find experienced personnel, however it is clearly an important issue as one investor did suggest that they would give more weight to the strategy than direct experience in the sector.

Leading on from the previous comment, fund managers need to be able to demonstrate that they have sufficient knowledge of the market and a credible pipeline which is difficult to 
achieve. The fund managers felt that they were able to do this to some extent by exploiting the existing investors in their established mainstream infrastructure funds. However, a fund manager must be able to demonstrate a credible pipeline as it is essential for attracting investment.

Track record of the fund managers' team is also an important assessment criterion for investors. If this is being considered solely in energy efficiency terms then it is difficult to achieve for the reasons previously stated, however it appears to be approached more along the lines of fund managers having met investment returns and of having deployed capital successfully in related fields such as infrastructure and property. The fund managers certainly believe that they are able to demonstrate that they can transfer that background into the energy efficiency sector. One investor identified the sector currently as very inflexible and therefore choosing a fund manager is important for the very reason that investors will not be able to exit investments very easily or not at all as there is no liquid market to do so. There are no ready investors to sell to, therefore investors will most likely be stuck with the initial fund manager. The decision on the fund manager is therefore a crucial one.

Familiarity with the fund manager and investor's existing relationships with them was seen as important. Investors' knowledge of the team members and their background helped enormously. The fund manager had therefore previously demonstrated its professionalism, depth of resource, robustness of its processes and its management of risk. Above all the fund manager would have already convinced investors of its level of integrity and a level of trust existed between them and the investor. With the GIB energy efficiency funds being very early funds in a new asset class or sector, trust between fund manager and investor is crucial.

Finally, generally most investors were positive when asked whether they would invest in further energy efficiency funds runs by unfamiliar fund managers who were inexperienced in energy efficiency investments, assuming of course that they had a positive experience and made or bettered the returns expected. This would ultimately assist in encouraging more fund managers into the sector and more institutional investors to make an investment.

Some respondents did provide some more interesting answers with one investor at first suggesting that he would absolutely invest in further funds run by other fund managers as long as the strategy works, as this provides diversification benefits, which is good practice for 
investors to achieve. However, he then went on to state that by doing so it would encourage more funds into the market which would, in turn, lower the returns. He was focused on maximising returns but of course if the market expands then he would have more opportunities to invest in.

One of the fund managers made the point that large investors need not only to report internally on the performance of investments made, but also on the overall performance of the fund manager. His view was that as the fund manager is managing other infrastructure funds that investors may also have invested in, they as a fund manager of an energy efficiency fund become more attractive to its existing investor base, as those investors would not have to report internally on an additional fund manager. They would have to do this should they have invested in an alternative energy efficiency fund run by a different fund manager with whom they do not already have funds invested. This may be an understandable viewpoint from a particular fund manager with a number of funds under management that likes to feel its investors would trust them with alternative investment types, but in the research this has not been echoed by any of the investors or those representing investors.

\subsubsection{UK government and EU polices}

It is important to gauge investors' attitudes to government policy as in the main they require a clear, stable and consistent regulatory environment. The application of the Renewable Heat Incentive and Renewable Obligation Certificates had gone some way towards satisfying this requirement, allowing some degree of security of revenues on qualifying transactions. This has been borne out by the responses given on this issue. The incentives and subsidies on offer only apply to certain technologies and leaves a whole swathe of potential energy efficiency transactions in the building retrofit area without any government support. This has surprised some of the research participants, given the governments commitments to reduce $\mathrm{CO}_{2}$ emissions. Comments such as 'there appears to be more sticks than carrots' were used by more than one participant. Government policies and commitments have influenced the investors' decision processes, however the government's decision to change the incentive regime by discontinuing ROCs is running the risk of destabilising the policy landscape and in turn discouraging further investment. 
It wasn't exclusively the case that all of the early participants agreed that government commitments, policies and incentives had an effect on their investment decision making processes, as some investors discounted this as a factor and asserted that all their decisions were driven by the level of returns.

\subsection{Conclusions and development of the conceptual model}

The research has focused on non-domestic energy efficiency in the context of energy efficiency funds and how to increase institutional investment at scale, therefore the revised conceptual model reflects both the investment landscape and the fact that the investment decision concerns investment into a fund and not as a direct investment.

The conceptual model of the energy efficiency decision making process required further refinement from its position after the first six interviews were carried out and at the time the research concluded. Further insights have been gleaned into the issues in order to develop and refine it. It is apparent that return and risk play an extremely important part in an investor's decision making process generally and that of course applies to investments in energy efficiency as it does to any investment. Therefore, within the revised conceptual model, return requirements remain an influencing factor but not highlighted as being specially related to an investment in energy efficiency.

Standardisation has been added to the model again as an influencing factor but not highlighted. This is important for a number of reasons. Firstly, if the underlying processes, protocols and contracts are standardised then it would facilitate a more distinctive investment and allow energy efficiency to develop as a definite sub asset class of infrastructure, or ideally as an individual asset class in its own right. Ambiguity over whether energy efficiency transactions are infrastructure, renewable energy or some other type of investment in a conservative world of prescribed investment asset classes has caused at least one investor to decline an investment in the sector. Secondly, contractual structure is clearly an important issue for investors and standardisation of approach will allow transaction contractual structures attractive to investors to be applied more readily. Finally, once a fully standardised approach is established, it will 
facilitate a transition from institutional investment in an energy efficiency fund to direct investment, as it will increase familiarity with the asset and increase the number of financeable transactions.

ESG considerations are coming into play in the value placed on them by trustees and individual pension holders. There is a debate going on among academics and practioners as to whether they should be a fiduciary issue alongside maximisation of return and in some instances take precedence over return. However, the research has not supported this view since those interviewed must comply with current expectations, although ESG issues are a consideration, but only in as much as they don't compromise return. For this reason, ESG consideration does not feature in the revised conceptual model as an influencing factor in its own right but the existing influencing factor 'Internal low carbon and sustainable policies' is amended to 'Internal low carbon, sustainable policies and ESG considerations'. The investment strategy of the fund managers and funds they manage has also emerged as a key issue in the decision to invest. Perhaps this is an obvious outcome, however the degree to which the fund is focused on energy efficiency as opposed to other forms of green investment is key to instil sufficient confidence that the fund managers have the expertise and knowledge required to be successful in the sector.

The contractual structure of the individual transactions is also an important issue that was clear from the early findings and from the wider research, as this provides a level of familiarity to investors, as does the very strong reliance on experienced and familiar fund managers. This issue of fund manager familiarity may restrict the expansion of the sector in the short term until investors themselves understand the underlying transactions better, based on them having a greater number of successful investments (via funds) and the continuing standardisation of the underlying transactions. This will place less reliance on familiarity of fund managers and widen out the number of fund managers able to operate in the sector and will ultimately allow direct investment to be made confidently as previously discussed. Transaction contractual structure and fund manager familiarity remain as significant influencing factors and are highlighted in the revised conceptual model.

Although the GIB presence is generally a positive incentive for investment by institutional investors, it is by no means universally the case, however with the GIB now in private ownership it is the UK government involvement, rather than the GIB, that is an influencing 
factor. The GIB influencing factor in the refined conceptual model has been amended accordingly. UK \& EU legislation, $\mathrm{CO}_{2}$ reduction targets and competing investment opportunities remain important factors.

Finally, the preferences for certainty and similarity have come through strongly, related to both the investments to be made and in respect of the fund manager. These two habits of prudence have therefore increased their prominence in the revised conceptual model.

The revised and refined conceptual model of the energy efficiency investment decision process is provided in Figure 24.

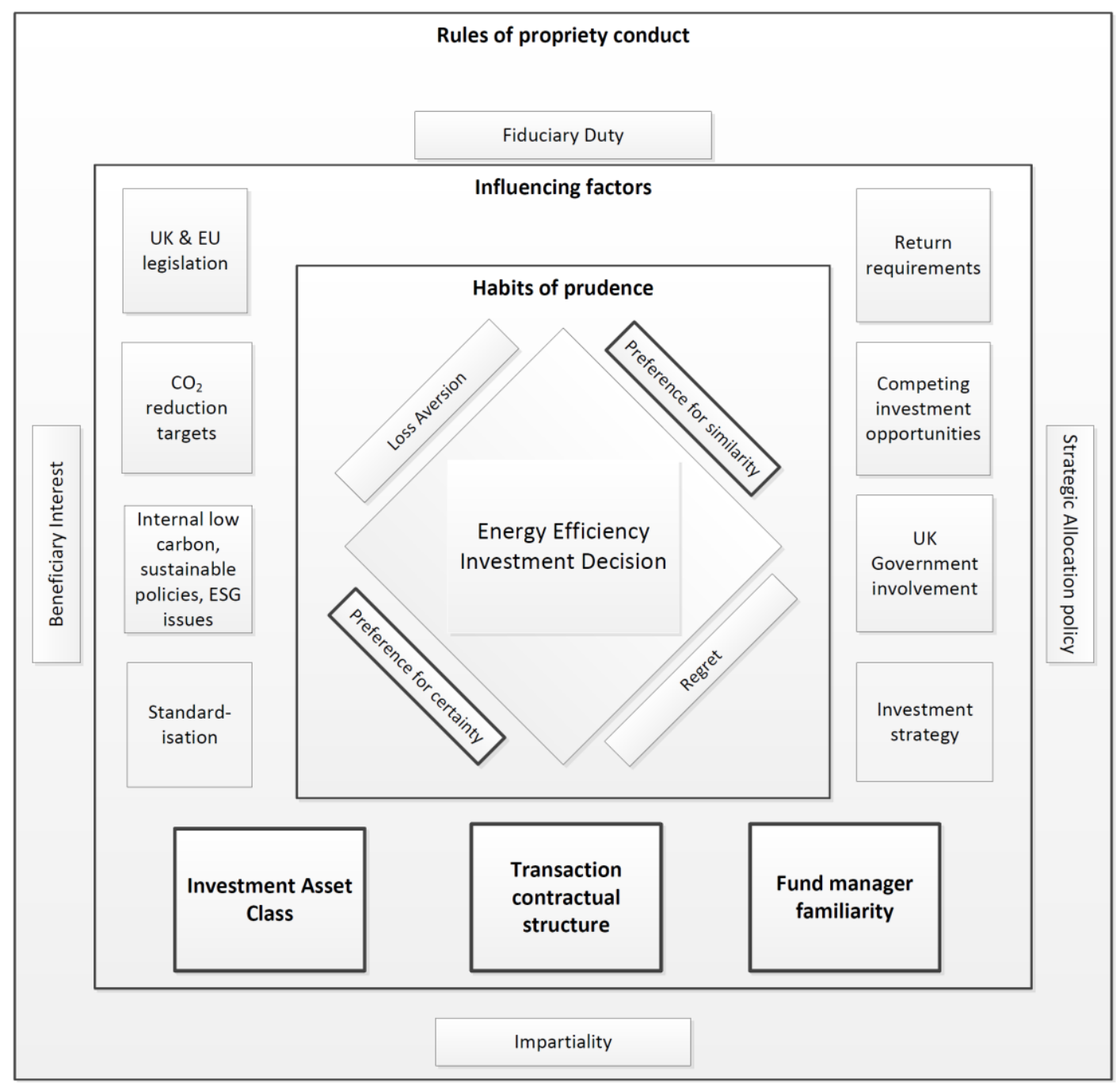

Figure 24: Energy Efficiency Investment Decision process - revised conceptual model 


\subsubsection{Review of the code frequency}

Of the 70 codes identified in the research and the 1,465 code assignments, Table 8 indicates the top 16 codes in terms of the frequency that they were assigned in the transcripts. This quasistatistical view in general supports the conclusions made in the research. The highest frequency is the level of return which would be expected and would be applicable to any investment decision. Asset classification has come through significantly as an issue concerning investors and their decision to invest, as has the fund manager in a number of different coding classifications. Code 0408 deals with fund or investment strategy of the fund manager, 0401 with the fund manager track record, 04 familiarity with the fund manager and 0402 its technical capability. Code 0901 Reliance is associated with trust in the fund manager. Although code 0505 Contractual structure is not near the top of the 'top sixteen' it is still highly referenced in the transcripts and as this research is qualitative in nature the researcher has highlighted this issue in the revised conceptual model as being seen as sufficiently important by the interview participants that commented on this issue to warrant it.

\begin{tabular}{|l|c|}
\hline \multicolumn{1}{|c|}{ Code or sub code } & Frequency \\
\hline 0103 Level of return & 79 \\
0502 Asset classification (eg infra, renewables, private equity) & 59 \\
0408 Fund Strategy / Fund Manager size & 51 \\
0401 Track record in infra, Renewable energy and EE & 41 \\
0101 Risk/reward - Fiduciary Duty & 38 \\
0203 Governement incentives & 38 \\
0701 Positive allowance for low carbon investments & 29 \\
04 Familiarity with (and capability of) the fund manager & 28 \\
0402 Technical capability of team & 28 \\
0201 Stable regulatory environment & 27 \\
0902 Preference for certainty & 27 \\
0903 Preference for similarity & 27 \\
0504 Risk/return approach (safer investment, higher allocation) & 25 \\
0505 Contractural structure & 23 \\
0508 EE investment models eg ESCO, Biomass etc & 23 \\
0901 Reliance & 23 \\
\hline
\end{tabular}

Table 8: The top sixteen codes in terms frequency of allocation 


\subsection{Response to research questions}

\section{What are the barriers to attracting capital investment at scale for energy efficiency in the context of institutional and pension fund investment?}

\section{How do institutional investors decide whether to invest in energy efficiency?}

The research reveals that, as in any type of investment, the level of return for a given level of risk is a key consideration for investors. They will weigh up the risks and as energy efficiency investments are a relatively new investment opportunity then the level of risk is not yet well known. The research investigates investment into a fund that is managed by a fund manager rather than direct investment, as institutional investors would neither have the level of understanding or the level of personnel required to acquire the necessary expertise or the will to acquire it for such an asset class.

For investors to invest in energy efficiency it will need to be either part of a defined asset class, such as infrastructure, or an individual asset class in its own right. The current position has led at least one investor to decline investing as it did not know how to classify it for its expected return requirements, etc. Currently investments made at scale have been through a fund manager and this is the focus of this research. Familiarity, experience and competence of the fund manager are key in this respect, together with the fund investment strategy. In time, as standard processes and protocols are introduced into the sector, a more distinct asset class can be demonstrated, with known levels of risk and greater volume of transactions. When this is achieved, direct investment could be made into individual deals or portfolios of deals, and investment at scale could be achieved through securitisation.

\section{Why, when environmental social and economic benefits are apparent, have} institutional investors not invested in energy efficiency at scale?

For investment to be made at scale, institutional investors need to be making significant investment. The research has demonstrated that this has not occurred to date as the transactions available have been small in nature with no standard approach to how they are structured. 
Investors do not have the in-house capability and experience in the sector to adequately assess the risks involved. There also has to be a sufficient number of viable projects to invest in. This is why the GIB took the decision to create and invest in a number of funds to 'kick start' institutional investment and ultimately develop a standardised investment asset class. Although there is a debate taking place, ESG consideration is not yet a key factor in driving investment decisions, except for certain niches investors.

\section{What are the enabling conditions that would facilitate institutional investors investing in energy efficiency at scale?}

From assessing the issues that have been discussed within this research dissertation a number of enabling conditions that would facilitate institutional investment in energy efficiency at scale have become apparent.

- Development of an asset class or distinct sub asset class so that investors can understand where energy efficiency transactions sit within their portfolio.

- In order to facilitate the development of the asset class, further standardisation of processes and protocols underlying the transactions should be encouraged building on the work of the Investor Confidence Project.

- Standardisation will also breed familiarity among investors and this would encourage wider participation by other fund managers and direct investment into the sector.

- Standardisation of processes could be extended to the standardisation of contractual transaction structures, which has come through as an important issue for investors and would facilitate an expansion of the sector.

- Encourage initiatives, such as DEEP, that provide energy efficiency transaction performance data to prospective investors which will further facilitate the securitisation of energy efficiency loans, ie the packaging of loans into a larger bond issuance for investment by institutional investors. 
- In order for wider participation by fund managers and direct investment by institutional investors, there needs to be a greater number of larger and financeable projects or packaged projects. The underlying standardisation of processes will also encourage this development.

- While the GIB involvement has encouraged institutional investment into their initial funds, it was not universally seen as a reason for investment but undoubtedly it was a positive factor. As the GIB has now been sold to a bank in the private sector, the UK government do not have a vehicle to expand their involvement. However, continued involvement of the UK government would facilitate the continued expansion of the sector. Perhaps a UK government loan / investment guarantee scheme would provide sufficient support.

- Government incentives for the investment in building retrofit schemes should be introduced to indicate further government support for energy efficiency investment as has been the case for renewable energy.

- Encouragement of investment regimes that incentivise investors to commit to the sector such as the use of Efficiency Services Agreement allowing for off balance sheet treatment for the client, the provision of index-linked returns to match investors' obligations and some form of government support.

The research outcome is just the beginning. Rather than the energy efficiency chasm having been crossed, the bridge is starting to be built. 


\section{References}

Affordable Warmth Scheme. (2017). Green Deal 2017 Relaunch [Online]. Affordable Warmth Scheme. Available: http://www.affordablewarmthscheme.co.uk/green-deal-2017/ [Accessed 15th May 2018].

Allcott, H. \& Greenstone, M. (2012). Is There an Energy Efficiency Gap? Berkeley: Energy Institute at Haas.

Altheide, D. \& Johnson, J. (1994). Criteria for assessing interpretive validity in qualitative research. In: DENZIN, N. \& LINCOLN, Y. (eds.) Handbook of qualitative research. Newbury Park, CA: Sage.

Arrow, K. (1969). The Organization of Economic Activity: Issues Pertinent to the Choice of Market versus Non-market Allocation. The Analysis and Evaluation of Public Expenditure: The PPB System: vol 1, U.S. Joint Economic Committee, 91st Congress, 1st Session, Washington, DC: U.S. Government Printing Office, 59-73.

Aviva. (2012) Infrastructure Transaction Investment Committee / Delegated Authority Proposal - Cambridge University Hospitals NHS Foundation Trust. London. Aviva Investors Real Estate, 7th November.

Aviva. (2014) Infrastructure Transaction Investment Committee / Delegated Authority Proposal - Gloucestershire Hospitals NHS Foundation Trust. London. Aviva Investors Real Estate, 22nd February.

Baddeley, M. (2013). Behavioural Economics and Finance Abingdon, Routledge.

Baddeley, M. (2017). Behavioural Economics: A Very Short Introduction Oxford, Oxford University Press.

Bardalai, A. (2018) UK Fund Management, April 2018 London TheCityUK.

Barnes, J. H. (1984). Cognitive biases and their impact on strategic planning. Strategic Management Journal, 5 (2), 129-137.

BEIS. (2016) The Renewable Heat Incentive: a reformed scheme London Department of Business, Energy \& Industrial Strategy.

BEIS. (2017). Policy paper: Contracts for Difference [Online]. London: Department of Business, Energy and Industrial Strategy. Available:

https://www.gov.uk/government/publications/contracts-for-difference/contract-for-difference [Accessed 15th May 2018].

Bekkers, N., Doeswijk, R. Q. \& Lam, T. W. (2009). Strategic Asset Allocation: Determining the Optimal Portfolio with Ten Asset Classes. SSRN eLibrary.

Bertoldi, P., Boza-Kiss, B. \& Rezessy, S. (2007) Latest Development of Energy Service Companies across Europe - A European ESCO Update- European Commission, Directorate General Joint Research Centre. EUR 22927 EN. 
Bertoldi, P. \& Rezessy, S. (2005) Energy Service Companies in Europe: Status Report 2005 European Commission, Directorate General Joint Research Centre EUR 21646 EN.

Better Buildings. (2014) Implementation Model: Citi Riverdale Data Center Energy Services Agreement (ESA). Washington. US Department of Energy.

Bikhchandani, S., Hirshleifer, D. \& Welch, I. (1992). A Theory of Fads, Fashion, Custom, and Cultural Change as Informational Cascades. Journal of Political Economy, 100 (5), 9921026.

Bikhchandani, S. \& Sharma, S. (2001). Herd Behavior in Financial Markets. IMF Study Papers, 47 (3), 279-310.

BIS. (2012) Managed Account/s for Investments in Non Domestic Energy Efficiency Infrastructure in the UK: Call for Expressions of Interest from Fund Managers London UK Green Investments, Department of Business, Innovation and Skills.

BNP Paribas. (2016). Sustainability: the new driver for institutional investors, 20 Jul 2016 [Online]. Available: https://cib.bnpparibas.com/sustain/sustainability-the-new-driver-forinstitutional-investors_a-3-97.html [Accessed 17th March 2017].

BNP Paribas. (2017). ESG, a factor in sustainable investment, 2nd Feb 2017 [Online]. Available: https://cib.bnpparibas.com/sustain/esg-the-sustainability-indicator-that-seesthrough-the-window-dressing_a-3-138.html [Accessed 17th March 2017].

Boyatzis, R. E. (1998). Transforming Qualitative Information London Sage.

Braun, V. \& Clarke, V. (2006). Using thematic analysis in psychology. Qualitative Research in Psychology, 3 (2), 77-101.

Braun, V. \& Clarke, V. (2013). Successful Qualitative Research London, Sage.

Caleb Management Services. (2009) The UK's approach to the thermal refurbishment of non-domestic buildings: A missed opportunity for bigger carbon emission reductions?

Carrington, J. (2011). Unlocking pension cash to fund energy efficiency improvements. In: ECEEE 2011 Summer Study, Energy Efficiency First: The Foundation of a Low-Carbon Society, 6-11 June 2011 Toulon, France. Stockholm: ECEEE, pp.195-203.

CBI. (2018). Market development: Aggregation, securitization, covered bonds [Online]. Climate Bond Initiative. Available: https://www.climatebonds.net/policy/policyareas/market-development [Accessed 14th May 2018].

CCC. (2008) Building a low-carbon economy - the UK's contribution to tackling climate change, 1st report London TSO Committee on Climate Change

CCC. (2013) Meeting Carbon Budgets - 2013 Progress Report to Parliament London Committee on Climate Change.

CCC. (2014) Meeting Carbon Budgets - 2014 Progress Report to Parliament London Committee on Climate Change. 
CCC. (2016) Meeting Carbon Budgets - 2016 Progress Report to Parliament London Committee on Climate Change.

Chan, L. K. C. \& Lakonishok, J. (2004). Value and Growth Investing: Review and Update. Financial Analysts Journal, 60 (1), 71-86.

CHL. (2015) Energy Performance Contracting, transforming service and improving resilience. CHL March 2015 board presentation. London. [Presentation] Capital Hospitals Limited.

Clark, G. L. (1998). Why convention dominates pension fund trustee investment decisionmaking. Environment and Planning A, 30 997-1015.

Clinton Foundation. (2009) Measurement and Verification and the IPMVP: EPC toolkit for Higher Education New York CCI.

Crabtree, B. E. \& Miller, W. L. (1999). Doing Qualitative Research London, Sage.

Creswell, J. W. (2009). Research Design: Qualitative, Quantitative, and Mixed Methods Approaches (3rd ed). Thousand Oaks, CA, Sage.

Department for Environment Food and Rural Affairs. (2006) Demonstrable Progress: The United Kingdom's Report on Demonstrable Progress under the Kyoto Protocol London DEFRA.

Department for Trade and Industry. (2001) Digest of United Kingdom Energy Statistics Government Statistical Services, London.

Department for Trade and Industry. (2003) Digest of United Kingdom Energy Statistics London Government Statistical Services.

Department of Energy and Climate Change. (2010). The UN and the Kyoto Protocol [Online]. London. Available:

http://www.decc.gov.uk/en/content/cmswhat_we_do/change_energy/tackling [Accessed 29th March 2010].

Dittrich, D. A., Guth, W. \& Maciejovsky, B. (2005). Overconfidence in Investment Decisions: An Experimental Approach. The European Journal of Finance, 11:6 471-491.

Easterby-Smith, M., Thorpe, R. \& Lowe, A. (2002). Management Research (2nd ed). London, Sage.

EBRD. (2015). Press Release 16th September 2015: 'Investing in energy efficiency makes econimic sense' [Online]. Available: http://www.unepfi.org/fileadmin/communications/20150916_IstanbulSEFFconference_pressr elease.pdf [Accessed 19th February 2015].

EEFIG. (2015) Energy Efficiency - the first fuel for the EU Economy: How to drive new finance for energy efficiency investments Brussels Energy Efficiency Financial Institutions Group. 
EEFIG. (2016). EEFIG Derisking Energy Efficiency Project (“DEEP”) November 2016 [Online]. Available:

http://eefig.eu/images/DEEP/DEEP_Comms_Slides_for_EU_Comm_FINAL.pdf [Accessed 25th November 2018].

EEFIG. (2017) EEFIG Underwriting Toolkit: value and risk appraisal for energy efficiency financing Brussels Energy Efficiency Financial Institutions Group.

Efficiency Valuation Organisation. (2009) International Performance Measurement and Verification Protocol (IPMVP) EVO.

Eisenhardt, E. (1989). Building Theories From Case Study Research. The Academy of Management Review, 14 (4), 532-550.

Energy for London. (2013). Tate Awarded first London Energy Efficiency Fund Investment [Online]. Energy for London. Available: http://www.energyforlondon.org/first-londonenergy-efficiency-fund-investment/ [Accessed 16th September 2018].

Fankhauser, P. (2012). EE for Institutional Investors - How to make Energy Efficiency Investments attractive to Institutional Investors. Energy Efficiency [Online], 4. Available: http://digital.ien.eu/digitalMagazine/printme/p1/8731/p2/undefined [Accessed 27th June 2012].

Fankhauser, P. (2014). Getting efficiency projects running through performance contracting. In: ECEEE 2014 Industrial Summer Study - Retool for a competitive and sustainable industry, Toulon, France. ECEEE, pp.745-751.

Fawkes, S. (2013a). Energy Efficiency: the definitive guide to the cheapest, cleanest, fastest source of energy Farnham, Gower Publishing.

Fawkes, S. (2013b). Emerging models for energy efficiency financing 2nd September [Online]. Available: http://www.onlyelevenpercent.com/emerging-models-for-energyefficiency-financing/ [Accessed 6th February 2018].

Fawkes, S. (2013c). ESCO Obsessions 25th June [Online]. Available: http://www.onlyelevenpercent.com/a-few-thoughts-on-esco/ [Accessed 6th February 2018].

Fawkes, S. (2013d). Energy performance contracts: Too good to be true? 1st July [Online]. Available: https://www.2degreesnetwork.com/groups/2degrees-community/resources/energyperformance-contracts-too-good-be-true/ [Accessed 6th February 2018].

Fawkes, S. (2014). The key to scaling up energy efficiency - new business models and structures [Online]. Available: https://www.onlyelevenpercent.com/the-key-to-scaling-upenergy-efficiency-new-business-models-and-structures/ [Accessed 14th May 2018].

Fawkes, S. (2015). What do we really mean by EPCs and ESCOs? [Online]. Available: https://www.onlyelevenpercent.com/what-do-we-really-mean-by-epcs-and-escos/ [Accessed 14th May 2018].

Fereday, J. \& Muir-Cochrane, E. (2006). Demonstrating Rigor Using Thematic Analysis: A Hybrid Approach of Inductive and Deductive Coding and Theme Development. International Journal of Qualitative Methods, 5 (1). 
Freshfields Bruckhaus Deringer. (2005) A Legal framework for the Integration of

Environmental, Social and Govenance Issues into Institutional Investment London UNEP FI.

Froot, K. A., Scharfstein, D. S. \& Stein, J. C. (1992). Herd on the Street: Informational Inefficiencies in a Market with Short-Term Speculation. The Journal of Finance. , 47 (4), 1461-1484.

GIB. (2013a) UK Green Investment Bank announces funding for small scale biomass boilers. London. Green Investment Bank, 17th May.

GIB. (2013b) Green Investment Bank announces funding for biomass boiler at whisky distillery. London. Green Investment Bank, 17th July.

GIB. (2013c) Tomatin Distillery reduces its carbon emissions by over 80\%. London. Green Investment Bank, 8th November.

GIB. (2013d) GIB provides funding of $£ 18 m$ for one of the UK's largest NHS energy centres. London. Green Investment Bank, 25th March.

GIB. (2013e) Case Study: Aviva Investors REaLM Energy Centres Fund, Cambridge University Hospitals NHS Foundation Trust Energy Centre $£ 50 \mathrm{~m}, \mathrm{c} £ 18 \mathrm{~m}$ first investment. London Green Investment Bank, 25th September.

GIB. (2014a) UK Green Investment Bank and Equitix announce energy efficiency deal with Bernard Matthews. London. Green Invesment Bank, 10th March.

GIB. (2014b) UK data centre to cut energy usage in first of a kind project. London. Green Investment Bank, 30th October.

GIB. (2014c) New energy efficiency deal for Lincolnshire poultry farms. London. Green Investment Bank, 25th November.

GIB. (2014d) SDCL announces landmark energy efficiency deal for St Bartholomew's Hospital in London. London. Green Investment Bank, 25th March.

GIB. (2014e) UK Green Investment Bank announces programme of support to finance NHS energy efficiency. London. Green Investment Bank, 3rd April.

GIB. (2015a) Multi-million pound investment sees construction on new green energy plant in Sheffield. London. Green Investment Bank, 17th July.

GIB. (2015b) Nottingham green energy facility secures £30m investment. London. Green Investment Bank, 25th September.

GIB. (2015c) UK's biggest ever LED financing package will cut Santander's energy use by half. London. Green Investment Bank, 8th December.

GIB. (2016a) GIB and Equitix commit £10m to expansion of Wick district heating scheme. London. Green Investment Bank, 2nd March.

GIB. (2016b) NCP saves $£ 34 m$ by doubling number of car parks using energy-saving LEDs. London. Green Investment Bank, 31st March. 
Goldstone, J. A. (1998). Initial Conditions, General Laws, Path Dependence, and Explanation in Historical Sociology. American Journal of Sociology, 104 (3), 829-845.

Golove, W. H. \& Eto, J. H. (1996) Market Barriers to Energy Efficiency: A Critical Reappraisal of the Rationale for Public Policies to Promote Energy Efficiency Berkeley Lawrence Berkeley National Laboratory, University of California, Berkeley. LBL-38059.

Gray, D. (2009). Doing Research in the Real World London, Sage.

Grubb, M. J. (1990). The cinderella options a study of modernized renewable energy technologies part 1-A technical assessment. Energy Policy, 18 (6), 525-542.

Guba, E. G. (1990). The alternative paradigm dialog. In: GUBA, E. G. (ed.) The paradigm dialog. Newbury Park, CA.

Guba, E. G. \& Lincoln, Y. S. (1994). Competing Paradigms in Qualitative Research. In: DENZIN, N. K. \& LINCOLN, Y. S. (eds.) Handbook of Qualitative Research. Thousand Oaks, Ca: Sage.

Habermas, J. (1970). Knowledge and interest. In: EMMETT, D. \& MACINTYRE, A. (eds.) Sociological Theory and Philosophical Analysis. London Macmillian.

Hansen, S. J. (2003) Investment Grade Audits [Presentation] INEE.

Hansen, S. J., Langlois, P. \& Bertoldi, P. (eds.) (2009). ESCO's Around the World: Lessons Learned in 49 Countries, Lilburn GA and Boca Raton FL: The Fairmont Press and CRC Press.

Hirst, E. \& Brown, M. (1990). Closing the efficiency gap: barriers to the efficient use of energy. Resources, Conservation and Recycling, 3 (4), 267-281.

HMRC. (2016). HMRC Internal Manual: Renewable Obligation Certificates (ROCs) [Online]. London: HM Revenue \& Customs. Available: https://www.gov.uk/hmrc-internalmanuals/vat-fuel-and-power/vfup4300 [Accessed 15th May 2018].

Hodgson, G. M. (1988). Economics and Institutions: A Manifesto for a Modern Institutional Economics Cambridge, Polity Press.

Howarth, R. B. \& Sanstad, A. H. (1995). Discount rates and energy efficiency. Contemporary Economic Policy, 13 101-9.

Huntington, H., Schipper, L. \& Sanstad, A. H. (1994). Editors' introduction. Energy Policy, 22 (10), 795-797.

ICP N.D. Investor Confidence Project, Europe [Online]. Available: http://europe.eeperformance.org/ [Accessed 18th October 2015].

IEA. (2011) 25 Energy Efficiency Policy Recommendations International Energy Agency.

IEA. (2017a) World Energy Report 2017 International Energy Agency.

IEA. (2017b) Energy Efficiency Indicators Highlights 2017 International Energy Agency. 
IEA. (2017c) Energy Efficiency 2017 International Energy Agency.

IEA. (2018) Energy Efficiency 2018: Analysis and Outlooks to 2040 International Energy Agency.

Inderst, G. (2009) Pension Fund Investment in Infrastructure OECD Publishing. No 32.

International Chamber of Commerce. (2014) Enabling frameworks to scale up investments in energy efficiency Paris ICC. 213/101.

IPCC. (2007) Climate Change 2007: Synthesis Report. Contribution of Working Groups I, II and III to the Fourth Assessment Report of the Intergovernmental Panel on Climate Change Geneva IPCC.

Jaffe, A. B., Newell, R. G. \& Stavins, R. N. (2004). Economics of Energy Efficiency. In: EDITOR-IN-CHIEF: CUTLER, J. C. (ed.) Encyclopedia of Energy. New York: Elsevier.

Jaffe, A. B. \& Stavins, R. N. (1994a). The energy-efficiency gap What does it mean? Energy Policy, 22 (10), 804-810.

Jaffe, A. B. \& Stavins, R. N. (1994b). The energy paradox and the diffusion of conservation technology. Resource and Energy Economics, 16 (2), 91-122.

Jahanzeb, A., Muneer, S. \& Rehman, S. (2012). Implication of Behavioral Finance in Investment Decision-making Process. Information Management and Business Review, 4 (10), 532-536.

Jansson, M., Sandberg, J., Biel, A. \& Gärling, T. (2014). Should pension funds' fiduciary duty be extended to include social, ethical and environmental concerns? A study of beneficiaries' preferences. Journal of Sustainable Finance \& Investment, 4 (3), 213-229.

Jordan, J. \& Kaas, K. P. (2002). Advertising in the mutual fund business: The role of judgmental heuristics in private investors' evaluation of risk and return. Journal of Financial Services Marketing, 7 129-140.

Kahneman, D. (2003). Maps of Bounded Rationality: Psychology for Behavioral Economics. The American Economic Review, 93 (5), 1449-1475.

Kahneman, D. \& Tversky, A. (1979). Prospect Theory: An Analysis of Decision under Risk. Econometrica, 47 (2), 263-291.

Kahneman, D. \& Tversky, A. (1982). The psychology of preferences. Scientific American, 246 (1), 160-173.

Kaminker, C. \& Stewart, F. (2012). The Role of Institutional Investors in Financing Clean Energy. OECD Working Papers on Finance, Insurance and Private Pensions. OECD Publishing.

Kates, R., Parris, T. \& Leiserowitz, A. (2008). Editorial - What Is Sustainable Development? Goals, Indicators, Values, and Practice [Online]. Evironment Magazine. Available: http://www.environmentmagazine.org/Editorials/Kates-apr05-full.html [Accessed 11th May 2018]. 
Katz, J. A. (1992). A psychosocial cognitive model of employment status choice. Entrepreneurship Theory and Practice, 17 (1), 29-37.

Krewitt, W., Simon, S., Graus, W., Teske, S., Zervos, A. \& Schäfer, O. (2007). The $2{ }^{\circ} \mathrm{C}$ scenario-A sustainable world energy perspective. Energy Policy, 35 (10), 4969-4980.

Laboul, A. (2013) G20/OECD High-level principles of long-term investment financing by institutional investors OECD Publishing.

Lakonishok, J., Shleifer, A. \& Vishny, R. W. (1994). Contrarian Investment, Extrapolation, and Risk. The Journal of Finance, 49 (5), 1541-1578.

Laurikka, H. (2008). A case study on risk and return implications of emissions trading in power generation investments. In: ANTES, R., HANSJÜRGENS, B. \& LETMATHE, P. (eds.) Emissions Trading: Institutional Design, Decision Making and Corporate Strategies. Heidelberg: Springer.

LEEP. (2012) Local Authority Green Deal Warehouse [Presentation] Local Energy Efficiency Project, February.

Lincoln, Y. S. \& Guba, E. G. (2000). Paradigmatic controversies, contradictions, and emerging confluences. In: LINCOLN, Y. S. \& GUBA, E. G. (eds.) Handbook of qualitative research. Thousand Oaks, CA: Sage.

London Assembly. (2018). Mayor’s £500m energy fund to help cut carbon emissions [Online]. London Assembly. [Accessed 18th September 2018].

Markowitz, H. (1952). Portfolio Selection. The Journal of Finance, 7 (1), 77-91.

Maslakovic, M. (2012) Fund Management, November 2012 London TheCityUK.

Maslakovic, M. (2014a) UK Fund Management 2014: an attractive proposition for internationl funds London TheCityUK.

Maslakovic, M. (2014b) Infrastructure 2014: Trends, Demands and Challanges London TheCityUK.

McClain, K. (2008) Introduction to CCI: Clinton Climate Initiative [Presentation] Sustainable University Symposium, 28th July.

Meadows, D. H., Meadows, D. L., Randers, J. \& Behrens, W. W. (1972) The Limits to Growth The Club of Rome.

Mertens, D. M. (1998). Research methods in education and psychology: Integrating diversity with quantitative and qualitative aproaches Thousand Oaks, CA, Sage.

Metrus Energy N.D. Available: http://metrusenergy.com/ [Accessed 6th February 2018].

Mills, A. J., Durepos, G. \& Wiebe, E. (2010). Thematic Analysis. Encyclopedia of Case Study Research. London: Sage. 
Moore, G. (2006). Crossing the Chasm: Marketing and Selling Disruptive Products to Mainstream Customers New York, Harper Business.

Natural Scotland. (2004). Central Energy Efficiency Fund (CEEF) [Online]. Natural Scotland. [Accessed 18th September 2018].

North, D. C. (1990). Institutions, Institutional Change and Economic Performance, Cambridge University Press.

OFGEM. (2014) Renewables Obligation: Guidance for Generators London ofgem e-serve.

Palm, J. \& Thollander, P. (2010). An interdisciplinary perspective on industrial energy efficiency. Applied Energy, 87 (10), 3255-3261.

Parker, M. \& Guthrie, P. (2016). Crossing the energy efficiency chasm: an assessment of the barriers to institutional investment at scale, a UK perspective. Journal of Sustainable Finance \& Investment, 1-23.

Pickard, J. (2015). UK poised to offload big stake in Green Investment Bank [Online].

Available: http://www.ft.com/cms/s/0/b2219248-1a55-11e5-a130-

2e7db721f996.html\#axzz3oveMnvcX [Accessed 18th October 2015].

Pinkse, J. \& Van Den Buuse, D. (2012). The development and commercialization of solar PV technology in the oil industry. Energy Policy, 40 (0), 11-20.

Pitz, G. F. \& Sachs, N. J. (1984). Judgment and Decision: Theory and Application. Annual Review of Psychology, 35 (1), 139-164.

Plimmer, J. \& Pickard, J. (2017). Green Investment Bank sold to Australia's Macquarie for $£ 2.3 b n$ [Online]. Available: https://www.ft.com/content/360c1478-25a5-11e7-8691-

d5f7e0cd0a16 [Accessed 12th November 2017].

Plumbridge, G. (2011) SDCL ESA Structure [Presentation] Sustainable Development Capital LLP.

Pout, C. H., Mackenzie, F. \& Bettle, R. (2002) Carbon dioxide emissions from non-domestic buildings: 2000 and beyond BRE.

Richards, J. (2016). Take-up of Green Deal loans “abysmal” finds PAC. Public Finance [Online]. Available: https://www.publicfinance.co.uk/news/2016/07/take-green-deal-loansabysmal-finds-pac.

Robinson, J. B. (1991). The proof of the pudding: Making energy efficiency work. Energy Policy, 19 (7), 631-645.

Samuelson, W. \& Zeckhauser, R. (1988). Status Quo Bias in Decision Making. Journal of Risk and Uncertainty, 1 7-59.

Sanstad, A. H. \& Howarth, R. B. (1994a). Consumer Rationality and Energy Efficiency. In: ACEEE 1994 Summer Study on Energy Efficiency. ACEEE. 
Sanstad, A. H. \& Howarth, R. B. (1994b). 'Normal' markets, market imperfections and energy efficiency. Energy Policy, 22 (10), 811-818.

SDCL. (2014a) Case Study: How we helped Kingspan. London. Sustainable Development Capital LLP, 10th July.

SDCL. (2014b) Case Study: How we helped National Car Parks (NCP). London. Sustainable Development Finance LLP, 10th July.

SDCL. (2014c) Case Study; How we helped St Bartholomew's London. Sustainable Development Capital LLP, 10th July.

Shama, A. (1983). Energy conservation in US buildings: Solving the high potential/low adoption paradox from a behavioural perspective. Energy Policy, 11 (2), 148-167.

Shefrin, H. (2007). Beyond Greed and Fear: Understanding Behavioral Finance and the Psychology of Investing Oxford, Oxford University Press.

Simon, H. A. (1955). A Behavioral Model of Rational Choice. The Quarterly Journal of Economics, 69 (1), 99-118.

Sitko, N. J. (2013) Qualitative Methods: Data Analysis and Validation Lusaka [Presentation] Indaba Agricultural Policy Research Institute.

Sorrell, S. (2005) The contribution of energy service contracting to a low carbon economy Tyndall Centre for Climate Change Research. Technical report 37.

Sorrell, S., O'Malley, E., Schleich, J. \& Scott, S. (2004). The Economics of Energy Efficiency - Barriers to Cost-Effective Investment Cheltenham, Edward Elgar Publishing Limited.

Sorrell, S., Schleich, J., Scott, S., O'Malley, E., Trace, F., Boede, U., Ostertag, K. \& Radgen, P. (2000) Reducing Barriers to Energy Efficiency in Public and Private Organisations Brighton SPRU. JOS3CT970022.

Stoner, T. (2003) Alternative Financing Models for Energy Efficiency Performance Contracting [Presentation] Financial Task Force.

SUSI Partners. (2017). SUSI Energy Efficiency Fund ("SEEF”): Customized financing solutions for investments in energy efficiency projects of industrial processes and buildings [Online]. SUSI Partners. Available: https://www.unece.org/fileadmin/DAM/energy/se/pp/geee/ws_ind.ee_jan2017/2.1_SUSI_A. Rothlin.pdf [Accessed 18th September 2018].

Sutherland, R. J. (1996). The economics of energy conservation policy. Energy Policy, 24 (4), 361-370.

Taylor, S. J., Bogdan, R. \& Devault, M. (2016). Introduction to Qualitative Research Methods: A Guidebook and Resource Hoboken, NJ, Wiley.

Thaler, R. (1980). Toward a positive theory of consumer choice. Journal of Economic Behavior \& Organization, 1 (1), 39-60. 
Thaler, R. H. (1999). Mental accounting matters. Journal of Behavioral Decision Making, 12 (3), 183-206.

Thaler, R. H. \& Shefrin, H. M. (1981). An Economic Theory of Self-Control. Journal of Political Economy, 89 (2), 392-406.

The Green Age. (2013). Why did the Green Deal fail? [Online]. Available: https://www.thegreenage.co.uk/why-did-the-green-deal-fail/ [Accessed 14th September 2018].

Thomas, G. (2009). How to do your Research Project London, Sage.

Tversky, A. \& Kahneman, D. (1974). Judgment under Uncertainty: Heuristics and Biases. Science, 185 (4157), 1124-1131.

UNEP. (2010) Global Trends in Sustainable Energy Investment 2010, Analysis and Trends and Issues in the Financing of Renewable Energy and Energy Efficiency Paris UNEP.

UNEP SEFI. (2007) Global Trends in Sustainable Energy Investment 2007: Analysis of Trends and Issues in the Financing of Renewable Energy and Energy Efficiency in OECD and Developing Countries UNEP SEFI, New Energy Finance.

United Nations. (1992). United Nations Framework Convention on Climate Change. FCCC/INFORMAL/84 GE.05-62220 (E) 200705. United Nations.

United Nations. (2009). Kyoto Protocol Status of Ratification modified on 14th January 2009. United Nations.

United Nations. (2015). Sustainable Development Goals [Online]. Available:

https://sustainabledevelopment.un.org/?menu=1300 [Accessed 1st February 2018].

Usher, E. (2008). Global Investment in the Renewable Energy Sector. In: HOHMEYER, O. \& TRITTIN, T., eds. IPCC Scoping Meeting on Renewable Energy Sources, 20-25 January 2008 Lübeck. Geneva: IPCC, pp.147-154.

Valentová, M. (2010). Barriers to Energy Efficiency - Focus on Transaction Costs. Acta Polytechnica, 50 (4), 87-93.

Van Der Like, R. (2007) Guide: Measurement \& Verification Of Energy Efficiency Projects EPC Watch.

Viederman, S. (2008). Fiduciary Duty. In: KROSINSKY, C. \& ROBINS, N. (eds.)

Sustainable Investing: The Art of Long-Term Performance. London, Sterling VA: Earthscan.

Warren, A. (2009) If we don't know how many buildings are out there, how can we plan cuts in emissions? EIBI, May.

Watson, I. (2013) Vanguard conference: Funding Heat Networks [Presentation] The Green Investment Bank, 21st November.

WCED. (1987) Our common future. Report of the World Commission on Environment and Development. Oxford: Oxford University Press. 
Weber, L. (1997). Some reflections on barriers to the efficient use of energy. Energy Policy, 25 (10), 833-835.

Whisky Intellegence. (2013) Tomatin Distillery reduces its carbon emissions by over 80\% Scotch Whisky News 14th November.

Whitehouse, S., Lacy, P., Veillard, X., Keeble, J. \& Richardson, S. (2011) Carbon Capital: Financing the low carbon economy London Barclays PLC.

Williamson, O. E. (1979). Transaction-Cost Economics: The Governance of Contractual Relations. Journal of Law and Economics, 22 (2), 233-261.

Wordpress. (2018). Development of Sustainability: the three key elements that makes sustainability [Online]. Available: https://jmburchall.wordpress.com/ [Accessed 1st February 2018].

Wüstenhagen, R. \& Menichetti, E. (2012). Strategic choices for renewable energy investment: Conceptual framework and opportunities for further research. Energy Policy, 40 (0), 1-10.

Wüstenhagen, R. \& Teppo, T. (2006). Do venture capitalists really invest in good industries? Risk-return perceptions and path dependence in the emerging European energy VC market. Internatinal Journal of Technology Management, 34 (1/2), 63-87.

Wüstenhagen, R., Wolsink, M. \& Bürer, M. J. (2007). Social acceptance of renewable energy innovation: An introduction to the concept. Energy Policy, 35 (5), 2683-2691.

Ya He, J. (2010) PACE - stepping up energy efficiency investment? Bloomberg New Energy Finance.

Ya He, J. (2012). Financing Mechanisms for Energy Efficiency in Buildings. Retrofit 2012. University of Salford.

Yin, R. K. (2009). Case Study Reseach: Design and Methods (4th ed). Thousand Oaks, CA, Sage. 
Appendix A: Examples of Energy Efficiency transactions made by each of the GIB funds

\section{GIB Fund - Equitix}

Outlined below are Equitix's investments, which all involve a biomass element which attracts government subsidies. They do look at building retrofit projects but their main focus is firmly on deals that attract subsidies.

\section{Roundwood Energy Limited - Biomass boiler}

The transaction involved a £10m investment via Roundwood Energy Limited (Roundwood) which replaced inefficient heating systems, in both public and private community facilities, with biomass boilers, refer to Figure 25. Roundwood is an energy services company and was responsible for financing, installing, maintaining and fuelling the new biomass boilers for 20 years. It was supported by its technology partner, Woodpecker Energy Limited, a wellestablished UK based manufacturer of wood pellet and wood chip biomass boilers. (GIB, 2013a)

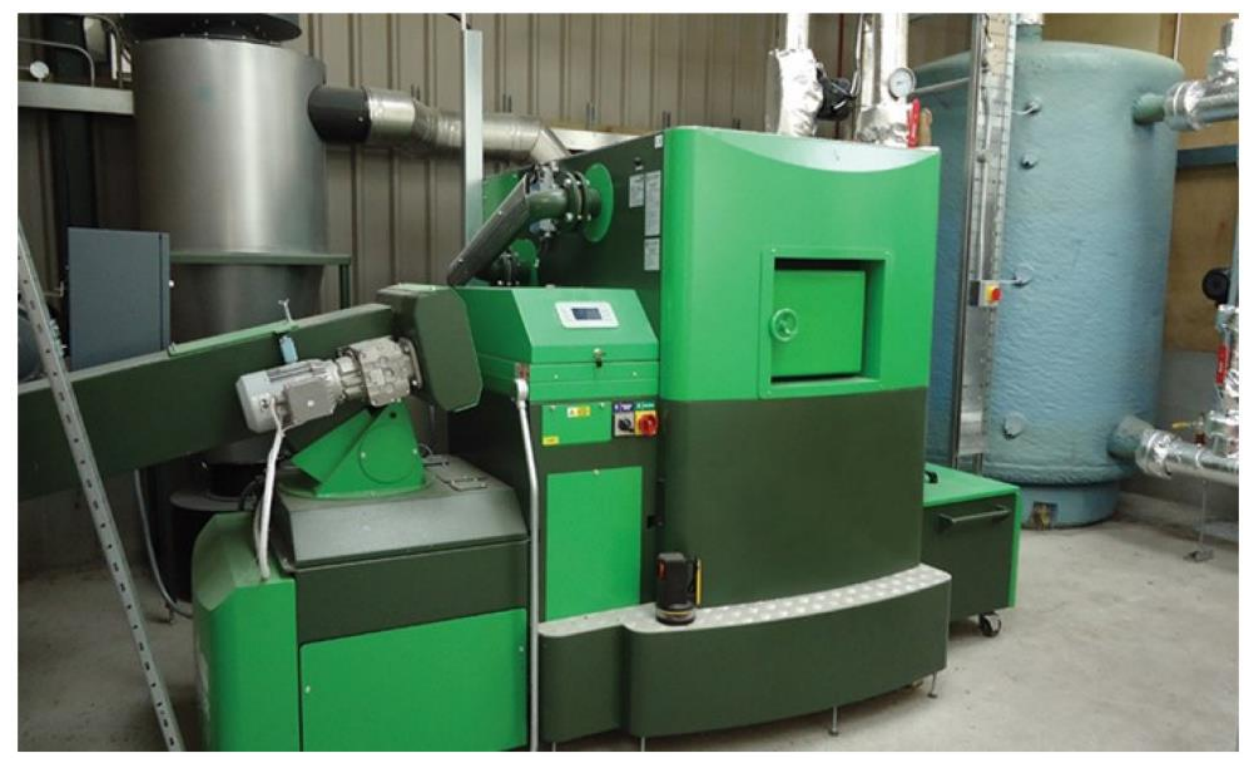

Source: GIB, 2013a

Figure 25: Biomass boiler in the Equitix Roundwood transaction 
The boilers are fuelled by sustainably sourced wood pellets and as a result $\mathrm{CO}_{2}$ emissions are expected to be cut by around 150,000 tonnes $\mathrm{CO}_{2}$ over the 20-year life of the investment. Sustainable ENplus A1 standard pellets are being used which conform to a standard which is regulated by the European Biomass Association. (GIB, 2013a)

\section{Tomatin Distillery - Biomass boiler}

This $£ 1.2 \mathrm{~m}$ transaction involved the installation of a new biomass boiler replacing the previous heavy-fuel oil usage of the distillery whisky making processes, refer to Figure 26. It was installed in conjunction with a company called Balcus as part of an Energy Supply Contract and is projected to improve the distillery's carbon emissions by over $80 \%$, saving an estimated 96,500 tonnes of $\mathrm{CO}_{2}$ over the 20-year life of the investment. This transaction also makes use of ENplus A1 standard pellets. (GIB, 2013c, GIB, 2013b, Whisky Intellegence, 2013)

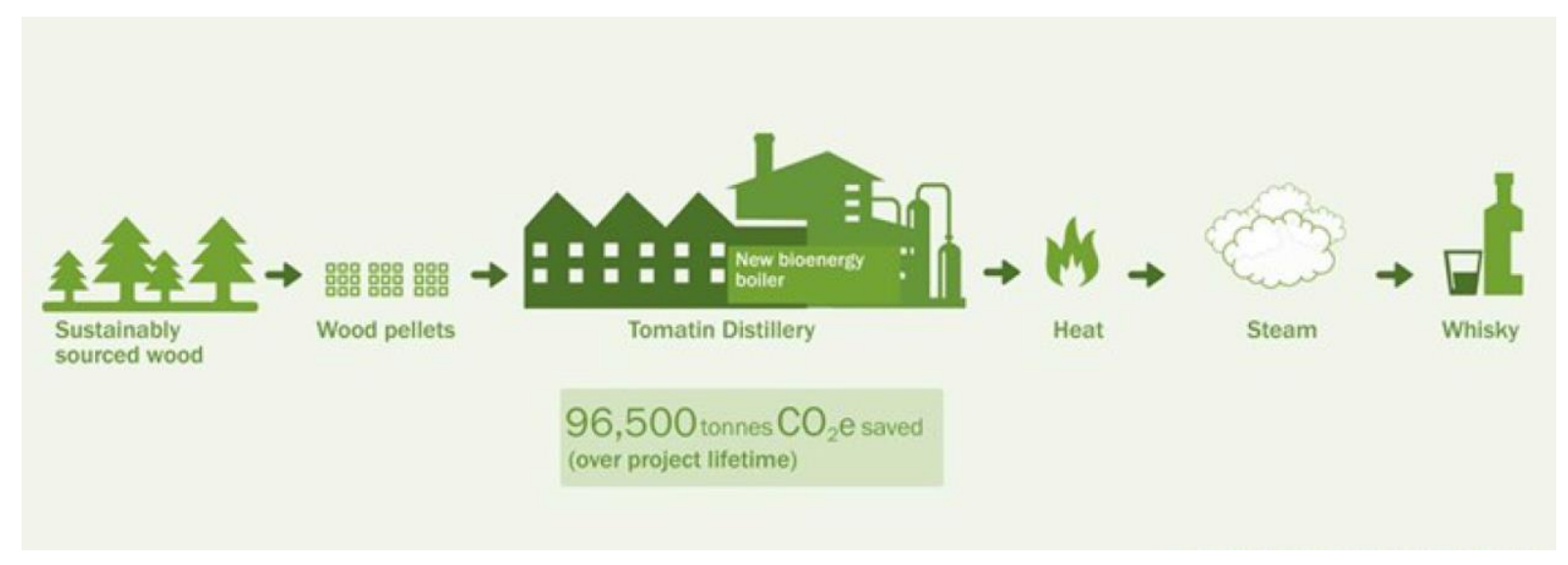

Source: GIB, 2013b

Figure 26: Biomass process at the Tomatin Distillery 


\section{Bernard Matthews' Turkey Farms - Biomass boiler}

A $£ 24.5 \mathrm{~m}$ investment to finance the installation of c. 179 new biomass boilers installed across 21 farms in Norfolk, Suffolk and Lincolnshire, covering 40 per cent of Bernard Matthews' estate. The dry heat biomass systems also produced a number of benefits due to the improved circulation of heat, including reduced ammonia levels, reduced ventilation requirements, and increased litter (bedding) quality. (GIB, 2014a)

\section{Sheffield CHP - Biomass boiler}

A £30m investment to build a new Combined Heat and Power plant incorporating a biomass boiler which is expected to cut $\mathrm{CO}_{2}$ emissions by approximately 12,700 tonnes of $\mathrm{CO}_{2} \mathrm{e}$ per year. The plant has been constructed by a specialist District Heating Design \& Build company. Since being operational the project sells electricity into the grid under a long-term power purchase agreement. (GIB, 2015a)

\section{Nottingham CHP - Biomass boiler}

A further $£ 30 \mathrm{~m}$ investment involving the building of new Combined Heat and Power plant incorporating a biomass boiler. The new plant is expected to generate $6.5 \mathrm{MW}$ of renewable electricity and to cut $\mathrm{CO}_{2}$ emissions by approximately 8,400 tonnes of $\mathrm{CO}_{2} \mathrm{e}$ per year. This transaction also sells electricity into the grid under a long-term power purchase agreement. (GIB, 2015b)

\section{Expansion of Wick district heating scheme - Biomass boiler}

A $£ 10 \mathrm{~m}$ acquisition of Ignis Biomass Limited, the owner and operator of a 3.5MW combined heat and power plant and associated district heating scheme, supplying heat via a biomass fuelled plant, in Wick in the north of Scotland. The scheme originally supplied local facilities such as Pulteney Distillery and Caithness General Hospital along with domestic residences. 
There are further plans to expand the district heating scheme by implementing a plan to build four new smaller scale stand-alone combined heat and power systems for major heat users in and around Wick. (GIB, 2016a)

\section{GIB Fund - Sustainable Development Capital Ltd (SDCL)}

SDCL has approached the issue of investment in energy efficiency in a very different way to Equitix, having embraced the EPC ESCO methodology and adapted it to benefit from the performance guarantee from an ESCO, while offering a performance-based energy savings arrangement with the building owner via an Efficiency Services Agreement or Energy Services Agreement (ESA), refer to Figure 27. This is akin to the Metrus Efficiency Services Agreement where the end user pays for energy saved, however in the SDCL model there is a Special Purpose Vehicle (SPV) company that is central to the contractual structure. Figure 19 illustrates the typical contractual structure that SDCL employ in their transactions. Due to the nature of the contractual relationships, the payments to the SPV by the Building Owner are operating expenses and therefore the assets are 'off balance sheet', which is an important issue when Building Owners consider these types of transactions. The majority of SDCL investments are structured in this way however they will also invest in biomass projects such as the Lincolnshire Poultry Farm transaction as outlined below.
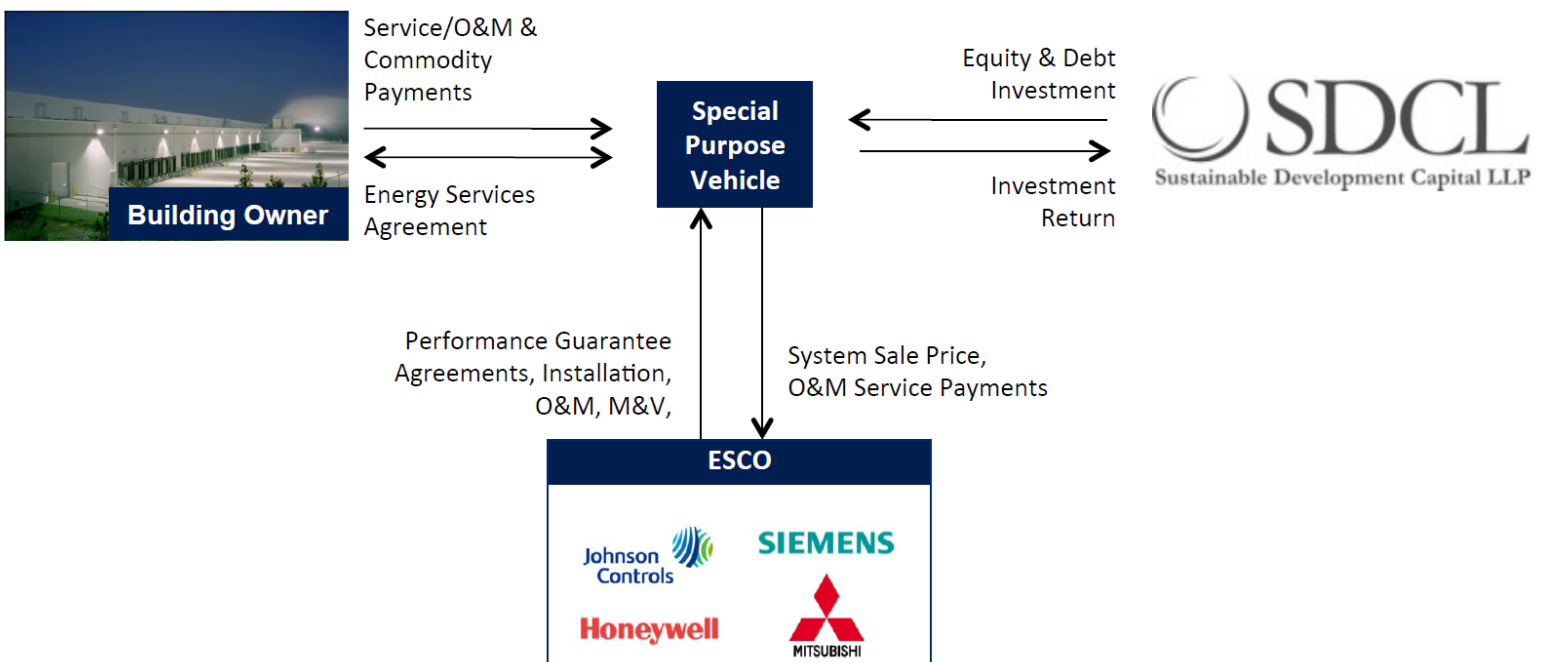

Figure 27: SDCL energy efficiency contractual structure 


\section{Kingspan - Building retrofit}

SDCL entered into an Energy Services Agreement transaction with Kingspan, a manufacturer of high performance insulation and other products for the building industry, to retrofit its UK industrial facilities with the aim of reducing its energy consumption by approximately $15 \%$. The transaction involved a $£ 5 \mathrm{~m}$ investment, with Johnson Controls Inc as an ESCO installing energy metering, building management systems, lighting upgrades with full digital addressable lighting interface control systems, compressed air system upgrade and fan optimisation measures. The full programme is estimated to save over 4,500 tonnes of $\mathrm{CO}_{2} \mathrm{e}$ emissions per year across the portfolio of facilities. (SDCL, 2014a)

\section{NCP - Building retrofit}

SDCL entered into a $£ 10 \mathrm{~m}$ ESA arrangement, backed by a UK government guarantee, with National Car Parks (NCP) to install new energy efficient lighting schemes at 149 locations nationwide. A second phase of the project involved a further 110 car parks. The two phases of the project combined cut NCP's energy use by an average of $70 \%$, cutting its Carbon emissions by over 12,000 tonnes of $\mathrm{CO}_{2}$ e per year. $\mathrm{NCP}$ expects to save around $£ 34 \mathrm{~m}$ over the lifetime of both phases of the project. (SDCL, 2014b, GIB, 2016b)

\section{Citi - Building retrofit}

SDCL entered into a $£ 5.2 \mathrm{~m}$ ESA arrangement with global banking group Citi to install two 1.4MW CHP systems expected to generate 24,000 MWh per year to power a data centre in London. The CHP systems will generate $71 \%$ of the facility's electricity requirements which were previously $100 \%$ supplied via the national grid with back-up diesel generators. The project will also involve the installation of energy efficiency cooling units and efficiency improvements to the building's air conditioning system serving the building computer servers. (Better Buildings, 2014, GIB, 2014b) 


\section{Poultry Farms - Biomass boiler}

An investment to finance the installation of 60 biomass energy centres at Moy Park farms in Lincolnshire. They will replace existing LPG heaters saving up to $18,500 \mathrm{CO}_{2}$ e per year. (GIB, 2014c)

\section{Santander - Building retrofit}

A $£ 17.5 \mathrm{~m}$ investment into a project that will install 90,000 new LED lamps in Santander's entire UK estate of 800 UK branches and 14 office buildings using an ESA arrangement. The project will generate more than 50\% energy savings and cut carbon emissions by more than 7,000 tonnes $\mathrm{CO}_{2} \mathrm{e}$ per year for the UK's fifth largest retail bank. (GIB, 2015c)

\section{Bart's - Energy centre}

A $£ 4.5 \mathrm{~m}$ investment to fund a $3.3 \mathrm{MW}$ Gas fired Combined Cooling Heating and Power (CCHP) system with 250W absorption cooling at St Bartholomew's Hospital in London. Under the transaction Bart's Health NHS Trust were guaranteed a year one saving of $£ 1.4 \mathrm{~m}(33 \%)$ of their utility charge with no upfront cost and $\mathrm{CO}_{2} \mathrm{e}$ savings of 18,300 Tonnes (69\%). The transaction was complicated by the fact that the hospital was a Private Finance Initiative (PFI) scheme and was run via a PFI Special Purpose Vehicle Project company, Capital Hospitals Limited (CHL) as the contractual arrangement had to include that entity. The contractual arrangement in Figure 28 indicates how this was achieved at the same time as providing a performance-based contract akin the Energy Services Agreement with Skanska as the Energy Performance Contractor. (SDCL, 2014c, GIB, 2014d, CHL, 2015) 


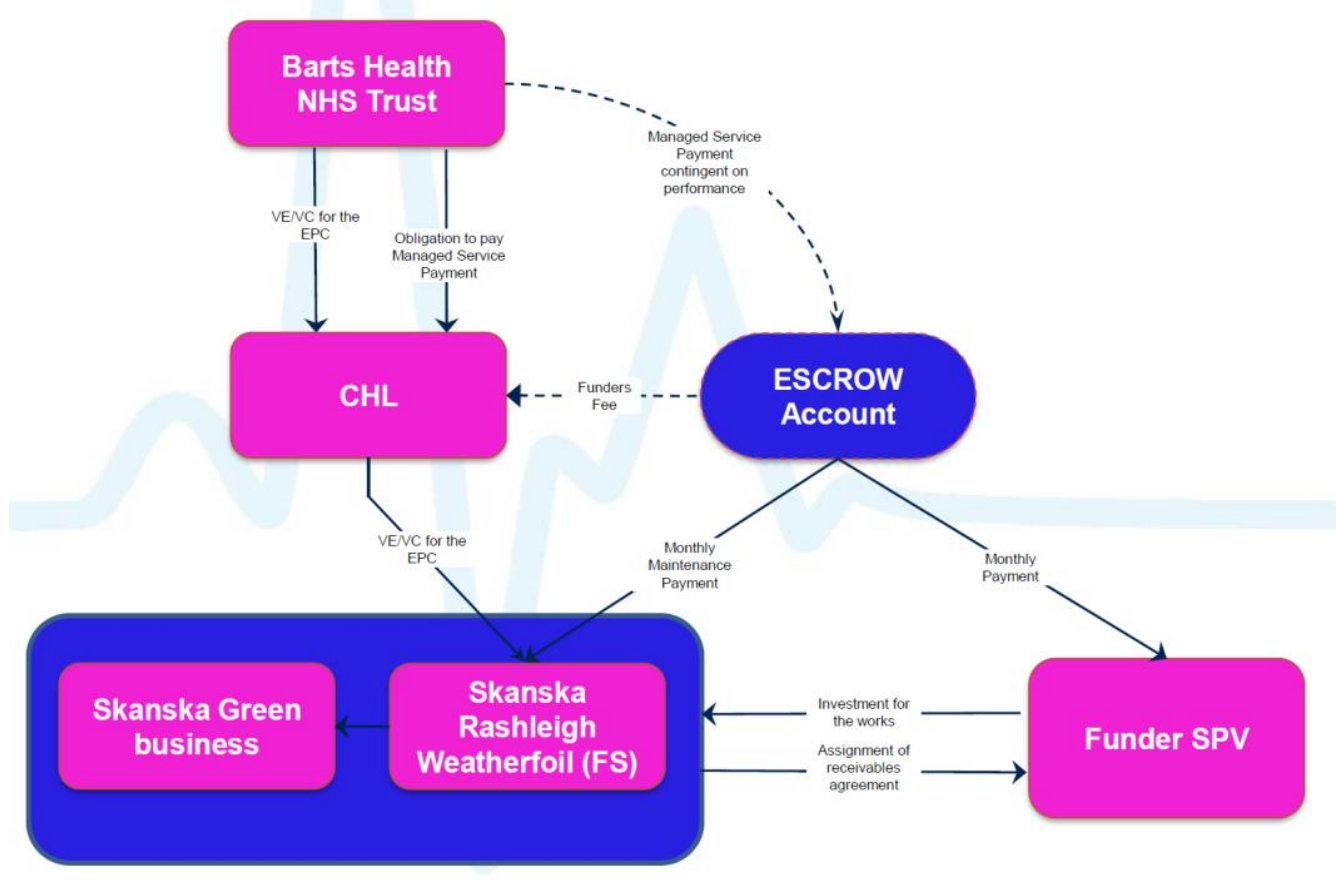

Source: CHL, 2015

Figure 28: Bart's energy centre contractual structure

Bart's Health NHS Trust issued a Variation Enquiry (VE) and accepted a Variation Confirmation (VC) from the PFI Project Company CHL. It pays for its Managed Service for utilities contingent on performance which is where it is similar to the Energy Services Arrangement. Ultimately the Funder SPV, which in this case is the SDCL SPV, receives a monthly payment derived from the Managed Service Payment in the same way as it receives the ongoing payments from the Building end user in the traditional ESA contractual arrangement. (CHL, 2015)

\section{GIB Fund - Aviva}

Aviva's approach to energy efficiency investment involves a different focus to both Equitix and SDCL. It works closely with NHS Trusts to invest in Energy Centre energy efficiency upgrades. Aviva structure the transactions in a way that the end user takes the operational risks of the deal and therefore their funding attracts a lower return. However, it is perceived as being 
a safe investment with the only real risk to the investor being that of default by the subsovereign counterparty in the transaction, the NHS Trust.

\section{Addenbrooke's - Energy centre}

Aviva made a $£ 36 \mathrm{~m}$ investment in a new Energy Centre for Cambridge University Hospitals NHS Foundation Trust. The technology installed is comprehensive and includes a Combined Heat and Power engine, biomass boilers, efficient dual fuel boilers and heat recovery from medical waste incineration. The project also includes energy conservation measures such as new lighting and improved heat and lighting controls, and is for a 25-year contract term. It is expected to save the Trust over $£ 20 \mathrm{~m}$ in energy costs and 25,000 of $\mathrm{CO}_{2}$ savings over the term. (GIB, 2013d, GIB, 2013e, Aviva, 2012)

\section{Cheltenham Hospital - Energy centre}

The project involves a $£ 2.2 \mathrm{~m}$ investment by the Aviva fund, alongside an $£ 900 \mathrm{k}$ grant from the Department of Health to finance the installation of a 1.3MW combined heat and power unit as Cheltenham General Hospital. The transaction is structured in such a way that the Trust does not have to make any upfront capital investment and the repayments will be paid for from the cost saving generated by the reduced electricity consumption. It is expected to cut the Trust's energy bill by $£ 150$ m per year or 20 per cent. (GIB, 2014e, Aviva, 2014) 
Appendix B: Case study protocol, information sheet and consent form

\section{Case Study Protocol - Based on Yin (2009), Ch 3}

A Introduction to the Case Study and Purpose of Protocol

A1 Background information, outline questions and constructs etc

A2 Substantive issues being investigated

A3 Case Study Purpose and setting

B Data Collection Procedures - Guidelines for the interviews and fieldwork

B1 Data collection plan

C Field Procedures

C1 Gaining access to key interviewees

C2 Ensure sufficient resources are available

C3 Clear schedule of data collection and interview process

D Interview Guide

D1 Overview of questions and interview process 


\section{INFORMATION SHEET \\ Crossing the Energy Efficiency Chasm: An Assessment of the Barriers to Institutional \\ Investment in Energy Efficiency at Scale \\ Martin Parker, October 2014}

1. Introduction

This document outlines proposed $\mathrm{PhD}$ research to be carried out by Martin Parker on a parttime basis through the University of Cambridge (contact: mob 07764 569392, email mcfp2@cam.ac.uk). The research aims to engage with institutional investors to investigate the decision making process when considering investments in energy efficiency.

2. Researcher

Martin Parker, chartered engineer and surveyor, director of an international financial institution working in infrastructure and project finance.

3. Research questions and sub questions

In order to meet the research aims the researcher seeks to address the following questions:

What are the barriers to attracting capital investment at scale for energy efficiency in the context of institutional and pension fund investment?

How do institutional investors decide whether to invest in energy efficiency?

Why, when environmental social and economic benefits are apparent, have institutional investors not invested in energy efficiency at scale?

What are the enabling conditions that would facilitate institutional investors investing in energy efficiency at scale?

4. Research method

The research method will involve the examination of an organisational case study of a Green Investment Bank (GIB) backed energy efficiency fund or funds. The fund(s) will have matched or bettered the initial $£ 50 \mathrm{~m}$ investment by the GIB with funds raised from institutional investors. The research method will involve:

- A series of semi-structured interviews with key relevant members of the fund organisation and of a number of institutional investors that either have invested in the fund or were approached to do so and are integral to the investment decision making process. Anticipated duration $1 \mathrm{hr}$ per interview.

- Examination of relevant corporate documentation, both publicly available and potentially confidential internal documents, viewed by agreement, which has a relevance to investment in energy efficiency at both fund and individual investment level. 
A member of the fund organisation would need to coordinate the research process with the researcher identifying the most appropriate organisations and personnel within them to take part in the interviews and the most appropriate documents for review.

\section{Confidentiality}

It's recognised that much of the information to be discussed and potentially viewed will be confidential to the organisation concerned, the organisation and interviewees will remain anonymous within the final research text. 


\section{Participant Consent Form}

\section{Crossing the Energy Efficiency Chasm: An Assessment of the Barriers to Institutional Investment in Energy Efficiency at Scale}

\section{Name of Researcher: $\quad$ Martin Parker}

1.

1. I confirm that I have read and understand the information sheet dated October 2014 for the above study. I have had the opportunity to ask questions and have these answered satisfactorily.

2. I understand that my participation is voluntary and that I am free to withdraw at any time, without giving any reason, without my legal rights being affected.

3. I agree that the interview be audio-recorded.

3a. I do not want the interview to be audio-recorded but agree for hand written notes to be taken instead.

4. I agree that data collected in the interview will be stored securely for 5 years

5. I agree to take part in the above study.
Please tick box
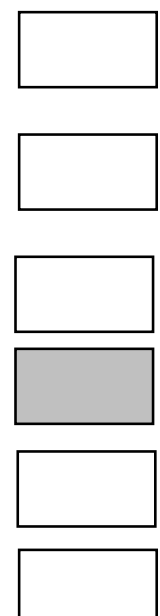

Name of Participant

(Please print)
Date

Signature

Name of Research Team member Date (Please print)

2 copies required: top copy for researcher; one copy for participant. 
Appendix C: Semi-structured interview questions

Interview guide for semi structured interviews with institutional investors.

\section{Introduction to the research}

\section{Background}

- Issue of $\mathrm{CO}_{2}$ emissions

- The UK governments commitment to $\mathrm{CO}_{2}$ emission reduction

- The significance of Energy Efficiency investment.

\section{Aims of the research and main research question}

- What are the barriers to attracting capital investment at scale for energy efficiency in the context of institutional and pension fund investment?

\section{Research method and methodology}

- Case studies of Green Investment Bank energy efficiency funds

- Review by semi structured interviews and examination of transaction documents

- The interviews will be audio-recorded (by agreement)

- Organisations and interviewees will remain anonymous

\section{Outcomes the research will hope to achieve}

- Develop a better understanding of the investment decision making process in relation to Energy Efficiency

- Identify the enabling conditions that would facilitate institutional investors investing in energy efficiency at scale

\section{Interview questions}

\section{Interviewee's organisation and role within it}

1. Please briefly explain the structure of your organisation and the investment decision making process.

2. What role and responsibility do you have within the organisation and the investment decision making process? 


\section{Asset allocation and return requirements}

3. Do you have strategic asset allocation policy, perhaps employing a Modern Portfolio Theory approach, if so can you briefly outline it. If not, do you have an alternative approach to investment diversification in order to decide the split of investment types and classes?

4. Do you invest in 'alternatives' such as renewable energy or infrastructure and if so can you briefly outline the organisation's approach to investing in this asset class?

5. Which of the asset classes you invest in would investments in energy efficiency fall into and how do they meet the criteria for each class? What is the approximate percentage of your overall investments allocated to each of those asset classes?

6. Do you require a minimum return percentage from your investments and would this equally apply to energy efficiency investments?

7. Does / would an investment in the Equitix Energy Efficiency fund meet the criteria for the appropriate asset class within your organisation, including meeting your minimum return requirements and if so how does it achieve this?

\section{Low Carbon investments}

8. Please can you explain your organisations approach to sustainable investment / low carbon investment and how this is expressed in the company?

9. Would you accept a lower return on your investment in Energy Efficiency than on your more mainstream investments if it met your low carbon investments criteria?

\section{Decision to invest / not invest}

10. What factors made you decide to invest in the Equitix Energy Efficiency fund? (Alterative question: What factors would make you consider investing in the Equitix Energy Efficiency fund?)

11. To what extent was the Green Investment Bank involvement a factor in your decision to invest or not to invest in the Equitix Energy Efficiency fund?

12. Would you reinvest in further Energy Efficiency funds that didn't have GIB or government involvement?

13. Did you invest in the Equitix Energy Efficiency fund at the expense of alternative opportunities? 
(Alternative question: Did you decide not to invest in (Would you not have invested in) the Equitix Energy Efficiency fund as you had (have) competing alternative investment opportunities that were (are) more attractive?

14. When deciding to make an innovative investment such as the one made in the Equitix Energy Efficiency fund, what are the issues that you consider when weighing it up with respect to potential alternative investments that may be more conventional?

(Alternative question: When considering an innovative investment such as the one that could have been made in the Equitix Energy Efficiency fund, what are the issues that you consider when weighing it up with respect to potential alternative investments that may be more conventional?

\section{Fund Manager}

15. What do you consider are the factors that are important when placing an investment with a fund manager particularly when the investment is a non-conventional one such as in Energy Efficiency?

16. How much did the familiarity with Equitix as fund manager influence your decision to invest or not to invest?

17. If familiarity with Equitix was a factor for the initial investment and you achieved or bettered your required returns from their Energy Efficiency fund, would you consider investing in further Energy Efficiency funds run by other fund managers?

\section{UK government and EU polices}

18. How have the UK and EU commitments and policies designed to reduce $\mathrm{CO}_{2}$ and the aim to encourage private institutional investment in Energy Efficiency improvements influenced your investment decisions?

19. What do you think the role of policy should play in encouraging further investment in Energy Efficiency and are there any government policy initiatives either at the UK or the EU level that, if introduced, you feel would achieve this?

\section{Any other issues}

20. Are there any other issues that you feel have a bearing on your decision to either invest in or not to invest in Energy Efficiency investments in general or the Equitix Energy Efficiency fund in particular?

21. What do you feel are the conditions that would need to exist to enable investment in Energy Efficiency to become a more mainstream investment or at least a more established asset class within the alternatives classification? 
Appendix D: Semi-structured interview questions, a priori constructs and research questions

\section{$\underline{\text { Semi structured interview questions }}$}

\section{Research questions}

What are the barriers to attracting capital investment at scale for energy efficiency in the context of institutional and pension fund investment?

1. How do institutional investors decide whether to invest in energy efficiency?

2. Why, when environmental social and economic benefits are apparent, have institutional investors not invested in energy efficiency at scale?

3. What are the enabling conditions that would facilitate institutional investors investing in energy efficiency at scale?

\section{$\underline{\text { A priori constructs: }}$}

- Investment return requirements (a) Q 1, 2 \& 3

- UK and EU legislation (b) Q 3

- $\mathrm{CO}_{2}$ reduction targets (c) Q 3

- Familiarity with fund manager (d) Q 1

- Strategic asset allocation, use of Modern Portfolio Theory (e) Q 1 \& 2

- Competing investment opportunities (f) Q $1 \& 2$

- Internal low carbon and sustainability policies (g) Q 1 \& 3

- Green Investment Bank (GIB) involvement (h) Q 1 \& 2

- Behavioural Finance, habits of prudence (i): Loss aversion Q 1 \& 2

Preference for certainty Q 1 \& 2

Preference for similarity Q $1 \& 2$

Regret Q 1 \& 2

- Behavioural Finance, norms of relationships (j): Reliance Q 1 \& 2 (with Fund Manager)

\section{$\underline{\text { Research questions with allocated a priori constructs }}$}

1. How do institutional investors decide whether to invest in energy efficiency?

Investment return requirements (a)

Familiarity with fund manager (d)

Strategic asset allocation, use of Modern Portfolio Theory (e) 
Competing investment opportunities (f)

Internal low carbon and sustainability policies (g)

Green Investment Bank (GIB) involvement (h)

Behavioural Finance, habits of prudence (i):

Loss aversion

Preference for certainty

Preference for similarity

Regret

Behavioural Finance, norms of relationships (j): Reliance

(with Fund Manager)

Reciprocity

Respect

2. Why, when environmental social and economic benefits are apparent, have institutional investors not invested in energy efficiency at scale?

Investment return requirements (a)

Strategic asset allocation, use of Modern Portfolio Theory (e)

Competing investment opportunities (f)

Green Investment Bank (GIB) involvement (h)

Behavioural Finance, habits of prudence (i): Loss aversion

Preference for certainty

Preference for similarity

Regret

Behavioural Finance, norms of relationships (j): Reliance

(with Fund Manager) Reciprocity

Respect

3. What are the enabling conditions that would facilitate institutional investors investing in energy efficiency at scale?

Investment return requirements (a)

UK and EU legislation (b)

$\mathrm{CO}_{2}$ reduction targets (c)

Internal low carbon and sustainability policies (g)

Questions - with coding back to research questions and a priori constructs

\section{Interviewee's organisation and role within it}

22. Please briefly explain the structure of your organisation and the investment decision making process.

23. What role and responsibility do you have within the organisation and the investment decision making process?

Asset allocation and return requirements 
24. Do you have strategic asset allocation policy, perhaps employing a Modern Portfolio Theory approach, if so can you briefly outline it. If not, do you have an alternative approach to investment diversification in order to decide the split of investment types and classes? Q 1 \& 2 (e)

25. Do you invest in 'alternatives' such as renewable energy or infrastructure?

Q $1 \& 2$ (e)

26. Which asset class would investments in energy efficiency fall into and what percentage is allocated to that asset class? Q 1 \& 2 (e)

27. Do you require a specific return percentage from your investments and would this equally apply to energy efficiency investments? Q 1, 2 \& 3 (a)

28. Does / would an investment in the Equitix Energy Savings fund meet your return requirements? Q $1,2 \& 3$ (a)

\section{Low Carbon investments}

29. Do you have a sustainable investment policy where you favour low carbon investments or are committed to making low carbon investments and if so is your investment in the Equitix Energy Savings Fund in response to that policy?

(Alternative question: Do you have a sustainable investment policy where you favour low carbon investments or are committed to making low carbon investments and if so did you consider investing in the Equitix Energy Savings Fund in response to that policy? Q $1 \& 3$ (g)

30. Would you accept a lower return on your investment in Energy Efficiency than on your more mainstream investments if it met your low carbon investments criteria? Q $1,2 \& 3$ (a) (g)

\section{Decision to invest / not invest}

31. What factors made you decide to invest in the Equtix energy efficiency fund? (Alterative question: What factors would make you consider investing in the Equtix energy efficiency fund?) Q 1 \& 3

32. Was the Green Investment Bank involvement a factor in your decision to invest or not to invest and if so how important was it? Q $1 \& 2$ (h)

33. Would you reinvest in further Energy Efficiency funds that didn't have GIB or government involvement? Q 1 \& 2 (h)

34. Did you invest in the Equitix energy efficiency fund at the expense of alternative opportunities? 
(Alternative question: Would you not have invested in the Equitix energy efficiency fund due to competing opportunities? Q $1 \& 2$ (f)

35. When deciding to make an innovative investment such as the one made in the Equiix Energy Savings Investments fund, what are the issues that you consider when weighing it up with respect to potential alternative investments that may be more conventional?

(Alternative question: When considering an innovative investment such as the one that was ultimately not made in the Equiix Energy Savings Investments fund, what are the issues that you consider when weighing it up with respect to potential alternative investments that may be more conventional? Q $1 \& 2$ (i)

\section{Fund Manager}

36. What do you consider are the factors that are important when placing an investment with a fund manager particularly when the investment is a non-conventional one such as in Energy Efficiency? Q 1

37. How much did the familiarity with Equitix as fund manager influence your decision to invest or not to invest? Q 1 (d)

38. If familiarity with Equitix was a factor for the initial investment and you achieved or bettered your required returns from their Energy Savings fund, would you consider investing in further Energy Efficiency funds run by other fund managers?

Q $1 \& 2$ (d) (j)

\section{UK government and EU polices}

39. Are you aware of the UK and EU commitments and policies designed to reduce $\mathrm{CO}_{2}$ and the aim to encourage private institutional investment in Energy Efficiency improvements and if so have they influenced your investment decisions?

Q $1 \& 3$ (b) (c)

40. Are there any government policy initiatives either at the UK or the EU level that you feel would encourage further investment in Energy Efficiency? Q 3 (b) (c)

\section{Any other issues}

41. Are there any other issues that you feel have a bearing on your decision to either invest in or not to invest in Energy Efficiency investments in general or the Equitix Energy Savings fund in particular? Q $1 \& 2$

42. What do you feel are the conditions that would need to exist to enable investment in Energy Efficiency to become a more mainstream investment or at least a more established asset class within the alternatives classification? Q3 
Appendix E: Code system, created using MAXQDA

Codes created prior to the commencement of the data analysis based on the a priori constructs

Codes created during the data analysis that were formulated inductively

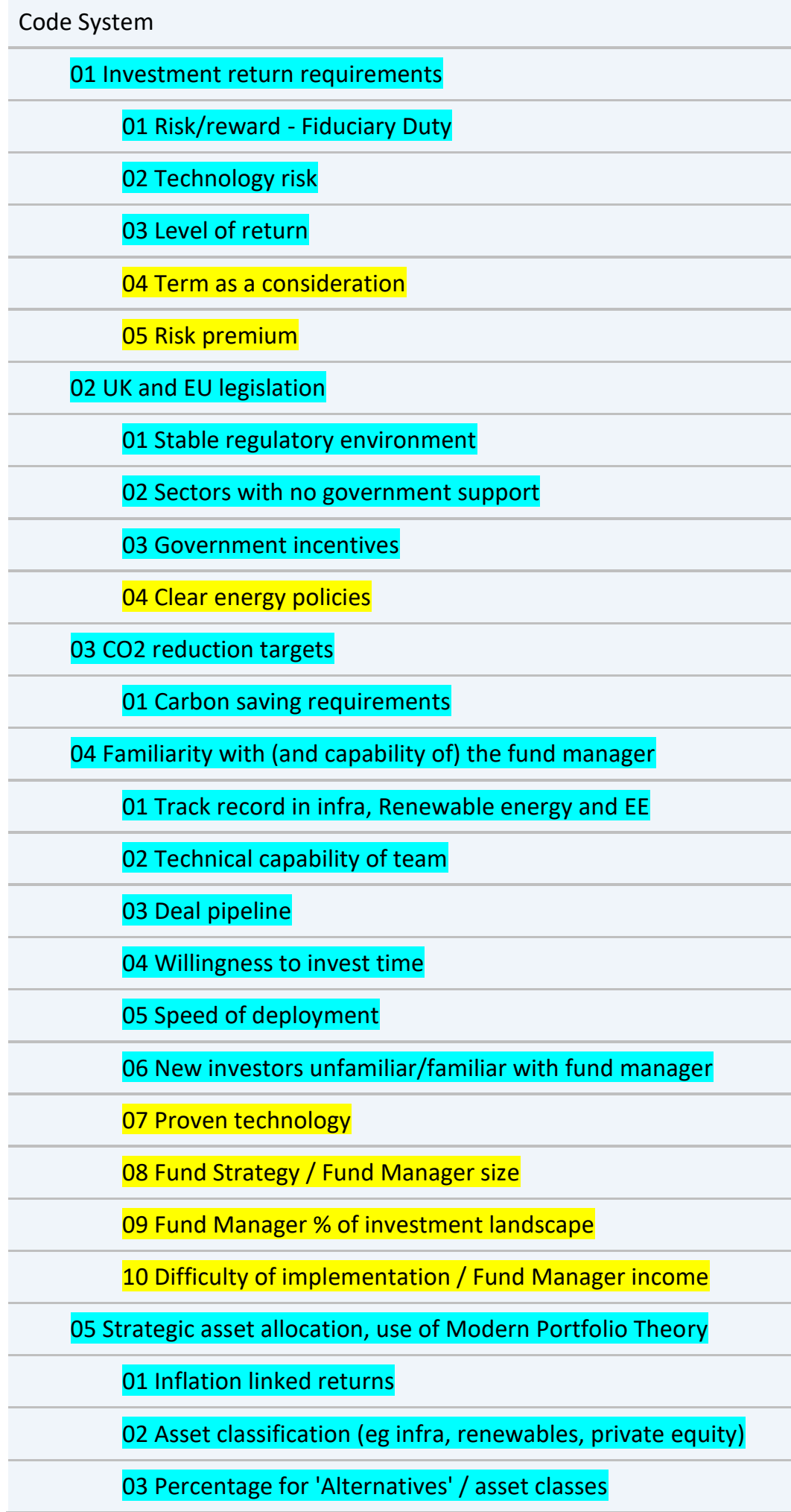


04 Risk/return approach (safer investment, higher allocation)

05 Contractual structure

06 Government backed income stream

07 Blended and diversified portfolio (un/collerated)

$08 \mathrm{EE}$ investment models eg ESCO, Biomass etc

09 Upstream risks, secure fuel source etc

10 Investment matching liabilities/not matching allocation pol.

11 Investment Strategy

06 Competing investment opportunities

$01 \mathrm{EE}$ a less mature market

02 Size of investment and projects

07 Internal low carbon and sustainability polices

01 Positive allowance for low carbon investments

02 Negative allowance for low carbon investments (return only)

03 ESG as part of Fiduciary Duty

08 Green Investment Bank (GIB) involvement

01 Did influence investors

02 Did not influence investors

03 will invest in further funds without GIB

09 Behavioural Finance, habits of prudence

01 Loss aversion

02 Preference for certainty

03 Preference for similarity

04 Regret

10 Behavioural Finance, norms of relationships (with fund manager)

01 Reliance

02 Reciprocity

03 Respect

11 Market conditions

01 Difficult for new Fund Manager entrants

02 Move to larger projects

03 Maturing market - track record demonstrates return

04 Scale 
05 Develop Technology

06 Market driven returns

07 Availability of suitable projects / investments - Demand

08 Tax treatment and breaks

09 Standardisation

10 Public Sector process

11 Energy as \% of costs in an organisation

12 Need to understand complexity of technology or asset

01 What is Energy Efficiency? 
Appendix F: Semi-structured interview questions with codes mapped

\section{$\underline{\text { Semi structured interview questions }}$}

Questions - with codes mapped

\section{Interviewee's organisation and role within it}

1. Please briefly explain the structure of your organisation and the investment decision making process.

2. What role and responsibility do you have within the organisation and the investment decision making process?

$\mathbf{0 3}(\mathbf{0 1})$

05

$05(01)$

\section{Asset allocation and return requirements}

3. Do you have strategic asset allocation policy, perhaps employing a Modern Portfolio Theory approach, if so can you briefly outline it. If not, do you have an alternative approach to investment diversification in order to decide the split of investment types and classes?

$01(01,03)$

$04(08)$

$05,05(01,02,03,04,06,07,08,10)$

4. Do you invest in 'alternatives' such as renewable energy or infrastructure and if so can you briefly outline the organisation's approach to investing in this asset class?

05

$05(01,02,03,04,07,10)$

11(06)

5. Which of the asset classes you invest in would investments in energy efficiency fall into and how do they meet the criteria for each class? What is the approximate percentage of your overall investments allocated to each of those asset classes?

$01(03)$

$05(01,02,03,04,05,06,08,10,11)$

07

$07(03)$

$09(01,02,03,04)$ 
6. Do you require a minimum return percentage from your investments and would this equally apply to energy efficiency investments?

01

$01(01,03)$

$04(01,08)$

05

$05(01,03,04,06,07,08,10)$

10(01)

7. Does / would an investment in the Equitix Energy Efficiency fund meet the criteria for the appropriate asset class within your organisation, including meeting your minimum return requirements and if so how does it achieve this?

$01(01,02,03,04,05)$

$04(03,05,08)$

$05(01,02,03,04,05,06,07,10,11)$

$06(02)$

07(01, 03)

$10(01,03)$

\section{Low Carbon investments}

8. Please can you explain your organisations approach to sustainable investment / low carbon investment and how this is expressed in the company?

01(01, 03)

$02(03)$

$05(04,07)$

$11(06,08)$

12

9. Would you accept a lower return on your investment in Energy Efficiency than on your more mainstream investments if it met your low carbon investments criteria?

$\mathbf{0 1}(\mathbf{0 1}, \mathbf{0 3})$

02(03)

$\mathbf{0 3}(01)$

04(08)

$05(02,04,07)$

07

$07(01,02,03)$

\section{Decision to invest / not invest}

10. What factors made you decide to invest in the Equitix Energy Efficiency fund? 
(Alterative question: What factors would make you consider investing in the Equitix Energy Efficiency fund?)

$01(01,03,04)$

$02(01,03)$

04(poss.)

04(01, 02, 03, 04, 05, 08)

$05(01,02,04,05,06,07,08,09,10)$

$08(01)$

$10(01,02,03,04)$

11

11(04)

12

11. To what extent was the Green Investment Bank involvement a factor in your decision to invest or not to invest in the Equitix Energy Efficiency fund?

04(02,08)

$\mathbf{0 5}(\mathbf{0 2})$

08

$08(01,02)$

$09(02,03)$

$10(01,02,03)$

12. Would you reinvest in further Energy Efficiency funds that didn't have GIB or government involvement?

$04(01,02,08)$

$05(02,07)$

$06(02)$

$08(01,02,03)$

09(02)

$10(03)$

$11(03,04,07,08)$

13. Did you invest in the Equitix Energy Efficiency fund at the expense of alternative opportunities?

(Alternative question: Did you decide not to invest in (Would you not have invested in) the Equitix Energy Efficiency fund as you had (have) competing alternative investment opportunities that were (are) more attractive?

$01(02,03)$

04(04, 06, 09

$05(01,02,04,06,08)$

06

06(01)

07(01, 03) 
14. When deciding to make an innovative investment such as the one made in the Equitix Energy Efficiency fund, what are the issues that you consider when weighing it up with respect to potential alternative investments that may be more conventional?

(Alternative question: When considering an innovative investment such as the one that could have been made in the Equitix Energy Efficiency fund, what are the issues that you consider when weighing it up with respect to potential alternative investments that may be more conventional?

$01(01,03,05)$

02

02(01)

$03(01)$

04

$04(01,02,03,04,05,08)$

05

05(01, 02, 04, 05, 06, 07, 08, 09, 10, 11)

$06(01,02)$

07

09

09(01, 02, 03)

$10(01,02)$

11

$11(03,04,06,09,10)$

12

\section{Fund Manager}

15. What do you consider are the factors that are important when placing an investment with a fund manager particularly when the investment is a non-conventional one such as in Energy Efficiency?

\section{4}

$04(01,02,03,04,05,08,11)$

$05(02,05,08,13)$

$08(01)$

$09(02,03)$

$10(01,02,03)$

16. How much did the familiarity with Equitix as fund manager influence your decision to invest or not to invest?

04

04(01, 02, 06)

$05(01)$

07(01)

09(02, 03)

$10(01,02,03)$ 
17. If familiarity with Equitix was a factor for the initial investment and you achieved or bettered your required returns from their Energy Efficiency fund, would you consider investing in further Energy Efficiency funds run by other fund managers?

04

$04(02,04,05,06,08,09)$

05

$05(02,04,05,07,08)$

$06(01)$

08

$09(02,03)$

$10(01,02,03)$

$11(01,02,03,07)$

\section{UK government and EU polices}

18. How have the UK and EU commitments and policies designed to reduce $\mathrm{CO}_{2}$ and the aim to encourage private institutional investment in Energy Efficiency improvements influenced your investment decisions?

$01(01)$

02

$02(01,02,03)$

03

$\mathbf{0 3}(\mathbf{0 1})$

04(09)

$05(08,10)$

07(01, 03)

08

11(05)

19. What do you think the role of policy should play in encouraging further investment in Energy Efficiency and are there any government policy initiatives either at the UK or the EU level that, if introduced, you feel would achieve this?

$01(03)$

02

$02(01,02,03,04$

$\mathbf{0 3}(\mathbf{1 0})$

$05(05,08)$

\section{Any other issues}

20. Are there any other issues that you feel have a bearing on your decision to either invest in or not to invest in Energy Efficiency investments in general or the Equitix Energy Efficiency fund in particular?

$01(01,02)$ 
02

$02(01,02,03)$

$04(02,05,07,08)$

$05(05,08,09,11)$

07(08)

$08(01$

09

$09(03)$

$11(03,04,06,07,08,09$

12

21. What do you feel are the conditions that would need to exist to enable investment in Energy Efficiency to become a more mainstream investment or at least a more established asset class within the alternatives classification?

$01(05)$

$\mathbf{0 2}(\mathbf{0 1}, \mathbf{0 2}, 03)$

$04(03)$

$05(05)$

$06(02)$

08

$09(02,03)$

11

$11(03,04,05,07,09)$ 